\title{
THE CONSIDERATION OF ENVIRONMENTAL MATTERS IN THE AUDIT OF FINANCIAL REPORTS
}

\author{
CHRISTINA CHIANG
}

\author{
A Thesis submitted to \\ Auckland University of Technology \\ in fulfilment of the requirements for the Degree of \\ Doctorate of Philosophy (PhD)
}

2008

School of Business

Primary Supervisor: Professor Deryl Northcott 


\section{TABLE OF CONTENTS}

ATTESTATION OF AUTHORSHIP ....................................................................ii

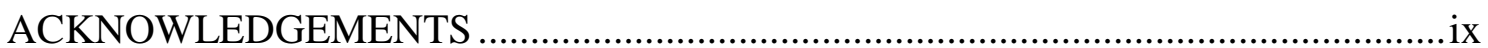

ABSTRACT

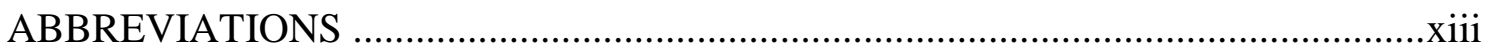

CHAPTER 1: $\quad$ INTRODUCTION TO THE RESEARCH …..................................... 1

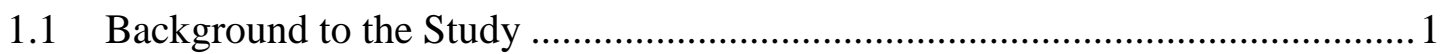

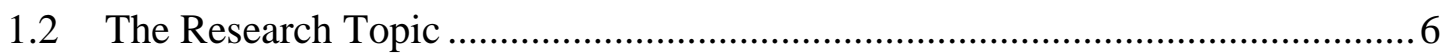

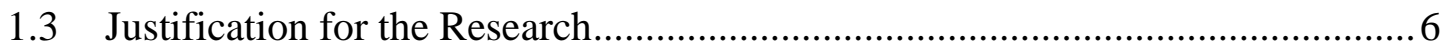

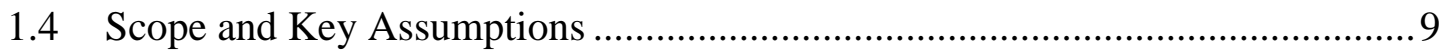

1.5 Overview of the Methodology and Methods ................................................... 10

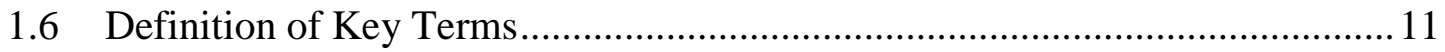

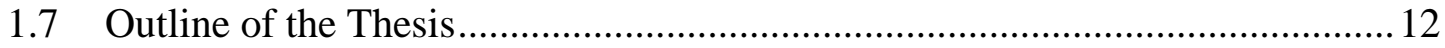

CHAPTER 2: $\quad$ FINANCIAL AUDITORS, AUDITING AND ENVIRONMENTAL

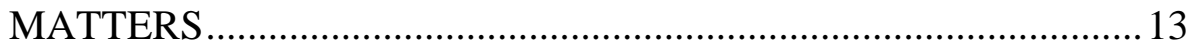

2.1 Corporate Environmental Accountability ....................................................... 13

2.2 Components of General Audit Practice …................................................... 17

2.2.1 The Business Risk Approach to Auditing .............................................. 17

2.2.2 Professional Judgement on Materiality .............................................. 21

2.2.3 The Application of Auditing and Accounting Standards...........................2 26

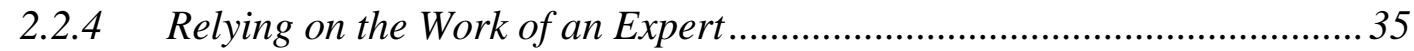

2.3 Financial Auditors and Environmental Matters ............................................... 37

2.4 Knowledge Gaps forming the Basis for the Current Research .........................41 


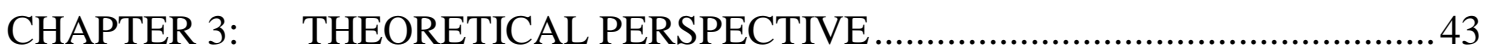

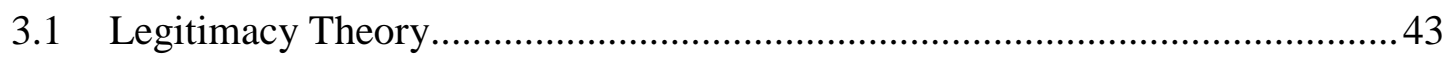

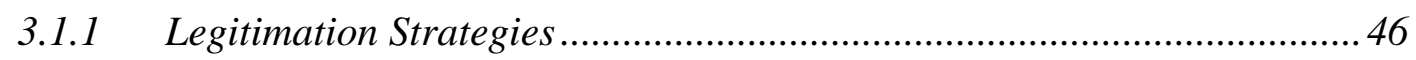

3.2 Studies that have not provided Strong Support for Legitimacy Theory ............52

3.3 Legitimacy Theory as a Potential Lens for the Current Study .........................53

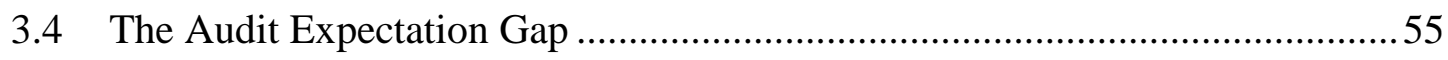

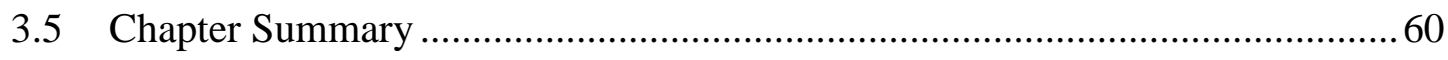

CHAPTER 4: RESEARCH METHODOLOGY AND METHODS .........................61

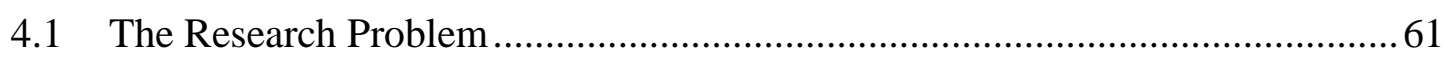

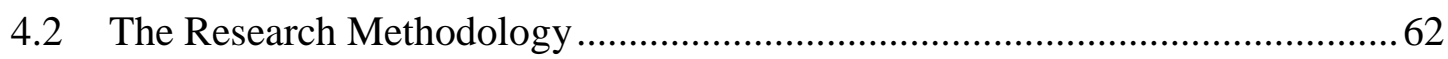

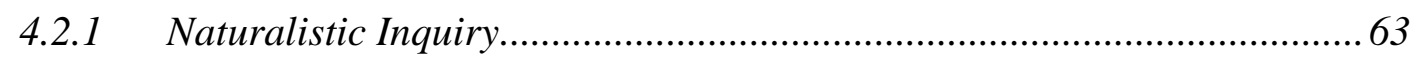

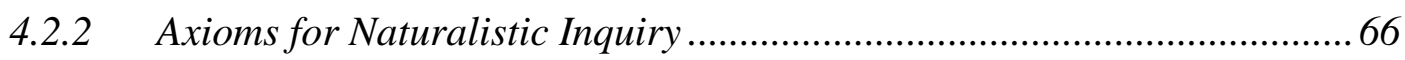

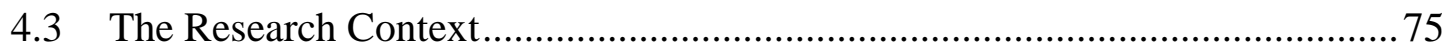

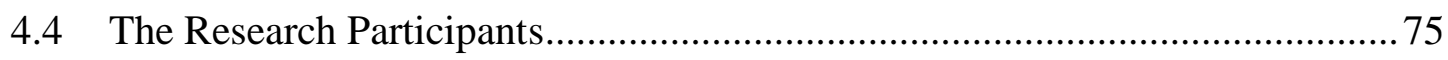

4.5 The Collection of Research Evidence .............................................................. 76

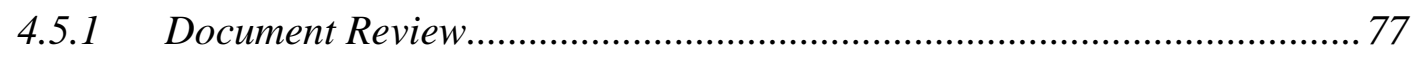

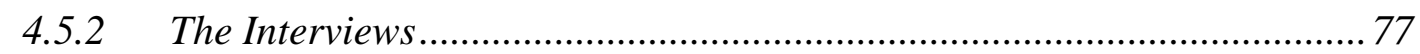

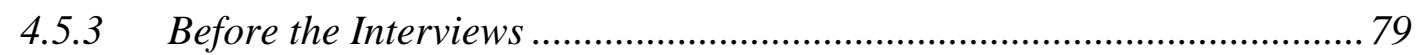

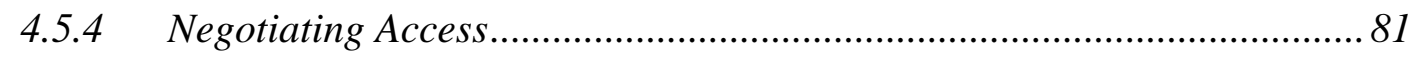

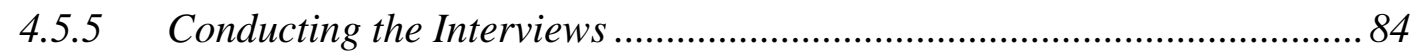

4.5.6 Taping and Transcribing the Interviews................................................. 86 
4.6 Analysis of the Interview Evidence

4.6.1 Reducing and Coding the Interview Evidence.....

4.6.2 Interpreting and Reporting of the Interview Evidence

4.6.3 The Researcher as the Sole Analyst of the Interview Evidence 90

4.7 Managing Interview Evidence Analysis with NVivo7

4.8 Process of Theorisation. 93

4.9 Chapter Summary 94

\section{CHAPTER 5: PRESENTATION, ANALYSIS AND INTERPRETATION OF} RESEARCH FINDINGS (PART ONE) 95

5.1 Auditors' Perceptions on the Consideration of Environmental Matters in the Audit of Financial Reports .96

5.1.1 Awareness of Environmental Matters for Accounting and Auditing

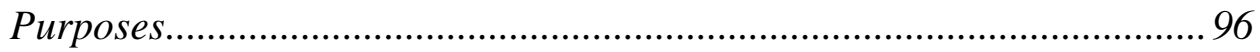

5.1.2 Perceptions of the Current Role of Auditors in the Audit Task ................ 98

5.1.3 Perceptions of the Significance of Environmental Matters .................... 104

5.1.4 Summary and Implications of Research Findings for Current Practice 107

5.2 Common Audit Approaches and Practices in Auditing Environmental Matters 113

5.2.1 The Business Risk Approach (BRA) to Audit Planning 113

5.2.2 Professional Judgement on Materiality.... 116

5.2.3 Application of Auditing and Accounting Standards. 122

5.2.4 Relying on the Work of an Expert 129

5.3 Chapter Summary 133 


\section{CHAPTER 6: PRESENTATION, ANALYSIS AND INTERPRETATION OF}

RESEARCH FINDINGS (PART TWO)

6.1 Auditors' Perceptions of AGS-1010 and its Impact on Current Audit Practice 135

6.2 A Critical Review of AGS-1010. 139

6.2.1 The Espoused Purpose of AGS-1010 139

6.2.2 The Exercise of Professional Judgement..... 140

6.2.3 Greater Reliance on Management and Other Experts 143

6.2.4 Consideration of Environmental Laws and Regulations 146

6.2.5 'Doublethink' and 'Doublespeak' in AGS-1010. 148

6.2.6 Summary and Implications of Research Findings 150

6.3 The Audit of Environmental Matters and Legitimacy. 154

6.3.1 The Auditing Profession, AGS-1010 and Legitimacy Theory...... 154

6.3.2 AGS-1010: A Legitimation Strategy 157

6.3.3 The Expectation Gap II 158

6.4 Auditors' Perceptions of Improvements and Further Development in Current Practice 164

6.4.1 Internal Drivers 164

6.4.2 External Drivers. 169

6.4.3 Summary and Implications of Research Findings 173

6.5 Chapter Summary 176

\section{CHAPTER 7: RESEARCH CONCLUSIONS, CONTRIBUTIONS AND} RECOMMENDATIONS. 178

7.1 Contributions to the Literature. 179 
7.1.1 Contributions to Qualitative Audit Research....................................... 179

7.1.2 Contributions to Extant Literature and Specific Knowledge Gaps ........ 180

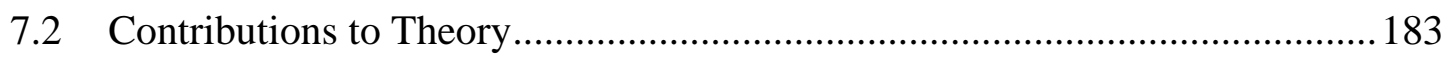

7.2.1 A Legitimacy Theory Perspective ......................................................... 183

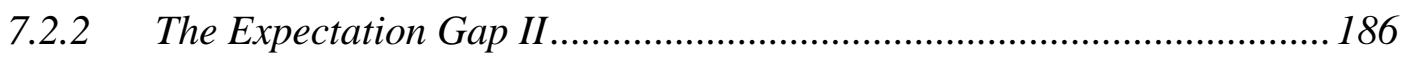

7.3 Contributions to Practice and Policy …..................................................... 187

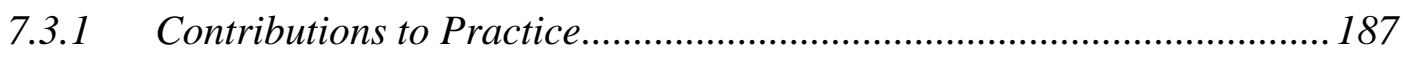

7.3.2 Contributions to Policy .................................................................. 189

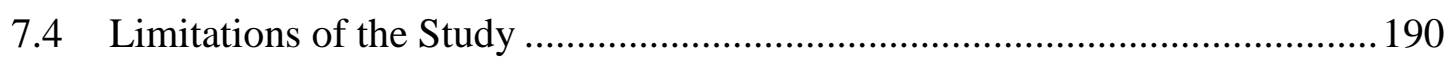

7.5 Recommendations for Future Research.................................................... 191

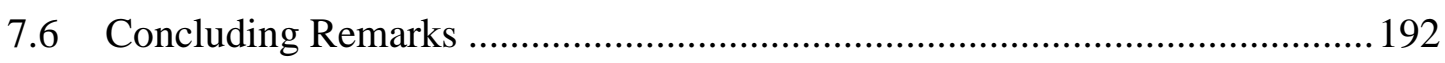

APPENDIX 1: JOURNAL PUBLICATIONS AND CONFERENCE

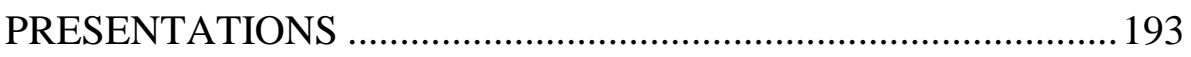

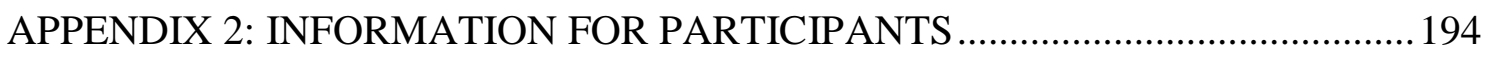

APPENDIX 3: CONSENT TO PARTICIPATE IN RESEARCH ............................... 195

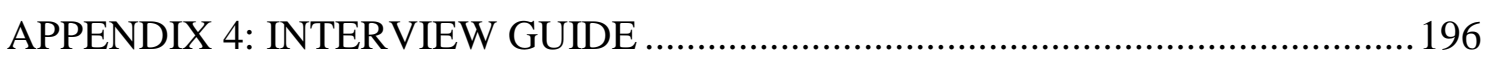

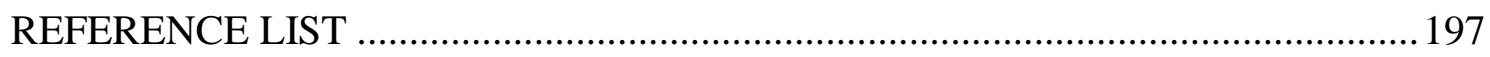




\section{TABLES}

Table 1: Components of the Audit Expectation Gap and means of reducing it..............58

Table 2: Categories of financial auditors interviewed ................................................ 76

Table 3: Components of the Expectation Gap II and the Means of Reducing it .......... 164

\section{FIGURES}

Figure 1: The Audit Expectation Gap (The expectation gap between society and

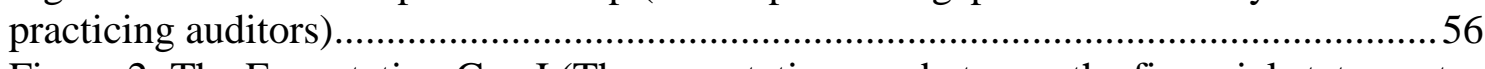

Figure 2: The Expectation Gap I (The expectation gap between the financial statements

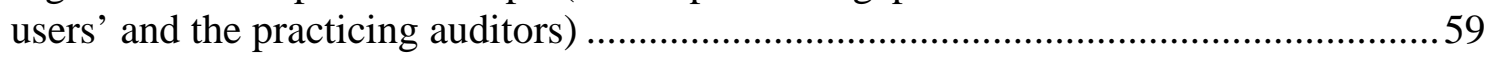
Figure 3: The Expectation Gap II (The expectation gap between the standard setters and

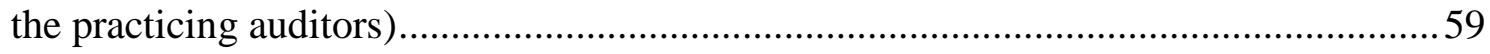

Figure 4: The Expectation Gap II (The expectation gap between the standard setters and

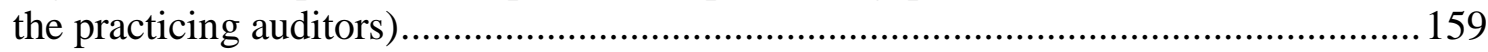




\section{ATTESTATION OF AUTHORSHIP}

I hereby declare that this submission is my own work and that, to the best of my knowledge and belief, it contains no material previously published or written by another person (except where explicitly defined in the acknowledgements), nor material which to a substantial extent has been submitted for the award of any other degree or diploma of a university or other institution of higher learning. 


\section{ACKNOWLEDGEMENTS}

The journey that I undertook to complete my thesis has been very fulfilling and rewarding, both intellectually and personally. However, without the support of various people along the way, this would not have been possible. Therefore, I wish to acknowledge the following support:

Professor Deryl Northcott, my Primary Supervisor. Deryl supervised the research endeavours and spent much time reading and commenting on the completed chapters. However, she gave me the liberty to craft my own $\mathrm{PhD}$ study, and in so doing enabled me to develop and gain much confidence in my intellectual capability.

Professor Keith Hooper, my Secondary Supervisor. Keith's 'big picture approach' to reviewing the thesis, and his insights, have been hugely beneficial, because he was able to inform me very quickly whether a completed chapter met required standards, and to identify writing that was "too wooden".

Ron Feasey, my previous Head of Department. Ron started me on the research and scholarship path by sending me to my very first international academic research conference in 1998. It was at that conference that I thought to myself "I can also do that. One day, I'd like to be presenting papers at international conferences too". Ron also encouraged and motivated me to embark on higher studies, starting with a Masters degree in Business Studies (Accounting) and culminating in the completion of this doctoral thesis.

The New Zealand Institute of Chartered Accountants. The Institute has supported me in my studies by awarding me a Doctoral Scholarship, and travel grants that enabled me to attend and present papers from my doctoral studies at various international conferences. Additionally, staff members at the Institute have assisted by providing me with the written comments on Audit Guidance Statement 1010 (exposure draft).

The interview participants. Despite busy work schedules, they gave their time willingly to participate in the research interviews.

James Prescott, Paul Wells, Rowena Sinclair. We are colleagues in the same department and each of us has a doctoral thesis to complete. We talk 'research', share research insights, tips, useful papers, etc, etc, etc... I very much appreciated their 
support and encouragement in every possible way; and their cheering me on to the next part of the doctoral journey.

Sue Knox. Sue formatted my 'long-document' and made the presentation of this thesis pleasing to the eyes. More so, she took away my stress and undue concerns about merging the seven chapters into a long document; and my dread of the "weird and horrible things' that might happen to the formatting when the chapters were merged, which was something I felt I could not possibly control.

Greg Sibthorpe. In the last year and a half, Greg assisted me in practical ways that enabled me to get on with the serious writing of my thesis and related papers for presentation at international conferences.

Personal friends and other colleagues at AUT University. They are too numerous to name individually, but they have unknowingly held me accountable by just being interested in my progress, asking me about my research, and cheering me on to complete the thesis.

My husband Chiok Ing and my sons, Daniel and David. They often joked that the doctoral studies were a good thing to 'keep me out of mischief'. Yes, I was kept very, very busy, and preoccupied for a very long time...Invariably, I could be found labouring in front of my computer, amid the messy piles of papers in my room at home and away from trouble!! Indeed, I have been blessed by their unconditional love, support and encouragement. I am particularly grateful to my husband. He showed understanding and tolerance when house chores were constantly neglected and the home was in a mess!!! In the evenings, he also endured many, many long hours on his own in front of the TV whilst I spent all that time buried in my studies. Now, that is sacrificial love and living!

Last, but foremost, I am grateful to my loving Heavenly Father who has walked this journey with me. At the beginning, when I was deciding whether to take on doctoral studies, He assured me that I "can do all things through Christ who strengthens me" (Philippians 4:13), and throughout the 'doctoral journey', He "met all my needs according to His glorious riches in Christ Jesus" (Philippians 4:19). He also placed in my heart an inner resolve to complete this doctoral journey successfully. For just being who He is to me, I especially dedicate this doctoral thesis to my Heavenly Father. 


\section{ABSTRACT}

There has been a dearth of research on 'auditors and environmental matters' since Collison (1996) and Collison and Gray (1997) completed their study on the views of UK auditors about whether auditing is changing, or should be changing, in relation to environmental concerns. It is now more than ten years since the publication of that study. Growing international concern for environmental matters has since led to the issue of International Auditing Practice Statement (IAPS) -1010: The consideration of environmental matters in the audit of financial report in 1998 and, in New Zealand, Audit Guidance Statement (AGS) -1010: The consideration of environmental matters in the audit of a financial statement in 2001. Yet, to date, there has been no examination of the impact of IAPS-1010 or AGS-1010 on either current audit practice, or the issues raised by Collison (1996) and Collison and Gray (1997).

This doctoral thesis has attempted to address the environmental impact gap in the auditing research literature. In particular, it has investigated the consideration of environmental matters in the audit of financial reports in the light of AGS-1010, with a view to understanding better the following issues: (1) how auditors generally perceive the consideration of environmental matters in the audit of financial reports; (2) the common approaches and practices auditors undertake when auditing environmental matters; (3) the challenges (if any) that auditors face in the audit of environmental matters (4) the impact (if any) of AGS 1010 on current audit practice and, finally, (5) how current practices in the audit of environmental matters may be improved and further developed to meet better the espoused aims of AGS-1010.

Qualitative interviews with twenty-seven senior financial audit practitioners and others in New Zealand provided the basis for the findings. The interviews were taped, transcribed and managed with the use of computerised qualitative analysis software (NViVo7).

Key findings from the research interviews were as follows: (1) the introduction of AGS1010 had little impact on current audit practice in New Zealand; (2) environmental matters were treated no differently from any other audit issues, and auditors tended to apply common, familiar audit approaches in dealing with environmental matters; (3) 
auditors found the effective auditing of environmental matters challenging owing to their inability to identify such matters, and their lack of relevant expert knowledge.

The most significant finding from this study is that, in general, common audit practices were riddled with issues of concern. These issues point to a broader and more significant problem. It would seem that current audit practices fail to consider many potential audit issues (including environmental matters) adequately in the audit of financial reports. For auditors to be more effective in their audit practice and in protecting the public interest, not only does audit methodology need a major review, but auditors themselves need to change their attitudes and mindsets in their approach to auditing. 


\section{ABBREVIATIONS}

\section{ACCOUNTING BODIES}

AICPA American Institute of Certified Public Accountants

APB Auditing Practices Board (UK)

AuASB Auditing and Assurance Standards Board (Australia)

IAASB International Auditing and Assurance Standards Board

ICAA Institute of Chartered Accountants in Australia (Australia)

ICAEW Institute of Chartered Accountants in England and Wales

ICANZ Institute of Chartered Accountants in New Zealand (Name changed to NZICA in 2005)

IFAC International Federation of Accountants

NZICA New Zealand Institute of Chartered Accountants (Name changed from ICANZ in 2005)

FSRB Financial Standards Reporting Board (NZ)

PCAOB Public Company Accounting Oversight Board

PPB Professional Practice Board (NZ)

FASB Financial Accounting Standards Board (US)

SEC The Securities Exchange Commission (United States)

\section{INTERVIEW PARTICIPANTS}

$\begin{array}{ll}\text { AP } & \text { Audit partner } \\ \text { AM } & \text { Audit manager } \\ \text { APR } & \text { Audit practice reviewer } \\ \text { OAG } & \text { Auditors from the Office of the Auditor General } \\ \text { PAS } & \text { Public sector auditors } \\ \text { PPB } & \text { Professional Practice Board (NZICA) } \\ \text { PPR } & \text { Professional Practice Reviewer (NZICA) }\end{array}$




\section{OTHER TERMINOLOGIES}

AGS Audit Guidance Statement (NZ and Australia)

AUTEC Auckland University of Technology Ethics Committee

BRA Business risk approach (in audit planning)

CAQDAS Computer assisted qualitative data analysis software

GAAP Generally accepted accounting practices

IAPS International Auditing Practice Statement

NZ IAS New Zealand equivalent to International Accounting Standard

PA Personal assistant(s) 


\section{CHAPTER 1: INTRODUCTION TO THE RESEARCH}

The role of the auditor continues to expand in scope and complexity as stakeholder demands for improved corporate accountability grow. A key issue auditors have faced in recent years is how to audit the 'environmental matters' that impact financial reporting appropriately, but little is known of how they are coping with the challenges this presents. The research presented in this thesis examines auditors' considerations of 'environmental matters'. Environmental matters are initiatives to avoid, remedy or mitigate any adverse effects of activities on the environment, or to deal with the conservation of renewable and non-renewable resources, in the audit of a financial report. This task is important because, as members of the accountancy profession, auditors are expected to act in the public interest (ICANZ, 2003a, Code of Ethics, paragraphs 14 and 15) and this includes assuring the objectivity and integrity of financial reports. However, when reading the published financial reports of some companies whose activities negatively impact the environment, one would not be alerted to the existence of environmental matters in every case, because oftentimes they are not fully accounted for, nor fully disclosed, in the financial report (Bebbington, Gray, Thomson, \& Walters, 1994). Nevertheless, the consideration of environmental matters in the audit of companies' financial reports is expected. To assist them in this task, in 1998, International Auditing Practice Statement (IAPS) 1010: The consideration of environmental matters in the audit of a financial report was issued, followed by, in New Zealand, Audit Guidance Statement (AGS) 1010: The consideration of environmental matters in the audit of a financial report issued in 2001. How well auditors are carrying out this task in relation to AGS-1010 is largely unknown, however. Hence, this research aims to fill a substantial knowledge gap in this area. Section 1.2 further discusses the research topic, and the next section provides the background to the research.

\subsection{Background to the Study}

It is not uncommon for company activities to impact the environment adversely and, within the last decade, greater public knowledge of adverse environmental impacts has made the general public more aware of environmental matters (Holmes, 1999; Surma, 1992). Examples of environmental disasters are as follows: the environmental catastrophe at Chernobyl, Union Carbide (at Bhopal); the toxic waste dumps discovered 
at Love Canal, New York, which took twelve years to clean up (Milne \& Patten, 2002); and the Alaskan oil spill, whereby Exxon Valdez, a super tanker fully loaded with Alaskan crude oil, struck a reef in Prince William Sound discharging more than eleven million gallons of its cargo. It required two billion dollars to clean up the spill and restore the Alaskan coastal environment (Economist, 1990). Hence, it is not surprising that society's concerns over pollution, resource depletion, and other environmental issues have become widespread (Rezaee, Szendi, \& Aggarwal, 1995).

On the other hand, researchers recognise the importance of environmental matters in the economic functioning of entities whose activities affect the environment (Collison, 1996; Collison \& Gray, 1997; Collison, Gray, \& Innes, 1996; Medley, 1997). Environmental matters also impact different aspects of accounting (Collison \& Gray, 1997; Collison et al., 1996; Gray \& Bebbington, 2000; Gray, Bebbington et al., 1998; Todd \& Stafford-Bush, 1995), manifesting themselves as contingent liabilities, provisions, reserves, valuation of fixed assets and depreciation policy (Collison et al., 1996). More specifically, the financial implications of environmental issues are usually in the form of liabilities for cleaning up contaminated land and liabilities for being in breach of environmental legislation and regulations (Gray \& Bebbington, 2001). For example, some companies with contaminated land will eventually have the problem of cleaning up the contamination, and at some stage they obviously have to pay for and consequently account for this (Munter \& Sacasas, 1996). The problem is pervasive and a significant issue for financial reporting.

Environmental matters can also very quickly lead to serious 'going-concern' issues. Observers assume that a company will survive beyond the short term as a goingconcern. However, a company may face closure if its business activities affect the environment significantly and it is sanctioned by law for the detrimental environmental effect (Fiedler \& Lehman, 1995). Therefore, “...environmental matters are important accountability issues" (Fiedler \& Lehman, 1995, p. 196) with significant implications for financial reporting and auditing (Blokdijk \& Drieenhuizen, 1992; Browning, 1994; Cornell \& Apostolou, 1991). Hence, companies (particularly for the more polluting/regulated industries) are urged to be more accountable for those environmental matters (Hackston \& Milne, 1996) having considerable profit and loss and balance sheet implications (Gray \& Bebbington, 2001). 
Therefore, the accountancy profession is impacted by environmental concerns (Gray, 1990). To some extent, accountancy professional bodies across countries are responding by addressing and raising their concerns amongst members of the profession and others (Bebbington \& Gray, 1990; Collison \& Slomp, 2000). An illustration of this is the following paragraph by the Institute of Chartered Accountants in England and Wales (ICAEW):

The importance of environmental matters is increasingly recognised. They often have implications for business and cannot be ignored by auditors and accountants (ICAEW, 2000, p.1). Where environmental factors will impact on a company's policy and activities and will impose costs on the company, or affect its asset values or liabilities, actual or contingent, the financial consequences need to be accounted for or reported in accordance with existing accounting requirements (ICAEW, 1992, p.3).

However, Gray, Collison, \& Bebbington (1998) expressed concern that one would hardly be aware of the existence of environmental matters by looking at most UK companies' financial statements or annual reports. The situation is similar for New Zealand companies (Gilkison, 1992). By way of an example, Gilkison (1994) reported a chemical company that closed in 1987, leaving behind large amounts of toxic waste on the land it occupied. Shortly after its closure, the company reported profits but, in calculating the profits, made no provision for the remediation of the toxic land. In retrospect, the financial statements were almost meaningless because the largest liability, a provision for the clean up, was omitted. Hence, from the reports, investors could not have inferred that the operations of the chemical company were unsustainable; or that liabilities were accruing. The chemical company's results would have been truer and fairer if environmental liabilities had been disclosed (Gilkison, 1994). Buhr (1998) also reported the inadequate disclosure of environmental liabilities in the case of acid rain, and Falconbridge, an international nickel mining and smelting company in Canada. Gilkison (1993) reminded directors and chartered accountants that they have a duty to produce reports showing a true and fair view of a company's operations, to enable investors to make judgements about prospects and viability.

More recently, Kirman (2003) reminded chartered accountants and, particularly auditors, of the need to assure the quality of information disclosed in annual reports. This reminder was in relation to a New Zealand company, which unlawfully discharged contaminants into the atmosphere from the company's resins and emulsions plant. 
When prosecuted in the Environmental Court, the company pleaded guilty and was fined NZ $\$ 55,000$. However, in past years' annual reports, the company had promoted itself as being socially and environmentally responsible. Hence, the court ordered the company to publish the facts that led to its conviction, and details of the penalty, in its 2003 annual report. The court also ordered that environmental matters become a mandatory item on all Board of Directors' meetings for a period of 24 months and required the publication of a notice to all its employees in New Zealand advising them of the conviction. This was the company's third conviction. However, a review of the company's 2003 annual report revealed that it claimed to have drawn the authorities' attention to the pollution although, in reality, its neighbours had repeatedly complained to the authorities of substance and odour pollution. Kirman (2003) warned that care must be exercised when making statements in the annual report, to ensure that they provide an accurate reflection of what really occurred.

In recent years, auditors have experienced what Baker (1977) referred to as "significant turbulence" in their operating sphere, leading to mounting criticism and public scrutiny of the audit profession. Despite the highly publicised news coverage of corporate environmental disasters, to date auditors have not been implicated. Some authors report that a significant majority of auditors are generally unaware of the importance and implications of the environmental agenda for their practice and for the organisations appointing them, particularly on such matters as contingent environmental liabilities (Bebbington et al., 1994). Indeed companies have been slow to deal with environmental contingencies in their financial statements (Surma, 1992). Moreover, Fleming (1993) commented that many accountants and auditors seemed unaware or unaffected by an entity's exposure to environmental matters that might potentially cost them directly as legal liability exposure. Seven years on, Gray (2000b, p. 255) observed that too few auditors seemed cognisant that "all organisations will be subject to increasing environmental exposure - if only through legislation [thus are slow in picking up] on the very real implications that environmental issues can have for the attestation of financial statements".

Environmental matters are unquestionably becoming significant to an increasing number of entities and, in some circumstances, may have a material impact on the financial reporting of those entities. These issues are of "growing interest to users of financial reports and they must be adequately recognised, measured and disclosed by 
management" (AGS-1010, paragraph 1). However, from the discussions in the previous paragraphs, it seems that the accounting treatment and disclosures of environmental matters for companies are less than satisfactory. Therefore, in an effort to safeguard the public interest, auditors must understand more than just the environmental risks inherent in their client's operations. They must also understand the basic framework of environmental regulations and proceedings in order to assess the appropriateness of the client's current accounting and disclosure standards (Surma, 1992). The financial audit must consider any environmental issues that affect the financial statements, focussing on the financial reporting aspects of environmental contingencies (Gray \& Bebbington, 2000). Environmental matters become an audit concern when there is a risk of their being materially misstated, omitted or inadequately disclosed; in which case the auditor needs to give consideration to environmental matters in the audit of the financial report (AGS-1010, paragraph 2). To assist auditors in developing good practice in the application of audit standards in cases when environmental matters are significant to a financial report (AGS-1010, paragraph 6), the New Zealand Institute of Chartered Accountants (from now on referred to as NZICA) issued Audit Guidance Statement (AGS) 1010: The consideration of environmental matters in the audit of a financial report (2001). AGS-1010 is materially consistent with International Auditing Practice Statement (IAPS) 1010: The consideration of environmental matters in the audit of a financial statement (1998) issued by the International Auditing and Assurance Standards Board (IAASB) and Auditing Guidance Statement (AGS) 1036: The consideration of environmental matters in the audit of a financial report (1998) issued by the Australian Auditing Standards Board.

Literature and research on auditors and environmental matters are limited. So far, only Collison (Collison, 1996; Collison \& Gray, 1997; Collison et al., 1996) has substantially investigated this area. These studies provided evidence of auditors' growing concerns about the potential risk exposure they faced consequential to the impact of business activities on the environment, and noted that the level of concern was such that the more one was aware of the potential impact of environmental issues, the more anxious one became. Collison also reported that a majority of audit firms did not have a detailed understanding of what environmental issues might mean for their clients and their financial statements. It is now more than ten years since Collison's (1996) research study. Other than Chiang (2006) as the only work in New Zealand, not much more is 
known about this research area. In particular, very little is known about auditors' current practices regarding the consideration of environmental matters in the audit of financial reports. Internationally, and in New Zealand, there has been no examination of how audit practitioners deal with environmental matters. The gap in the research literature on financial auditors and environmental matters is the motivation for this study. The next section outlines the research topic.

\subsection{The Research Topic}

This research addresses the gaps in our current knowledge since the completion of the study by Collison (1996) which investigated the current practice then, for considering environmental matters in the audit of financial reports. This study examines the same issue in the New Zealand context, in the light of the introduction of AGS-1010. Additionally, it identifies legitimacy theory as an appropriate lens, based on the literature and the research questions. However, there are competing concepts of legitimacy. One concept involves the role of audit in producing legitimacy in organisations and society, and a second concept refers to the audit profession itself in producing and seeking legitimacy in society. The second concept emerges as the one that provides the more relevant explanation for the findings from this research. More specifically, the research addresses the following questions:

1. How do auditors generally perceive the consideration of environmental matters in the audit of financial reports?

2. What common approach and practice do auditors undertake when auditing environmental matters?

3. Do auditors face any challenges in the audit of environmental matters? If so, what might they be?

4. Does AGS-1010 impact current practice and if so, how?

5. How may current practice be improved and further developed to better meet the espoused aims of AGS-1010?

The next section focuses on the justification for this study.

\subsection{Justification for the Research}

The limited evidence from Chiang's (2006, p. 22) survey of auditors indicated that auditors are generally "unwilling to tackle auditing of environmental matters in financial reports". This research is therefore timely in providing a more transparent picture of the current role and practice of auditors on the broad issue of environmental accountability by companies. Interview evidence from this study should therefore be of 
significance to the accountancy profession in its deliberations on how effective practice standards for the audit of environmental matters may mitigate any further criticisms of the audit profession for potentially negligent practices.

A number of authors have called for this type of qualitative research into audit practice. Hopwood (1996), Jeppesen (1998) and Humphrey and Moizer (1990) observed that much of audit and its associated technologies remained a 'black box'. Cooper and Robson (2006, p. 240) emphasised the value of knowing how professional audit works, and how "competence and skill [are] constructed and reproduced across countries". However, Power (2003) and Beattie, Brandt and Fearnley (2001) observed that overall, the study of auditing in action is lacking. Additionally, Humphrey (2008) agreed with Power's (2003) assertion that auditing in practical settings and its role in producing legitimacy were under-documented and under-researched. This led Humphrey (2008) to strongly encourage research which seeks "to bridge a knowledge gap and enhance the understanding of the practical realities of audit practice" (p. 172); and to investigate "what is being done in the name of audit practice and how such practices relate to, influence and are influenced by, broader social, organisational and regulatory contexts" (p. 185). This study helps to answer some of the concerns raised by various commentators and exemplifies the type of research Humphrey (2008) encouraged in order to close the identified knowledge gap.

Gray, Collison, French, McPhail, \& Stevenson (2001) observed that the ideas and experiences of international auditors are global in nature. Since a large number of New Zealand auditors are affiliated with global firms, they will face fundamentally similar audit issues as the international auditors. Moreover, the auditing standards which New Zealand auditors are expected to comply are consistent in all material respects with international auditing standards (ICANZ, 1998a, AS 100: Objective of and general principles governing an audit, p. 11). In addition, the audit methodologies and practice standards which the 'Big 4s' and other audit firms apply are universally adopted by their global firm partners. Therefore, research findings from this study would be relevant to the international audit profession.

Very little is known about how auditors undertake the consideration of environmental matters in the audit of environmental matters in the context of AGS-1010. Few empirical studies have been carried out internationally (and none to date in New 
Zealand) on this topic. Hence, this research should enhance the understanding of an audit phenomenon that is not widely known. The reporting of this research will also add a geographical variation to existing literature, making a timely contribution to the international literature on audit practice at both theoretical and professional practice levels. The research also determines how current practice might be improved and further developed to better meet the espoused aims of AGS-1010. On a policy and service provision level, this should assist auditors to benchmark current practice and potentially reduce the widespread criticism of, and litigation against, auditors, thereby improving public and stakeholder/investor confidence in auditors' work.

A study by Ball, Owen and Gray (2000) found that corporate environmental reports are usually verified by non-auditors, and are not independent audits in the same way that financial audits are. Thus, they provide little assurance to stakeholders. Ball et al. (2000, p. 4) were also concerned about "the extent to which verification statements promote organizational transparency and the empowerment of external parties". Their study suggests that verification statements that appear alongside environmental reports are virtually worthless. It is therefore of interest to determine the role that financial auditors have, when verifying management's representation of environmental matters, since financial auditing is the only independent assurance that stakeholders may rely on. The need to define the financial auditor's role provides a further motivation for the current study.

In summary, this thesis will contribute to the extant literature on auditors, auditing and environmental matters, audit theory, and the policy and practice of auditors. Particularly, the findings of this research will address the audit knowledge gap identified by Power (2003) and Humphrey (2008), regarding the realities of audit practice, and how such practice relates to, influences, and is influenced by, broader social, organisational and regulatory contexts. Most particularly, the research findings will provide a more transparent picture of the current role and practices of auditors on the broad issue of environmental accountability by companies. The research aims to make a timely contribution to the knowledge gap in an area seemingly neglected by researchers and commentators since the completion of a study by Collison (1996). It should be of interest to the international audit profession and community, because such an understanding has tremendous potential in assisting auditors and the audit profession 
to benchmark best practices on both the policy and service-provision levels. The next section discusses the scope and key assumptions of the current research.

\subsection{Scope and Key Assumptions}

This study focussed on financial auditors and audit methodology - i.e. current audit practices in the consideration of environmental matters for a company whose activities have a negative impact the environment. Audit methodology concerns more than just the verification of environmental matters in financial reports; it covers the detection of omitted, undisclosed, misstated or distorted reports of identified existing environmental matters. It is important to note that this study did not aim to examine how (or what) environmental matters are disclosed in financial reports. The relevant literature reviewed for this study therefore concerned financial auditors, auditing and environmental matters. The broader literature on the nature and content of corporate reporting of environmental matters (refer to section 1.1 (page 3); and section 2.1 (page 14 and 15) fell outside the scope of this study and was therefore not a focus.

While it has been noted that information on company environmental matters may be reported in (1) annual financial reports; (2) a document containing an audited financial report or (3) stand-alone environmental reports (Gray \& Bebbington, 2001), this study considered only environmental information reported in (or omitted from) annual financial reports and the document containing the audited financial report. These documents directly affect accountants and auditors in their traditional and statutory roles as financial report preparers and auditors under the New Zealand Companies Act 1993. On the other hand, stand-alone environmental reports fall outside the accountants' 'traditional' ambit because such information provision is usually voluntary. Besides, this is an area where most of the assurances are undertaken by other specialists, nonmembers of the auditing profession (Simnett, Vanstraelen, \& Chua, 2007).

Furthermore, this study did not examine the physical environments in which companies operate. Instead, it examined the manifestations of the environment that affected the financial measurement of economic events at a material level. For example, the researcher did not examine the destruction of a habitat; rather the focus was on the fines a company might receive for destroying that habitat.

Although this research was conducted in New Zealand, the research findings are likely to be of international interest. As in other countries, companies in New Zealand face 
environmental concerns that have significant implications for financial reporting. Accounting and auditing practices in New Zealand parallel those common in the Western world. The audit guideline on the consideration of environmental matters in the audit of a financial report issued by New Zealand Institute of Chartered Accountants (NZICA), the International Auditing and Assurance Standards Board (IAASB) and the Australian Auditing Standards Board (AuASB) are mutually consistent in all material regards. Therefore, although this research was conducted in New Zealand and in the context of the promulgated audit guideline AGS-1010, the research evidence should be relevant and applicable internationally, especially since so few studies have been conducted in this field. The next section presents an overview of the research methodology and methods used for the study.

\subsection{Overview of the Methodology and Methods}

The methodology and methods for this study are discussed in detail in Chapter 4. However, this section gives an overview of the research methodology and methods. The research reported in this thesis sought to know more about current practices in the consideration of environmental matters and in the audit of environmental matters, about any challenges faced by auditors in their current practice, and about how current practices might be improved and further developed to better meet the espoused aims of AGS-1010. Hence, it is appropriate to adopt an interpretive approach for this research (Cavana, Delahaye, \& Sekaran, 2001; Silverman, 2005). In particular, naturalistic inquiry was chosen for this qualitative interpretive research, and the method used for uncovering and understanding the little known phenomena was qualitative interviews.

The researcher interviewed twenty-seven financial and public sector auditors (as chartered accountant members of NZICA) and conducted most of the semi-structured interviews in Auckland. The different aspects of conducting the interviews (before the interviews; negotiating access; during the interviews and taping and transcribing the interviews) are discussed in section 4.5. A number of authors (Cavana et al., 2001; Lincoln \& Guba, 1985; Silverman, 2005) provided insight into how interview evidence can be analysed. However, this study focussed predominantly on the work of Miles and Huberman (1994). The researcher performed the data analysis with NVivo7, a computerised qualitative data-analysis software package. A discussion of its use forms section 4.7. The process of theorising, particularly the 'top-down' approach where some 
established theoretical concepts are considered, is discussed in section 4.8. The next section lists the key terms used and their definitions.

\subsection{Definition of Key Terms}

The following is a list of the key terms used in this thesis. Many of these terms also appear in the auditing standards and audit guidance statements.

An audit is a professional engagement designed to enable an independent auditor to provide a high, but not absolute, level of assurance to users through the issuance of a positive expression of an opinion that enhances the credibility of a written assertion, or set of assertions, about a matter of accountability ('attest audit").

Auditor is a term generally used when referring to both financial auditors and public sector auditors.

Audit risk is the risk that an auditor fails to reach proper conclusions about the company and its financial information.

Business risk is the risk that the audited entity will fail to achieve its objectives because of external or internal pressure and forces.

Environmental issues are the contamination of soil and groundwater, the contamination of surface water or air pollution; the use of hazardous substances; the generating or processing of hazardous waste; or business activities that may have an adverse impact on customers, employees, or people that live in the neighbourhood of the entity's sites (ICANZ, 2001a, AGS-1010, paragraph 21).

Environmental $\underline{\text { matters }}$ are initiatives to avoid, remedy or mitigate any adverse effects of activities on the environment, or to deal with conservation of renewable and nonrenewable resources (such initiatives may be required by environmental laws and regulations or by contract or they may be undertaken voluntarily); consequences of violating environmental laws and regulations; consequences of environmental damage done to others or to natural resources; and consequences of vicarious liability imposed by law (for example, liability for damages caused by previous owners) (ICANZ, 2001, AGS-1010, paragraph 10b). 
Environmental risk means the risk of material misstatement of the financial report due to environmental matters.

Financial auditor is the person with final responsibility for an audit of companies (in addition to other entities). A financial auditor is a chartered accountant and member of the New Zealand Institute of Chartered Accountants.

Material: A statement, omission, fact or item (in an audit of a financial report) is material if it is of such a nature or amount that its disclosure, or the method of treating it, given full consideration of the circumstances applying at the time the financial report is completed, has the potential to influence likely users of the financial report in making decisions or assertions.

Public sector auditor is the person appointed by the Auditor-General. The AuditorGeneral is an Officer of Parliament and the auditor of all 'public entities', including the Crown, government departments; Crown entities; local authorities; statutory boards and other public bodies. A public sector auditor is also a chartered accountant and member of the New Zealand Institute of Chartered Accountants.

The accountancy profession includes both accounting and auditing professionals.

The next section provides an outline of the thesis structure.

\subsection{Outline of the Thesis}

The remainder of this thesis is structured as follows: Chapter 2 reviews the literature on financial auditors, auditing and environmental matters, and identifies the gaps in knowledge that assisted in establishing the research questions for investigation. Chapter 3 discusses legitimacy theory at the organisational level and the audit function level and the rationale for its choice and appropriateness for this study. Chapter 4 explains the research methodology and methods used in collecting and analysing the research evidence. Chapter 5 analyses and interprets findings for the first three research questions and Chapter 6 discusses findings for the last two research questions. The thesis concludes with Chapter 7, which discusses the contributions of the research evidence to the literature, theory, practice and policy; the limitations of the research study; and recommendations for future research. 


\section{CHAPTER 2: FINANCIAL AUDITORS, AUDITING AND ENVIRONMENTAL MATTERS}

Chapter 1 discussed the background to the current research study and outlined the justification for carrying it out in New Zealand. The objectives of the current chapter are to summarise the relevant literature, and to identify the knowledge gaps that form the basis for the key research questions underpinning this study. Essentially, this chapter presents a review of three main themes from the literature: (1) corporate environmental accountability (2) components of general audit practice, and (3) financial auditors' expanding role in the audit of environmental matters. A summary of the knowledge gaps and the consequent research questions is presented in section 2.4. The next section reviews the literature on corporate environmental accountability.

\subsection{Corporate Environmental Accountability}

Accountability is "the requirement for one party to account to another party for its performance over a given period" (ICANZ, 1993, Statement of concept, paragraph 3.3). Accordingly, company managers are accountable to shareholders and other stakeholders for proper stewardship of corporate funds. Sherer and Kent (1983) suggested ways of discharging this accountability obligation: first, by providing financial information on corporate fund stewardship in the form of a financial report; and second by "submitting the financial report to an examination, or audit, on behalf of the owners" (p. 1).

In recent years, increasing public awareness of some business activities that negatively impact on the environment (Holmes, 1999) has led to a dramatic expansion in public interest and concern for environmental deterioration (CICA, 1993). As a consequence, there is a proliferation of laws and regulations which require greater responsibility for the remediation of environmental damage (Chadick, Rouse, \& Surma, 1993). Commentators have also stressed the importance of environmental issues as accountability factors (Billing, Buisman, Willis, \& Wilson, 1994; Lucy \& Hayes, 2004; Turner, Grownow, \& Prescott, 1993). Hence there is significant pressure for corporate disclosures of social, environmental and economic issues (Schacter, 2005). This pressure on companies appears to be expanding the accountability obligation (Fiedler \& Lehman, 1995) and some authors have advocated the reporting of environmental matters in corporate annual reports and financial statements (Blokdijk \& Drieenhuizen, 
1992; Browning, 1994; Cornell \& Apostolou, 1991; Deegan \& Rankin, 1997; Russell, 1992; Salome \& Galluccio, 2001).

Authors have commented that environmental issues pose major challenges to the accountancy profession (Adamson \& Shailer, 1998; Billing et al., 1994; Dixon, Mousa, \& Woodhead, 2004; Hines \& Jackson, 1994; Rogers, 2004; Vaughan \& Mulliken, 2007). Although there were difficulties in environmental accounting (Chadick et al., 1993; Hooks, 1996; Medley, 1997), Bebbington and Gray (1992) regarded the accountancy profession's commitments to the 'public interest' as a major reason for 'greening accountancy'. Consequently, Billing et al. (1994) remarked that environmental risk assessment and management were now part of corporate governance. Thus, auditors should be not only aware of entities with significant environmental matters, but prepared to determine their impact on financial statements (Billing et al., 1994; ICAEW, 2000). For example, if a company's business impacts negatively upon the environment (for example by violating pollution laws), it is potentially liable for a fine and eventually, may incur the costs of cleaning up and abating future pollution (Simunic, 1994). Therefore, the financial report for this company must present the environmental costs, liabilities and contingencies of the company's activities fairly (Teasley, 1995). If the financial report is then subject to an audit, the auditor has a responsibility to ensure that environmental matters are properly accounted for and reported (Chadick et al., 1993; Gray, 2000a; Gray \& Bebbington, 2000; Gray, Collison et al., 1998; Huizing \& Dekker, 1992).

Given the central importance of financial reports and growing environmental concerns to various stakeholders, environmental reporting in financial statements should be expected of companies whose activities affect the environment adversely. However, some authors have observed that a majority of companies studied were not reporting environmental information and, where environmental information was reported, the reporting was mixed, inconsistent (Adams, Hill, \& Roberts, 1995; Deegan \& Rankin, 1996) and of insufficient quality and quantity to meet users' needs (Adams et al., 1995; Deegan \& Rankin, 1996; Harte \& Owen, 1992). Some other studies also found that most corporate environmental reporting was descriptive, self-congratulatory, alluded to good intentions rather than actual environmental programmes, and rarely reported a company's adverse effects on the environment (Adams et al., 1995; Deegan \& Rankin, 1996; Harte \& Owen, 1992). Additionally, some companies had not even acknowledged 
the financial implications of environmental matters in their annual reports and financial statements (Gray, Bebbington et al., 1998).

After studying the annual reports of Finnish companies published between 1985 and 1996, Niskanen and Neiminen (2001) concluded that:

Environmental reporting of the sample firms cannot be considered as objective since the proportional share of negative events reported was negligible compared to the respective percentage for positive events ( $p$. 29).

Indeed their findings echo those of previous studies in other countries (Ingram \& Frazier, 1980; Rockness, 1985; Wiseman, 1982). This suggests that the poorest performers, in fact, issue the largest numbers of positive environmental disclosures. The implication is that firms try to mislead their audiences through unreliable environmental reporting.

Therefore, as suggested by Sherer and Kent (1983), to discharge a company's accountability obligation, the credibility of financial and environmental information in company reports should be audited. Auditing is a systematic process of objectively obtaining and evaluating evidence regarding assertions about economic actions and events in order to ascertain the degree of correspondence between those assertions and established criteria; followed by the communication of results to interested users (ICANZ, 1998a, AS-100: Objective of and general principles governing an audit.).

For example, an audit of an entity's compliance with environmental laws and regulations is designed to provide reasonable assurance to the auditor that the entity has complied, in all material aspects, with the environmental laws and regulations appropriate to the entity" (ICANZ, 1998a, AS-100: Objective of and general principles governing an audit, paragraph 15).

Hence, corporate environmental accountability is being discharged by audited environmental reporting. For the current research, the focus is on reporting environmental matters in financial reports.

A number of authors claimed that company management influences environmental accountability for its own benefit. This phenomenon is known as 'managerialism' or 'managerial capture' (O'Dwyer, 2003; Owen, Swift, Bowerman, \& Humprey, 2000; Owen, Gray, \& Bebbington, 1997; Power, 1991). Maltby (1995) found that an 
environmental audit is largely an internal management-oriented activity, and the environmental consultants who conducted environmental audits normally reported to management. Ball, Owen, and Gray (2000, p. 17) commented that even leading edge environmental reporting is "manifestly managerial in its orientation, stating clearly that the report is prepared mainly as a managerial aid, although it is made publicly available". They further commented that when accountants are commissioned to verify (independent) environmental reporting, they observed a significant degree of "intertwining between the reporter and the verifier" and "the degree of control over the verification process exercised by corporate management: in short, managerial capture" (Ball et al., 2000, p. 18). Gray (2000b) argued that a managerially-captured environmental reporting or attestation process offers little or nothing to environmental accountability. AGS-1010 states that auditors should enquire and discuss with management “the entity's policies and procedures on compliance with relevant environmental laws and regulations [and those] adopted for identifying, evaluating and accounting for litigation, claims and assessments" (ICANZ, 2001a, AGS-1010: The consideration of environmental matters in the audit of a financial report, paragraph 39). The question that requires an answer is whether such a suggestion would lead to managerial capture.

The survey findings reported in Chiang (2006) indicate that although the surveyed auditors acknowledged a role in environmental matters, they questioned the integration of financial and environmental stewardship attestation within the statutory audit. Moreover, the auditors seemed unwilling to audit environmental matters in financial reports because they perceived their current audit role as sufficiently demanding. Auditors, like other professionals, do have demanding roles. The question is whether client management influences their unwillingness to audit environmental matters. Moreover, the extent of their reliance on management and whether managerial capture of the environmental audit exists are less known. Chiang (2006) further indicated that although auditors are perceived as being concerned about the seriousness of environmental problems, their concern does not seem to affect their professional practice. These research issues will be covered in this study.

Rodgers and Housel (2004) conducted a research experiment on how auditors process environmental risk information and financial information in their decision-making. From the experiment, they concluded that, during audit, judgement and decision choice 
phases, auditors tended to downplay their perceptions of environmental risk information as opposed to traditional financial information. The authors also concluded that when auditors faced conflicting information, they tended to rely more on financial rather than environmental risk information. However, the authors did not determine the factors that contributed to auditors' downplaying environmental risk information in their decisionmaking. Again, managerial capture may be implicated in this case.

As part of the audit, an auditor reviews information in the director's report and the annual report to ensure that they are consistent with information in the financial report, because "the credibility of the audited financial report may be undermined by inconsistencies which may exist between the audited financial report and other information" (ICANZ, 1998e, AS 518: Other information in a document containing an audited financial report, paragraph 11). Since qualitative environmental reporting may be found in the Directors' report, the annual report and independent reports, AS-518 requires an auditor to verify environmental information across the various sources. Whether auditors undertake this audit task diligently is not known. The next section reviews relevant literature on the components of general audit practice.

\subsection{Components of General Audit Practice}

Various components make up generally accepted audit practice, but in the extant literature, authors have tended to focus on: (1) the business risk approach to auditing; (2) professional judgement on materiality; (3) the application of auditing and accounting standards; and (4) reliance on the work of an expert. Each of these four main components is discussed in the following sections.

\subsubsection{The Business Risk Approach to Auditing}

According to the New Zealand accountancy profession, the purpose of auditing financial reports is to determine:

......if the financial report complies with generally accepted accounting practice and if it does not, the respects in which it fails to comply; if it gives a true and fair view of the matters to which relates; and in addition whether proper accounting records have been kept as far as it appears from the auditor's examination of those records (ICANZ, 1998f, AS-702: The audit report on an attest audit, paragraph 37(a)).

However, every audit exposes the auditor to a level of audit risk. 'Audit risk' is the risk that an auditor fails to reach proper conclusions about the company and its financial 
information (ICANZ, 1998d, AS-402: Risk assessments and internal control). Hence for every audit, the auditor would aim to reduce his or her exposure to audit risk (Gray \& Manson, 2005) because an inappropriate audit opinion may implicate the auditor in court for negligence. When planning an audit, auditors use the audit risk model, which is likely to reduce auditors' exposure to audit risk. Its application causes the auditor to focus audit efforts on transactions or balances where material misstatements or omissions are most likely to occur (Gay, 2002). Thus, for a company whose activities impact materially on the environment, and whose financial report is audited, the auditor will apply the audit risk model, which should lead to consideration of the environmental risk of material misstatements inherent in a company's financial report (Lemon, Tatum, $\&$ Turley, 2002). The auditor will also make decisions on the type and amount of audit evidence to be gathered in the area of environmental matters (Gay, 2002).

Application of the audit risk model requires the auditor to have good understanding of the business subject requiring audit. However, the model does not require reference to the wider business objectives of the company. Hence many in the audit profession considered this approach as somewhat narrow (Lemon et al., 2002). Consequently, in the 1990s the Big audit firms developed audit methodologies based on the business risk assessment approach (BRA) (Lemon et al., 2002). A majority of auditors in the audit profession now use the BRA (Gay, 2002). Business risk is defined as "the risk that the audited entity will fail to achieve its objectives" because of external or internal pressure and forces (Lemon et al., 2002, p.1). Gay (2002) also referred to business risk as the risk associated with the company's profitability and survival.

The assessment of business risk is broader than the assessment of audit risk because audit risk focuses mainly on financial statement misstatements whilst business risk focuses more widely on company objectives that may have no implications for financial reporting. It is designed to give a top-down, business-risk orientation to audit work (Bell, Marrs, Solomon, \& Thomas, 1997). However, Guy (2002, p. 68) considered the BRA as essentially "an extension on the traditional audit risk model, placing greater emphasis on understanding the client's business and the risks it faces".

The BRA requires auditors to spend more time obtaining a broader knowledge of the company's business in order to determine whether financial report assertions are valid. The auditor begins by discussing, with management, the company's exposure to those 
risk factors that prevent it from achieving its business objectives. The auditor then assesses the specific business risks the company faces to determine if they might result in errors, fraud, or other irregularities and, ultimately, in a materially misstated financial report (Gay, 2002). It is said that "an analysis of business risk informs the assessment of audit risk" (Gray \& Manson, 2005, p. 175) because business risk affects audit risk (Gay, 2002). It also affects the nature, timing and extent of the auditor's work through the required level of detection risk (being the risk that an auditor's procedures will not detect a misstatement in accounting transactions or account balance). Based on the knowledge acquired through BRA, auditors then perform detailed substantive tests related to accounts for which substantial residual risk remains after accounting for the effectiveness of business process controls and performance measures (Bell et al., 1997). However, the final objective in giving an audit opinion on an annual financial report does not change, despite the initial focus of the BRA being wider than the focus of a traditional audit (Lemon et al., 2002).

The actual impact of BRA on practice is somewhat problematic. Although auditors "tended to exhibit a competent understanding of business risk [they are uncertain] as to how it actually informed the audit" (Flint, Fraser, \& Hatherly, 2008, p. 146). Lemon et al. (2002) further explained that the BRA requires partners and managers to be more involved in the planning process than previously, since "business risk approaches emphasise judgement and the broad skills [needed] to assess the position of a business in its environment, matters of strategy, operation and finance [which has] consequent effects on the costs of audit [particularly at the planning stage] or the content of other procedures" (Lemon et al., 2002, p. 21, 22). Some authors (Gray \& Manson, 2005; Power, 2000) have indicated that a consequence of more involvement by audit managers and partners is a reduction in detailed testing of account balances (in order to counterbalance the increased cost at the preliminary planning stage of the audit). However, a study of an actual BRA assignment by Curtis and Turley (2007) found that substantive tests did not seem to decrease as indicated. Nevertheless, Daniel Goelzer, a member of the US Public Company Accounting Oversight Board, was reported by Weil (2004) as saying that when auditors adopt the BRA, they focus less on the details of individual transactions. The BRA appears to rely more on qualitative evidence such as the effectiveness of internal controls and on analytical evidence such as financial ratios. 
A bigger part of the audit was spent on the 'process' of obtaining knowledge of the business rather than on the details of individual transactions (Gray \& Manson, 2005). Crawford and Stein (2002, p. 127) cautioned that "viewing risk at entity level in this way does not perform the same function as risk assessment at operational level". Gray and Manson (2005) suggested that BRA may lead to under-auditing, which would be problematic and might consequentially increase both detection risk and audit risk. Contrary to this, Curtis and Turley (2007) reported evidence of 'over-auditing' in a study of an actual BRA assignment. Nevertheless, Gay (2002, p. 68) cautioned that "care needs to be taken that it [the BRA] does not exacerbate expectation gap issues". Humphrey (1991, p. 7) defined 'the expectation gap' generally as "a representation of the feeling that auditors are performing in a manner at variance with the beliefs and desires of those for whose benefit the audit is carried out".

Knechel (2007, p. 15) further noted that BRA requires auditors to interview nonaccounting personnel in order to look for evidence beyond the accounting function. This is a new challenge for auditors since "such conversations would not be part of the normal lexicon of their prior experiences". Rogers (2004, p. 55) explained that auditors generally rely on company employees to disclose known environmental liabilities; but depending on the questions asked, “....employees may not provide the auditor with a comprehensive list of environmental obligations beyond those pending legal action”. This may potentially lead auditors to miss verifying the completeness of company disclosures.

As reported by Weil (2004, p. A3), Goelzer explained that the BRA should work well if an auditor is good at identifying the areas where misstatements are most likely to occur; however he pointed out that "the problem is, there's not a lot of evidence that auditors are very good at assessing risk". Bell and Solomon (2002) and Bell, Peecher and Solomon (2005) also made similar observations. Knechel (2007, p. 17) added that "translating knowledge about business risks into evidence that can support conclusions about the financial statements is probably the most difficult challenge that auditors faced". Gay (2002) advised that increased emphasis on strategic management in the BRA means auditors need greater training in those methodologies and techniques.

Hatherly (1998) observed that the BRA requires auditors to significantly rely on management for information about company business and this may lead to auditors' 
bias in seeing the business through the same eyes as management. Bazerman, Loewenstein and Moore (2002, p. 100) cautioned that close relationships between auditors and their clients may lead to unconscious biased judgements. They put this theory to the test and found that "auditors' judgements were strongly biased toward the interests of their clients; and their tendency to be influenced by clients' biases". However, they saw such biases as inevitable because "auditors have strong business reasons to remain in clients' good graces and are thus highly motivated to approve their clients' accounts" (Bazerman et al., 2002, p. 99).

Morrison (2004) highlighted a significant concern in management's control of information flowing to an auditor, when the auditor is reliant on management for information. He also noted that this element was a primary cause of the Enron audit failure. As a result of auditors having to work closely with management, stakeholders may also perceive auditor independence to be or appear to be threatened (Lemon et al., 2002) because management may be in a position to influence specific audit objectives (Gay, 2002). Further, Flint et al. (2008, p. 147) asserted that the "BRA represented both an external legitimation and an internal justification of audit within the large firms".

In summary, although the BRA is commonly applied by most auditors, and its application would potentially also impact the audit of environmental matters, the literature discussed above has identified issues around: auditors' ability to ask the right questions when interviewing client staff and to assess risk and translate that assessment into evidence; the significant reliance on management for company information; and management's control of information to the auditors, as major challenges in applying BRA. While the BRA is commonly applied in audit planning, (1) how or whether auditors apply the BRA when considering environmental matters and (2) how its application would potentially impact the audit of environmental matters remain unclear, because it has not received much attention in the audit literature. The current research intends to focus on those issues. The next section reviews the literature on 'professional judgement on materiality'.

\subsubsection{Professional Judgement on Materiality}

The second component of general audit practice is professional judgement on materiality. According to Bell et al. (1997) and Hatherly (1999), the very essence of auditing lies in 'auditors' professional judgement'(Bell et al., 1997; Hatherly, 1999). 
Gray, Owen and Maunders (1991) added further that professional judgement is made throughout the audit:

It begins when the [audit] firm decides to accept an appointment as auditors; and continues through the analytical review, the assessment of audit risk, the determination of levels of materiality, the areas of the company's activities on which to concentrate, the size of samples, the form of evidence to be sought, the decision to accept or not the directors' choice of accounting treatment and disclosure and culminates in the conclusions of whether or not the financial statements do show a true and fair view and whether or not to sign off a clean audit report (p. 139).

Iskandar (1996) observed that while many professional judgements are made during the audit, the decision on audit materiality is the most fundamental. The concept of materiality for the purposes of an audit is explained as follows:

Materiality is concerned with assessing whether omission, misstatement or non-disclosure of an item of relevant and reliable information could affect the perceptions of financial report users. Materiality applies to non-financial and narrative information as well as to the financial contents of general-purpose financial reports. The materiality judgement is primarily a quantitative one, however, the nature of the item or transaction [qualitative factors] also must be considered (ICANZ, 1998c, AS-304: Audit materiality, paragraph 8).

How the materiality concept is applied is an important aspect of audit practice. The auditor's greatest concern for each audit is the possibility that a material misstatement, omission or non-disclosure is not detected by the audit procedures carried out (detection risk) and the auditor may be exposed to audit risk. In particular, for a company whose activities impact the environment, the auditor's concern is whether the existence of material environmental matters that impact financial reporting are not being detected by audit procedures. This may consequently lead to audit risk, which is the risk that the auditor expresses an inappropriate audit opinion. Hence, when planning an audit, the auditor must consider what could cause the financial report to be materially misstated in order to reduce the exposure to audit risk to an acceptably low level. In developing the audit plan, the auditor establishes a materiality level acceptable for detecting material misstatements that may occur in the financial report (ICANZ, 1998d, AS-402: Risk assessments and internal control)). This, in turn, enables the auditor to decide which items to examine and what appropriate procedures to perform. However, McKee and Elifsen (2000, p. 54) have cautioned that choosing the wrong materiality level affects 
decisions about the nature, extent and timing of the fieldwork, and "these decisions, in turn, affect the effectiveness or efficiency of the audit".

At the completion of an audit, the amount of misstatement detected is compared with the pre-determined 'tolerable misstatement' amount, defined as "the amount by which the account or class of transactions can be misstated and not be considered material" (Messier Jr., Martinov-Bennie, \& Eilifsen, 2005, p. 205). Financial statement users' decision-making would not be considered distorted where the amount of misstatement detected is lower than the maximum tolerable amount ('materiality' level). In that case, auditors would not need the client to make any audit adjustments. This process enables the auditor to determine if the misstatements are material enough to require adjustments to the client's books (Messier Jr. et al., 2005). However McKee and Elifsen (2000) raised a concern that the audit standard on materiality does not give guidance on how to implement materiality concepts when applying the appropriate audit judgement to evaluating the significance of detected misstatement. Nevertheless, Fogarty, Graham, \& Schubert (2006) have suggested that the common benchmarks of quantitative measures are net income, revenues and net assets.

Carmichael (2006) has stated that qualitative considerations do influence the evaluation of audit findings, however according to McKee and Elifsen (2000), auditors prefer to quantify their materiality judgements. Rogers (2004) observed that financial executives, accountants and auditors routinely apply the 5\% and $10 \%$ 'rule of thumb' (that is any value under $5 \%$ is considered immaterial, and any value over $10 \%$ is considered material). There are authors (Weinstein, 2007; Zuber, Elliot, Kinney Jr, \& Leisenring, 1983) who believed that materiality is essentially a quantitative consideration of what is important to the presentation of a company's financial statements, principally net income or earnings per share. They considered any matter with no quantifiable effect on current or future financial statements, including the notes and statement of accounting policies, to be outside the scope of the auditor's responsibilities.

There are a number of criticisms against auditors' preference for a quantitative materiality level. The US Securities Exchange Commission (SEC) (1999, p. 1) warned that blindly following a numerical rule of thumb in materiality decisions is clearly not acceptable because "misstatements are not immaterial simply because they fall beneath a numerical threshold". The SEC asserted that company management and auditors need 
to also understand the client's situation and the risks that are represented by qualitative considerations in reporting and disclosure decisions (Chewning \& Higgs, 2002). Additionally, Burrowes (2006) reported that the US Public Company Accounting Oversight Board (PCAOB) has criticised the auditing profession for being too quantitative, especially in the judgement field. The PCAOB asserted that evaluating materiality requires the exercise of judgement, based on an assessment of what constitutes reasonable assurance under the circumstances, and not the mechanical application of a pre-determined formula. Kranacher (2007), the editor-in-chief of the CPA Journal warned that:

Quantitative measures provide a deceptive sense of comfort, especially for those accustomed to dealing with numbers.... the qualitative aspects of a misstatement cannot be disregarded or excused for merely quantitative reasons. The issues behind the numbers often tell us more than the numbers alone. If CPAs ignore these clues, if they set aside their professional judgement, they do so at their own peril (p. 80).

When establishing an acceptable 'materiality level', AS-304: Audit materiality (paragraphs 14 and 15) states that auditors should take into account qualitative considerations such as "any legislation or regulation or specific provisions contained in the audit mandate, compliance with authorities, legislative concern and issues of public interest". Also, when assessing a company's exposure to environmental risk, AGS 1010: The consideration of environmental matters in the audit of a financial report (paragraph 4) states that auditors should refer to AS-208: Considerations of laws and regulations in an audit, which indicates the need for considering environmental laws and regulations pertaining to a company:

Even though certain non-compliance with laws and regulations may not have a direct financial effect on the financial report, they may still influence the decisions or assessments of users and therefore be material. The particular characteristics of non-compliance with laws and regulations mean the auditor should, more so than for other "errors", consider the effect of non-compliance on the decisions or assessments of users in terms of both its nature and amount" (ICANZ, 1998b, AS 208: Considerations of laws and regulations in an audit, paragraph 17).

This assessment...provides a basis for the auditor to decide whether there is a need to pay attention to environmental matters in the course of the audit of the financial report (ICANZ, 2001b, AGS-1010, paragraph 4).

Considering together the requirements in AS-304, AGS-1010 and AS-208, it can be said that, when an auditor assesses a company's exposure to environmental risk, (i.e. the risk 
of material misstatement in the financial report due to environmental matters), the auditor needs to determine the report users' perception of significant environmental laws and regulations that may influence their decision making, even though they may not have any direct financial effect. Fogarty, Graham, and Schubert (2006) further claried that auditors should consider the needs of users as a group, not just the needs of specific individuals. Hence, Chewning and Higgs (2002) have suggested that financial statements should disclose information that affects stakeholder decisions, based on their perceived needs (Gist \& Shastri, 2003). The implication is that "if investors believe that more environmental disclosure is necessary to make informed investment decisions, then such information is by definition material" (Rogers, 2004, p. 55). Although AGS1010 and AS-208 are not explicit on the separate disclosure of environmental matters in the financial report, Gray, Collison and Bebbington (1998) have recommended their separate disclosure, because they think environmental issues are qualitatively and potentially quantitatively different from all other issues with financial impacts. This is also the recommendation of CICA (1993). In particular, Gray et al. (1998) would like to see separate disclosures for (1) fines and penalties for non-compliance with environmental regulations and (2) abandonment/decommissioning costs.

In addition to the observations and comments made by various authors, there is also empirical evidence supporting the materiality of environmental information to users of annual reports. Deegan and Gordon (1996) observed increasing community appeal for environmental information; Tilt (1994) found that environmental groups relied on annual reports to assess the environmental performance of reporting entities. Deegan and Rankin (1997) reasoned that managers of reporting entities must convey environmental information material to report users, because a number of them provide voluntary environmental disclosures. Their survey study also provided evidence that "some groups within society do perceive environmental issues as material to their decision-making processes, and they seek information on environmental matters in the annual report" (Deegan \& Rankin, 1997, p. 567). Ingram (1978) and Anderson and Frankie (1980) found that the market reacted to social disclosure.

Thus, the literature indicates that information on environmental matters is material to financial report users in their decision-making and AS-208 and AGS-1010 deem environmental matters to be an audit issue of public interest and material matters of corporate accountability. Nevertheless, little is known about auditors' perception of the 
environmental matters that exist for some companies, and whether they impact upon the audit significantly, while not necessarily having a direct financial effect. The factors considered by auditors when assessing the materiality of a company's exposure to environmental risk are also little known. These issues are examined in the current research. The next section presents a review of the literature on auditors' compliance with generally accepted audit standards in their audit practice, and the application of accounting standards in assessing the truth and fairness of information reported in the financial report.

\subsubsection{The Application of Auditing and Accounting Standards}

The third component of general audit practice is 'the application of audit and accounting standards'. AS-702: The audit report on an attest audit states that an audit must be conducted (1) in accordance with New Zealand auditing standards and (2) to assess whether the amounts and disclosures in a financial report comply with generally accepted accounting practice. The first part of this section reviews the literature on the application of audit standards (AS) and audit guidance statements (AGS) at audit practice level and the second part examines the application of accounting standards in the audit of financial reports.

\section{The Application of Audit Standards and Audit Guidance Statements}

The New Zealand Institute of Chartered Accountants (NZICA) ${ }^{1}$ issues audit standards and audit guidance statements on the performance of audits. Audit standards are mandatory for auditors and they "contain basic principles and essential procedures for the conduct of an audit" (ICANZ, 1998a, AS 100: Objective of and general principles governing an audit, paragraph 39 ). On the other hand, audit guidance statements:

... do not contain standards but have been issued to provide guidance on procedural matters or accepted practice in the performance of an audit or when an underlying principle in an Auditing Standard requires clarification, explanation or elaboration (ICANZ, 1998a, AS 100: Objective of and general principles governing an audit, paragraph 6(c)).

By their nature, audit standards and audit guidance statements are general, and some authors have noted that they "are issued as a form of self-regulation" (Willekens, Steele, \& Miltz, 1996, p. 249). van Peursem, Locke and Harnisch (2005, p. 110) have

\footnotetext{
${ }^{1}$ Name changed from Institute of Chartered Accountants in New Zealand (ICANZ) in 2005
} 
suggested that the accountancy profession "may intentionally or otherwise, create a manner of 'self' through their standards: a self that is constitutive in its own light". According to the authors, the accountancy profession communicates about itself through the audit standards to every auditor and to the general public: "it is a profession's view of itself, uncensored" (van Peursem et al., 2005, p. 110). Since the accountancy profession has a stated obligation to serve the public interest (ICANZ, 2003a), van Peursem et al. (2005) expected to see that obligation played out throughout the 'Going Concern' audit standard they examined. Instead they found that the audit standard did not convey a forceful mandate and did not seem to impose any requirements on the auditor, indicating that the 'expanded' standards "give the appearance of improving professional benchmarks by virtue of greater volume, a volume not necessarily commensurate with a greater quality or a more forceful mandate" (van Peursem et al., 2005, p. 128). Humphrey et al. (1993a) commented that the significance of audit standards is not in the detailed matters of practice, but in the potential power of the image it created, using them to reassert auditors' public interest commitments.

Sikka, Puxty, Willmott and Cooper (1998) and Stamp and Moonitz (1978) expressed their concerns about the 'looseness' of audit standards. Chandler (1997) stated that audit standards do impact auditing practice, and the experiment conducted by Frazer and Lin (2004) confirmed the statement. However, much of the critical literature argued that audit standards have been ineffective, and that they are mere articulations of existing auditing practice, driven by professional self-interest (Humphrey \& Moizer, 1990; Humphrey et al., 1993a). Pong and Whittington (1994, p. 167) criticised the fact that audit standards and guidelines "did not attempt to re-think or extend the scope and technique of the audit. Rather, they attempt to consolidate the status quo, and in particular to limit the obligations and responsibilities of the auditor". Woolf (1994) highlighted the difficulty in interpreting audit standards in practice and, most particularly, in relation to evidence.

Power (1999, p. 24) made critical comments about the audit guidance statement on fraud. He claimed that, when first issued, the audit guidance statement simply codified "what had always been common knowledge". For all its purposes and despite the rhetorical text, it was intended to be "business as usual" for the auditors. He further commented that the texts of the guidance seem to give "external visibility" and the 
impression of "a solution to the problem" (Power, 1999, p. 24). However, even though the audit guidance statement did look "practical enough to look like guidance to outsiders", they would not be able to "replicate or judge it" without the assistance of auditors, because the interpretation of the rules and instructions in the guidance are discretionary and subject to interpretations and personal judgements (Power, 1999, p. 25). Power (1999, p. 25) then concluded that "in this way, disturbances to the system, in the form of new demands, or old demands with a new rhetoric, can be managed by transforming the unfamiliar and intractable into the familiar and possible".

Young (2003) raised the concern that audit standard-setting might involve deliberate ambiguities in the language of the standards, so as to be acceptable to people holding opposing views. This gives rise to suggestions of 'doublethink' and 'doublespeak' (Robb, 2003a, 2003b). Doublethink means "the power to hold two contradictory beliefs in one's mind simultaneously and accept both of them, and doublespeak involves the ability to speak or write of two or more contradictory ideas without the speaker or writer being aware of the contradiction" (Robb, 2003a, p. 18). Robb (2003b) argued that doublethink and doublespeak allow audit standard setters to present contradictory ideas of what are actual underlying events. Robb (2003b) gave an example of doublethink and doublespeak in the discussions of an earlier audit standard on auditor's responsibility to detect fraud. He explained that doublethink means that while auditors have the knowledge to detect material fraud and should plan the audit accordingly, it is not their responsibility to find fraud (Robb, 2003b). The possible role of doublethink and doublespeak in New Zealand audit standard and guideline setting is unknown, and will be explored for AGS-1010: The consideration of environmental matters in the audit of a financial report; the focus of the current study.

The stated purpose of AGS-1010 is to guide auditors in exercising professional judgement for determining the nature, timing and extent of audit procedures with respect to: (i) a knowledge of the audit environment (AS-302); (ii) risk assessments and internal control (AS-402); (iii) a consideration of laws and regulations (AS-208) and (iv) other substantive procedures, e.g. using the work of an expert (AS-606)" (paragraph $3 \mathrm{c})$. In the light of the many comments made about audit standards and audit guidance statements in the literature, the current research will analyse critically the effectiveness of AGS-1010 in guiding auditors in their consideration of environmental matters in the audit of financial reports. 
Since accountancy professional bodies in various countries prepare audit standards and guidelines regularly, it is of interest to discuss the literature on audit standard-setting to understand better its background, and some related issues and concerns. The structure for audit standard-setting and its enforcement differ significantly from that of accounting standard-setting. Across countries, external independent bodies regulate the accounting standard setters (Brown, 2001), but auditing standard-setting is selfregulated by the accountancy professional bodies themselves (Baker, 1993; Chandler, 1997; Willmott, Cooper, \& Puxty, 1993). When audit standards were first promulgated, the objective was to improve the quality of audits by disseminating information about audit best practices (McEnroe \& Nikolai, 1983). Currently, the standards and guidelines are intended to provide a framework for audit decisions. They are also meant to ensure that auditors are fully aware of modern audit techniques (Gay \& Simnett, 2003). Furthermore, auditing standards and guidelines also help to narrow down areas of differences and variety in audit practice, by setting out what is believed to be best practice acceptable to auditors (Ferrier, 1985). As a result, uniformity of audit practice within each country is imposed by standards as well as encouraged by guidelines (Ferrier, 1985).

A survey on audit regulation conducted by the Institute of Chartered Accountants in Ireland (ICAI) indicated that its members expressed strong opinions in favour of the Institute opting out of agency regulation. The main driver for this view was that a regulator outside the Institute ensured that there was an even playing field for all practitioners; i.e. that everyone was subject to the same level of regulation. Some participants felt that the Institute placed too much emphasis on regulation "to the detriment of support and advisory services" (Walsh, 2000, p. 18). This issue was also raised by Swift \& Humphrey (2000a), who questioned whether a professional body could act both as regulator serving the public interest, and "trade association" serving the interests and needs of its members.

A comparison made of the various audit standard-setting boards (the Auditing Standards Board (ASB) in the United States; the Auditing and Assurance Standards Board (AuASB) in Australia; the Auditing Practices Board (APB) in the United Kingdom and the Professional Practice Board (PPB) in New Zealand) indicated that they all seemed to have similar characteristics and common practices. All the boards fully controlled the audit standards and guidelines setting process. Working parties within the boards, or the 
boards themselves, initiated the standard-setting process. It appeared that the working parties in all the boards were agents that influenced the audit standard-setting process significantly through the recommendations they brought to the boards for consideration. Again, the boards decided on the acceptance of the comments received and the modifications made thereafter. By casting votes, all the boards also decided on the final exposure draft, its exposure for comments, and the approval of the final audit standard.

Comments and representations received from public scrutiny of the exposure drafts were considered and incorporated into the final audit standard, but how these comments and representations were recorded is not known. Myddelton (2004) raised some issues regarding responses to comments made to exposure drafts. He observed that many UK auditors did not bother to respond or comment on their agreement or disagreement with an exposure draft. He speculated, “...nobody expects the APB to take much notice of anything" (p. 58). Since equal weighting was not given to all views, Myddelton deduced that exposure for comment by no means made standard setting a democratic approval process. He further observed that the scrutiny of exposure drafts merely gave people a chance to express disapproval that standards-setting boards might then choose to ignore. Myddelton questioned whether "the Boards have to abide by the majority view if one is apparent" (Myddelton, 2004, p. 58). Myddelton's speculations and observations have yet to be confirmed, since little is known about the decision-making process by which exposure draft comments are considered.

Pong \& Whittington (1994) provided further explanations for the poor rate of submission of comment letters in response to the public scrutiny of an exposure draft. They suggested that this might be due to a lack of sufficient incentive on the part of members of the public to act for the public good, rather than to the inadequacies in the consultation process. Another reason for the dearth of submissions might be the lack of perceived net benefits; respondents perceive that their submission could not have any effect on the outcome of the process. Rahman (1991) observed that when submissions are made to a standard setter, respondents are usually unaware of the arguments of other respondents. At that stage, the standard-setting mechanism receives the views of outsiders, but it does not provide for open debate. Apparently, audit standard setters do consider the participation of different parties in the process important, because it provides them with information that may help them to gauge the potential reaction of interest groups to their standards. Georgiou (2002) suggested that standard setters find 
the explanations that various parties give for their individual actions useful in their attempts to build consensus and resolve conflicts amongst these parties. Whether NZICA considered any comments made on AGS-1010 before it was promulgated is not known and thus will be investigated in this study.

As discussed in the earlier paragraphs in this section, audit standards and guidelines have been the subject of various criticisms. Similarly, the audit standard-setting process and the audit standard setters themselves have also been criticised in the literature. Sikka et al. (2001) viewed standard setters as prejudiced bodies acting in the interest of the few groups embedded in their membership of the profession, for example large professional accounting firms and large multi-national companies. Under such a view of standard-setting bodies, standard-setting is not considered pluralistic. The process is seen as being designed to promote the self-interest of a few powerful interest groups to the detriment of other interest groups (Sikka, 1992). Certain issues are felt to be kept off the standard setters' agenda, and real power is exercised in standard-setting when potential issues are kept out of consideration, rather than when a party enters the public consultation process (Sikka, 2001). However, in contrast, Manson \& Zaman (1999) felt that auditing firms did have a positive attitude towards their greater responsibility for the audit function.

Some commentators have seen the promulgating of auditing standards as a means of self-regulating professional body members in order to serve the public interest (Baker, 1993, 2004; Carmichael, 1995; McEnroe \& Martens, 1998; Sikka, Willmott, \& Lowe, 1989; Walsh, 2000; Willmott, 1986; Willmott et al., 1993; Woolf, 1994; Zeff, 1998). However, the accountancy professional bodies have been seen by some as unable to serve the public interest and protect public confidence, because auditing standard setters are thought to act in the interest of the public accounting profession rather than the wider public (McEnroe \& Martens, 1998; Pong \& Whittington, 1994; Sikka et al., 1989). Auditing standard-setting has appeared to some to be a "self-serving exercise by those whose conduct is being regulated" (Zeff, 1998, p. 536). Baker (1993) suggested that the real motivation behind auditing standard-setting was to forestall government activities that would threaten self-regulation of public accounting. Sikka (2002) had the opinion that audit standard setting bodies seem not to owe a duty of care to any stakeholder, even though standard-setting is meant to serve the public interest. 
Since the standard-setting group is totally within the audit profession, its inherent secrecy and the credibility of the process have also been questioned (McEnroe, 2000, 2002; Sikka et al., 1989). This issue is an extension of the problem of independence and secrecy, and can give scope for overtly self-interested behaviour or the impression that such behaviour occurs even when it does not. Before an audit standard is issued, lobbying of the standard setter often occurs, when interested parties are given the opportunity to influence the outcome of the process (Georgiou, 2002; Manson \& Zaman, 1999; Myddelton, 2004; Pong \& Whittington, 1994; Weetman, 2001). "Thus secrecy encourages conspiracy theories about the standard-setting process", according to (Pong \& Whittington, 1994, p. 159).

If the purpose of standard-setting is to serve the public interest then, perhaps, a wider community of stakeholders should be invited to comment. However, “....important lobbying may have already been done non-publicly before the issuance of the ED [exposure draft]" (McEnroe \& Martens, 1998, p. 8). Hence, comments received following the exposure of 'final' exposure drafts might not carry much importance (Manson \& Zaman, 1999; McEnroe \& Martens, 1998, p. 7). Rahman (1991) suggested that at the initial exposure stage, there may be much negotiation between the parties who are specifically interested in the issue under investigation, and some of the options may be modified several times, or dropped completely, before the outcome is disclosed to the general public. This stage is not open to outsiders, and some of the options may never be disclosed to outsiders for consideration. However, according to J.B. Sullivan, the chairman of the Auditing Standards Board, “...the request for comments is not a popularity contest but rather a way to learn of issues that may not have been considered in drafting the proposal" (Craig, 1994, p. 46). In New Zealand, exposure drafts are publicly exposed to members of the Institute and other interested parties, but no information is available about the submission rate or the process of deciding how each comment received is considered and incorporated in the final audit standard.

Although many authors have examined the shaping of accounting standards (Baylin, MacDonald, \& Richardson, 1996; Craig \& Diga, 1996; Fogarty, 1994, 1998; Hronsky \& Houghton, 2001; Street \& Shaughnessy, 1998; Xiao \& Pan, 1997), “...little is known about the shaping of auditing pronouncements and the social relations promoted by such policies” (Sikka, 1992, p. 350). Across the countries, little empirical research has been done to examine the actual decision-making processes within these accountancy 
professional bodies and standard-setting boards. Information on individual boards and audit standard-setting in general, is also limited. There are many issues regarding the decision-making processes in audit standard-setting that require answers, such as the selection of Board members, the selection of an individual Board member, or the existence of outsiders involved in the standard-setting process. Such issues are significant because, presently, members of the boards completely control the standardsetting process from beginning to end. The same questions may be asked regarding the selection of working groups or task forces set up by the boards. Although projects are prioritised and worked on by a [research] working group set up by the boards, some questions still remain regarding the established criteria for selecting an issue for future standard-setting; who raises and prioritises the issues for consideration; who writes the exposure drafts and how they are written up. Also questioned, is who decides on the contents of these exposure drafts? There are more questions than answers on audit standards and guidelines setting.

Regarding the establishment of AGS-1010, questions remain over whether the public and users were given the opportunity to determine the final form of the audit guidance standard; and over the process by which comments received for the exposure draft AGS-1010 were incorporated into the final audit guidance statement. The setting of AGS-1010 is affected significantly by each of these remaining questions both of which are examined in this study. The next section discusses the application of accounting standards in auditing.

\section{The Application of Accounting Standards}

AGS-1010, paragraph 17 affirms, “...there are few authoritative accounting standards that explicitly address the recognition, measurement and disclosure of the consequences for financial reporting arising from environmental matters". Hence, NZICA and other overseas accountancy bodies have generally sought, so far, to confine their attention on environmental matters to existing, generally accepted accounting practice (ICAEW, 1996; ICANZ, 2001; IFAC, 1995). Various authors have cited contingent liabilities as the most widely experienced type of financial statement impact (Gray, Collison et al., 1998; ICAEW, 1996; ICANZ, 2001a; IFAC, 1995), and considered 'provisions and contingent liabilities' as the appropriate accounting treatment for environmental matters (Hines \& Jackson, 1994; McGuinness \& Sharpe, 2001; Medley, 1997; Specht, 1992). Some authors have also provided guidance for disclosures of environmental risks and 
their impact on key financial items (Bell, 1992; Collier, Doolittle, \& Broke, 1993 August; Munter \& Sacasas, 1996; Specht, 1992).

In New Zealand, AGS-1010 suggested some examples of environmental matters affecting the financial report:

(a) the introduction of environmental laws and regulations may involve an impairment of assets and consequently a need to write down their carrying value;

(b) failure to comply with legal requirements concerning environmental matters, such as emissions or waste disposal, or changes to legislation with retrospective effect, may require accrual of remediation, compensation or legal costs;

(c) some entities, for example in the extraction industries (oil and gas exploration or mining), chemical manufacturers, agribusinesses, local authorities or waste management companies may incur environmental obligations as a direct by-product of their core operations;

(d) constructive obligations that stem from a voluntary initiative, for example an entity may have identified contamination of land and, although under no legal obligation, it may have decided to remedy the contamination, because of its concern for its long-term reputation and its relationship with the community;

(e) an entity may need to disclose in the notes the existence of a contingent liability when the expense relating to environmental matters cannot be reasonably estimated; and

(f) in extreme situations, non-compliance with certain environmental laws and regulations may affect the continuance of an entity as a going concern and consequently may affect the disclosures in and the basis of preparation of the financial report (ICANZ, 2001a, AGS1010: The consideration of environmental matters in the audit of a financial report, paragraph 15).

AGS-1010 also suggested that auditors apply the New Zealand equivalent to International Accounting Standard (NZ IAS) 37: Provisions, contingent liabilities and contingent assets to the recognition and disclosure of contingent losses ensuing from environmental matters. NZ IAS 37, paragraph 10 described 'provisions' as those obligations arising from past events existing independently of an entity's future actions: a liability of uncertain timing and/or amount. Therefore, if something is disclosed as a provision this should alert the reader to the uncertainties inherent in its ultimate payment. Examples of such obligations are penalties or clean-up costs for unlawful 
environmental damage. NZ IAS 37 further explained 'contingent liabilities' as possible obligations at balance sheet date. Their existence at balance sheet date will be confirmed only by the occurrence or non-occurrence of one or more uncertain future events that are not wholly within the control of the company. Hence, so long as an obligation has a possibility of occurring, even though a monetary estimate cannot be attached to it, (that is, to be a contingent liability, there may be a possible obligation only, and no monetary estimate is required), it is considered a 'contingent liability' and should be disclosed in the notes to the accounts.

Apart from the need for legislation to compel companies to remediate contaminated land, questions remain as to how a company should account for the 'obligation' associated with cleaning up such a site. Deegan and Samkin (2006) took the view that such a liability should be recognised not only when there is a legal requirement to remediate a site, but also when usual prudent business practices would suggest that such remediation is necessary. Deegan and Samkin (2006) therefore considered financial reports that failed to disclose material liabilities relating to expected clean-ups to be misleading. Since AGS-1010 made strong suggestions for environmental matters to be treated as, 'provisions or contingent liabilities', auditors should audit environmental matters as such. However, Gill, Cosserat, Leung, and Coram (2001) cautioned that environmental matters (considered as contingent liabilities) were unlikely to be recorded in the accounting records until the occurrence of the uncertain future event. Therefore, there was a high risk that they would not be disclosed completely and properly. Hence, during audit testing and, particularly in searching for unrecorded liabilities, the auditor should remain alert to the possibility of contingent liabilities in general and environmental matters in particular, because contingencies that are often the highest risk to auditors are associated with litigation. In practice, issues of interest include: (1) how auditors account for environmental matters for financial reporting purposes, (2) what the audit approaches are in verifying the accounting treatment in accordance with generally accepted accounting practice and (3) what the challenges are. These will be explored in the research interviews conducted.

\subsubsection{Relying on the Work of an Expert}

The fourth component of general audit practice is an 'auditor's reliance on the work of an expert'. AS-606: Using the work of an expert recognised that auditors are not expected to have expertise in other fields. When auditing financial statements, auditors 
may need special knowledge on certain matters that are potentially material to the fair presentation of financial statements. They may judge this to require the work of an expert. For example, if an auditor, unfamiliar with environmental issues is auditing a client with possible environmental violations, he or she would need to consult an environmental expert or consultant and utilise their work (Colbert \& Scarbrough, 1993, p. 28). Durbin and Summo (1994) observed that auditors were increasingly relying on the work of experts and there are many examples given throughout AGS-1010 where experts' work may be relied on. Generally, an auditor might rely on the work of environmental consultants in assessing environmental clean up obligations or seek technical advice from experts, such as lawyers, engineers or other environmental experts, on whether a particular event or condition is a breach of environmental laws and regulations. However, when an auditor decides to rely on the findings of an environmental audit as audit evidence, the auditor has to decide whether the environmental audit meets the evaluation criteria in AS-606: Using the work of an expert. Important criteria to be considered are:

(a) the impact of the results of the environmental audit on the financial report; (b) the competency and skill of the environmental audit team and the objectivity of the environmental auditors, especially when chosen from the entity's staff; (c) the scope of the environmental audit, including management's reactions to the recommendations that result from the environmental audit and how this is evidenced; (d) the due professional care exercised by the team in the performance of the environmental audit; and (e) the proper direction, supervision and review of the audit. (ICANZ, 2001a, AGS 1010: The consideration of environmental matters in the audit of a financial report, paragraph 51).

Power (1997) noted that, although an auditor is not expected to have the detailed knowledge and experience of experts, the auditor is obliged to form an opinion on the need for specialist knowledge and on the expert's competence and objectivity. He further stated that the audit standard assumed "competence is normally indicated by technical qualifications, membership of a recognized professional body or even experience and general reputation in the market" (Power, 1997, p. 78). From that assumption, Power deduced that professional qualifications provided evidence of the reliability of the expert: that "in principle the auditor audits the [expert] and not their work” (p. 78). In other words, “... [expert] techniques become generally accepted if the practitioners are credible; and if the [experts] are credible, their expertise can be relied upon and the numbers they produce become auditable" (Power, 1997, p. 80). 
In 2001, Chiang surveyed New Zealand auditors to determine their perceptions of various issues regarding the environment. The findings from that nationwide survey were reported in Chiang and Lightbody (2004) and Chiang (2006). Chiang and Lightbody (2004) reported findings on the nature and extent of financial auditors' involvement in environmental audits. Their findings indicated that, generally, financial auditors did not offer environmental audit services because they did not have the appropriate expertise in environmental matters. Hence, to meet any demands for such services, auditors would need "to contract-in the services of 'outside experts"” (Chiang \& Lightbody, 2004, p. 232).

AS-606: Using the work of an expert acknowledges, “....an auditor is not expected to have the expertise of a person trained for, or qualified to, engage in the practice of another profession or occupation" (paragraph 7). That the auditors in Chiang and Lightbody (2004) admitted their lack of expertise in environmental matters, suggested they may need to 'contract-in' non-accounting 'outside experts' to assist with the audit of environmental matters for companies with significant environmental issues. However, Chiang's (2006) study of New Zealand auditors did not examine their use of 'outside experts', or their entering into joint arrangements with other professionals, to assist them in their audit of environmental matters in financial reports. Since the current study aims to identify current practices in the audit task, auditors will be asked about their engagement of non-accounting 'outside experts. The next section continues with a review of the literature on financial auditors and environmental matters.

\subsection{Financial Auditors and Environmental Matters}

A financial auditor appointed under the New Zealand Companies Act 1993 is responsible for a financial audit, which culminates in an audit report. As members of NZICA, financial auditors are required to comply with The Code of Ethics, which asserts that its primary objective is to meet the public interest requirement:

[The profession] recognises that its members have an important role and position in society and will act in the public interest. It defines 'public interest' as the collective well-being of the community of people and institution the profession serves. The accountancy profession's public consists of client, governments, employers, employees, investors, the business and financial community, and others who rely on the objectivity and integrity of members for sound financial accounting and reporting (ICANZ, 2003a, Code of Ethics, paragraphs 14 and 15). 
Further, the American Accounting Association described accountants' mission as:

To provide information which is potentially useful for making economic decisions and which if provided will enhance social welfare (Association, 1973, paragraph 10).

The responsibility for environmental matters has led some authors to perceive a widening in the scope of financial auditing and auditor's duty of care in order to explicitly incorporate environmental matters (Bewley, 1993; Dixon et al., 2004; Sylph, 2005). In New Zealand, the stated purpose of AGS-1010 is as follows:

Its [AGS-1010] purpose is to assist auditors, and the development of good practice, by providing guidance on the application of the Auditing Standards in cases when environmental matters are significant to the financial report of the entity. The extent to which any of the audit procedures described in this Statement may be appropriate in a particular case requires the exercise of the auditor's judgement in the light of the requirements of the Auditing Standards and the circumstances of the entity (ICANZ, 2001a, AGS-1010, paragraph 10b).

AGS-1010 is explicit on the need for auditors to consider environmental matters in financial audits. It further indicated that "environmental matters can be complex and may therefore require additional consideration by auditors" (AGS-1010, paragraph 3). However, Fleming (1993) observed that many accountants and auditors in [country of Fleming's study] seemed oblivious of their responsibility for environmental matters (for example environmental cleanup): an oversight that could expose them to legal liability. Although more than ten years have passed since Fleming's observation, it is not known whether contemporary auditors around the world have become more attentive to environmental matters for their audit engagements.

Sylph (2005), the International Federation of Accountants (IFAC) Executive Director, expected auditors to ensure greater corporate environmental accountability. He asserted that accountants [and auditors] "have a role in making corporations and governments sensitive to the environmental results of their actions" (Sylph, 2005, p. 1). Similarly, Lickiss (1991) the ex-president of ICAEW, also asserted that accountants and auditors must measure up to the environmental challenge if they are to fulfil their duty to promote public interest. Gray (1990, p. 65) observed that growing concerns for the environment had resulted in specific changes to business practices, and "that these changes will affect the accounting profession". Some professional accountancy bodies have responded by addressing environmental questions and by bringing the issues into 
the open (Bebbington \& Gray, 1990; Collison \& Slomp, 2000). For example, AICPA convened a two-day environmental issues roundtable in New Orleans (Fleming, 1993) and, in 1998, IFAC released International Auditing Practice Statement (IAPS) 1010: The consideration of environmental matters in the audit of financial statements which provides "practical guidance on the application of international standards on auditing when environmental matters are significant to the financial statements of such entities" (Anonymous, 1998, p. 5). ICAEW (2000) recognised the importance and implications of environmental matters for businesses, and cautioned auditors and accountants not to ignore them.

In New Zealand, the NZICA Professional Practice Board issued AGS-1010 in 2001, and in it stated that:

When environmental matters are significant to an entity, there may be a risk of material misstatement (including inadequate disclosure) in the financial report arising from such matters. In these circumstances, the auditor needs to give consideration to environmental matters in the audit of the financial report [and] when forming an opinion on the financial report, the auditor should consider whether the effects of such environmental matters are adequately treated or disclosed (ICANZ, 2001a, AGS 1010: The consideration of environmental matters in the audit of a financial report, paragraphs 2 and 55).

AGS-1010, paragraph 3 also warned, “...environmental matters can be complex and may therefore require additional consideration by auditors". Nevertheless, no further comments were made by NZICA regarding its application. Hence the issuance of AGS1010 raised questions about the motivation for its promulgation and how the impetus for the new AGS-1010 developed.

A search of extant literature in New Zealand revealed very little discussion on environmental matters (Cox, 2001; Kirman, 2003; McGuinness \& Sharpe, 2001; Todd \& Stafford-Bush, 1995); New Zealand auditors were apparently silent on their responsibility for considering environmental matters in financial audits. Their silence raised further questions on New Zealand auditors' perceptions of their responsibility for auditing environmental matters, current audit practices, and the impact AGS-1010 might have on current audit practice. This study will focus on these questions.

Collison's (1996) interview study questioned whether, in view of environmental concerns, auditing is changing or should change. He sought auditors' views on specific 
audit procedures, practical issues and experience, and on the scope of regulatory guidance and their perceptions of clients' views on environmental matters. On the basis of Collison's (1996) findings, a large scale survey of a wide range of auditors was carried out and the findings reported in Collison and Gray (1997). The combined findings from Collison (1996) and Collison and Gray (1997) established that, although auditors acknowledge a growing importance of environmental awareness, that awareness needs to be raised. Even though auditors think it useful to have some (nonprescriptive) audit guidance on environmental issues, they do not think it necessary to have 'green' financial reporting standards because any formal regulations would further add to their already oppressive burden and could increase their exposure to potential liability (Collison \& Gray, 1997). Additionally, the auditors felt that environmental risk issues were covered by existing accounting guidelines. The research evidence also indicated that larger audit firms ran training courses and had 'industry specific' guidance on environmental risk. Although the auditors recognised a need to rely on other environmental specialists, they were concerned that specialist advice was not usually sought when, arguably, it should be because, for many audit firms, the first stage of awareness of possible environmental risk is absent. Overall, Collison and Gray (1997) concluded that auditors risked under-emphasising environmental issues and their financial consequences, and that risk was inversely proportional to firm size (Collison \& Gray, 1997).

Both Collison (1996) and Collison and Gray (1997) have informed the current research study significantly. It is now more than ten years since their studies were reported and more than fourteen years since their research interviews were conducted. In the meanwhile, growing international concern for environmental issues and increasing expectations of environmental reporting in financial reports has led to the issue of IAPS-1010: The consideration of environmental matters in the audit of financial statements in March 1998, which was followed in New Zealand by AGS-1010: The consideration of environmental matters in the audit of financial statements in 2001. AGS-1010 is consistent in all material respects with IAPS-1010 (AGS-1010, Appendix 1). Nevertheless, no other studies have examined the issues which Collison (1996) and Collison and Gray (1997) identified in their studies. Therefore, it is of great interest to determine if audit practice has developed further over time or if AGS-1010 has been influential. Collison and Gray indicated that they "look forward to reports from other 
jurisdictions of practitioners' responses to these issues" (Collison \& Gray, 1997, p. 148). Their comments provided added motivation for the current study. Overall, the current research is intended to advance and update Collison (1996) and Collison and Gray (1997). The literature review has revealed a number of knowledge gaps. These gaps formed a basis for the current study, and they are discussed in the next section.

\subsection{Knowledge Gaps forming the Basis for the Current Research}

A review of the literature led to the identification of knowledge gaps in financial auditing and environmental matters. It has also led to additional research questions. The extant literature does not report auditors' perceptions of the importance of environmental matters as an issue of public concern. It is also not known whether auditors are attentive to environmental matters for their audit engagements. Chiang (2006) indicated that auditors are unwilling to audit environmental matters because of their demanding roles, but questions remain as to why they are unwilling, and what are New Zealand auditors' perceptions of their responsibility for auditing environmental matters. In fact, little is known about practice related to the audit of environmental matters. In summary, the knowledge gaps identified in the literature are:

(1) How do auditors apply the BRA in the audit of environmental matters?

(2) How do auditors assess a company's exposure to environmental risk?

(3) How do auditors treat the consequences of environmental matters in financial reporting?

(4) How do auditors approach environmental reporting outside the financial report?

(5) Do auditors rely on management when auditing environmental matters?

(6) Do auditors rely on non-accounting 'outside experts?

(7) Do auditors face practical challenges in their current practice?

(8) What was the motivation for issuing AGS-1010?

(9) How effective is AGS-1010 in guiding the audit of environmental matters?

(10) How may current practice be improved and further developed?

These knowledge gaps formed the basis of the current study. Categorising the above ten issues resulted in the following five key research questions: 
1. How do auditors perceive the consideration of environmental matters in the audit of financial reports?

2. What is the current audit practice in the audit of environmental matters? (Questions 1 to 6 ).

3. Do auditors face any challenges in their current practice? If so, what are they? (Question 7).

4. Does AGS-1010 impact current audit practice? If so, then how? (Questions 8 and 9).

5. How may current practices be improved and further developed to meet the espoused aims of AGS-1010? (Question 10).

Since the studies by Collison (1996) and Collison and Gray (1997), no further studies have examined the impact of audit standards and audit guidance statements on the audit of environmental matters. Hence, the current research will advance and update the work of Collison (1996) and Collison and Gray (1997) by carrying out interviews with New Zealand auditors. Chapter 4 explains the research methodology and the methods used to collect and analyse the interview evidence.

\subsection{Chapter Summary}

The objective of this chapter was to demonstrate the linkages between extant literature about the consideration of environmental matters in the audit of financial reports and the knowledge gaps that informed the development of key research questions for this study. This chapter presented a review of the literature on: (1) corporate environmental accountability (2) components of general audit practice and (3) financial auditors' expanding role in the audit of environmental matters. Specific issues derived from the literature review were then categorised to construct the research agenda for the current study.

In the next chapter, theoretical concepts underlying 'legitimacy theory' in the context of organisations, and justifications for its choice and appropriateness in informing the current research study are discussed. Chapters 5 and Chapter 6 present and discuss the findings for the above five main research questions. 


\section{CHAPTER 3: THEORETICAL PERSPECTIVE}

The aim of this chapter is to discuss the concepts underlying legitimacy theory and the rationale for choosing legitimacy theory to inform this study. This chapter also explains the concept of the audit expectation gap and its relevance to the notion of legitimacy in the audit profession. In particular, it focuses on the expectation gap II, which was first introduced by Specht and Waldon (1992), and asks whether it exists between auditors and standard setters in relation to New Zealand's AGS-1010. The next section discusses the concepts of legitimacy theory in the context of the extant audit literature. Key points relevant to the research topic are then used to build the rationale for using legitimacy theory to inform the interpretation of findings from this study.

\subsection{Legitimacy Theory}

Legitimacy theory is based on the notion of a 'social contract' between an organisation and the society in which it operates (Deegan, 2002b; Guthrie \& Parker, 1989; Llewelyn, 2003). The 'social contract' is used to describe society's expectations of an organisation's conduct of its activities and operations; and organisations are expected to comply with the terms (expectations) embodied within the social contract (Deegan, 2006). To fulfil the terms of a social contract, an organisation agrees to perform various socially desired actions "in return for approval of its objectives, other rewards, and its ultimate survival” (Guthrie \& Parker, 1989, p. 344). In so doing, society 'confers' upon the organisation a "state of legitimacy" (Deegan, 2002b, p. 292).

Shocker and Sethi (1973) further explained the implications of the social contract:

Any social [organisation] - and business is no exception - operates in society via a social contract, expressed or implied, whereby its survival and growth are based on: (1) the delivery of some socially desirable ends to society in general, and (2) the distribution of economic, social, or political benefits to groups from which it derives its power. In a dynamic society, neither the sources of institutional power nor the needs for the services are permanent. Therefore, an [organisation] must constantly meet the twin tests of legitimacy and relevance by demonstrating that society requires its services and that the groups benefiting from its rewards have society's approval (p. 67).

Legitimacy was defined by Dowling and Pfeffer (1975, p. 122) as "congruence between the social values associated with or implied by [organizational] activities and 
the norms of acceptable behaviour in the larger social systems”. Suchman (1995, p. 574) clarified the concept as follows: "legitimacy is a generalised perception or assumption that the actions of an entity are desirable, proper, or appropriate within some socially constructed system of norms, values, beliefs, and definitions". Alternatively, Lindblom (1993, p. 1) explained that legitimacy exists:

When an entity's value system is congruent with the value system of the larger social system of which the entity is a part. When a disparity, actual or potential, exists between the two value systems, there is a threat to the entity's legitimacy.

Thus, a legitimate organisation is one whose role in society is justified; and its norms appear in conformity with social norms, values and expectations. Legitimacy is said to "attract resources and the continued support of its constituents" (Ashforth \& Gibbs, 1990, p. 177). Therefore, a legitimated organisation is able to continue its pursuits and activities and provide for their long-term survival (Savage, Cataldo, \& Rowlands, 2000). However, an organisation's contract to continue functioning in society could effectively be revoked if societal expectations of the legitimacy of an organisation's operations are not met (Deegan, 2002a). Thus, an organisation would always want to be adjudged legitimate; it would also want to ensure that the social contract is not revoked and that it is able to continue functioning in society. (Lindblom, 1993)

A review of the extant literature revealed two broad strains of audit literature using legitimacy theory as the interpretive lens: the first strand covers the role of audit in producing legitimacy in organisations and society (Humphrey \& Owen, 2000; Pentland, 2000; Power, 1997; 2003), and the second strand covers the audit profession itself as a legitimacy-producing and legitimacy-seeking institution. Each strain is explained in the following paragraphs.

The first strand of the audit literature considered accounting and auditing positioned as legitimation tools that business entities use to manage perceptions of their constituencies and to legitimise their behaviour (Humphrey \& Owen, 2000; Pentland, 2000; Power, 1997; Power, 2003). Power (2003) explained that audits produce assurance or increased confidence in the subject matter of the audit and "financial statements are regarded as more reliable than they would be without an audit" (Power, 2003, p. 380). 
Some authors have explained the process of environmental accountability and issues related to it in terms of legitimacy theory. Power (1997), for example, indicated that accounting is an important means by which organisations respond to environmental pressures in order to enhance their legitimacy. Taylor, Sulaiman, and Sheahan (2001) provided evidence that environmental management systems and related environmental audit functions are impositions to be complied with so as to maintain the credentials of ISO 14001 certification. Further, O'Dwyer (2001) expressed concerns that financial auditors were called upon to audit environmental reports, even though they lacked experience and expertise in qualitative aspects of social audits, because of the need of management to be seen to be audited. Arena and Azzone (2007) concluded that organisations adopt internal audit departments in order to increase their legitimacy and their survival prospects. Hence it appears that auditing practices legitimise corporate disclosures, property rights and social relationships of power (Mitchell \& Sikka, 1993).

The second strain of audit literature locates the accountancy professional body as an organisation functioning "within a society's framework of legitimate authority" (Pasewark, Shockley, \& Wilkerson, 1995, p. 77). Chandler (1997) explained that a legitimation crises occurs when the accountancy profession is perceived to have broken the (unwritten) code of conduct in protecting the public interest. At such times, the accountancy profession must respond to public concerns or risk losing its own legitimacy in the form of its authority to act for the public interest (Pasewark et al., 1995). Thus, to respond to public concerns and to justify the accountancy profession's co-existence with society in the midst of 'problematic legitimacy', authors suggested that the accountancy profession adopt whatever legitimation strategies are required in order to comply with the expectations of society and safeguard its own self-interest (Pasewark et al., 1995; Savage et al., 2000).

Ashforth and Gibbs (1990, p. 177) cautioned that "legitimacy is always problematic" because social values and expectations are often contradictory, evolving, and difficult to operationalise (Shocker \& Sethi, 1973). Furthermore, “...legitimacy is time and place dependent" (Deegan, 2006, p. 162). Thus an organisation is not able to remain indefinitely in a state of legitimacy because "what might be considered legitimate at one point of time might not be considered legitimate at a future point in time because of changing community attitudes" (Deegan, 2006, p. 163). If a larger collective social interest perceives a threat because of the actions of an organisation, the legitimacy of 
the organisation is likely to be challenged. Organisational legitimacy is therefore always threatened, giving rise to a 'legitimacy gap' (Dowling \& Pfeffer, 1975). A legitimacy gap is "the difference between the relevant public expectations relating to how an organisation should act, and how it is perceived that the organisation has acted" (Deegan, 2002b, p. 304).

Sethi (1978) explained the factors that contribute to the legitimacy gap. First, even if the organisation operates in its usual manner, a gap may arise due to changes in societal expectations. Second, a gap may arise as the result of public disclosure of previously unknown information. Nevertheless, “...if society's expectation about performance changes, then an organisation will need to show that what it is doing is also changing" (Deegan, 2006, p. 164). It follows that, on perceiving a threat to legitimacy, an organisation will initiate one or more legitimation strategies to close the gap and ensure its legitimacy continues (Dowling \& Pfeffer, 1975). "Legitimation is a social process" (Boyd, 2000, p. 344) whereby "an organisation justifies to a peer or subordinate system its right to exist" (Maurer, 1971, p. 361, cited in Dowling and Pfeffer, 1975).

Suchman (1995) suggested three general purposes of legitimation: (1) for 'gaining' legitimacy as a consequence of embarking something new, (2) for 'maintaining' legitimacy in order to safeguard legitimacy enhancing accomplishments and (3) for 'repairing' legitimacy as a consequence of an unforeseen and immediate crisis. Some authors have indicated the availability of different legitimation strategies to meet the different purposes of legitimation (O'Donovan, 2002; Suchman, 1995). The next section discusses each of the different legitimation strategies.

\subsubsection{Legitimation Strategies}

An organisation may employ either 'substantive' or 'symbolic' means to seek legitimation. Substantive activities involve real and material changes to the organization's goals, structures, processes or institutionalized practices (Ashforth \& Gibbs, 1990; Suchman, 1995). The change is then communicated to the relevant public by education and information (Lindblom, 1993). Symbolic activities do not involve any real changes in its actual behaviour (Lindblom, 1993), yet still attempt to portray organisation activities as compatible with societal norms and values (Ashforth \& Gibbs, 1990; Pfeffer, 1981). This is by manipulating the perception of, or deflecting attention from, the issue of concern to other related issues through an appeal to, for example, 
emotive symbols; and/or changing external expectations of its performance (Lindblom, 1993). Substantive management produces actual change by or within the organisation, whilst 'symbolic' management refers to an attempt to appear consistent with one's external expectations in order to be able to continue business as usual. Examples of substantive and symbolic strategies are listed and discussed below.

\section{Role Performance (Substantive Strategy 1)}

This requires an organisation to actually change its performance, methods of operation, and/or its output in order to satisfy the performance expectations of members of society on whom it depends for critical resources (Dowling \& Pfeffer, 1975) because of a legitimacy gap as a result of actual performance failure by the organisation (Gray, Kouhy, \& Lavers, 1995). "Typical examples of role performance include providing a good return on shareholder's equity, reliable and reasonably-priced products for customers, and a fair wage and job security for employees" (Ashforth \& Gibbs, 1990, p. 178).

Okike's (2004) study also illustrated 'role performance' as a legitimation strategy. When the Nigerian government was dissatisfied with the performance of auditors in Nigeria, the legitimacy of the auditing profession and its members were challenged and questioned. This led the auditing profession to step up on their 'role performance' in order to restore public confidence in their members and to re-establish the legitimacy of their continued existence. The profession made substantial changes to their roles and practices and as a result, they had to discipline and make examples of members who contravened the Code of Ethics. The profession also started issuing audit standards and guidelines for its members and paid closer attention to the activities of one-partner firms.

\section{Coercive Isomorphism (Substantive Strategy 2)}

This is a strategy that forces an organisation in a population to change its organisational characteristics in order to "to conform to the values, norms, and expectations of constituents" (Ashforth \& Gibbs, 1990, p. 178). Coercive isomorphism indicates that the organisation is willing to fulfil the constituents' role expectations (Ashforth \& Gibbs, 1990). For example, in direct response to a government mandate, manufacturers adopted new pollution control technologies to conform to environmental regulations; (DiMaggio \& Powell, 1983). The difference between 'role performance' and 'coercive 
isomorphism' is that the first involves actual change to an organisation's performance whilst the second involves actual change to its organisational characteristics.

Examples of coercive isomorphism can also be found in the literature. Baylin, MacDonald, and Richardson (1996) observed that when social values changed and the community of constituents became increasingly diverse, the standard-setting process sought legitimation from a wider community which might not be entirely conversant with technical matters though, in the past, legitimation had been sought from technical professionals only. Carpenter and Feroz (1992) concluded that the New York State's decision to adopt generally accepted accounting principles was an attempt to regain legitimacy for the State's financial management practices. However, no compelling evidence was found to indicate, “...that producing GAAP financial information has significantly altered the state's financial management practices" (p. 613).

\section{Altering Socially Institutionalised Practices (Substantive Strategy 3)}

This is an attempt to alter the societal definition of legitimacy through communication, so that the amended definition reflects the organisation's activities. For example:

Intensive lobbying against government legislation and initiatives designed to limit the discretion of tobacco interests, advertising and sponsoring special events, litigating against and negotiating with regulators, and awarding huge research grants to co-opt influential organizations in the medical and scientific communities to build a knowledge base for refuting claims that smoking endangers health...such responses and any changes they facilitate...can affect the subsequent social construction of reality and evolving value system ("If cigarettes are advertised and widely available, they can't be that bad") (Ashforth \& Gibbs, 1990, p. 180).

\section{Espousing Socially Acceptable Goals (Symbolic Strategy 1)}

This involves the organisation giving an impression that it advocates socially accepted goals while pursuing less acceptable ones. For example, an organisation may "disclose ethical policies, but fail to implement procedures to monitor compliance" (Savage et al., 2000, p. 49).

The study by Forgarty et al. (1991) is an example of the symbolic strategy espousing socially acceptable goals. In that study, the authors observed that, when a reporting problem arises, public accountants typically respond with a search for a solution that claims to have the potential to remove concerns and criticisms. The solution, however, is rarely implemented. 


\section{Denial and Concealment (Symbolic Strategy 2)}

This occurs when organisations simply deny, prevent access to, or suppress information about activities that might undermine legitimacy (Ashforth \& Gibbs, 1990). For example, Ashforth and Gibbs (1990) described, “...how managers ... who had filed for Chapter 11 bankruptcy avoided situations in which they would have had to reveal that fact and actively misrepresented their firm's status".

\section{Offering Accounts (Symbolic Strategy 3)}

This occurs when organisations offer excuses and justifications designed to remove the organisation from a situation that might adversely affect its image or legitimacy (Ashforth \& Gibbs, 1990). Wells (1988) cited in Ashforth and Gibbs (1990) gave the example of Beech-Nut, a juice manufacturing company's practice of selling adulterated juice. When information on the company's practice became public, its employees rationalised the company's practice in saying, “...everybody is doing it; the juice is perfectly safe and the tests are inconclusive".

\section{Offering Apologies (Symbolic Strategy 4)}

This involves offering apologies that lead to delaying or minimising loss of legitimacy. However, in expressing remorse for a negative event, management of the organisation, “...may potentially expose itself to charges of incompetence or corruption and to financial damages". Thus, although it is an available tactic, “...organisations tend not to apologize except for the most flagrant or trivial events" (Ashforth \& Gibbs, 1990, p. 181).

\section{Ceremonial Conformity (Symbolic Strategy 5)}

This strategy requires an organisation to adopt practices that are seemingly "consistent with social expectations while leaving the essential machinery of the organisation intact" (Ashforth \& Gibbs, 1990, p. 181). This enactment is strictly "for its symbolic quality... to provide the appearance of action without the substance [with the intention of fostering] the belief among constituents that the organization's activities and ends are congruent with the expectations, values, and norms of constituents" (p. 182). It suggests that the rituals and ceremonies necessary to achieve legitimacy are loosely coupled to the operations of the organisation or form of government (Richardson \& Dowling, 1986). 
The following audit studies are examples of the symbolic ceremonial conformity legitimation strategies adopted by the accountancy profession. Nue (1991) indicated that the promulgation of audit standards was a significant legitimation strategy. Curtis and Turley (2007) asserted that at the level of the auditing profession, audit standards were perceived as reflecting ideas that inform audit methodologies. They also explained that audit standards served as a body of knowledge designed to justify claims of professional expertise and audit practices. As such, the promulgated standards were regarded by some authors merely as symbols, the product of a ritual, having a role in creating illusions that guide cognition and legitimize acceptance through the business community (Mills \& Bettner, 1992; Pentland, 1993). Byington and Sutton (1991, p. 318) added that the mere issuance of published standards could "provide the perception of significant change to external parties", even though audit practice did not change (Baker, 1993). This led Chandler (1997) to believe that the practice of auditors as a profession might not be the same as that deduced by others who read and relied upon the audit standards; and also led Byington and Sutton (1991, p. 319) to suggest that individual auditors might claim to carry out audits in accordance with audit standards whilst actually performing a below-par service". Hence, these constituted examples of 'ceremonial conformity', enactments that give the appearance of action without the substance (Ashforth \& Gibbs, 1990). Milne and Patten (2002, p. 375) added that the decoupling of words and actions from the operational code is an effort to achieve organisation legitimacy, but these initiatives can be nothing more than an "elaborate and convincing façade designed or adopted to conceal the 'back stage' activities from prying eyes".

Humphrey et al. (1992, p. 148) asserted that audit standards and guidance statements amounted to "little more than codifications of established practices of the largest audit firms [pointing] to a concern with legitimacy and the maintenance of an appearance, rather than the active pursuit of high professional standards and the protection of the public interest". Such audit standards and guidance statements are thought by some to represent practice in auditors' interest instead of providing a rigid standard of acceptable performance (Booth \& Cocks, 1989). In view of this, Humphrey et al. (1992) argued that the promulgation of audit standards and guidance statements gives "an appearance of standardisation and a rationalistic basis to audit expertise" although they note that details about standard promulgations are insufficient to gauge the nature of audit 
expertise and audit performance (Humphrey et al., 1992, p. 148). Thus, organisational influence on audit standards and guidance statements is questionable, and made further so by the standard or statements' use of subjective terms such as "reasonable, materiality, adequacy, relevance, reliability, sufficiency and judgement" (Humphrey et al., 1992, p. 48). Additionally, audit guidance statements are not deemed mandatory by the accountancy professional bodies. The current study will determine if the promulgation of AGS-1010 has the characteristics of a symbolic strategy for maintaining the legitimacy of the accountancy profession during such times when there is greater public acknowledgement of growing environmental awareness and concerns.

Lee (1994, p. 32) asserted that the written content of audit standards and guidance statements "is sufficiently vague and ambiguous to prevent detailed scrutiny". Power (1993, p. 195) further added that the words used in such guidance, though acceptable to regulators, prevents external definitions of key concepts, thus maintaining a "zone of discretion" for auditors. Such a strategy is perhaps one of doing 'nothing' (Briloff, 1990; Fogarty et al., 1991; Humphrey et al., 1992). This strategy used in promulgating an audit standard or guidance statement gives the appearance of "addressing issues seriously, but without altering the status quo" (Lee, 1994, p. 40). It also leads to maintaining "a zone of discretion for professional judgment" (Power, 1993, p. 283). The current study will analyse AGS-1010 critically in order to determine whether the comments made by the different authors are true for AGS-1010.

\section{Avoiding, Trivialising or Skirting around the Issue (Symbolic Strategy 6)}

This occurs when an organisation does not give a full explanation, trivialise or fail to address the issue directly, hence the full information is not clearly communicated or may simply be implied (Savage et al., 2000).

In summary, it can be said that the accountancy profession is always under some legitimacy threat and, up until recent times, has successfully overcome its challenges, mostly by using symbolic legitimation strategies. Substantive strategies are carried out only when its role performance is very obviously deficient, e.g. for investigating the Nigerian auditing profession. Fogarty et al. (1991) pointed out that symbolic strategies underlay a strategy of 'doing nothing', and their primary objective is to give the appearance of addressing the issue in order to provide comfort [that] it is being attended to, even though the status quo is maintained. "The outcome [of symbolic strategies] is to 
control the debate over the body of knowledge of accounting and auditing" (Fogarty et al., 1991, p. 433). However, Lee (1994) pointed out that a strategy of 'doing nothing' is risky, since consumers of audit services may eventually see through the rhetoric. The next section discusses published studies that have not provided strong support for legitimacy theory.

\subsection{Studies that have not provided Strong Support for Legitimacy Theory}

Whilst there are a large number of studies that support the tenets of legitimacy theory including those discussed above - it should be acknowledged that there are also a number of studies that have not provided strong support for legitimacy theory. For example, the research conducted by O'Dwyer (2002) found that social and environmental disclosure policies only sometimes appeared to be motivated by legitimacy-related factors. Also, when Campbell (2000) reviewed the social disclosures of the UK organisation Marks and Spencer, he found that legitimacy theory did not provide any explanation for its social disclosure practices. Instead he found that individual traits, such as the identity of the chairman, seemed to provide better explanations of the corporate disclosure policies. Similarly, Guthrie and Parker (1989) found that apart from in regard to environmental disclosures, their research failed to find strong support for legitimacy theory.

Whilst the number of studies supporting legitimacy theory seems to outweigh those that do not, it needs to be acknowledged that empirical support for legitimacy theory is not universal. Deegan (2002b) explained the rationale for the findings of the studies by O'Dwyer (2002); Campbell (2000) and Guthrie and Parker (1989). Legitimacy theory is based on perceptions: (1) of how the public (or a particular group of stakeholders) views the organisation; (2) of whether what the organisation has done is perceived as acceptable to the public (or a particular group of stakeholders). That is, only when an organisation faces a legitimacy crisis, and public concerns are raised, would the organisation adopt whatever legitimating strategies are necessary for complying with the expectations of society and safeguarding its own self-interest (Pasewark et al., 1995; Savage et al., 2000). Otherwise, the organisation carries on business as usual.

Deegan (2002b) further explained that organisational strategies driven by a desire to legitimate are not the same as organisational strategies driven by the organisation's 
requirement to comply with certain rules, or a need to keep up with bigger players in a similar organisational or professional environment. Further, Deegan, Rankin and Tobin (2002) reasoned that where there is no perception of any "social threat" and an organisation is simply reacting or responding to existing operating conditions, then the notion of legitimacy does not come into play. The many studies providing results consistent with legitimacy theory demonstrate also that unless specific concerns are raised, no legitimacy strategies appear to be required (O'Dwyer, 2002; Campbell, 2000 and Guthrie and Parker (1989). In the light of the above discussions and reflections on legitimacy theory, the following section will discuss the appropriateness of legitimacy theory as a potential lens for the current research.

\subsection{Legitimacy Theory as a Potential Lens for the Current Study}

There is a social contract between auditors and their clients, and that contract specifies that the auditors will provide social value in the form of audited financial statements in exchange for a virtual monopoly of audit practice, and self-regulation (Baker, 1977). In other words, auditors must meet clients' requirements in exchange for the audit fees they pay. This relationship supports the legitimacy of the auditing profession.

In recent times, scrutiny by the media and public of a number of high profile international corporate failures has resulted in significant, mounting criticisms overseas of the auditing profession (Chandler, 1999). Moreover, commentators observed that highly publicised news coverage on environmental disasters at Exxon Valdez, Chernobyl, Love Canal, and Union Carbide at Bhopal have changed public and political general awareness, attitudes and concerns towards environmental issues (Gilkison \& KPMG, 1999; Gray \& Bebbington, 2000; Rubenstein, 1992; Watson \& Mackay, 2003). Hence, there appears to be tremendous turbulence in this aspect of the area in which the auditing profession operates (Baker, 1977).

For its status and position, the audit profession relies on the perception that its members are performing an important task and that they execute this task with proficiency and with the backing of a legitimate professional body. The maintenance of organisational legitimacy is therefore critical to upholding the audit profession. However, the prevailing environmental crises and overseas audit failures have resulted in the audit 
profession generally facing a crisis of investor confidence in financial reporting and auditing (Weirich \& Rouse, 2003), and:

[The auditing profession as] a professional body could lose its legitimacy if the public expected a change in performance that was not forthcoming. In the present dynamic social environment, continuance of previous practices may not be sufficient to maintain legitimacy, even if the performance related to that practice is maintained or even improved. Legitimacy is a moving target. If society recognises a need for either different or additional information, then accountants [and auditors] are expected to provide the needed information" (Reynolds \& Mathews, 1999, p. 89).

Empirical studies presented in the preceding sections raised many questions about audit standards and audit guidance statements: whether the promulgation of audit standards is a significant legitimation strategy (Nue, 1991); whether they are perceived as reflecting ideas that inform audit methodologies and a body of knowledge to justify the claims of professional expertise and audit practices (Curtis \& Turley, 2007); whether they are regarded as symbols creating illusions which guide cognition and legitimize acceptance through the business community (Mills \& Bettner, 1992; Pentland, 1993); whether their mere issuance "provides the perception of significant change to external parties" even though audit practice did not change (Baker, 1993); whether the practice of auditors is the same as that deduced by those who read and rely upon the audit standards or guidance statements (Chandler, 1997); whether "they are merely codifications of established practices rather than the active pursuit of high professional standards and the protection of the public interest" (Humphrey et al., 1992, p. 148); whether the written content of audit standards and guidance statements "is sufficiently vague and ambiguous to prevent detailed scrutiny" (Lee, 1994, p. 32). These questions may be asked similarly in this research, as they are also relevant to the current research topic.

The current study sought interview evidence on the following research questions:

1. How do auditors generally perceive the consideration of environmental matters in the audit of financial reports?

2. What common approaches and practices do auditors undertake when auditing environmental matters?

3. Do auditors face any challenges in the audit of environmental matters? If so, what are they?

4. Does AGS-1010 impact current practice and, if so, how? 
5. How may current practice may be improved and further developed to meet better the espoused aims of AGS-1010?

Individual practicing auditors will be asked the above questions, specifically in the light of AGS-1010 issued by NZICA Professional Standards Board. At the practice level, the over-arching issue is whether New Zealand auditors are actively and effectively covering environmental matters in their current audit practices, or whether they are merely giving lip-service to it because they perceive the New Zealand public expects environmental matters to be considered. Should interview evidence indicate that current practices are not satisfactory, the next question leading on from that is whether AGS1010 represents some form of legitimation strategy. Given these issues are to be examined in this study, it is anticipated that legitimacy theory might offer an appropriate lens for interpreting the research evidence.

The next section discusses the concept of the 'audit expectation gap', which is an important dimension when examining legitimacy issues in the audit profession.

\subsection{The Audit Expectation Gap}

The debate on the audit expectation gap has been around for more than one hundred years (Humphrey et al., 1992). The term 'audit expectation gap' is used to describe the difference between the public's expectation of auditors and the auditors' actual performance (Gray \& Manson, 2005). However, its definition varies somewhat according to different authors. Humphrey (1991, p. 7) defined the audit expectation gap as "a representation of the feeling that auditors are performing in a manner at variance with the beliefs and desires of those for whose benefit the audit is carried out". He also indicated that the audit expectation gap could be more narrowly defined as a roleperception gap: that is, a comparison of users' expectations of auditor capability with a predetermined notion of what it is reasonable to expect auditors to provide. This might be caused by an ignorance gap that could be narrowed by educating users. Monroe and Woodliff (1994) defined the audit expectation gap more narrowly as the difference in beliefs between auditors and the public about the duties and responsibilities assumed by auditors, and the message conveyed by audit reports. Jennings, Kneer and Reckers (1993) however, defined the audit expectation gap as the difference between what the public expects from the auditing profession and what the profession actually provides. Similarly, Porter (1993) defined the audit expectation gap as the gap between society's 
expectations of auditors and auditors' actual performance as perceived by society. It is important to note that for all these studies, the two parties involved are the auditors and the stakeholders or public: also that the main issue focussed upon is the expectations of financial statement users towards auditors' actual performance (refer to Figure 1 below).

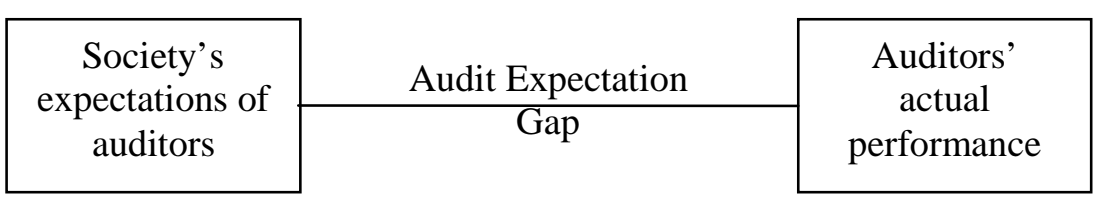

\section{Figure 1: The Audit Expectation Gap (The expectation gap between society and practicing auditors)}

Over the last two decades, various empirical and experimental studies have confirmed the existence of the audit expectation gap between auditors and financial statement users (Best, Buckby, \& Tan, 2001; Dixon \& Woodhead, 2006; Fadzly \& Ahmed, 2004; Humphrey, Moizer, \& Turley, 1993b; Monroe \& Woodliff, 1994; Porter, 1993), and between the public sector auditors and audit report users (Chowdhurry \& Innes, 1998). Some of the major issues associated with the audit expectation gap include: auditor independence; the definition and role of an audit; auditor responsibility and accountability; skill and competency of auditors; and scope and quality of audit work (Humphrey, 1991). These studies suggest that auditors' performances are not in accordance with the wishes of those who requested them (Humphrey et al., 1992; Humphrey et al., 1993b).

Simunic (1994) suggested that audit guidance on the consideration of environmental matters in the audit of a financial report is a response to the expectation gap between auditors and financial statement users. Other commentators have identified technical competencies, precise responsibilities of auditors; the limits of audit function, the adequacy of audit standards and the quality of audit delivery as issues central to the debate on the audit expectation gap (Humphrey et al., 1992; Swift \& Humphrey, 2000b). These issues are further complicated by Hines' (1989) argument that audit work is based, not on a body of auditing knowledge only, but also on claims, or at least the appearance, of auditing knowledge embodied in audit standards and guidance statements. 
Porter (1990a; 1990b; 1990c) extended knowledge of the audit expectation gap by determining its components and considering means to narrow it. According to Porter, there are two components to the audit expectation gap, namely: (1) the 'feasibility gap' which is the gap between what the public expects auditors to achieve and what they can reasonably be expected to achieve; and (2) the 'performance gap' which is the gap between what the public can reasonably expect auditors to accomplish and their actual performance. Porter further identified contributors to the performance gap as (1) 'deficient standards', considered as the gap between what can reasonably be expected of auditors and auditors' duties as defined by audit standards and guidelines; and (2) 'deficient performance', considered as the gap between auditors' duties as defined by audit standards and guidelines, and auditors' actual performance. In order to narrow the feasibility gap, Porter recommended that the audit profession modify the public's expectation about what auditors can reasonably achieve via public education and communication. Porter suggested that to narrow the performance gap (deficient standards)' the audit profession should re-define its duties where public expectations are reasonable. To narrow the performance gap (deficient performance), the audit profession should take steps to rectify sub-standard performance via compulsory continuing education for auditors, and monitor and enforce audit standard compliance, using stronger disciplinary action when sub-standard audit performance is found (refer to Table 1 on the next page). 
Table 1: Components of the Audit Expectation Gap and means of reducing it

THE AUDIT EXPECTATION GAP

\author{
Components of the \\ audit expectation \\ gap
}

\author{
Issues exemplifying \\ the audit \\ expectation gap
}

Strategies to narrow
the audit
expectation gap

\section{Feasibility Gap}

Deficient

Performance

Rectify sub-standard performance via

- Compulsory continuing education

- More stringent monitoring and enforcement of audit standards

- Stronger disciplinary actions
Performance Gap

Deficient

Standards

Redefine auditors' duties

Porter (1990a; 1990b; 1990c)

Specht and Waldon (1992) examined auditors' perceptions of the effectiveness of 'the expectation gap standards' with respect to their stated and overall objectives. The standards were meant to reduce the gap between public expectations and the perceptions of auditors in regards to: (1) addressing public concerns on detection of errors, irregularities and illegal acts, (2) assisting auditors in planning effective audits, (3) improving external auditor communications and (4) improving internal communications. Their study was based on the perception that "those [auditors] who must implement the standards will always influence the outcome" (p. 88). They further explained, “...individuals often behave in ways that ensure that their expectations will be fulfilled" (p. 88). The study found "a significant gap in existence between what the expectation gap standards were intended to accomplish and auditors' perceptions of what the standards will accomplish" (Specht \& Waldon, 1992, p. 90). Hence, Specht and Waldon (1992, p. 90) suggested the existence of a previously unrecognised 'expectation gap': “one between those responsible for formulating auditing directives [such as the expectation gap standards] and those responsible for implementing such directives, the auditing community". They termed this phenomenon "the expectation gap II" (refer to Figure 3 below); and the gap between the expectations of financial 
statements users and auditors as 'the expectation gap I' (refer to Figure 2 below). The distinguishing difference is that 'the expectation gap I' focuses on the expectations of financial statement users and the auditors, whilst 'the expectation gap II' focuses on the expectations of standard setters and the auditors.

\begin{tabular}{|c|c|c|}
\hline $\begin{array}{c}\text { Financial statements } \\
\text { users' expectations of } \\
\text { auditors }\end{array}$ & The Expectation & $\begin{array}{c}\text { Auditors' actual } \\
\text { performance }\end{array}$ \\
\cline { 3 - 3 } & Gap I & \\
\hline
\end{tabular}

Figure 2: The Expectation Gap I (The expectation gap between the financial statements users' and the practicing auditors)

\begin{tabular}{|c|c|c|}
\hline $\begin{array}{c}\text { Standard setters' } \\
\text { expectations of auditors }\end{array}$ & The Expectation & $\begin{array}{c}\text { Auditors' actual } \\
\text { performance }\end{array}$ \\
\cline { 3 - 3 }
\end{tabular}

Figure 3: The Expectation Gap II (The expectation gap between the standard setters and the practicing auditors)

Eleven years after Specht and Waldon (1992) initiated the study on 'the expectation gap II', Specht and Sandlin (2003) confirmed its continuing existence between standard setters and practicing auditors. Both Specht \& Waldon (1992) and Specht and Sandin (2003) asserted that the implementation of audit standards and guidance statements depended on the auditors' perceptions of the efficacy of the promulgations: achievement and motivation were linked to perceptions. This led to the belief that there was a higher probability of implementation if the auditor perceived that the audit standard or guidance might be successfully implemented. Likewise, auditors' perceptions of a low probability of success could result in decreased motivation and effort toward implementation of the audit standard or guidance (Specht \& Waldron, 1992). However, studies by Specht and Sandin (2003) and Specht and Waldron (1992) did not investigate the components of the expectation gap II or strategies to narrow the gap. The current study intends to determine if the expectation gap II between standard setters and auditors exists for AGS-1010. If it does exist, the components of the gap and strategies for narrowing the gap will also be considered. 


\subsection{Chapter Summary}

This chapter discussed the concepts underlying 'legitimacy theory' and its appropriateness as the interpretive lens to inform the current research. It then discussed various symbolic and substantive strategies for gaining, maintaining or repairing organisational legitimacy. The literature identified the promulgating of audit standards and guidance statements as a significant symbolic strategy, and raised the question of whether the promulgation of AGS-1010 was a legitimation strategy for maintaining legitimacy of the accountancy profession. The next chapter covers the research methodology and methods for this study. 


\section{CHAPTER 4: RESEARCH METHODOLOGY AND METHODS}

This chapter explains the research methodology and methods used in collecting and analysing the research evidence. This study is qualitative and interpretive. Qualitative interviews were used to collect evidence from practicing auditors. The interviews were then transcribed and analysed using NVivo7, a qualitative data-analysis software package. This chapter demonstrates that appropriate procedures were followed, and is organised around (4.1) the research problem (4.2) the research methodology; (4.3) the research context; (4.4) the research participants; (4.5) the collection of research evidence; (4.6) the analysis of research evidence; (4.7) managing the research evidence analysis with NVivo 7 and (4.8) the process of theorisation. Finally, a summary is presented at the end of the chapter. The following sections discuss each of the above eight areas.

\subsection{The Research Problem}

As noted, little is known about current practices in the audit of environmental matters when auditors verify financial reports. Hence, the fundamental aim of this research is to develop a better understanding of the day-to-day realities of financial auditors, providing insight on the research topic and then questions arising from it. In particular, the purpose of the current study is to explore current practices and relate them to both the requirement of AGS-1010 (and other relevant auditing standards), and to the expectations that arise from prior literature. This involves collecting the views of audit practitioners in New Zealand on the following questions:

6. How do auditors generally perceive the consideration of environmental matters in the audit of financial reports?

7. What common approaches and practices do auditors undertake when auditing environmental matters?

8. Do auditors face any challenges in the audit of environmental matters? If so, what are they?

9. Does AGS-1010 impact current practice and, if so, how?

10. How may current practice may be improved and further developed to meet better the espoused aims of AGS-1010?

The rationale for the choice, and the development of the research methodology, are discussed next. 


\subsection{The Research Methodology}

As stated in section 4.1, this is a qualitative interpretive research study. However, before discussing the background and key features of the research methodology, an explanation for deciding on a qualitative approach for the current study follows. Gendron (2006) observed that large sample of quantitative studies on audit issues were "too far removed from the practitioners", and the tendency was for audit research to stay 'on the outside', analysing audit practice from a distance (Humphrey, 2001). Accounting practitioners themselves have "complained about quantitative accounting [and auditing] research (predicated on publicly available information) being too far removed from the realities of practice" (Humphrey, 2001, p. 51). Therefore, Gendron (2000; 2006) and Sullivan (1993) were led to believe that accounting practitioners and stakeholders would be more interested in research studies of real-life aspects of day to day accounting [and auditing] practices which can eventually impact the formulation of organisational and regulatory policies. Such research could also exert a key influence on would-be practitioners in university classrooms, through the "development of teaching material and cases that aim to reflect real-life aspects of accounting [and auditing] practice" (Gendron, 2006, p. 51). Hence, Covaleski, Dirsmith, Heian, and Samuel (1998) and Gendron and Suddaby (2004) advised researchers to investigate realities from the perspective of interviewees. Since auditors' thoughts and viewpoints need to be investigated, "it follows that such research should usually be predicated on qualitative data" (e.g. interviews) (Gendron, 2006, p. 49). Therefore, in agreement with the views of the various authors, the researcher developed the current study to research real-life aspects of audit practice. This research is therefore qualitative because it relied on "non-quantitative (or nonstatistical) modes of data collection and analysis" (Prasad \& Prasad, 2002, p. 6). The issue of methods will be taken up later in this chapter.

This research seeks to understand the relatively unknown experiences of practising auditors in auditing environmental matters as part of financial report verification. It therefore follows that an interpretive research approach, which aims at deep understanding of the nature of human phenomena is appropriate, and is used to uncover and understand what lies behind that for which little is yet known (Cavana et al., 2001; Silverman, 2005; Strauss \& Corbin, 1990). In qualitative interpretive inquiry, initial curiosities for research often come from real-world observations, the researcher's direct 
experience, implied theories, interest in practice and growing scholarly interests (Chua, 1986).

"There are two major strains of interpretive work: the naturalistic and the critical" (Putnam, 1983, p. 31-32). Naturalistic research focuses on the constitution of organisational reality. The researcher seeks to understand the "symbol systems, rules, and norms that account for everyday routines and organizational practices" (Putnam, 1983, p. 47) and then interprets the whole in the light of its parts. Throughout the process, the researcher accepts the organisational reality as it is, without passing any judgements or questioning its potential. In critical research, however, “...evaluation governs the processes of describing, explaining and understanding. Researchers function as critics of the status quo and as visionaries for what the social reality could become" (Putnam, 1983, p. 48). The ultimate goal is the "development of a dialectial self-criticism to monitor social reality" (p. 48). Tomkins and Groves encouraged the use of naturalistic inquiry for accounting and auditing research (Goddard \& Powell, 1994). In particular, naturalistic inquiry is chosen for this qualitative interpretive research.

Chua (1986) identified some assumptions made in qualitative interpretive research: (1) that theory is used to provide explanations of human intentions. Its adequacy is assessed via logical consistency, subjective interpretation, and agreement with the actors' common-sense interpretations; (2) that reality is socially created and objectified through human interactions and human action which are intentional and its meaning is grounded in the social and historical context; (3) that accounting theory seeks to explain action and to understand how social order is produced and reproduced. Silverman (1985) further added that a qualitative interpretive research approach assumes that the respondent's perspective on the phenomenon of interest should unfold as the respondent views it, not as the researcher views it. Since the research questions for the current study justify a qualitative interpretive approach as most appropriate, the dominant assumptions made by Chua (1986) are accepted and the current research study is based on those assumptions. The nature of naturalistic inquiry and justification for its use are discussed in the next sections.

\subsubsection{Naturalistic Inquiry}

Lincoln and Guba (1985) discussed at length the use of naturalistic inquiry in the context of case studies. However, this approach can be adopted in other forms of 
qualitative research. They described naturalistic inquiry as a qualitative discoveryorientated approach, which is holistic and sought to understand the totality of a phenomenon within its context. It "stresses the consequent relationship between information; meaning and action" (Lincoln \& Guba, 1985, p. 15). Components of a phenomenon should be studied as part of this process; however, they should not be examined in isolation, but rather as a part of a whole.

Naturalistic inquiry requires a researcher to have direct, personal contact with the participants and to be solely responsible for gathering and interpreting the data. The researcher does not intervene or manipulate any aspect of the phenomenon to be studied, but studies the information as it is gathered. Inductive research evidence analysis is used whereby, through the evidence collection process, an understanding of the phenomenon and the inter-relationship between its dimensions emerge. In this approach, there are no hypotheses developed a priori. This contrasts with "the deductive analytic approach that characterises experimental designs whereby variables and specific research hypotheses are specified in advance, with data collection geared toward testing the hypotheses and developing an understanding of the interrelationships among key variables" (Smith, 1981, p. 586).

There are systematic rules for conducting the research carried out in a number of stages: "entrée and access to the site, data collection, interpretation and analysis, writing, and finally leaving the site" (Searcy \& Mentzer, 2003). Naturalistic inquiry leads to theory development through its inductive process. From observing the phenomenon, and by reviewing the extant literature, the researcher induces a theory for the observed phenomenon (Tomkins \& Groves, 1983a). Tomkins and Groves (1983a) argued for accounting and auditing research to consider engaging with the naturalistic forms of inquiry because of the benefits that might accrue from it (for an extended debate on the use of naturalistic/qualitative methods in accounting research, see Abdel-Khalik \& Ajinkya (1983), Morgan (1983), Tomkins \& Groves (1983a) and Willmott (1983a).

Tomkins and Grove (1983b) explained that accounting or auditing research which considers naturalistic forms of inquiry focused on:

How practitioners perceive their worlds, what issues concern them, why these issues concern them and how they perceive them affecting accounting [or auditing and] the influence accounting [or auditing] has [on them]. In this way it is far more likely that academic research can be 
linked up with practitioners and their views of the world; in this way it is more likely that reliable theories about accounting [or auditing] in action and theories about the effects of alternative accounting [or auditing] procedures can be developed (p. 364).

Tomkins and Groves (1983b) then reasoned that :

'Naturalistic approaches' (a) will help to focus research on what is of interest to the practitioner, $(b)$ will persuade [the practitioner] to be more interested in our research because we will then be focussing on life as [the practitioner] sees it, (c) will therefore perhaps persuade [the practitioner] to sponsor it, (d) are perfectly respectable and rigorous even if they are not the dominant accounting research paradigm...(e) might help discover accounting research problems of which we have not previously been conscious" (p. 410).

Tomkins and Groves (1983a; 1983b) further explained that the emphasis of naturalistic approaches is that a state of reality is not independent of the observer, and that there are multiple views of reality. Therefore "if behaviour in relation to accounting [or auditing] information and its interpretation is the product of specific situation and group interactions, the ...naturalistic methodology is recommended" (Grimwood \& Tomkins, 1986, p. 259). Morgan (1983) explained that when a researcher adopts the naturalistic approach seriously, accounting theory may be brought much closer to accounting practice; and a theory of practice may be developed from the perspective of practitioners.

Very little is known about current practice in auditing environmental matters when auditors verify financial reports, an observation that led to this research. In particular, how New Zealand auditors deal with environmental matters in the light of AGS-1010 is not widely known. This concern was voiced by many audit practitioners at a seminar conducted by NZICA in 2003 for discussing newly promulgated auditing standards and guidance statements (Fisher, personal communication, June 20, 2003). Therefore, auditors should be genuinely interested in the research topic. Based on the discussions in Grimwood and Tomkins (1986), Morgan (1983), Schwandt (2001) and Tomkins and Groves (1983a) in support of naturalistic inquiries in accounting and auditing research, the researcher decided that a qualitative interpretive study with naturalistic orientation was most appropriate for this research study. Such an approach allows the probing of different views on current audit practices rather then suggesting them outright to the auditors (as in surveys). However, the current research was not carried out in an objective environment. In order to facilitate dialogue and detailed explanations, the 
researcher needed to interact with the research subjects, then interpret and make sense of the dialogues in order to arrive at 'thick' descriptions of the phenomenon under study (Schwandt, 2001).

Lincoln and Guba (1985) discussed fourteen axioms that have implications for the conduct of naturalistic inquiry research. However, as pointed out earlier in this chapter, their discussions were made in the context of case studies. Therefore, some of the axioms would not apply to the current research, which engaged qualitative interviews. Nevertheless, the axioms that are relevant to the current research actually provided further justifications for the choice of naturalistic inquiry. Moreover, by working through the implications of relevant axioms for the current research, the researcher was able to think more deeply about their operationalisation in the research plan, structure and strategy. Lincoln and Guba (1985) explained the terms used as follows:

The plan is the overall scheme or program of the research. The structure ... is the outline, the scheme the paradigm of the operation of the variables. Strategy ...includes the methods to be used to gather and analyse the data. In other words, strategy implies how the research objectives will be reached and how the problems encountered in the research will be tackled (p. 221).

The implications of each of the relevant axioms, and how they guided natural inquiry for this research study, are explained in the following sections.

\subsubsection{Axioms for Naturalistic Inquiry}

Lincoln and Guba (1985) listed fourteen axioms for naturalistic inquiry research. They are: (1) natural setting; (2) the human instrument; (3) tacit knowledge; (4) qualitative methods; (5) purposive sampling; (6) inductive data analysis; (7) grounded theory; (8) emergent design; (9) negotiated outcomes; (10) the case report; (11) idiographic interpretations; (12) tentative application; (13) focus-determined boundaries and (14) special criteria for worthiness. As previously indicated, the implications of some of the axioms do not fit this research because the focus of Lincoln and Guba is case study research. However, reflecting on each of the fourteen axioms was beneficial as it provided confirmation that the current study is indeed a naturalistic inquiry, even though not all fourteen axioms fit perfectly. Each of the fourteen axioms that do fit this research is discussed in the following sections. 


\section{Natural Setting (Axiom 1)}

Lincoln and Guba (1985) stated that naturalistic inquiry should be studied in the natural setting because:

Naturalistic ontology suggests that realities are wholes that cannot be understood in isolation from their contexts, nor can they be fragmented for separate study of the parts (the whole is more than the sum of the parts) (p. 39); [and that] no phenomenon can be understood out of relationship to the time and context that spawned, harboured, and supported it (p. 189).

Axiom 1 has implications for case study research and the explanation given by Lincoln and Guba (1985) indicates that axiom one does not provide a perfect fit for the current research, which engaged qualitative interviews that ask questions about auditors' actual practices. However, the current research is not a laboratory experiment or a simulation. Instead, it is grounded in the 'natural setting' of real day-to-day experiences. Thus, naturalistic inquiry can be said to be relevant for the current research and its choice is driven by research questions which are opinion seeking.

\section{The Human as Instrument (Axiom 2)}

Lincoln and Guba (1985) noted characteristics that "uniquely qualify the human as the instrument of choice for naturalist inquiry" (p. 39). Holstein and Gubrium (1998) also noted that 'the researcher' fits the characteristics indicated by Lincoln and Guba (1985), and added that the researcher is also capable "of grasping and evaluating the meaning of the differential interaction" between the instrument and respondents (p. 96). For this study, the researcher is the primary data-gathering instrument conducting and taping interviews with the respondents. The researcher enquired, and sought to gather and understand the different perspectives offered through interviews and document reviews. The researcher was not interested in testing any specific hypothesis, but rather sought to form as thorough as possible, an understanding of the dimensions of the 'audit of environmental matters when auditors verify financial reports', and to portray the totality of those dimensions as accurately as possible with the intention of building a body of knowledge in this area and thereby offering some insight to other individuals and organisations interested in undertaking a similar venture.

\section{Tacit Knowledge (Axiom 3)}

Lincoln \& Guba (1985) explained that there are some things that must be experienced to be understood; but it is impossible to describe or explain everything one 'knows' in 
language form. The researcher had previously worked as an auditor in one of the Big Six audit firms (now the Big Four firms). That prior experience has added to her intuitive 'felt knowledge' and it was used to understand the multiple realities about audit procedures and practices. The researcher's 'felt knowledge' not only guided the flow of the interviews, it also facilitated the process of understanding current practices in the audit of environmental matters.

\section{Qualitative Methods (Axiom 4)}

Naturalistic inquiry elects qualitative methods over quantitative methods (Lincoln \& Guba, 1985). The focus of the current study was aimed at a deep understanding of the nature of a current audit phenomenon. Hence, a qualitative approach was the appropriate method to use because it is more able to capture the multiple realities of the respondents in a deeper and more meaningful way than quantitative methods. The qualitative methods used for the naturalistic inquiry were interviews and document reviews. These methods were used to yield information on the five aforementioned areas of interest that served as the boundaries for the inquiry.

\section{Purposive Sampling (Axiom 5)}

"Naturalistic inquiry is...in favour of purposive... sampling" because it exposes more directly the exchanges between the researcher and the respondents (Lincoln \& Guba, 1985, p 40). Lincoln and Guba (1985) explained purposive sampling as "sampling done with some purpose in mind" (p. 202). Patton (1990) added that purposive sampling seeks information-rich cases which can be studied in depth. The objective of this study is to detail the many specifics that give context its uniqueness. On the other hand, random sampling, whose goal is to capture all possible cases for the whole range, would ignore the characteristics and idiosyncrasies of respondents, which is exactly what is of interest in this study. Hence, this study has appropriately engaged purposive sampling using snowballing techniques that led to a range of participants who formed a rich source of varied research evidence. This is interesting with regard to themes emerging from evidence collection and analysis.

\section{Inductive Evidence Analysis (Axiom 6)}

Inductive data analysis is a process for "making sense of field data" (Lincoln \& Guba, 1985 , p. 202). This analysis method was applied to the current research. The current research was driven by evidence gathered by qualitative interviews conducted at the participants' offices using an inductive approach. This meant that the researcher worked 
"from the interview evidence specific of participants to a more general conclusion" (Schwandt, 2001, p. 125). The researcher's interaction with the participants was guided by their different perspectives and values; and between the respondents and the process that took centre stage. Section 4.6 contains detailed explanations of the analysis of research evidence.

\section{Grounded Theory (Axiom 7)}

Lincoln and Guba (1985) suggested the implementation of grounded theory in naturalist inquiry. Where appropriate, the following aspects of the grounded theory approach: constant comparative analysis and sensitivity; and theoretical coding, were used to support data analysis for the current research. Details of actual data analysis are covered in section 4.6.

\section{Emergent Design (Axiom 8)}

Lincoln and Guba (1985) explained that "naturalistic inquiry elects to allow the research design to emerge, rather than to construct it, because what emerges as a function of the interaction between inquirer and phenomenon is largely unpredictable in advance" (p. 41). The implication of Axiom 8 does not provide a perfect fit for the current research because its general direction and focus were somewhat theoretically driven. However, the researcher did keep an open mind, eyes, and ears in order to adapt to the challenges and opportunities of qualitative research inquiry. Insights, theoretical elements, questions and gaps were identified and pursued further as the research progressed.

\section{Negotiated Outcomes (Axiom 9)}

Lincoln and Guba (1985) required that the researcher go back to the respondents with the tentative results and refine them in the light of the context "which can be best verified and confirmed by the people who inhabit that context" (p. 42). The University's ethics approval for this research project required a copy of any publication arising from the research to be sent to the participants for their comments prior to submission for publication. Where amendments were needed based on the comments received, a copy of the final version was to be sent to participants upon their request. This requirement will be adhered to before any publications arising from the research are being disseminated. Participants were informed that any publication arising from the research would be sent to them for verification and amendments would be made based on their comments, before submission for publication. They were also given the option of receiving a copy of the final report from the research. 


\section{Case Study Reporting Mode (Axiom 10)}

Case study reporting mode is said to be "suited to the naturalistic paradigm" (Lincoln \& Guba, 1985, p. 214) and is preferred to "the scientific or technical report" (p. 41). Lincoln and Guba (1985) explained that case study reporting provides "thick descriptions [which] is a means for bringing [the reader's] own tacit knowledge to bear, [which is] thought to be so essential for enabling transferability judgements" (p. 214). It was also said that "the purpose of a case report is not to represent the world, but to represent the case [or phenomenon]" (Stake, 2000, p. 448). This axiom is specifically for case study research and therefore does not provide a perfect fit for the current research. However, it may be inferred from the explanations given that for the current research the reporting mode should be such that it provides 'thick descriptions' of the issues and background information on the audit of environmental matters when auditors verify financial reports, with the researcher concentrating on the multiple realities of audit practitioners in order to provide pictures of "the value positions of investigator, substantive theory, methodological paradigm, and local contextual values" (Lincoln \& Guba, 1985, p. 42). The researcher has adopted this approach in writing up the current research.

\section{Idiographic Interpretations (Axiom 11)}

Lincoln and Guba (1985) indicated that "naturalistic inquiry is inclined to interpret data (including the drawing of conclusions) ideographically (in terms of the particulars of the case) [or phenomenon] rather than nomothetically (in terms of law-like generalizations) because different interpretations are likely to be meaningful for different realities" (p. 42). Thus, findings from the case study have "meaning for that context at that time only" (p. 216), because all of the research evidence is obtained from a single site only. This is another axiom which is not a perfect fit for the current research because the current research is not a case study which focuses on one single site only, rather it is a qualitative interview study which seeks the views of auditors from a number of locations, on the research questions.

\section{Tentative Application (Axiom 12)}

Lincoln and Guba (1985) cautioned that it would not be easy to apply findings from a particular naturalistic study to other contexts. The researcher accepts that, although some general principles and insights were gained from the richness of the description, exact replication and repetition in different environments or contexts might not yield 
similar results or effects, since world dynamics are ever-changing and over time become less known. Therefore, given the specificity of the data obtained from a study of a group of practising auditors, the findings cannot be generalised beyond the context and participants of the study. However, since not much is known about current practices in the audit of environmental matters when auditors verify financial reports, the findings from this study will contribute to the limited literature.

\section{Focus-determined Boundaries (Axiom 13)}

Lincoln and Guba (1985) asserted that the focus of the study guides naturalistic inquiry. They also stressed the importance of defining the boundary for a study: for this research study, the focus is the 'research aim'. They also explained that the establishment of a focus should define and guide the scope and concentration of an inquiry, and delineate the type of information that is of interest and relevance. They further noted that, with a naturalistic approach, the boundaries of an inquiry can - and usually do - change during the course of study in response to information, understanding, and questions that emerge during the data collection process.

The research aim of this study is to determine current practice(s) in auditing environmental matters when auditors verify financial reports. Given the lack of information on the topic, it was important to start work at the conceptual level, focusing on simply understanding how financial auditors approached their efforts to audit environmental matters. Hence, the focus defined the boundary of the naturalistic inquiry for the current research. This involved an exploration of the many dimensions that either comprised, or helped yield, an understanding of the research topic. The first dimension addressed by the naturalistic inquiry was the context of auditors and auditing in society, and that focus helped in understanding the 'audit practice'. The second dimension the naturalistic inquiry studied was current practices in the audit of environmental matters when auditors verify financial reports. The third dimension investigated auditors' response to aspects of AGS-1010 and their impressions of its effectiveness in guiding audit practice. The fourth dimension focussed on any challenges and issues that concerned auditors in their current practices; and the final dimension studied strategies on how current practices could be improved and further developed. 


\section{Special Criteria for Trustworthiness (Axiom 14)}

Research must be trustworthy. However, Lincoln and Guba (1985) noted, “...conventional trustworthiness criteria (internal and external validity, reliability and objectivity) are inconsistent with the axioms of naturalistic inquiry" (p. 42). Hence they made suggestions for "credibility, transferability, dependability and confirmability" as substitute criteria that, together with "corresponding empirical procedures", should "absolutely affirm the trustworthiness of naturalistic approaches" (Lincoln \& Guba, 1985 , p. 43). Since the issue of trustworthiness is of critical importance to naturalistic inquiry, the substitute criteria for trustworthiness: credibility, transferability, dependability and confirmabilty; are discussed in depth in the following sections.

\section{Credibility}

'Credibility', as the naturalistic inquiry equivalent to the conventional concept of 'internal validity', aims at confirming that the findings are credible constructions of reality (Silverman, 2005). However, Silverman (2005) asked: "How are [researchers] to convince themselves (and their audience) that their findings are genuinely based on critical investigation of all their data and do not depend on a few well-chosen examples?" (p. 211). Some authors have suggested method and data triangulation and/or respondent validation as ways of responding to the question asked by Silverman (2005). Triangulation refers to "the attempt to get a 'true' fix on a situation" (Silverman, 2005, p. 212). It adds to credibility by applying multiple sources, methods, investigations or theory to a study (Lincoln \& Guba, 1985; Patton, 2002). For this study, triangulation was achieved by inclusion of data from different sources (for example auditors in public practice, private practice and government auditors) which enabled novel insights from different perspectives. Convergence of observations from multiple respondents also enhanced confidence in the findings.

Theoretical generalisability also enhances credibility. The pre-conditions for generalisability, common for all accounting studies irrespective of the research approach "are theoretical knowledge of the subject, prior empirical results and their interpretations, and empirical results and their interpretations provided by the study in question" (Lukka \& Kasanen, 1995, p 84).

However, the extent to which research findings and conclusions can be generalised: 
Is done more in terms of the variety of experiences to be expected rather than in terms of an average value [and] the extent to which conclusions are consistent with both the literature and ...theory. [If] findings are based on the expected range of social settings that are likely to contribute to a particular experience, this strengthens the generalisability of the conclusions. If conclusions are consistent with the literature, while still adding something new, this strengthens conclusions, demonstrating that idiosyncratic interpretation has not been generated" (Daly \& Lumley, 2002, p. 299).

Spicer (1992) reiterated Daly and Lumley (2002), also noting that generalisability is "not to draw inferences to some larger population based on sample evidence, but rather to generalise back to theory" (p. 12). Other commentators also noted that a "tight theory goes a long way in strengthening the validity of the research study" (Searcy \& Mentzer, 2003, p. 159). Therefore, generalisability for qualitative naturalistic research is the ability to generalise back to theory.

Silverman (2005) explained theories as ideas that help to define or explain some phenomenon. Without a theory, such a phenomenon cannot be understood:

Theory provides a footing for considering the world, separate from, yet about, that world. In this way, theory provides both a framework for critically understanding phenomena and a basis for considering how what is unknown might be organised. [For generalisibility,] theories are self-confirming in the sense that they instruct us to look at phenomena in particular ways (Silverman, 2005, p. 99).

Llewellyn (2003) affirmed that qualitative researchers should view 'theory' as a representation of observed reality and explanation of regularities and relationships between empirical phenomena. She asserted that theories generate expectations of the world and are drawn upon "to gain theoretical leverage for a point of view of everyday discussion" (p. 665). She further commented that theorisation (or conceptual framing) adds value to qualitative academic research; and that empirical issues under discussion are better understood by theorisation. Llewellyn (2003) then explained that theory and data are inter-dependent. Theory enables the meaning of data to be accessible and data validates theories. The adequacy of theory is judged on the 'criteria of utility'. Llewellyn (2003) further identified and discussed five levels of theorization that are available to qualitative empirical research: "metaphor, differentiation, conceptualization, context-bound theorization of settings; and context-free 'grand' theorizing" (p. 676). 
In order to substantiate the requirement of 'credibility' for the current research, conscious effort was made at identifying possible theories that would provide appropriate explanations for the research findings. In doing so, many different established theories in the literature were read. This process led to identifying legitimacy theory as the most likely to be relevant to the research questions. However, it was only after the interviews were completed and the themes that came out of the interview findings identified, that legitimacy theory was confirmed as the most appropriate lens for interpreting and drawing meaning from this research. Chapter 3 discussed the underlying concepts for legitimacy theory and its relevance to audit research. Chapter 6 will discuss the implications of the research findings in relation to legitimacy theory.

\section{Transferability}

'Transferability' as the naturalistic equivalent to the conventional concept of external validity shifts the responsibility for transfer of the research findings from the researcher to the reader. In order to do this:

Thick description [is] necessary to enable someone interested in making a transfer to reach a conclusion about whether transfer can be contemplated as a possibility...[Thus the researcher] is responsible for providing the widest possible range of information for inclusion in the thick description...that makes transferability judgement possible on the part of potential appliers (Lincoln \& Guba, 1985, p. 316).

Therefore, to establish transferability for the current research, as much information as possible about the research study and findings were included in the write-up of the thesis.

\section{Dependability and Confirmability}

'Dependability' is the naturalistic equivalent of the conventional concept of reliability and 'confirmability' is the naturalistic equivalent of objectivity. Lincoln \& Guba (1985) suggested that an 'audit trail' be maintained carefully throughout the course of the naturalistic research to provide a level of assurance for dependability and confirmability. An audit trail "consists of documentation of the nature of each decision in the research plan, the data upon which it was based, and the reasoning that entered into it" (Owens, 1982, p. 13). It will enable the verification of the consistency and credibility of research procedures and make it possible to reproduce the study at another time. 
A researcher's personal log should provide the audit trail. It should record all the contacts made throughout the study from beginning to end, explanations and reasoning for every decision made as the investigation unfolds and the hunches, guesses, feelings and perceptions of the researchers as they occurred during the course of the investigation (Owens, 1982, p. 13).

Moreover Ahrens and Dent (1998) added that "diaries, charts and records of interactions and observations ... are of course crucial in establishing the credibility of stories" ( $\mathrm{p}$. 10). Following the suggestions made by Owens (1982) and comments made by Ahrens and Dent (1998), the researcher kept a naturalistic research plan and a personal log, which detailed strategies for collecting and analysing data, and any other information considered relevant. The researcher used information from the personal research log to substantiate the thick descriptions in the write-up of the thesis.

In summary, the above section discussed the methodology adopted for this research study. It is a qualitative, interpretive research study, and adopted a naturalistic inquiry approach. Justification for adopting naturalistic inquiry and the implications of the fourteen axioms for naturalistic inquiry were also discussed. Qualitative interviews were conducted to gather research evidence for the research questions listed in section 4.1. Discussions on the methods used in evidence collection and analysis follow on from here. However, before the methods are discussed, the research context and participants are described in the next two sections.

\subsection{The Research Context}

The interviews were mostly conducted in Auckland, the largest city in New Zealand and location of the majority of audit firms. The researcher is also situated in Auckland and, thus, efforts were made to secure as many interview sessions as possible in the Auckland region. However, the researcher did travel to Wellington and Christchurch to interview individuals whose names were suggested by interviewees as persons with an interest, or expertise, in environmental risk assessment. The research participants are discussed in the next section.

\subsection{The Research Participants}

The following table provides a breakdown of the participants for this research study. Altogether, twenty-seven participants were interviewed in thirty-two individual and six group-interview sessions during the months of June to November 2005. Table 2 present the categories of participants interviewed in the different cities. The interviews were 
held in the participant's office. The maximum number of interviews was reached when participants started to give similar information (i.e. saturation point).

Table 2: Categories of financial auditors interviewed

\begin{tabular}{lrccc}
\hline Financial auditors & Total & Auckland & Wellington & Christchurch \\
\hline $\begin{array}{l}\text { Financial auditors (FA) } \\
\quad \text { the Big 4's }\end{array}$ & 10 & 8 & 2 & \\
$\quad$ Medium sized firms & 8 & 8 & & 2 \\
\hline Public sector auditors (PSA) & 7 & 3 & 2 & \\
\hline $\begin{array}{l}\text { Government Auditors - from the } \\
\begin{array}{l}\text { Office of the Auditor General } \\
\text { (OAG) }\end{array}\end{array}$ & 2 & & 2 & $\mathbf{2}$ \\
\hline Total - Financial auditors & $\mathbf{2 7}$ & $\mathbf{1 9}$ & $\mathbf{6}$ & \\
\hline
\end{tabular}

The primary aim of the research was to interview auditors for their comments on the research questions. Audit partners and managers were selected for the interviews, because they are the ones in the audit teams with the expertise, experience and technical competence required to assess potential environmental risks at the audit planning stage, before audit fieldwork is conducted. Eighteen of the auditors interviewed were from chartered accounting firms; seven were public sector auditors, two were government auditors from the Office of the Auditor General and four were from environmental audit companies. All the other auditors interviewed were chartered accountants and members of NZICA. Essentially, they were financial auditors with a role in verifying the truth and fairness of financial reports. The next section discusses the research instrument and the methods used for collecting research evidence.

\subsection{The Collection of Research Evidence}

Semi-structured qualitative interviews were conducted to gather comments from the auditors on the research questions listed in section 1.2. Relevant audit standards and AGS-1010 were also examined for professional standard requirements and guidance on current audit practice. The next section discusses the review of audit standards and AGS-1010 and, following that, the conduct of the semi-structured qualitative interviews is discussed. 


\subsubsection{Document Review}

The current study is intended to explore audit practice in relation to AGS-1010. Therefore, an understanding of AGS-1010 itself is of importance to the research. Hence, that audit guidance standard was critically reviewed and analysed to determine its effectiveness in guiding audit practice. AGS-1010 referred to the application of other auditing standards when considering environmental matters: Audit Standard (AS) 302: Knowledge of the audit environment; AS 402: Risk assessments and internal control and AS 208: Consideration of laws and regulations in an audit. Each of these promulgations in turn was reviewed to determine any linkages to AGS-1010, and any inconsistencies in their requirements when compared with those of AGS-1010. Official comments submitted to NZICA on AGS-1010 when it was just an exposure draft were also obtained from NZICA and examined. Reading the official comments led to a deeper understanding of the issues identified in AGS-1010 with which auditors were contending. Secondary documents such as newspaper accounts and journal papers were also read and they provided much of the context for the current research. Generally, reading and critically analysing primary and secondary documents facilitated the development of research questions and assisted in determining potential theories within which to frame the research. The next section discusses the interviews conducted.

\subsubsection{The Interviews}

Interviews assisted in identifying factors that cannot be observed directly, and issues of immediate importance to the interviewees (Gillham, 2000).

The interview method also allows the respondent's own perspective to emerge and the researcher to gain insight into particular experiences, find out motives behind decisions, get a view of informal procedures, consider apparent contradictions between attitudes and behaviour, and allow respondents time to provide their answers. Interviews are good ways of eliciting opinions on complex and sensitive issues (Hannabuss, 1996, p. 26).

Interviews have particular strengths. An interview is a useful way to get large amounts of data quickly. It facilitates an understanding of the meanings that people attach to their everyday activities (Appleton, 1995). It also allows any ambiguous or unclear questions that may be misinterpreted by participants to be clarified by the interviewer during the interview (Silverman, 2005). Interviews are appropriate when people are accessible; when most of the questions are 'open' and require an extended response with prompts and probes; when the material is sensitive in character so that trust is involved; when 
anonymity is not an issue though confidentiality may be; when depth of meaning is central and research aims mainly require insights and understanding (Appleton, 1995; Hannabuss, 1996).

However, interviews are not without limitations and weaknesses. They are often intensive and time-consuming to carry out, and may cover only a small and possibly unrepresentative sample of respondents (Silverman, 2005). Accessibility to the respondents may be an issue. Respondents need to be approached, but people are busy and may be suspicious. They may be widely dispersed geographically and may need to be approached through gatekeepers in organisations who steer the researcher towards unrepresentative respondents or even block the researcher's access altogether (Lincoln \& Guba, 1985). Interviews involve personal interactions and co-operation is essential. However, participants may be unwilling or unable to share all that the researcher hopes to explore, or may be uncomfortable with doing so. They may hide or misrepresent information, making it difficult to obtain accurate experiential information. Participants may not want to talk 'on the record' (Jarratt, 1996; Patton, 2002).

Despite the potential limitations of participant interviews, they are particularly suited to qualitative naturalistic inquiry (Patton, 2002). Interviews were used for the current research study because of this method's particular strengths in allowing the researcher to obtain insights and depth of understanding about auditors' and other experts' opinion on the audit consideration of environmental matters in financial reporting. The duration of interviews were kept to no more than one hour, thus they were not overly timeconsuming. People whose names were obtained by snowball sampling were known by the participants, thus access was not a problem when contacts were made. Generally, people were willing to be interviewed. Every participant had a special interest in the research topic and hoped to see the audit of environmental matters move forward from the present position. Thus, participants were willing to dialogue on the research topic. They were also candid with their views.

Interviews are often categorised into different types: the informal conversational interview, the general interview guide approach, the standardised semi-structured and the open-ended interview (Patton, 2002). In particular, a face-to-face, individual, standardised semi-structured interview was chosen for the current research. A review of the literature had led to particular issues being identified and these were tested in the 
current study with the use of standardised semi-structured interview questions. However, within the structure, open-ended questions were asked to further explain or discuss a particular point of interest. To some extent, this approach did facilitate the organisation of the findings. However, Patton (2002) cautioned that the purpose of open-ended interviewing is not to put ideas into someone's mind. Practical aspects of research interviews, namely: (1) steps taken before the interviews; (2) negotiating access; (3) conduct during the interviews; and (4) taping and transcribing the interviews are discussed next.

\subsubsection{Before the Interviews}

Before the actual interviews took place, the researcher applied for ethical approval, prepared the participant information- and consent- sheets, and developed the interview guide. Each aspect of the preparation before the actual interview is now elaborated on.

\section{Application for Ethical Approval}

Ethical approval was required because this research involved human participants. Application was made and ethical approval (AUTEC reference no: 05/84 dated 16 May 2005 for a period of three years until 16 May 2008) was granted by the Auckland University of Technology Ethics Committee (AUTEC). The ethical approval for the current research was given based on the key principles that AUTEC used in its decision making to ensure a high level of ethical research. The key principles are: (1) Social and cultural sensitivity, including a commitment to the principles of the Treaty of Waitangi/Te Tirti O Waitangi; (2) Informed and voluntary consent; (3) Respect for rights of privacy and confidentiality and (4) Respect for property and intellectual property rights.

\section{Participant Information Sheet}

Before contacting the auditors and other participants, an information sheet on the research project (refer to Appendix 2) was prepared. It stated the objective of the research study; specified the target interviewees (auditors) and duration of the interview (about one hour). It also stated that upon completion, participants might request results of the study published in aggregate form via the doctoral thesis, academic papers and conference presentations. It also assured participants' confidentiality, since published data would not report the names of affiliations of informants and would use generic job titles only. The document ended by emphasising the researcher's commitment to follow AUT University Ethical Committee's ethics guidelines. 


\section{Participant Informed Consent Sheet}

A consent sheet (refer to Appendix 3) was also prepared and given to the participants to sign before the interview commenced. It confirmed that the participant had read and understood the information provided on the research project; had an opportunity to ask questions and have them answered; had understood that the interview would be audiotaped and transcribed; could withdraw from participating or withdraw any information provided for the study at any time prior to completion of data collection without being disadvantaged in any way; and was aware that all relevant tapes and transcripts, or parts thereof would be destroyed on their decision to withdraw from the interview.

\section{The Interview Guide}

Auditors are busy people and a number of them had indicated that they were able to allocate no more than one hour for their interview. Hence, before the interviews took place, the researcher prepared an interview guide (refer to Appendix 4). The aim of this was to ensure that the available time was used well to cover the research issues. Covering similar questions for each interview delimits the issues to be explored in advance to only those that focus on the main research questions. This made interviewing a number of people more systematic and comprehensive (Patton, 2002).

The interview guide used for the current research was made up of standardised semistructured questions, which every participant was asked. There are many advantages in using standardised semi-structured questions. With each participant asked the same questions, interviewer effects and subjectivity were minimised. Since the interview was systematic, the necessity for interviewer judgement during the interview was reduced. Data analysis also became easier because each auditor's answer to the same question could be quickly located and organised. However, Patton (1990) cautioned that the purpose of standardised open-ended interviewing is not to put ideas into someone's mind. A further advantage of using standardised open-ended questions is that decision makers and information users are able to inspect the exact instrument used in the evaluation. In addition interviews were highly focussed and interviewee time more carefully used (Lofland \& Lofland, 1984).

A semi-structured interview guide (refer to Appendix 4) was designed, guided by the research questions, previous research, and the researcher's own 'tacit knowledge' gained through practical audit. However, the interview guide was designed specifically 
for this study, as no previous research studies in this area were available. The interview questions were written in advance in the order in which they were asked during the interview. However, the researcher incorporated some flexibility in exploring further, any emerging paths that arose from the interviews.

After the above tasks were completed, access was negotiated with potential participants. A list of confirmed participants for the interviews was then prepared. Steps taken in negotiating access are discussed next.

\subsubsection{Negotiating Access}

Financial auditors and non-financial auditors were the two groups of people initially approached for participation. It was more difficult to gain access to financial auditors and the following is a discussion on how the researcher negotiated access to them. The researcher first made a list of contact addresses and telephone numbers of audit firms and individual auditors from the Telephone Yellow Pages and results of a Google internet search for "Chartered Accounting firms in Auckland". The researcher then gathered from the audit firm's internet web pages more information on the firm's audit department and audit staff. A list of possible contacts was then compiled.

In total, fifty-five financial auditors (from now on known as 'auditors') were approached either by email or by telephone. Each non-replied email was followed up with a telephone call. Of those approached, twenty-seven were willing to participate in the interviews. Fifteen auditors did not reply to the numerous attempts to contact them and thirteen answered negatively. Of the thirteen who refused participation, six said that they did not have clients with environmental problems and therefore were not able to assist. One auditor said: "I had not read AGS-1010 and I do not know its content. Thus, I do not know how much I can be of help to you”. The number of refusals to provide research data may be subject to criticisms of representativeness. This criticism is addressed by highlighting it as a limitation of this study (refer to section 7.4).

A number of auditors had misunderstood the research topic. Three auditors thought that the research study was on 'environmental auditing' and two auditors thought that the research was on 'the audit of independent stand-alone environmental reporting'. This indicated that for a number of auditors approached, they were not entirely sure or clear about their position with the audit of environmental matters in financial reports. This 
study is therefore timely in bringing into the open an audit phenomenon that seemed unclear.

Turley (2004) forewarned that "a frequent problem in research design is achieving the desired level of access, which can be thwarted by the barrier of client confidentiality", used to deny access even though specific identification of clients was not needed ( $\mathrm{p}$. 455). He also added that, sometimes, there was initial scepticism about the research agenda, and the threats that agenda might pose for the firm (Turley, 2004). Turley (2004) and Gendron (2000) also pointed out other potential obstacles and made suggestions for a few practical guidelines for overcoming them. Each of the issues raised and the suggestions made by Turley (2004) and Gendon (2000) are discussed next in the context of the current research study.

First, Turley (2004) and Gendron (2000) observed that audit partners and managers are busy people and their meetings are scheduled and organised by their personal assistants (PAs). This led them to suggest that the PAs should be approached first to explain the research and to request an interview with the auditor. For this study, establishing a line of communication with each of the PAs often led to securing appointments for interviews. The PAs were first rung to establish contact, in order to build the kind of confidence that would facilitate access. In fact, approaching the PAs first for interview appointments, rather than directly approaching the auditors was more successful. It usually took a day or two before the PA rang back after our initial conversation. If the auditor agreed to an interview, the PA made an appointment with the researcher.

Second, Turley (2004) mentioned that if participants were uncertain about what was being requested, then access was more difficult. Thus, before attempting any telephone contact, information on the research study was first emailed to potential participants. This strategy led to many successful outcomes. When a PA was contacted for assistance in making appointments with the auditor, the PA appeared to have an understanding of the research study already, and was obliging with the request for an interview with the auditor. Their knowledge of the research study indicated that they had access to their bosses' emails and other correspondence, and explained the PA's ability to respond quickly.

The third potential obstacle noted by Turley (2004) is the busy peak period when auditors are time-pressured and thus less willing to be interviewed. In order to mitigate 
this concern, many of the interviews were planned for the months of June and July, which is not generally the busiest period of the financial year for auditors. Six interviews were conducted at six o'clock in the evening and three interviews were conducted at seven-thirty in the morning. At such times of the day, the auditors did not have to give account on their use of time. One particular participant did not feel right in using chargeable time for the interview, so he suggested a meeting during his lunchtime. Since he was from another city, he did not have any transport, and had to be driven to a shopping mall to buy his lunch, which he ate in the car while being interviewed.

Fourth, Turley (2004) remarked that providing a benefit to participation might lead to more success in securing an interview. Hence, it was indicated on the information sheet to potential participants that results of the study published in aggregate form via the doctoral thesis, academic papers and conference presentations would be made available to them if they requested for them. Some of the participants accepted the offer.

In addition to the recommendations made by Turley (2004) and Gendron (2000), the researcher employed additional strategies. In line with ethical requirements, the assurance of utmost confidentiality was emphasised to the participants. Furthermore, the information sheet emphasised that the researcher is a Chartered Accountant who was awarded a scholarship by ICANZ (currently called NZICA) to pursue the current research study. This helped in establishing the researcher's credibility. Similar steps were also taken by the researcher when negotiating access with other non-financial auditor experts.

Generally, there were no significant access problems encountered. However, there were the inevitable odd occasions when participants cancelled scheduled meetings at the last minute or asked for someone else to be interviewed instead. On two occasions, the intended interviews were cancelled when the researcher arrived at the auditor's office. A third frustrating episode involved one auditor who had initially agreed to be interviewed and then decided half way through the actual interview that he was not the right person to be interviewed. He then decided to cut short the meeting. In a forth incident, four audit partners of the same Big 4 firm who were approached separately conferred with each other. They decided that since their clients were 'clean' and they did not think their client's business activities affected the environment; they would decline the invitation to be interviewed. Instead, they got their Sustainability Manager to 
participate in the interview. He was interviewed but the information provided was somewhat irrelevant to the research topic. In yet another incident, an auditor of a different Big 4 firm would not commit to an interview, but promised that he would get a staff member to contact the researcher. The person who finally made contact was a junior staff member on secondment from Canada. He was inexperienced in environmental matters, so felt that he could not help with the research. However, no other audit partner or manager of that firm was willing to participate. It could be said that reasons for their reluctance to be involved in the qualitative interviews (if probed further) would provide rich information on the research topic. However the problem is one of access and is highlighted as a limitation of this study, (refer to section 7.4). The next section discusses the conduct of the interviews.

\subsubsection{Conducting the Interviews}

As a preamble to the actual interview, appreciation of time given to the researcher was communicated to the auditors. The auditors were also reassured that the researcher was not judging current practices; rather the researcher was only seeking useful information for the study. This often put the participants at ease. During the interviews, they appeared to have an open attitude and made very helpful comments, using examples they had come across during their audits to illustrate their comments. However, they were very careful not to mention the names of the companies that had environmental problems, and which they had audited. All the auditors interviewed appeared genuinely interested in the research even though some of them had indicated they did not have any clients with environmental matters in their financial reports. In their situation, they spoke of what could be done if they had detected any environmental concerns for their clients.

Interview protocols were followed for each interview. During the first minutes of the meeting, appreciation for the participants' involvement was acknowledged. Some 'small talk' quite unrelated to the research, but of relevance to the profession ensued. This was followed by thanking the interviewee for participating in the study and then introducing the informed consent form (refer to Appendix 3) as a University requirement for ensuring that the researcher's conduct was ethical. The consent form was also used to describe the broad objective of the research, ask for permission to tape the interview; specify the interviewee's right to refuse answering any question, and to describe the steps taken to ensure anonymity. The participant was than asked to sign the form. All 
the participants willingly signed the forms without asking any questions. Perhaps the comprehensiveness and official ethical procedures had provided them with assurance of trustworthiness.

The participants were then asked questions from the interview guide (refer to Appendix 4) which was handed to them a week before the interviews. During the interview, attentiveness was required in order to prompt for further elaboration or clarification of the issues that emerged. At the same time, notes were also written. Towards the end of each recorded interview, the participant was always asked whether anything important was omitted and whom the participant would recommend for the next interview. The participants were often very helpful in suggesting people whom they felt would be knowledgeable in the research topic area. They were also willing to disclose additional information that they considered important to the research study. The last two questions asked at the end led to a good closure to the interview because in asking those questions, the interviewees appeared to be feeling valued for their opinion and suggestions.

Even after the tape recorder was turned off, there was a requirement to be alert for any additional information that the participant might disclose. Often though, when the tape recorder was turned off, the participant very quickly showed the researcher out of the interview room, feeling very conscious of the time spent and rushing back to work. Finally, before leaving the participant's office, the researcher always indicated to the participants that they might be contacted to clarify some answers and then thanked for the information provided. Also after each interview, time was given to modifying interview questions that were perceived to be 'less effective', and to writing notes on ideas that might later be useful in making sense of the data.

The interviews were conducted during the months of June to November 2005. Guba (1978) outlined the criteria for when to stop the data collection process: 1) exhaustion of resources; 2) emergence of irregularities and 3) over-extension, or going too far beyond the boundaries of the research. For the current research "interviews were discontinued at the stage when analysis of further interviews was seen to not reveal new information" (Kurunmaki, 2004, p. 343); "when little or relevant data seemed to emerge from the later interviews, which tend to imply that the interview results were becoming theoretically saturated" (Herrbach, 2006, p. 401). For this study, the interviews were 
discontinued when the information given became repetitive. The next section discusses the taping and transcribing of the interviews.

\subsubsection{Taping and Transcribing the Interviews}

How to record interview data is largely a matter of personal preference. For instance, Patton (1990) considered a tape recorder as "indispensable" (p. 25), while Lincoln and Guba (1985) “do not recommend recording except for unusual reasons" (p. 241) because they felt that tape recorders were intrusive and might fail technically. However, twenty years on, most people are very comfortable with being taped (Silverman, 2005). Recordings have the advantage of capturing data more faithfully and accurately than hurriedly written notes. Recordings also make it easier for the researcher to focus on the interview. It is for these main reasons that the researcher decided to tape record the interviews with a digital tape recorder even though there was the risk that the presence of a tape recorder might prevent participants from disclosing some information. None of the interviewees objected to the use of a tape recorder. Before each interview, the tape recorder was tested to ensure that it was in good working order, and the internal label with the interviewee's name and date of the interview was prepared.

The taped interview was then transferred and saved on the computer as a voice file. All the transcribing was done by a transcriber who signed an agreement on confidentiality and non-disclosure. She was also given the contact details of the researcher and encouraged to get in touch should any questions arise.

The researcher undertook the following steps to ensure that the transcription was as accurate as possible. First, the researcher explained the project to the transcriber. Second, a copy of the interview guide was provided to give the transcriber some idea of what to expect, rather than having to tackle the transcription task 'cold'. Third, a completed transcription was given as an example. Fourth, the researcher explained and emphasised the importance of adhering to instructions on formatting the transcriptions as MSWord documents in a standard format for uploading to a computerised qualitative data analysis programme (NVivo 7). Next, the transcriptions were set out clearly in question/answer format, in accordance with the actual course of the interview in order to facilitate data analysis. Last, each completed transcription was checked for accuracy when it was emailed back to the researcher. The transcriber was also requested not to delete her record of the transcription until the researcher confirmed that it has been 
received. Any other notes written manually were attached to the transcription for later analysis.

Once all the taped interviews were transcribed, the transcriptions were prepared for analysis. NVivo7, a qualitative data analysis software programme was used to manage the analysis of the interview transcriptions. The next section covers the method of analysing the interview transcriptions, followed by a discussion on the use of NVivo7 for managing the actual analysis process.

\subsection{Analysis of the Interview Evidence}

Bogdan and Biklen (1982) defined qualitative analysis as "working with research evidence, organising it, breaking it into manageable units, synthesising it, searching for patterns, discovering what is important, what is to be learned and deciding what you will tell others" (p. 145). Patton (1990) observed that qualitative researchers tended to use inductive analysis of research evidence, meaning that the critical themes emerge out of the evidence. The challenges in qualitative analysis are: to place the raw evidence into logical, meaningful categories; to examine them in a holistic fashion; and to find a way to communicate this interpretation to others (Patton, 1990). For the current study, analysis of the research evidence was informed by a number of research papers (Cavana et al., 2001; Lincoln \& Guba, 1985; Rubin \& Rubin, 2005; Silverman, 2005) but focussed specifically on the work of Huberman and Miles (1994) and Lincoln and Guba (1985). The analysis was directed by the semi-structured interview questions and research topic, and subjected to "the three-stage analysis method" described by Huberman and Miles (1994, p. 10): (1) reducing and coding the interview evidence; (2) reporting the interview evidence and (3) drawing conclusions. Each of these three stages is discussed next.

\subsubsection{Reducing and Coding the Interview Evidence}

Research evidence reduction refers to the process of selecting, focussing, simplifying, abstracting and transforming the evidence (Appleton, 1995) as the researcher elicits insights from the participants' perspectives (Lincoln \& Guba, 1985). In the initial stages of evidence reduction, each paragraph of the interview transcript was numbered according to the question number to which it related in the interview guide (refer to Appendix 4). The actual process of analysing the interview evidence began when the text of the interview transcriptions was read and re-read in order to become familiar 
with the data. During the preliminary reading of the interview transcripts, evidence that did not add meaning or value to the analysis was removed. Semi-structured interview questions were used for evidence collection. All the interview evidence for each question was gathered together and then first coded to each of the preset categories and later to emergent categories as they became apparent. Preset categories were preconceived themes and concepts from the research topic that formed the focus of the research.

For the current research, the preset categories were the five research questions. They provided direction for what to look for in the interview evidence. Preset categories were identified before the interview evidence was coded by searching the interview evidence for text that matched the preset categories. Emergent categories, on the other hand, were categories that emerged from the interview evidence, and were defined after the researcher had worked with the interview evidence. They were themes or issues that recurred in the interview evidence, and were not anticipated. These new categories were added to the preset categories. To make the analysis more manageable, interview evidence in each of the three preset categories were re-analysed and broken down into several sub-categories. During this process the emerging patterns were continuously questioned and searched for other plausible explanations of the interview evidence (Anderson-Gough, 2004). The text was also read and re-read to ensure that the interview evidence was correctly coded.

The task of analysing research evidence is reflective, subjective and iterative. After the first coding phase, the same evidence was re-coded a second time to ensure consistency in the coding. As the interview evidence was organised into categories and subcategories, patterns, themes and connections, both within and across categories, began to emerge. These themes and connections were then interpreted and the interpretations were used to explain and communicate the research findings. Reflecting on the research findings also enabled connection with the extant academic literature and possible theories, which assisted in pointing to an appropriate theoretical perspective for framing and interpreting this doctoral research. However, the actual evidence analysis was managed with the use of NVivo7, a computerised, qualitative, evidence-analysis software programme. An outline of its use follows the discussion on reporting the interview evidence and drawing conclusions (refer to section 4.7). The next section discusses the interpretation and reporting of the interview evidence. 


\subsubsection{Interpreting and Reporting of the Interview Evidence}

Ahrens and Dent (1998) provided advice on reporting interview evidence. First, “...informants' literal, unedited statements" must be clearly "...distinguished from the researcher's own opinion" (p. 10). Second, the structure of the reporting must be carefully thought through because "to structure an account is effectively to provide an explanation" (p. 10). Ahrens and Dent (1998), referring to Krieger (1984), suggested two rules of presentation:

The first was to construct the report almost entirely by paraphrasing from the interview and documentary evidence. According to this rule, she would allow herself little interpretive comment in the body of her text, her only commentary being in connectives moving the reader from one paraphrased passage to the next. The second rule was that her account should not be partial to any one person or point of view, representing " $a$ particular angle of vision, line of interpretation or a single theory". Rather, it should capture the complexity of the composite whole, setting out "a pattern in which everything was important" (Ahrens \& Dent, 1998, p. 10).

Ahrens and Dent (1998) also noted that "it was important to present data in sufficient depth to allow the linking from data to theory to be traced and also the researcher's own opinions to be distinguished from participants' literal unedited speech statements" (p. 24). Their advice was followed when reporting the research findings for this study. It enabled patterns to be discerned for theory building. In the current research study, qualitative evidence was presented in the form of narrative text supported by excerpts from the data. The process of pattern making led to the emergence of descriptive themes which are "suggestive of quite particular theoretical implications" (Ahrens \& Dent, 1998, p. 31).

The evidence gathered from interviews conducted with twenty-seven practising auditors in chartered accounting practice, the public sector and the government office was analysed as follows. First, all the interview comments were considered and dominant common themes were identified. The interview evidence that captured best the spirit of these common themes was then reported in the thesis. However, in order to account for the variety of comments made by the interviewers - some of which did not accord with the common themes - an indication was given of the percentage of interviewees that communicated similar views and examples of discordant views were included to provide context. Chapter Five and Chapter Six report this interview evidence. The next paragraph describes how conclusions were developed from the analysis. 
Huberman and Miles (1994) advised that what 'things' mean should be decided on from the commencement of evidence collection. In this study, preliminary conclusions were drawn as the interviews were analysed, and conclusions were drawn after evidence collection was over. 'Confirmability' of the evidence was tested as outlined in section 4.2.2 (Axiom 14). The next section discusses the researcher as sole analyst.

\subsubsection{The Researcher as the Sole Analyst of the Interview Evidence}

The researcher was the sole analyst of the interview evidence. A second person was not engaged to ensure 'inter-coder agreement' (Abeysekera \& Guthrie, 2003): interpreted as the accuracy of the performance of one coder as compared with the accuracy of another coder. The decision made not to engage a second coder was based on Abeysekera and Guthrie (2003) who indicated that a dual assessment would be considered as a test of stability, rather than accuracy according to an accepted norm. They further contended that inter-coder agreement, also referred to as 'consensus coefficients' have some weaknesses. A low coefficient can create doubt about the reliability of data and a high coefficient can seem trustworthy even if it is unreliable owing to a high frequency of false data (p. 90). Similarly, Krippendorff (2004) explained this phenomenon as follows:

Two coders in the same event who hold the same conceptual system, prejudice, or interest may well agree on what they see but still be objectively wrong. Because content analysts have acquired a language and concepts that make them see the world from the unique perspective of their academic discipline, their observations and readings are based in a consensus that is not likely shared by many people outside of their scholarly community (p. 213).

The reliability and validity of inter-coder agreement have also been criticised. Ahuvia (2001) argued that inter-coder reliability in no way indicates that the coding reflects a popular or widespread interpretation of the texts. Even when referring to 'independent' replicability, he argued that inter-coder assessment merely provides evidence that the coding rules were followed. When coders have received training on how they should code the texts, then they are following coding rules and not their own intuitions. Moreover, he argued that multiple coders work cooperatively rather than independently, and that may defeat the purpose of ensuring validity. Krippendorff (2004) added that “even though most investigators publish respectable indices of inter-coder agreement in categorising the responses, these are open to serious questions. Usually the published inter-coder agreement is based on two people who have worked together intimately in 
the development of a coding scheme, and who have engaged in much discussion of definitions and disagreements" (p. 130).

Some observers also argue that, in principle, a single coder is sufficient (Ahuvia, 2001) because well-specified decision categories with well-specified decision rules reduce the need for multiple coders (Milne \& Adler, 1999). Abeysekera and Guthrie (2003) asserted that "the results of the sole researcher's judgment should be trusted in semantic analysis, as this seems to be the only feasible way of attaining a measurement of the veracity of data concerning semantic content" (p. 90). The next section discusses the management of the research evidence using NVivo 7.

\subsection{Managing Interview Evidence Analysis with NVivo7}

NVivo 7, a computer-assisted, qualitative data-analysis software program (CAQDAS) was used to manage the evidence analysis process. It is a software program for qualitative evidence administration and archiving rather than a tool for actual analysis. It facilitates the processes of identifying categories or themes in the evidence; marking them with code words and then retrieving them for further analysis and theory testing (Crowley, Harre', \& Tagg, 2002). Walsh and Lavall (1998) summarised CAQDAS as follows:

Qualitative research $(Q R)$ software is not magic. You must find the themes and evolve theories. But software facilitates your work by letting you take notes, mark quotations, connect them conceptually or graphically and add memos that explain your reasoning. When you are done, a good QR program will help you to demonstrate to your client why your analysis has captured what is happening. You can show where each theory is grounded in what people said and did. You can show how the theories connect together to make a general picture or story that explains what is going on and suggests a solution (p. 42).

There are many authors who applaud the advantage of harnessing computer processing power in dealing with the tedium of clerical tasks involved with qualitative research (Conrad \& Reinharz, 1984; Davies, 1993; Drass, 1980). This use of the computer also releases the researcher for the analytic process (Lee \& Fielding, 1991). However, CAQDAS "is no substitute for thoughtful coding and intelligent analysis" (Dolan \& Ayland, 2001, p. 386). This remains the task of the researcher who is "still very much involved with the key activities of qualitative analysis such as searching for meaning, interpretation and identifying serendipitous findings" (Dembkowski \& Hammer-Lloyd, 
1995, p. 59). "The development of theories is still dependent on individual researchers and their ability to expand the data through interacting with and thinking about it" (Dolan \& Ayland, 2001, p. 379). All CAQDAS can do is to follow instructions predefined by the researcher (Tesch, 1991). It is not aware of anything other than the text properties of the data, and cannot interpret, or make deductions and generalizations from the data (Brent, 1984; Drass, 1980).

A question commonly asked of researchers is whether the use of CAQDAS strengthens the validity of their conclusions. Huberman and Miles (1994) advocated transparency of data and procedures in qualitative studies by careful retention, in an easily accessible form, of all study material. A more detailed discussion is covered under the sub-heading: Special criteria for trustworthiness (Axiom 14) (refer to section 4.2.2). According to Richards and Richards (1991), CAQDAS has the ability to log the steps taken and to show very rapidly the context of quotations used to substantiate conclusions which opens the whole process to checking and verification. Thus, the soundness of conclusions can be further strengthened by the use of the computer to assist the analytic process "removing the uncertainty and tentativeness of conclusions" (Richards \& Richards, 1991, p. 38). Since there are many advantages in using a CAQDAS, and particularly since the researcher is in full control of the data coding and analysis and CAQDAS is able to strengthen the validity of research conclusions, it was decided to use CAQDAS for the current research study.

The following steps were taken to manage the data analysis. First, all the transcription documents (saved as MSWord documents) were imported into the NVivo7 project platform, ready for coding. Second, nodes (or 'empty containers) were created for the preset categories and emergent categories. Each node was labelled and given a description to ensure consistent coding. Nodes for pre-set categories were created before the interview transcripts were coded. However, nodes for emergent categories were created as they emerged from the interview evidence, and defined. The third step was the actual coding of the transcription documents previously imported into NVivo 7. As each transcript was read, words, phrases or paragraphs that seemed significant were noticed, and coded to the appropriate nodes straight away. Once coding of the interview transcripts was completed, coding reports were made for finding texts from all the interview transcriptions that were coded at the selected nodes. These coding reports were then examined for patterns, themes and connections, both within and across 
categories. Subsequently, the patterns, themes and connections were analysed, and interpretations of the analysis formed the basis for the research findings and theorising.

NVivo 7 is compatible with and works well for MS Word documents. Hence, before importing the interview transcripts into NVivo 7, an MS-Word template was set up. This was done by opening a blank document in MS Word. Each question on the interview guide was then entered into the document. The questions were kept as brief as possible. The required heading style was then applied to each question. This procedure was applied for each question, followed by a blank line (to enter the response into later). Once all the questions had been entered, the document was saved as a document template. Each interview document was created from the document template (to aid consistency) for each interviewee, and responses to the questions were entered into the relevant sections. This process was repeated for all the interviews. These interview documents were then imported into NVivo7. The central activity when using NVivo7 is coding. Codes were first generated based on the research questions of interest and information that became salient as the interviews were undertaken and the transcripts read. This is standard practice for generating the codes (Anderson-Gough, 2004). Miles and Huberman (1994) stated that coding is analysis, because generating and agreeing on a list of codes required a certain amount of interpretation. Based on the codes generated, the researcher did value coding as part of the evidence management and analysis process. Once the interview evidence had been managed and coded with NVivo7, the evidence was interpreted and translated into the research findings that formed a basis for theorising. The process of theorising is discussed in the next section.

\subsection{Process of Theorisation}

Nielsen (2005) explained that qualitative research is about "how researchers convert everyday experiences into theoretical knowledge through researchers' interpretations and translations of data into theoretical concepts" (p. 117). This helps to "lift the empirical experiences in serving the important task of providing insight and understanding" (p. 119) of "how individual actions relate to each other and add up to a coherent whole" (Ahrens \& Dent, 1998, p. 10). Ahrens and Dent (1998) went on to explain, “...theorization is the product of conscious, self-critical analysis in which unsatisfactory theories have been discarded". They then provided practical guidance to the process of theorisation (p. 24). The process of theorising for the current research started with the search "for a pattern [that represented the world observed] and 
synthesizing [interview data] into recurrent themes" (Ahrens \& Dent, 1998, p. 9). However, Ahrens and Dent (1998) cautioned that this process of seeing patterns is often the most difficult and least codified part of [qualitative research] because "seeing patterns and developing theory is an emergent process in [qualitative research], in which the researcher iterates between insights and the [qualitative evidence]" (p. 9).

There are two main approaches to theorisation. The first is the 'top-down' approach, where some established theoretical concepts are imported and applied (Nilsen, 2005), and second is the 'bottom-up' approach where an effort is made to generate new theoretical concepts grounded in the empirical data (Glaser \& Strauss, 1967; Strauss \& Corbin, 1990). For this research, the top-down approach to theorisation was applied. A review of the extant literature led to the discovery of legitimacy theory as providing insight and understanding of the empirical experiences in many auditing research studies (Dedoulis, 2006; Herrbach, 2006; O'Dwyer, 2001; Power, 2003; Taylor et al., 2001); and its consideration as the most likely theory to be relevant to the research questions. Analysis of the interview findings confirmed legitimacy theory as the most appropriate lens for interpreting and drawing meaning from this research. Legitimacy theory in the context of organisations, and justification for its choice and appropriateness for the current research study, has been discussed in Chapter 3 .

\subsection{Chapter Summary}

The research methodology and the methods used in gathering and analysing research evidence were presented in this chapter. First, the reasons why a qualitative interpretive methodological perspective was chosen were discussed. Second, this chapter also discussed the adoption of a naturalistic inquiry approach in the context of qualitative interviews. The implications of each of the fourteen axioms for naturalistic inquiry and the way they guided the current study were also outlined. Third, the research context, research participants, research instrument and method used in evidence collection were presented, followed by a detailed discussion of the interviews conducted. The discussion covered practical and organisational issues. The analysis of interview evidence and the use of NVivo 7 for managing the analysis of the research evidence were then reported, followed by an explanation of the theorisation process. The next chapter presents the findings from the research interviews. 


\section{CHAPTER 5: PRESENTATION, ANALYSIS AND INTERPRETATION OF RESEARCH FINDINGS (PART ONE)}

As stated in Chapter 1, the objective of this study is to examine the consideration of environmental matters in the audit of financial reports. Specific research questions for this study are:

1. How do auditors generally perceive the consideration of environmental matters in the audit of financial reports?

2. What common approaches and practices do auditors undertake when auditing environmental matters?

3. Do auditors face any challenges in the audit of environmental matters? If so, what are they?

4. Does AGS-1010 impact current practice and, if so, how?

5. How current practice be improved and further developed to meet better the espoused aims of AGS-1010?

The procedures used to collect interview evidence for this research were discussed in Chapter 4. In particular, Chapter 4 discussed the descriptive data for the research participants, the research interview approach, the method used to analyse the transcribed interviews and the process followed in reporting the common themes from the interview evidence.

Research findings for the above five research questions are presented and discussed in the current and next chapter. This chapter covers the first three research questions and Chapter 6 covers the last two. However, research question three, which considers challenges in the audit of environmental matters, will not be discussed in a separate section. Instead, the relevant challenges are discussed as and when they arise in the context of the interview evidence for research questions one and two. The current chapter is organised as follows. First, gaps identified in the literature are summarised for each research question. Second, interview findings that provide 'answers' to the research questions are presented, supported with direct quotations from the interviews. After that, the implications of the interview findings for each of the research questions are discussed. 
Altogether, twenty-seven audit practitioners were interviewed: eighteen were financial auditors, seven were public sector auditors and two were government auditors. The interview quotations presented in the following sections were selected on the basis that that captured best the spirit of the common themes extracted from interviewees' comments. Interesting and discordant views were also included to provide context. To preserve the anonymity of the auditors interviewed, the quotes of the interview evidence were referred to by a numbering system. For example, an audit partner is 'AP', an audit manager is 'AM' and an audit practice reviewer is 'APR'. Assigned numbers 1, 2 etc. are code numbers for each of the individual interviewees. Unless indicated that the interview evidence had been provided by a public sector auditor, most of the interview evidence had been provided by auditors in chartered accounting practices (henceforth referred to as 'financial auditors'). The next section discusses interview evidence for the first research question.

\subsection{Auditors' Perceptions on the Consideration of Environmental Matters in the Audit of Financial Reports}

Chapter 2 reviewed studies on auditors' perceptions of environmental matters (Chiang, 2006) (refer to section 2.1) and responses to environmental matters (Collison, 1996) (refer to section 2.3). Although AGS-1010 was issued in 2001, no one subsequently has studied financial auditors' perception of the task of incorporating environmental matters in their audits. Therefore, for the current study, twenty-seven auditors were asked to comment on these perceptions which covered the following three areas: (5.1.1) perceptions of awareness of environmental matters for accounting and auditing purposes, (5.1.2) perceptions of the current role of auditors in the audit task and (5.1.3) perceptions of the significance of environmental matters to auditors.

The following paragraphs present interview evidence for each of the above three areas. At the end of this section, the key findings are summarised and analysed, and their implications for audit practice are discussed in section 5.1.4. The next section presents interview evidence on the auditors' perceptions of their personal awareness and other auditors' awareness of environmental matters for accounting and auditing purposes.

\subsubsection{Awareness of Environmental Matters for Accounting and Auditing Purposes}

The findings of this study indicated that all the auditors interviewed are familiar with how business activities can affect the environment. This is not a recent phenomenon; 
and one of the interviewed auditors further indicated that general awareness dated as far back as the early 1990s. He remembered that in those days, study requirements for NZICA's professional qualifying examinations and technical articles in accounting journals kept accountants and auditors up to date:

It is something accountants and auditors have been aware of even before 1995 when I was studying for professional membership. We studied the impact of industry upon the environment and the effect it has on financial records. I remembered studying an example of a clean up operation that was taking place at Mapua which is in the north of the South Island. The Mapua disaster was considered huge in the 1990s and there was a proliferation of technical accounting journal articles covering 'the impact of industry upon the environment and the effect it has on financial accounting'. However, the topics mostly covered accounting issues but virtually nothing on auditing issues [AM 1].

Another interviewee recalled that, initially, there was difficulty in developing an accounting standard for environmental matters. In time, environmental matters evolved as environmental liabilities and became one of the many audit issues an auditor had to consider:

In the 1990s, environmental matters were very topical issues trying to gain some traction. As a result, the Institute [NZICA] and the international accounting bodies were keen to promulgate an accounting standard for environmental matters. However, it was very difficult to have any accounting standard on environmental matters in place, which accountants could actually agree and report on. Subsequently, environmental matters evolved as environmental liabilities. Once environmental matters were treated as environmental liabilities, they were no longer considered a special issue. They became just one of the many audit issues that the auditors had to consider alongside the entities' many other obligations [AP 12].

Yet another interviewee remarked that the Enron debacle was perhaps a contributing factor to the diminishing perceived importance of environmental matters:

Suddenly, quite unexpectedly, environmental matters apparently lost their prominence. The speculation for this phenomenon was that "the Enron debacle" had perhaps replaced environmental matters as a significant issue in financial reporting and became the new flavour of the month as far as accounting and auditing were concerned [AM 1].

The next section presents interview findings on the perceived current role of auditors in the audit task. 


\subsubsection{Perceptions of the Current Role of Auditors in the Audit Task}

Responses to the survey conducted by Chiang (2006) (discussed in section 2.1) provided only limited information on auditors' perceptions on environmental matters because the survey respondents were not probed for further explanations. The study by Chiang (2006) indicated that auditors seemed unwilling to audit environmental matters in financial reports because they perceived their current role as sufficiently demanding. Findings from the interviews for the current study threw more light on other factors contributing to auditors' unwillingness to extend the audit by including environmental matters.

All the financial auditors interviewed highlighted similar concerns. First concern is that their current role in auditing environmental matters was potentially exposing them to greater legal liability, because the work undertaken to form an opinion on environmental matters is permeated by professional judgement in their assessment of a company's exposure to environmental risk:

The responsibility for all this [environmental matters] is just growing and growing; auditors' exposure to risks is quite frightening in that it requires a large breadth of knowledge outside the field of accounting. Before, the focus is: "does it comply with the International Financial Reporting Standards, or does it comply with the local 'generally accepted accounting practice'?" Now you are looking at environmental issues and asking whether there are going to be any legal claims as a result of doing something. Whatever it may be, you're looking at the environmental risk and you have to make a call on where you believe the risk is. Unfortunately if you get that call wrong, it could be to your detriment [AP 2].

The second concern is their (in)ability to detect environmental matters:

It is harder to detect an environmental issue then actually searching out for those unrecorded liabilities [AP 17].

All of the financial auditors interviewed further explained that their greater concern is their ability, or rather inability, to detect environmental matters in the first instance for companies not operating in a specific industry or sector that is exposed to significant environmental risks. In this situation, they all indicated that they relied heavily on management representations. However, if management was not aware of, or had no intention of disclosing the existence of any environmental risk, then the auditors would likely miss it in their audit: 
Although some companies are not in that particular industry, their activities may impact the environment unknowingly, or contravene some laws, and that is problematic. If they're not aware of anything either, then it makes it kind of difficult [AP 2].

Finding it [environmental issues] for the first time is the hard part. You are reliant on the organisation having processes for those issues to get flushed up to the top level...You are in some way reliant on the client to tell you in your relationship with the client if they have got any environmental issues. Everything is dependent on what the client tells you [AM 3].

Basically, from discussions with the owners and/or directors of an entity, you'd ask, "What is impacting upon the operation of the business?" If they're not aware of anything either, then it makes it kind of difficult [AM $1]$.

One financial auditor shared her experience of environmental matters. Her narrative indicated that management sometimes ignored environmental matters when the financial implication was deemed immaterial:

My personal experience is with contaminated land and there was leaching of some kind of chemicals - the issues were tied up about 4-5 years ago with one of our managers who was on a site tour, She asked, "What's in that shed?" They knew she was pregnant at the time, and said, "We can't go anywhere near there because it's all contaminated and it's not good for you as you are pregnant". And she asked, "What do you mean it's contaminated?" They had just been accumulating waste into a big shed. So then, as far as I understand it, the company management realised that there were some issues, but it is not huge dollars. However, management started investigating the extent of potential problems; it was being careful and went through environmental audits. That was how we then started investigating what we needed to do [AM 3].

When this example was presented to another financial auditor who was interviewed, he explained that whether environmental matters are discussed at the Board level is often dependent on the requirements of corporate governance and regulatory compliances:

Some companies keep better minutes and make better decisions than others. In that scenario that you mentioned about the pregnant lady down at the site being told about the contaminants, I could imagine it wouldn't make it into every company's Board minutes. I mean, whoever kicked the bucket over or knocked the chemicals over would not have put their hand up for it, and their manager could have said that they'll deal with it or whatever. A lot of it probably depends on corporate governance and how the business is run, how they comply with not only financial reporting but everything else that they're meant to comply with [AM 11]. 
Another financial auditor gave an example to illustrate that unless the environmental matter is obvious, management could also miss detecting its existence:

If the auditors would go out to a freight forwarders company (say), all they would see are trucks and storage facilities. Some freight forwarders transport chemicals. The company may not be taking into consideration that there's a hazardous material storage facility there. What would happen if the hazardous materials leaked? I should imagine whoever audits the company should take into consideration the environmental impact of chemicals transported. But I know from a trucking firm I used to audit, I don't think it made up a major consideration because it wasn't a key part of their business [AM 1].

A third example given by yet another financial auditor interviewee indicated that the hardest part is detecting environmental matters in the first instance:

A sign writing company may potentially have an environmental issue because it's got inks and dyes that leached into the ground. However, I wouldn't necessarily consider that majorly unless I was going round the site and found there was a whole bunch of spools and containers out the back and they'd be just sitting on the ground. Then I'd say "Look, we have issues in relation to disposing of this correctly". The District Council or the Regional Council might lay claim to this and say, "You're not disposing off your wastes correctly; you need to remediate this site". The hardest part of the audit is to detect it in the first instance. But once it is found out then you can work through the issues. It is quite tough up to this point [AM 1].

Again, all the interviewed financial auditors commented that newer clients were also a concern, as auditors were not entirely familiar with them and would not have all the necessary background information to assist them in detecting environmental matters in the first instance:

It's more a problem for your newer clients, especially if there has been an incident in the past and they change auditors. It would be hard to get all the background information [AM 8].

Six of the eighteen (33\%) financial auditors interviewed merely accepted the difficulties in their audit role and did not elaborate further, but twelve of the eighteen (67\%) financial auditors admitted that they were generally unable to keep up their awareness of clients' exposure to environmental risks:

Often you don't become aware of it until something comes out of the woodwork. It's often unexpected largely because for so long auditors are concentrating more on the financial figures. The environment is just the 
environment and people don't really think so much how it impacts the financial statements or the performance of a particular entity [AM 14].

The challenge is the extent of the auditor's awareness of the company's potential environmental risk exposure [AP 9].

There are still issues with completeness of knowing where and what the environmental contamination is [AP 24].

Additionally, the same $67 \%$ of the financial auditors interviewed were also concerned that they were not entirely familiar with the prolific environmental laws and regulations, thus they were unable to check whether their clients were actually complying with legal requirements:

We wouldn't know all the environmental laws and regulations. I mean obvious stuff might jump out at us, but it would be very difficult to check that the entity is complying with all the laws and regulations [AM 11].

Environmental laws are different from normal laws and regulations. If you don't comply with a normal law and regulation, you can actually estimate the effects faster. If you don't comply with environmental laws, you may not know you're not complying for some time [AP 15].

I don't think auditors are particularly $O K$ with any of the environmental legislation. We're aware it's there, we're aware of certain aspects of it but we're not chapter and verse qualified in it. You will find the majority aren't [AM 1].

Yet another concern raised by the $67 \%$ of the financial auditors was that even though auditors were required to have a general understanding of environmental matters, they had to rely on experts for specialist knowledge. This led one of the financial auditors to suggest that auditors are probably unable to form an opinion on environmental matters:

We are reliant on experts for specialist knowledge; hence I certainly wouldn't say a Chartered Accountant is qualified to form a view on environmental matters, or the impact of that environmental matter [AP 2].

Generally, all the financial auditors were unhappy about their perceived current role, which they considered onerous, increasing the scope of the audit and consequently resulting in additional costs:

It sort of creates more workload for us in an area we are not experts in [AP 19].

The additional audit responsibility is quite onerous for certain clients because you really have to always keep environmental matters in mind [AM 8]. 
I'm not sure whether it's an area we really want to get into as auditors. I don't really want to increase the scope of my responsibility as an auditor any further than what it already is and, certainly I don't want to go any further than I have to [AM 11].

Audit of environmental matters appears to be too much hassle and adds to the cost of the audit [AM 8].

There appeared to be some contradictions in these interview findings. The interviewed financial auditors expressed a number of major concerns about their perceived current role. Thus, one might expect auditors to exercise greater care and attention to environmental matters so as not to expose themselves to undue legal liability. However, it appeared that environmental matters were treated no differently from any other audit issue. Ten of the eighteen (56\%) interviewed financial auditors had not even considered environmental matters in their daily work and, hence, they had not extended the scope of any of their audits to include the consideration of environmental matters:

Although they are significant challenges for auditors, they are not unique in that they are similar to a range of potential liabilities or asset impairment type issues that auditors have to deal with [AP 17].

I almost see environmental matters as just another box of understanding; although an area that is not the core competency of the auditor [AP 4].

How much detailed consideration is given to environmental matters for each audit depends on the clients; and for the large majority, truthfully it's not much. There is high risk in audit work on environmental matters [AP 4].

Really, in our day to day work to date, we don't explicitly consider environmental matters [AM 11].

Eight of the eighteen (45\%) interviewed financial auditors who were also from the Big 4 firms give some regard to environmental matters at the audit planning stage because of the questions prompted by the audit questionnaire they have to complete in order to assess client company's exposure to various risks:

Audit planning is driven by an 'Expert Software' which requires us to give information about a client's exposure to environmental risks (AP 3 ).

It is interesting to note that only one of the eighteen financial auditors interviewed spoke about the obligation to serve the public interest:

Environmental matters have become so much more of an issue for auditors in New Zealand simply because that's what the people expect. It is critical that we actually don't misuse that trust, and by that I mean, if 
the public expects us to be dealing with environmental matters, then we need to deal with them [AM 10].

Of the ten financial auditors interviewed who indicated that they would not normally consider environmental matters for their auditors, six said they knew of some company directors who did not wish to disclose their company's environmental liabilities. However, they were pragmatic in their agreement with the stance taken by these company directors. In doing so, they were exposing their self-interest and conflict of interest in serving management instead of the public interest:

For companies whose published financial statements are being filed with the Companies Office, their directors often resist any disclosures of environmental liabilities so that they are not available for other people to see [AM 1].

They probably wouldn't want to disclose it if they are abusing the environment [AM 20].

To some extent, we need to satisfy our clients because there's obviously going to be some issues that the clients don't want to disclose and expose themselves [AM 10].

However, in contrast, all the public sector and government auditors interviewed presented an entirely different perspective. These interviewees formed part of the office of the Auditor General (OAG). The Auditor General is an appointed officer of the New Zealand Parliament. The interviewees asserted that the consideration of environmental matters in their audits of financial reports was mandated by the Local Government Act 2002, which required all public and government entities to report on environmental matters:

The Auditor General has a very strict mandate about the environment which he's got to operate under and that is why he's got this wider focus [which includes environmental matters]. It's all driven by the Local Government Act 2002. So there's a whole lot of reporting requirements that public sector auditors have to do, but that is driven by legislation [AM 22].

The new Local Government Act 2002 places a lot of emphasis on the environment, and the councils and local authorities now need to factor environmental consideration in their decisions making. From the [public sector] auditors' perspective, we need to audit and give an audit opinion on environmental considerations [AP 21].

Therefore, the Local Government Act 2002 appeared to be the main driving force for the public sector auditors' specific focus on environmental matters for every audit. On 
the other hand, without a specific legislated requirement for direct focus on environmental matters, financial auditors tended not to do so. The next section presents interview findings on auditors' perceptions of the significance of environmental matters.

\subsubsection{Perceptions of the Significance of Environmental Matters}

The interview findings on auditors' perceptions of the significance of environmental matters have two aspects: (1) the auditors' general perceptions (2) the auditors' perceptions of environmental matters that already exist for some companies. The interview findings are presented as follows.

\section{Auditors' General Perceptions}

All the financial auditors interviewed perceived environmental matters to be significant for companies in obviously environmentally sensitive industries. Hence, they would plan for the consideration of environmental matters only for those obviously environmentally risky companies, as the following illustrative quotes indicated:

Environmental issues are more likely to impact the financial statements of some companies in some specific industries. For those companies exposed to environmental risks, I think that it is already a key focus and is routinely a part of audit planning; something that an audit partner, manager and team are quite conscious of [AP 17].

For example, if it is a freezing works [a New Zealand term for a meat abattoir] or a chemical storage facility or mining company, verifying environmental matters is an obvious part of the audit planning process when you're assessing the risks [AM 1].

All the financial auditors interviewed further added that they would not consider environmental matters for those companies operating outside the industries or sectors which they considered as normally exposed to environmental risks:

If you've got a client operating outside the 'environmentally risky' industries, it is probably very unlikely that it would come up as part of the audit engagement [AM 1].

However, two interviewees admitted that they tended to ignore environmental matters for some companies, for example:

If it's a manufacturer with limited exposure per our risk assessment to environmental issues we just ignore it - sorry not ignore it, but take less notice of it [AM 3]. 
Seven of the financial auditors interviewed indicated that environmental matters were not normally considered in audit planning for banks and financial institutions:

Environmental matters is something that at the planning stage we've never really had to consider, primarily because our client base consists of very standard, finance service type providers [AM 10].

I believe one would not expect to see environmental matters in the planning for an audit of a bank [AP 17].

On the other hand, all the public sector and government auditors indicated that environmental matters are significant for every audit (refer to section 5.1.2). Overall, it seemed that the nature of a firm's industry was an important determinant of whether auditors seek out environmental matters when auditing the firm's financial reports. The next section presents auditors' perceptions of the impact of environmental matters that do not have a direct financial effect on financial reporting or the audit, and that (already) existed for some companies.

\section{Auditors' Perceptions of Environmental Matters that (already) existed for some Companies}

Fifteen of the eighteen (84\%) financial auditors interviewed admitted that their focus on financial figures had distracted them from considering deeply how environmental matters that (already) existed for some companies might impact financial reporting or the performance of the company:

Until something comes out of the woodwork, then you become aware of it [environmental matters]; but often it's sort of unexpected largely because for so long auditors are concentrating more on the financial figures. The environment is just the environment and auditors do not generally think so much on how it impacts on the financial statements or the performance of a particular entity [AM 14].

Of the above fifteen financial auditors, ten (56\%) perceived existing environmental matters for companies operating outside certain industries exposed to significant environmental risk as generally insignificant, so scarcely considered their existence during audit planning:

Very few New Zealand companies would have significant environmental obligations on [their] balance sheet. No, it is not hidden; it's just that it's not significant. Hence, right at the front end, at the audit planning stage, auditors generally are not directed to the existence of environmental risk because it would very rarely be significant. It may be in some specific industries yes, but in others it wouldn't be a large key risk so we wouldn't 
be addressing it. It'd be just another one of those compliance risks [AP $15]$.

I don't doubt that there are probably some minor issues going on in lots of companies. Minor breaches are not reported because they're not significant, so they do not concern us [AM 3].

The above ten interviewees further explained that the costs and penalties for noncompliances and environmental law breaches were generally very insignificant compared to the 'crime' hence they did not warrant any further audit investigation:

Auditors are always governed by the 'materiality assessment' [AM 10].

I've never heard of any New Zealand director or manager responsible for any environmental problems actually sent to prison, and I've never heard of any company being fully fined up to the $\$ 200,000$ maximum; normally its $\$ 25,000$ or $\$ 50,000$. If you are looking at a company with a turnover of $\$ 400$ million, and a profit bottom line of say between $\$ 20$ million and $\$ 50$ million, a \$50,000 fine is considered small change, so it slips under the higher materiality level. The auditors as part of the enforcers don't seem too serious about it [AM 1].

Additionally, the above ten interviewees admitted that they would not make any particular effort to search out environmental matters that already existed for some companies, because they often were not separately disclosed:

Environmental matters are not usually separately disclosed, often buried with other things, are not visible to the users of financial statements and so auditors do not make the effort to search for them. Besides, as auditors we hold ourselves responsible for the audit report for one year only [AM $10]$.

On the other hand the Local Government Act 2002 required all the public sector and government auditors to search out the existence of environmental matters for every audit client:

There is no choice in the matter. The Local Government Act 2002 requires us to search out the existence of environmental matters for every audit client [AM 20].

Overall, the interview findings indicated that environmental matters were often not investigated because they were considered as insignificant audit issues with immaterial financial implications. The next section summaries and analyses the main research findings from the interview findings on auditors' perception of the task of considering environmental matters in the audit of financial reports. 


\subsubsection{Summary and Implications of Research Findings for Current Practice}

This section highlights and brings together the main research findings on auditors' (5.1.1) perceptions of awareness of environmental matters for accounting and auditing purposes, (5.1.2) perceptions of their current role in the audit task and (5.1.3) perceptions of the significance of environmental matters. When analysing the interview findings and then discussing their implications, all the findings are taken together.

The interview findings confirmed that environmental matters were prominent current issues as far back as the early 1990s. In those days, many articles on environmental issues published in accounting journals, together with study materials for accountancy professional membership, kept accountants and auditors up to date. However, over the years, environmental matters seemed to have lost traction and appeared to have lost their importance in the accounting journals. Their prominence was eventually replaced by the "Enron debacle". Regardless, environmental matters are still occurring at various levels for a number of companies, even if they are not operating in particular industries or sectors exposed to significant environmental risks (Rezaee et al., 1995). Therefore, auditors should continue to keep up to date, in order for them to have the first stage awareness of possible environmental risk and to be able to consider them at the preliminary audit planning stage. First stage awareness of possible environmental matters is critical to planning an audit because unless it is being considered, it would not be factored into audit planning. Auditors would then omit environmental matters entirely in the audit of financial reports, which could potentially expose them to greater legal liability.

The findings of this study suggested that auditors considered the actual task of including consideration of environmental matters in financial reports as onerous and often incurring added costs, because the scope of the audit had to be extended. Some of the auditors interviewed also felt that the consideration of environmental matters might perhaps be a never-ending audit task. They admitted their inability to keep up their awareness of clients' exposure to environmental risks, and noted the proliferation of environmental laws and regulations. Thus, it was no wonder that auditors were very concerned that the audit task exposes them to high potential legal liability because, not only did the audit work require judgemental decisions to be made, but auditors were also reliant on experts for specialist knowledge in an audit area that they were not 
entirely familiar with. This led some auditors to question their own ability to form an opinion on environmental matters. The audit task of considering environmental matters in financial reports seemed to extend the boundary of financial audits and reflected unreasonable expectations of auditors' knowledge of environmental issues. The reality was that the auditors really did not want to have to consider environmental matters in the audit of financial reports. If the auditors themselves were reluctant and currently having trouble verifying environmental matters, they will surely also struggle to meet the future challenge of verifying carbon accounts, which will be required of New Zealand companies as part of the New Zealand Government's signing of the Kyoto Protocol (Cummins, 2007).

In view of the significant issues raised, and the greater potential for exposure to legal liability, one might expect auditors to exercise even greater diligence and duty of care in the audit task. Yet, with the introduction of AGS-1010 in 2001, auditors' focus on environmental matters appeared to have remained the same, and the scope of audits not usually extended to consider environmental matters specifically. However, regardless of the quantum, the existence of environmental matters may affect the decision-making of financial statement users, especially when there is a possible or probable future obligation. In this case, NZ IAS 37 requires the environmental liability to be disclosed in the notes to the accounts. In fact, the auditors interviewed for this study appeared to be so financially focussed that they did not really reflect on how the environmental matters that existed for some companies might affect financial reporting or the performance of the company. The costs and penalties for non-compliance and environmental law breaches were generally considered insignificant compared with the 'crime'. Hence, they were perceived not to warrant any further audit investigation. In fact, some auditors admitted that they did not particularly search for environmental matters that could be 'buried' in the provisions or contingent liabilities accounts. Perhaps this might be the reason for Rodgers and Housel's (2004) (refer to section 2.1) observation that auditors tended to downplay environmental risk information compared with traditional financial information. For most of the time, the interviewed auditors perceived that even what appeared to be significant environmental risks, were considered as insignificant for audit purposes, because the financial impact always seemed to fall under the materiality assessment. The concept of 'materiality', and how it 
is applied to assessing a company's exposure to environmental risk, is covered in section 5.2.2.

Hence, even for companies that generated direct environmental impacts, it appeared that auditors usually perceived environmental matters to have little impact on a financial report audit. Nonetheless, Steadman, Green and Zimmerer (1995, p. 52) warned that environmental contingencies and liabilities "can create considerable uncertainty about the long term economic viability of clients". However, despite the current litigious climate, nothing much seemed to have changed since Collison, Gray and Innes conducted their study in 1996. Then, it was already apparent that auditors risked underemphasising environmental issues and their financial consequences. In fact, Fleming's (1993) observation that some auditors during his time seemed oblivious to their responsibility for environmental matters, also applies to some of the auditors interviewed for this study.

When discussing the audit of environmental matters, financial auditors did not appear to consider their obligation to serve the public interest. In fact, there were auditors who were aware of, and in agreement with, their clients for not disclosing information on environmental liabilities. These auditors were therefore exposing their self-interest and conflict of interest in serving management instead of the public interest. It appeared that financial auditors were pragmatic in being prone to agreeing with management decisions not to disclose to the public the company's environmental liabilities. This stance by some New Zealand company managers (and their auditors) appeared to be in line with some authors' current thinking that "the only purpose of a business is to make profits for its owners and environmental concerns can only detract from this goal" (Hunter, 1999, p. 20). These managers seemed to have forgotten that their major role is to provide information for informed decision-making and, with more and transparent reporting and disclosures, companies would be offering greater accountability. On the other hand, all the public sector auditors interviewed indicated that the Local Government Act 2002 requires them to focus on environmental matters in their audits, because their priority is to protect the public interest. Since commentators are continually stressing the importance of environmental issues as accountability factors (Billing et al., 1994; Lucy \& Hayes, 2004; Turner et al., 1993), the financial report should present the environmental costs, liabilities and contingencies of company activities fairly (Teasley, 1995), and auditors for the companies have a role in auditing 
the truth and fairness of the information. Accountability for environmental matters is also considered part of good corporate governance (Billing et al., 1994; Fiedler \& Lehman, 1995; Vaughan \& Mulliken, 2007) and since "the audit provides an external and objective check on the way in which the financial statements have been prepared and presented" (Cadbury, 1992, p. 36, paragraph 5.1), auditors should ensure that management engages in good governance in corporate environmental accountability and reporting. This is also in line with the assertions made by Sylph (2005) and Lickiss (1991) that auditors are expected to ensure greater corporate environmental accountability by making companies sensitive to the environment as a result of their actions in their professional duty to promote the public interest.

The discussions in section 2.3 note that the accountancy profession's primary objective is to meet the 'public interest' and its mission is to provide useful information for making economic decisions. The implication is that a claim to professionalism seems to relate largely to the decision-usefulness of information provided and its contribution to the public interest through the efficient allocation of capital and resources. Financial reports, for example, might convey information to the readers as to which companies are most worthy of support and investment but, by ignoring environmental costs, companies may be overstating profits. Since financial reports help to define which company is potentially successful and which is not, and information on environmental matters (considered as issues of public concern) is often inadequate and incomplete (Gilkison \& KPMG, 1999), auditors should meet the public interest requirement. Hence, the accountancy profession's duty to the collective well-being of the community requires important questions to be asked on how the public interest requirement can be better served. The auditors interviewed for this study were generally reluctant to extend the scope of the audit to include environmental matters, and their willingness to support management's non-disclosure of environmental liabilities was acknowledged in the interview findings. This implied that there could be serious difficulties of achieving change to current perspectives and practices. However, familiarity with environmental issues is at least a good start. If the accountancy profession were able to use its expertise and influence to protect and enhance the environment (which is what the OAG in New Zealand is doing for the public sector via its legislated mandate), it might perhaps enhance its claim to be serving the public interest. 
The public sector auditors, on the other hand, are required by the Local Government Act 2002 to consider environmental matters in the audit of public sector and government entities' financial reports. The driving force for public sector auditors' direct focus on auditing environmental matters is the legislated mandate and environmental matters are considered for every audit. On the other hand, financial auditors are expected to decide first whether environmental matters are significant for a company. Only if they are deemed significant does the auditor then consider them in audit planning. Left to their professional judgement, financial auditors usually considered environmental matters as significant only for companies in obvious environmentally sensitive industries. For companies operating outside environmentally risky industries or sectors, environmental matters were generally considered insignificant and, therefore, were very often given no consideration in audit planning. This led many auditors to ignore environmental matters when planning audits for banks and financial institutions, for example. However a recent study by Thompson and Cowton (2004) suggested that banks were in fact structurally exposed to environmental risks owing to their facilitation of environmentally damaging activity by the allocation of loan capital. This, they argued, extends the environmental accountability of banks, making them potentially more, rather than less, environmentally sensitive than some other sectors are, up to now, presumed to be. Further, Harding (1994) explained that the risk of environmental liability for banks falls into two categories: indirect and direct risks. Indirect risks are those arising only through the effect of environmental matters on a customer's ability to repay its borrowings. Direct risks are those that can result in a bank becoming directly liable for damage due to the environmental impact caused by its customers' business activities, and may involve liability for sums vastly in excess of a bank's lending to those customers.

The research findings also indicated that auditors were concerned about their lack of ability to detect environmental matters generally and specifically, in the first instance, for companies not operating in an industry or sector exposed to significant environmental risks, or for newer clients. They also indicated that they tended to rely on management to inform them of any existing environmental matters, but audit concerns may be further exacerbated if client companies are unaware that their activities are affecting the environment. AGS-1010 paragraph 21 clearly indicated that an entity does not need to operate in one of the obvious industries or sectors to be exposed to 
significant environmental risks. Potential exposure to significant environmental risks may arise for any entity that owns or holds security over sites contaminated by previous owners; or that has a business whose operational processes could cause contamination of soil and groundwater, contamination of surface water or air pollution; use hazardous substances; generate or process hazardous waste; or may have an adverse impact on customers, employees, or people that live in the neighbourhood of the entity's sites (AGS-1010, paragraph $21 \mathrm{~b}, \mathrm{~d}$ ). Therefore, if an auditor does not consider an entity's exposure to potentially significant environmental risks when planning the audit because the entity is not classified as being within an industry or sector that is exposed to obvious environmental risks initially, then the audit of environmental matters would not be included in the audit of that entity (e.g. a bank, other financial institution, or other entity). Hence, the audit procedures would not allow the auditor to detect environmental matters and, if material, to determine whether they are omitted, misstated or not disclosed in the financial report. An auditor neglecting environmental matters in this case would be exposing himself or herself to potentially significant legal liability. Therefore, financial auditors would be better off in following the public sector auditors' approach of considering the existence of environmental matters for every audit of financial reports.

Despite the auditors' awareness that environmental matters are exposing them to potentially significant legal liability because they are not entirely capable of dealing with these matters in their audits, auditors continue to have the attitude of 'business as usual'. It might be understandable that they carry on 'as usual' given the constraints and pressures they appear to face.

The preceding section summarised and analysed the main interview findings on auditors' perception of the task of considering environmental matters in financial report auditing, and discussed their implications for current practice. The next section presents interview findings on common audit approaches and practices in auditing environmental matters. 


\subsection{Common Audit Approaches and Practices in Auditing Environmental Matters}

The international literature indicates that when auditing environmental matters, and similarly with other audit issues, both financial and public sector auditors tended to follow a common approach (Gilkison, 1994; Gilkison \& KPMG, 1999; Gray \& Manson, 2005; Leung, Coram, \& Cooper, 2006; van Puersem \& Pratt, 2003). First, they obtained an understanding of the company's business, environment and control structure in order to plan the audit. Second, based on an understanding of the client's business environment, the auditor made preliminary judgements on materiality levels and considered the risk of potential misstatements, omissions and non-disclosures of significant assertions in the financial report. Third, the auditor prepared the audit programs and carried out appropriate audit procedures to verify the assertions. Finally, the auditor considered the implication of any significant audit concerns (indicated by audit evidence) for audit reporting. The New Zealand interviewees in this study confirmed these audit steps and processes documented in the literature. Hence, when the interviews were conducted to determine common approaches and practices to auditing environmental matters, the four components of audit practice were focussed on.

The literature indicated a general tendency for authors to focus on the following four components of audit methodology: (1) the business risk approach (BRA) to auditing (Bell et al., 1997; Gay, 2002; Gray \& Manson, 2005; Knechel, 2007); (2) professional judgement on materiality (Bell et al., 1997; Iskandar, 1996; Messier Jr. et al., 2005); (3) the application of auditing (Chandler, 1997; Humphrey \& Moizer, 1990; van Peursem et al., 2005) and accounting standards (Bell, 1992; Collier et al., 1993 August; Munter \& Sacasas, 1996; Specht, 1992); and (4) relying on the work of an expert (Colbert \& Scarbrough, 1993; Power, 1997). The following sections are structured according to each of these four components. First, the interview findings are presented, then the main points are highlighted and analysed and their implications for audit practice discussed. The next section covers the business risk approach to auditing.

\subsubsection{The Business Risk Approach (BRA) to Audit Planning}

The literature considers the BRA as a common audit approach to planning. However, a review of the literature (refer to section 2.2.1) raises the issues of (1) whether or how the BRA is applied when considering environmental matters and (2) how its application 
could potentially impact the audit of environmental matters. Interview findings for these issues are now presented.

First, all the interviewees (financial, public sector and government auditors) indicated that they applied the BRA in planning, and environmental matters were one of the factors they considered when assessing a client's risk profile:

The [BRA] model that we use for planning our audit forces us to consider environmental issues and the impact they have on the client. So we are forced at the planning stage to either dismiss it, saying it's not an issue or to say these are the potential issues. You'd first need to understand what environmental issues a client might have, and you do that through the planning process with this business risk model that we use. You'd pick up environmental matters from reviewing the Board minutes, talking to management, knowing what they do, looking at macro economic factors, press coverage; anything like that which might trigger your concern for environmental matters [AM 3].

All the planning is 'client specific'. When you're assessing business and the accounting processes within the business risk model, you have to assess all the factors that impact a client's risk profile. The environment is one of them that would be assessed as part of the planning process [AM 1].

However, one interviewee explained that the initial consideration of environmental matters in the audit was often triggered by its reporting in the financial reports:

The initial consideration of environmental matters is really initiated by the fact that the company has something in the accounts that would indicate the existence of significant environmental matters [AM 11].

Various interviewees reflected on how the application of BRA might affect the audit of environmental matters. The senior audit staff first initiated discussions on a company's exposure to environmental risks and the existence of environmental issues:

We are dependent on the more senior members of the audit team to understand their client's business [AP 17].

It is our more senior staff who would talk with clients and ask about environmental issues [AM 14].

Depending on the client, audit procedures range from a minimum of asking management to having discussions with management around any potential environmental issues [AP 4]. 
Second, the initial identification of environmental matters very much depended on disclosures by client management:

In your relationship with the client, you are in some way reliant on the client to tell you if they have any environmental issues. Everything is dependent on what the client tells you plus your reading of the Board papers and minutes. You also ask questions. We don't talk to just the people in the finance department, you'd talk to internal lawyers and external lawyers, and hope that somewhere along that line, if there is something that is material it would be identified [AM 3].

However, accurate and full disclosures by management depended on auditors persistently asking the right person the right questions:

Auditing is often about ensuring that you've asked the right questions, ensuring that you find the right person and ensuring that you are persistent enough to gain access to information on how they are managing (AP 17).

The research findings indicated that all auditors applied the BRA to the consideration of environmental matters. However, environmental matters were considered only if a company's accounts indicated their existence. The interview findings also indicated that all the interviewees were generally dependent on lawyers and, even more, on management's disclosures. Generally, what was being disclosed very much depended on the auditor's ability to ask the right people in the company the right questions in order to locate environmental matters possibly omitted from the financial report.

The research findings implied that, unless information on environmental matters was disclosed to the auditors, they could completely miss detecting any omissions (Rogers, 2004). According to Hatherly (1998) and Bazerman, Loewenstein and Moore (2002), the close relationship between auditors and management; auditors' undue reliance on management, and their ability to control the level of information disclosed, meant that auditors were unduly influenced by management's biases, and auditor independence could be threatened (Bamber \& Iyer, 2007; Lemon et al., 2002). Besides, even though the application of the BRA meant that auditors were required to apply their experience and expertise to assess business risks (Curtis \& Turley, 2007), the basis of the BRA is very much dependent on the kind of information management communicates to the auditor. Therefore it appears that the BRA and, specifically, the consideration of environmental matters are often managerialistic in their orientation and, as Gray (2000b) argued, a managerially captured attestation process offers little or nothing to 
environmental accountability. This 'greater reliance on client management' is further discussed in section 6.2.3. The next section presents interview findings on the exercising of professional judgement on materiality.

\subsubsection{Professional Judgement on Materiality}

The literature reviewed in Chapter 2 indicated that environmental matters are material to financial statement users. They are also regarded as an audit issue of public interest and a material matter of accountability. However little is known about the factors auditors consider when assessing the materiality of a company's exposure to environmental risk. The findings from the interviews on this little known research issue are reported here.

Four of the eighteen (22\%) financial auditors interviewed took into consideration both qualitative and quantitative factors when assessing materiality. However, the remaining fourteen of the eighteen (78\%) assessed the 'materiality' of an issue predominantly in relation to the financial impact on financial statements, for example:

'Materiality' is in respect of the financial impact on the financial statements. I don't think an auditor can give an opinion on anything but the financial statements [AP 2].

Of the fourteen interviewees, one further explained the assessment of materiality:

I think if there is a direct major pollution issue, you don't need to be a rocket scientist to figure out that there's an oil spill on land and that it is leaching through. You pretty much have to insist that the client makes the effort to quantify it and then the auditor would check to see what the quantification was. For example, I've audited a dairy company which had issues with discharge of milk into a river. They had holding pens up against a river bank. Effluents leaked into a river and the company had issues with the local environmental council, which exposed them to fines. That was approximately 8 years ago and the fines were not that significant as far as the audit was concerned. If that company was to pollute the river again, and if I was to be auditing the company now, I'd probably look more closely at it because the scope of the fines has increased quite dramatically, and therefore the risk to the client is greater [AM 1].

The above fourteen financial auditors also felt very strongly that environmental matters must be quantifiable before an opinion could be given on them:

Environmental matters must always be quantified if an audit opinion is to be given on them, because in a narrow sense the auditors specify only the pages in the financial report. Hence, if I couldn't quantify it, some expert out there would need to quantify it [AP 2]. 
They then explained that unless an environmental matter is quantifiable, it would not be considered for audit reporting purposes:

Company directors are quite correct in saying, "Well, if you can't quantify, what the heck are you fiddling around with it for in audit reporting?" [AM 10].

All the interviewed financial auditors indicated that they felt no urgency to verify environmental matters and risk unless they had a 'material' financial impact on financial reporting:

Well unless there's a financial impact for such matters, as things stand now there's little to push auditors to look at those things explicitly [AM $20]$.

Even if AFFCO [a meat processing company] was fined five million dollars for polluting a river in South Auckland by discharging the off-cuts from the processed meat into the nearby river instead of building a waste treatment plant, yet in terms of the company's balance sheet and profit and loss account, the fine meant absolutely nothing in terms of materiality; hence we would not bother with it [AM 11].

They all then indicated that they would delve into any non-compliance with environmental legislation only if the non-compliance had a material financial impact on the reporting entity:

If there's no legislative requirement it's going to be hard to quantify it and it would be hard to convince the client that it should be disclosed [AM 20].

If we think an entity is not complying with a piece of legislation we'd let the company know through the management report. However, generally non-compliance with environmental laws wouldn't have a material impact on the accounts unless it had a significant financial obligation [AM 20].

They also felt that quantifying environmental matters was challenging, as it depended on the co-operation of the client, and the benefit in doing so compared with the cost:

There are problems you know. How do you quantify it [environmental matters]? Is the client willing to quantify it? Do you go to the trouble of quantifying it? [AM 1].

If the company land is poisoned, it is very difficult to determine the impact; to assess and measure the materiality of its impact and how it can be measured in financial terms or even provide for it [AM 14]. 
Nevertheless, the fourteen interviewed financial auditors seemed comfortable only when working with quantifiable information. Hence, their concern was whether they were able to turn qualitative environmental information into quantifiable information:

The challenge is definitely in being able to measure these things [environmental matters] and actually turn qualitative information into quantitative dollars and cents [AP 2].

Of the four interviewed financial auditors who considered both qualitative and quantitative factors when assessing materiality, one was a retired audit partner who was also an audit practice reviewer. He said that in the earlier years of a young auditor's professional life, the young auditor would consider materiality only as a quantitative assessment, but as the auditor matures with age and experience, he or she began to realise the importance of qualitative factors in the assessment of materiality:

After many years of managing and also reviewing junior auditors' work, I find that to get them out of the notion that materiality is a 'quantitative measure' is quite hard work. They grow up eventually, but it takes a little while. I also have to put my hand up. While I was a trainee accountant many years ago, I also assessed materiality 'quantitatively'. Assessing materiality 'qualitatively' comes with experience and understanding the nature of information. It's hard though as a partner because I've had to argue with clients about disclosures and they'll say "well it's not material" [APR 18] [emphasis added].

This audit practice reviewer further explained that although the assessment of materiality can be based on quantitative factors, the explanations for the assessment varied from none to something quite elaborate. Nonetheless, the audit practice reviewer indicated that one significant qualitative factor impacting the assessment of materiality is an understanding of who the readers are and what matters to them:

As I review other auditors' files, I would say that at least a third don't have anything written down at all and the others range from writing down a number with no explanation to sometimes quite elegant assessments of how materiality should be assessed. So there's a very wide range there. Nevertheless, the more experienced auditors do have an unwritten sense of what is material. For some of them it's still very much based on 'quantitative factors', for others though, materiality is based on both 'qualitative and quantitative factors' which is simply a case of understanding who the readers are and what matters to them [APR 18] [emphasis added].

On the other hand, all the interviewed public sector and government auditors have a very different perspective on their materiality assessment of an entity's exposure to 
environmental risk. Their assessment was based not only on quantifiable information, but also on significance to the users of financial statements; i.e. the users' perception of materiality:

No, if you can't quantify the environmental risk, that wouldn't make it immaterial. Materiality is linked to the impact, which is linked to the users of the financial statement. So if we thought that non-disclosure of an environmental matter would impact a user's decision-making, then we might consider that it should be disclosed. Certainly when it comes to ratepayers [for example], they should have certain points of view about the environment and we would consider their perception of materiality [AM 20].

They all further explained that they considered environmental matters as essentially non-financial information, thus their assessment of environmental risks was not wholly concentrated on the financial aspect. In fact, the assessment was extended to include public risk, health risk and safety risk factors:

I see information on environmental matters as non-financial reporting, and we use a different kind of materiality assessment for non-financial information. Our materiality assessment takes into consideration public risk and safety risk; these are not financial risk. For example, if anything leaked into the water system, it's unsafe to drink the water. Council needs to meet the requirements of the health standards by ensuring that the water is safe for drinking and we should to able to assess the cost to meet health standards in order to safeguard the interest and wellbeing of the consumers. So when you assess the risks exposure, it's no longer materiality; its high public risk exposure that is the consideration. That means you have to concentrate on the exposure to high public risk. That is a major risk from the [public sector] auditor's perspective and so we need to make sure that the client report properly. Even if the figures are out by $0.1 \%$, it is still a big deal because the public is at risk, because the water is polluted. Hence we don't concentrate just on the financial aspects, but also the high public risk, health risk and safety risk factor [AM 22].

Regardless of whether the materiality assessment was based on qualitative or quantitative factors, all the interviewees stressed that practical auditing is very much based on professional judgement, imagination and common sense; and there are many possible solutions to consider:

The audit approach just gives you guidelines to audit but practical auditing is based on professional judgement, imagination and common sense [AM 22]. 
You make a judgement call based on knowledge and audit experience, but how far can you make that call and hope that you got it right? [AP 2].

The following paragraphs summarise and analyse the main interview findings from the preceding paragraphs. They also discuss their implications for audit practice.

The interview findings indicated that generally auditors determined acceptable levels of 'materiality' by evaluating financial considerations. The findings also indicated that the auditors were more comfortable working with quantifiable information. Hence, they preferred quantifiable information on environmental matters and, were concerned whether they were able to turn qualitative environmental information into quantifiable information. Thus, the general perception among auditors was that if environmental matters cannot be quantified then they are considered immaterial, do not warrant separate disclosure and do not need to be verified. Similarly, the interview findings also indicated that auditors would investigate non-compliance with environmental legislation only if the non-compliance was thought to have a material impact on the entity's financial results. Hence, the interviewed financial auditors reasoned that oftentimes they did not investigate the fines and penalties imposed on New Zealand companies for breaching environmental laws (which are typically less than NZ \$100,000), because they were considered immaterial when the quantitative 'rule of thumb' was applied. The implication is that auditors are generally not complying with AS-304: Audit materiality, which requires auditors to consider the nature of the item or transaction when judging materiality; and with AS-208: Considerations of laws and regulations in an audit, which states that in addition to the amount, the nature of non-compliance with laws and regulations should be considered. Even if they do not have a direct financial effect on the financial report, by its nature, the non-compliance may still influence the decisions of users and therefore is material. Hence the interview findings provided evidence of the existence of the 'expectation gap II', being a gap between standard setters' expectation of auditors and the perceived performance by auditors (Specht, 1992; Specht \& Sandlin, 2003) (refer to section 3.3). This will be further discussed in Chapter 6.

Various authors (Burrowes, 2006; Chewning \& Higgs, 2002; Kranacher, 2007) (see section 2.2.2) have criticised auditors' dominant focus on financial considerations when determining acceptable levels of 'materiality'. The interview findings confirmed the validity of the criticisms. Since the interviewed financial auditors preferred quantifiable environmental matters, they might have easily overlooked qualitative information on 
environmental matters that influenced the evaluation of audit findings. Besides, it is not always possible to use a purely quantitative basis to decide whether an item is material, because for example, the emission of a small amount of toxic substance (for example dioxin or mercury) can be material to the receiving environment (Blokdijk \& Drieenhuizen, 1992). Thus, reliance on a numerical threshold when assessing materiality may result in under-auditing or no auditing of environmental matters. In reality, qualitative considerations are just as important as quantitative considerations, especially for environmental matters and, therefore, should not be neglected because the issues behind the numbers often reveal more information than the numbers alone (Kranacher, 2007). Also, relying on quantitative measures indicates that auditors are setting aside their professional judgement and missing the clues revealed in qualitative information (Kranacher, 2007). However, auditors continue to be financially focussed on quantitative factors when assessing audit materiality despite such objections made by Kranacher (2007) and the PCOAB as reported by Burrowes (2006). This is a further, more glaring example of the existence of the 'expectation gap II' between practicing auditors and standard setters.

Of greater significance in New Zealand, is the requirement in AGS-1010 for auditors to treat environmental matters in terms of 'provisions, contingent liabilities and contingent assets'. According to NZ IAS 37, a contingent liability has only to be a possible or probable obligation; no monetary obligation is required, as oftentimes the amount is uncertain. Hence, even if environmental matters are not readily quantifiable, they should be considered as contingent liabilities and, thus, disclosed in the notes to the accounts. Therefore, the comments made by a number of the interviewed auditors about not bothering with 'unquantifiable' environmental matters indicates that their interpretation of the materiality assessment would fundamentally preclude them from even considering environmental matters as contingent liabilities that must be disclosed in the notes to the accounts. This is perhaps the most fundamental factor impairing the consideration of environmental matters in the audit of financial reports.

The strong financial focus also implies that financial auditors have not considered the public interest or the financial report users' perception that information on environmental matters does actually influence their decision-making (Deegan \& Rankin, 1997). On the other hand, the interview findings indicate that public sector auditors did determine the acceptable level of 'materiality' in terms of what was considered 
significant to the users of financial statements; that is the users' perception of materiality. Additionally, their assessment of environmental risks took into consideration public risk, health risk and safety risk factors, in addition to financial risk factors.

It therefore appears that, regarding the audit of environmental matters, public sector auditors were fulfilling their role and position in society better than financial auditors, whose general audit practices showed signs of managerial capture. They also seemed more diligent in searching out omitted environmental matters and verifying the validity, accuracy and completeness of the information on environmental matters. However, their environmental matters-conscious mentality was being driven by the legislative mandate imposed by the Local Government Act 2002. Hence, AGS-1010 would perhaps need to be made an audit standard in order to achieve a consciousness for environmental matters amongst auditors.

McKee and Elifsen (2000) cautioned that the international audit standard on materiality did not give guidance on how to implement materiality concepts in general audit practice, hence it is not surprising that the research findings indicated a variety of practices in determining the necessary level of materiality.

Since materiality considerations are overarching and the fundamental driving force of an audit, the best way forward is to develop specific accounting standards that override the traditional 'materiality test'. Such standards would require disclosure of particular items regardless of the quantum involved. A similar prescription could be developed for environmental matters. The next section presents interview findings on the application of accounting standards when auditing environmental matters.

\subsubsection{Application of Auditing and Accounting Standards}

The third component of audit practice is the application of auditing and accounting standards. However, this section will focus only on interview findings covering the application of accounting standards. Since Chapter 6 focuses on the application and impact of AGS-1010 on current New Zealand audit practice, the discussion on the application of audit standards and guidance statements at audit practice level is also covered there. The following sections cover the application of accounting standards. 
AGS-1010 paragraph 17 indicates that there is no specific accounting standard for environmental matters, and that accountants and auditors are directed to apply NZ IAS 37 on 'Provisions, Contingent Liabilities and Contingent Assets' for the purposes of financial reporting (AGS-1010, paragraph 17). Therefore, in the absence of a specific accounting standard, the research questions raised are: (1) how do auditors account for environmental matters for financial reporting purposes, (2) what is the audit approach in verifying the accounting treatment in accordance with generally accepted accounting practice, and (3) what are the challenges? The following sections present interview findings related to these research questions.

All of the interviewees confirmed that environmental matters were treated no differently from any other provisions and contingent liabilities; and the accounting standard for provisions and contingent liabilities was generally referred to when accounting for, or auditing, environmental matters:

Generally, we do not consider environment matters as a separate topic; it would be considered along the lines of contingent liabilities and provisions, which is one of our planning checklist items [AM 11].

However, the difficulty is that environmental matters could easily be disguised as contingent liabilities, and some probing is required to unearth them:

Environmental matters are liabilities emerging without you knowing it. It's hidden. You walk along the site yet you wouldn't know that the company has any environmental problems [AP 15].

It's in a set of issues for auditors that are difficult to see on the surface, so it's something that needs a bit of probing [AP 17].

However, nine of the eighteen (50\%) financial auditors felt that, while it was appropriate to apply the accounting standard for 'provisions and contingent liabilities' to environmental matters, there are practical difficulties in doing so. Although there was a presumption by the auditors that environmental matters were considered a contingent liability issue, all the interviewed financial auditors in medium sized firms (eight out of eighteen) (44\%) questioned whether auditors, in general, were searching out environmental matters disguised as contingent liabilities proactively, because their audit checklist often does not ask questions on environmental matters specifically:

I think applying the accounting standard for 'provisions and contingent liabilities' when accounting for environmental matters is sufficient. 
However it is dependent upon how proactive the auditor is in reviewing 'contingent liabilities'. You will find, as with a number of audit functions, the 'contingent liability' review often consists of interviewing one director and ticking a few boxes as to what the contingent liabilities for the company are. No, I do not think that you are going to pick up any potential [environmental] liabilities this way if the audit checklist doesn't ask specific questions on environmental matters [AM 1].

However, the same eight financial auditors further explained that environmental matters were not considered when planning an audit unless the auditor was aware of their existence initially. This is not surprising because of the BRA commonly followed by most auditors:

Our audit program is pretty much similar to the Big Four in that it is a generic audit program but the audit steps that pop out are dependent upon the information that is put in at the beginning [AP 2].

The same eight interviewees also expressed concern that they had to rely on estimates made by non-accountants when quantifying environmental matters:

Environmental areas can be a bit grey at times because you need to estimate how much you want to spend on the environmental obligation. When a landfill is closed, it still needs to be maintained, leached and the gas that comes out of the landfill released. Thus, council's landfill affects the environment for the next 50 years. So what are your environmental obligations? And who do you ask to calculate the cost to the council? Sometimes we get an engineer or a quantity surveyor to quantify that. From the auditors' perspective, we know we will have to check if it is properly calculated. You need to discount your obligations for the next 50 years into present day value [AM 22].

[So] the big risk is estimating how much it will be and what method the company will use to restore it; and of course the extent of restoration that's required [AP 15].

Although all the interviewed financial auditors applied the accounting standard on provisions and contingent liabilities to environmental matters, they perceived the accounting standard as being 'not prescriptive'. This raised further practical issues regarding its actual recognition:

If the environmental matter meets the definition of a contingent liability, you need to make a provision for environmental obligations under the current Financial Reporting Standard, FRS-15 (Contingent liabilities). However, when is it a contingent liability? When does it fall within a definition of provision? Well we've all got contingent liabilities but when are they actual obligations that have to be accounted for in the balance sheet? [AP 15]. 
The interviewees explained that if a polluting company had no obligation to remedy the pollution, the company did not have to account for it nor disclose any information on it. Hence, auditors generally appeared to be unconcerned about it. However, though a company might not have a present obligation, the future is uncertain and laws can change. Although environmental matters might be of no concern, and unquantifiable currently, they might well give rise to possible or probable future obligations, which, according to NZ IAS 37, require full disclosure in the notes to the accounts, as one of the interviewed financial auditors commented:

If the company has pollution issues, but there's no call on the company to mitigate it, the environmental matter wouldn't have to be in the company accounts... If the company has caused some pollution, but it is not breaching any concerns, there's no obligation on the company to clean it up. The company wouldn't need to provide for the clean up and the auditors do not have to deal with it [AM 3].

All the interviewees asserted that the audit objective in verifying environmental matters is 'completeness', that is, auditors must verify that all existing environmental matters are properly accounted for in financial reporting. Hence, an important audit task is to search for unrecorded environmental liabilities. However, ten of the fourteen $(56 \%)$ interviewed financial auditors admitted that searching out unrecorded environmental liabilities was not easy because they were less obvious:

I think the audit difficulty is that although they [environmental matters] have important financial statement implications for some industries and clients, they are less obvious. Hence, environmental matters are harder to detect. Actually it is difficult to search out for those unrecorded environmental liabilities. That is the issue [AP 17].

As stated previously by the interviewees, since they lacked the ability to quantify environmental matters, they had to rely on accounting estimates prepared by nonaccountants, management, and independent verifiers to quantify and certify the costs:

You've got to assess what the risk is and discover if any documentation is being entered into; knowing whether the client is actually addressing this risk, and whether they're quantifying it. We're not experts in quantifying what the remedial costs would be for cleaning up a site where there's a spill. All we can do is encourage the client to make efforts to quantify the costs themselves and get some sort of independent verification. If it's not quantified it may still be reported as a potential contingent liability which requires disclosure in the financial statements [AM 1]. 
Since auditors were expected to refer to the accounting standard on provisions and contingent liabilities when auditing environmental matters, there was an expectation that environmental matters would be discussed during training sessions. Nevertheless, twelve of the eighteen (67\%) financial auditors interviewed admitted that they were not given any kind of training on environmental matters:

We are just generally aware of environmental matters as opposed to being specifically trained for it. However, any significant articles on environmental matters are photocopied and sent round or just flagged to people for them to be aware of [AM 11].

On the other hand, four of the eighteen (23\%) indicated that only when a company has significant environmental matters then specific training is given, mostly on a 'need to know' basis:

Environmental matters are not covered in general audit staff training. If a client has environmental issues, then staff is trained on that specific job to deal with it; that is, on a need to know basis [AM 14].

Further, the same four interviewees indicated that, to a small extent, information on environmental matters is mentioned in relation to contingent liabilities:

To a very small extent; we just mention them potentially in regards to contingent liabilities, but other than that, no [AM 10].

Two interviewees from the 'Big Four' indicated that their lack of specific training is compensated by their ability to access resources from their global firms through the global network:

There is not a lot of information from the New Zealand perspective so we only would tap into that resource [the global network] if we needed to. We have access to information on environmental matters from the global firm. Often the overseas firms have greater resources and they might have more companies dealing with environmental matters. [AM 14].

We've got access to information on a huge data base. So when I had to research an environmental issue that I had with my recent client, I've been able to access globally virtually on everything that [the firm] have concluded on any environmental issue. I may have 40-50 different examples of scenarios and their implication for the audit and I can go down the list of 40 and pick the one that is most similar to what I've got for this situation [AM 3]. 
In contrast, all the public sector and government auditors are up to speed with the audit methodology because of the intensive training given to them. The forces driving the training initiatives are the Local Government Act 2002 and the Auditor General.

\begin{abstract}
A lot of our focus comes directly from the Auditor General. We have many different sectors to audit: the local government sector, the health sector. For each of those sectors, the Auditor General makes sure that there is appropriate training provided on environmental matters and any other relevant audit issues. There's a big focus on training; a huge focus. I'd never done so much training in all my life until I joined the Auditor General's office [AP 21].
\end{abstract}

An audit practice reviewer raised an alarm when he indicated that auditors outside the Big Four were not yet in any position to consider environmental matters in their audit. Their audit methodology was still considered extremely rudimentary:

In most of the files I look at it is very easy to see that environmental matters are not being considered at all. On a practical level, the non-Big Four auditors in New Zealand are very unsophisticated and we as audit practice reviewers are still finding practitioners who need to be reminded of the importance of really basic auditing procedures like having a written audit plan, which is as basic as you can get. So if I found anyone who had had a written and signed engagement letter; a written audit plan, audit program and documented evidence when I review the audit file, I would be delighted. So the importance of auditing environmental matters is something that can wait. We are still unfortunately working very much on the basics. As I say there are exceptions, but there are quite a lot of practitioners out there whose knowledge of 'how to do an audit' is extremely rudimentary [APR 18].

The following paragraphs summarise and analyse the key interview findings, and discuss their implications for audit practice.

As might have been expected from AGS-1010 paragraph 17, the interview findings confirmed that all the interviewed auditors treated environmental matters no differently from any other 'provisions and contingent liabilities' and that they referred to the accounting standard for provisions and contingent liabilities when accounting for or auditing environmental matters. However, the auditors perceived NZ IAS 37 as not being prescriptive and its interpretation as subjective. Such a mindset, combined with their dominant perception of materiality as requiring quantitative measurement (refer to section 5.2.2), could lead auditors to miss environmental-type contingent liabilities during their audits of financial reports. In so doing, auditors would, yet again, be exposed to unnecessarily high audit risk. 
It is often said that knowledge is power. Therefore, professional development should enhance a person's knowledge base, and one would expect auditors who had admitted their lack of knowledge on environmental matters to up-skill in this area. However, the interview findings indicated that auditors are generally not trained to audit environmental matters. For some auditors, environmental matters were superficially covered during training on the audit of contingent liabilities. Yet for others, training was on a 'need to know basis', i.e. when auditing a company with significant environmental matters. An audit practice reviewer raised the alarm that many auditors outside the Big Four were not yet in a position to consider environmental matters for their audits, because they still, in general, lacked a rigorous audit methodology. However, auditors from the Big Four were advantaged, because they could access information resources from their global firms through the global network and database. On the other hand, public sector auditors were given intensive training on various environmental subjects. The Local Government Act 2002 was behind this initiative, forcing public sector auditors to consider environmental matters. This is a significant research finding. It appeared that financial auditors might begin to notice environmental matters only if a legislated mandate that required them to do so were promulgated.

The interviewed financial auditors explained that if a polluting company had no obligation to remedy the pollution, the company did not have to account for it nor disclose any information about it, in which case they were not concerned. These auditors appeared short-sighted in their approach, because Lickiss (1991) has cautioned that contingent liabilities can very quickly turn into actual ones when legislation is enacted to make companies more responsible for the costs of the environmental damage they were causing or had caused in the past. Additionally, AGS-1010, paragraph 36, cautioned New Zealand auditors on the changes in environmental legislation that could have significant consequences resulting in a liability relating to past events not formerly governed by legislation. Besides, if there is no obligation for clean-up, the asset (e.g. polluted land) should be reviewed for impairment (NZ IAS 36: Impairment of assets, paragraph 9). Hence, it is obvious that some auditors may not have read, and certainly not completely understood, AGS-1010, NZ IAS 37 and NZ IAS 36. Additionally, the approach of the auditors interviewed to accounting for environmental matters in terms of 'provisions and contingent liabilities' differed from Deegan and Samkin's (2006) more conservative approach, which requires environmental matters to be reported when 
usual prudent practices suggest that remediation is necessary. These apparently different perspectives confirm that the accounting treatment for environmental matters was subjective and, thus, a high risk area.

The auditors interviewed outlined their audit approach in auditing environmental matters. They indicated that the objective in verifying environmental matters is 'completeness', that is, ensuring that all existing environmental matters are properly included in financial reporting. Thus, some auditors questioned whether auditors in general were actually searching for environmental matters embedded in contingent liabilities, because the audit checklist they used did not ask questions on environmental matters specifically: especially when the auditor was unaware of their existence and, thus, did not even consider their possible existence when planning an audit.

The research findings substantiate Rezaee et al.'s (1995) observations that a lack of authoritative accounting standards and uncertainties associated with identification, evaluation and measurement of environmental matters and also contingent liabilities in general has resulted in inconsistent accounting treatment of environmental matters in current practice. Therefore, it is often difficult to evaluate the accounting and disclosure requirements applicable to environmental issues adequately (Munter \& Sacasas, 1996). Hence, the question Baker and Owsen (2002, p. 786) raised as to "whether any form of audit can be effective without strong standards of reporting", can also be raised for the audit consideration of environmental matters; and the answer appears to be 'no'. Besides, research findings indicated that the application of general audit methodology would not assist in the detection of any misstatements or omissions in environmental matters in financial reports. Thus, until the accountancy profession addresses issues related to measurement, recognition and disclosures of environmental matters, auditors are exposing themselves to high audit risk should they continue to apply inconsistent accounting rules to environmental matters and fail to give due regard to AGS-1010. The next section presents the interview findings on auditors' reliance on the work of experts when auditing environmental matters.

\subsubsection{Relying on the Work of an Expert}

AS-606: Using the work of an expert acknowledged that generally, auditors are increasingly relying on the work of non-accounting professional experts. However, regarding the audit of environmental matters specifically, little is known about the 
extent to which auditors rely on the work of experts. This section presents interview findings on this little known audit issue.

All the interviewees admitted that they were not specialists in environmental matters and thus had to rely heavily on the work of non-accounting experts:

We rely heavily on the work of experts really. We're not experts in environmental matters so we have to rely on other people to give us support [AM 14].

At the end of the day, it's [environmental matters] not something that we've particularly come across all the time to gain a great deal of expert knowledge on [AM 11].

In terms of our level of understanding of [environmental] risk areas and identifying it as a risk area that can have an impact on the financial statements, we would need to employ independent experts [AM 20].

Ten of the eighteen financial auditors interviewed said that the experts used were appointed by the client company:

You'd always get the client to get the expert if you need to rely on them or use third party reports or advice [AP 9].

We haven't gone out and engaged the services of a non-audit expert. It has generally been the client who appointed the experts. We just review their work [AP 14].

All the interviewed financial auditors indicated, however, that they were generally more sceptical about the work of experts appointed by the company:

We would not be fulfilling our audit obligations if we placed total reliance on any expert without questioning their qualification, their level and areas of expertise in the field and their approach to preparing whatever piece of advice that we are going to rely on. We would apply an appropriate degree of scepticism to any expert engaged by the company rather than by us [AP 17].

The issue of the independence of experts (appointed by company management) was raised. It seemed that all the interviewees did expect the experts to have a level of independence and objectivity. In fact, they perceived an expert's membership of professional bodies and their requirements to comply with professional and ethical guidelines and standards as measures of professional independence and objectivity. However, beyond that expectation, the interviewees safeguarded themselves with professional indemnity insurance. Hence, six of the eighteen (34\%) financial auditors 
interviewed said they would counter-sue the experts should there be any legal implications:

We obtain a representation from the expert giving assurance of their independence and objectivity, and that they are aware that we are going to rely on their information. Really, the question of independence comes back to professional membership. The experts are all professionals in their own field, they're all members of professional bodies and those professional bodies all have their own ethical standards and guidelines that must be adhered to. However, if we came down to a crunch and got attacked, we would turn around and just pass the risk and liability back to the expert because the expert is aware that we as auditors are relying on them as a professional body I guess. To that extent, that's why they pay for professional indemnity insurance just like we do [AM 10].

Again, it seemed that, as an appropriate measure of professional competence, the professional membership of experts was regarded highly by interviewees; as indicated by one audit partner:

There's a whole range of different professional expertise available these days. So to assess the professional competence of any expert, you have to determine from the market; you may need be talk to the expert's membership institute. They may be members of professional body. Make sure the professional body is of good standing and is recognised. A number of these experts would have international links so you could confirm that they are recognized and appropriate for use. In a large part, they were recommended by the entity being audited [AP 12].

An audit practice reviewer gave an example of the assessment of professional competence based on professional membership:

I have reviewed an audit whereby the auditor relied very heavily on the value of some exploration licenses which was really a valuation of intangibles. In the audit file were 2 reports, one from an expert in Australia and another from New Zealand. The Australian expert had a string of letters after his name as he is a member of various institutes. On the face of it, he seemed qualified. On reading his report, I felt like he was someone who knew what he was talking about. Actually his report gave a sense of assurance. The New Zealand expert, on the other hand did not state his qualifications at all on the draft report. It was also not signed, so I had to take the auditor whose work is being reviewed to task for failing to ascertain the qualifications of the New Zealand expert. He was quite probably qualified, but there was no evidence... so the auditor has to ask, "How can I rely on this?" [APR 18].

Eight of the eighteen financial auditors (45\%) and all the public sector and government auditors are confident that the experts they approach are technically able. Nevertheless, 
ten of the eighteen (56\%) financial auditors interviewed were concerned about finding the right specialist to advise and give information relevant to the audit because there are only a few of them in New Zealand:

The biggest issue would be finding a specialist particularly within a New Zealand environment who would be in a position to give an auditor the type of information that we'd need. Internationally I guess it's not too much of an issue but if you are in the New Zealand environment it's the biggest problem. I guess we've got to be careful who we rely on for that sort of stuff as well [AM 10].

Hence, the ten interviewees conceded that relying on experts for advice on a subject outside core accounting might prove subjective and dangerous:

They [auditors] have to rely on experts - further and further away from core matters - very subjective, very dangerous [AP 19].

All the interviewees admitted that they were not specialists in environmental matters and, thus, had to rely heavily on the work of non-accounting experts. This is not surprising because "auditors are not expected to have the expertise of a person trained for or qualified to engage in the practice of another profession" (AS-606, paragraph 7). However, all the interviewees said that the client companies appointed the experts. This raised the question of whether the experts can be objective and independent.

All the interviewees expected the experts to be independent and objective. They perceived an expert's membership in professional bodies, the requirement to comply with professional and ethical guidelines and standards as appropriate measures of professional independence, objectivity and professional competence.

As indicated by Power (1997) and assumed by AS 606: Using the work of an expert, professional competence, objectivity and independence are somewhat assured by technical qualification and membership of a recognised professional body. This is exactly the same assumption the interviewed auditors made. They have given membership in a recognised professional body very high priority when assessing an expert's professional competence and independence. To them, membership to a recognised professional body indicated that the expert's techniques should be generally acceptable. However, in that assessment, the auditor had not considered the actual quality of work done by the expert (AS 606: Using the work of an expert, paragraph 9). The implication is that the auditor assumes the quality of the work performed by the 
expert, even though they admitted their lack of knowledge in environmental matters and, therefore, cannot always challenge an expert's assumptions, criteria and methods.

The interviewed auditors are concerned that there are only a few experts in New Zealand able to advise and provide information relevant to the audit. Hence, they conceded that relying on experts for advice on a subject outside core accounting might prove subjective and dangerous; again exposing the auditors to legal liability for audit work done in a high-risk area. This issue is further discussed in section 6.2.3.

\subsection{Chapter Summary}

This chapter has presented the interview findings on the first three research questions: (1) how do auditors generally perceive the consideration of environmental matters in the audit of financial reports; (2) what common approaches and practices do auditors undertake when auditing environmental matters; (3) do auditors face any challenges in the audit of environmental matters and, if so, what are they? The findings were then analysed and their implications for audit practice discussed. The following paragraphs highlight the significant research findings.

Generally, the New Zealand auditors interviewed for this study considered the audit of environmental matters to be onerous, adding cost to the audit; and they felt unable to keep up with their responsibility for a client's exposure to environmental matters. Despite the introduction of AGS-1010 in 2001, the focus has not changed; environmental matters are treated no differently from any other audit issue and are usually not brought to bear in daily audit work. Some auditors even admitted they do not seek out environmental matters in particular. Generally, financial auditors apply the four components of audit practice to the audit consideration of environmental matters: (1) the business risk approach to auditing; (2) professional judgement on materiality; (3) application of auditing and accounting standards and (4) relying on the work of an expert. However, there are problems with these four components that do not assist audit practice.

In contrast, the audits of public sector auditors are driven by the Local Government Act 2002 and they are required to consider environmental matters for every audit. The public sector auditors are also intensively trained to search out environmental matters. Therefore, a way to focus financial auditors' attention on environmental matters, amongst other audit issues, may be to put in place a legislative mandate. In general, 
financial auditors were very concerned that the audit task could expose them to serious legal liability. Some auditors even questioned their own ability to form an opinion on environmental matters. However, the interview evidence indicated that they had not prepared themselves by way of professional training, or even factored environmental risk specifically into their audit methodology. The research evidence thus pointed to the existence of "the expectation gap II" in the audit consideration of environmental matters, which is further discussed in Chapter 6. The overall and most significant conclusion from this study is that current audit approaches and practices are not likely to facilitate the consideration of environmental matters in the audit of financial reports.

The next chapter presents and discusses the interview findings on (1) whether AGS1010 has impacted upon current audit practice and (2) how current practice might be improved and further developed to meet better the espoused aims of AGS-1010. 


\section{CHAPTER 6: PRESENTATION, ANALYSIS AND INTERPRETATION OF RESEARCH FINDINGS (PART TWO)}

This chapter follows on from the Chapter 5 discussion of the interview findings on the first three research questions. It discusses the interview findings on the remaining two research questions:

4. Does AGS-1010 impact current practice and, if so, how?

5. How may current practice be improved and further developed to meet better the espoused aims of AGS-1010?

The format for this chapter is similar to that of Chapter 5. First, gaps identified in the literature are summarised for each research question. Second, interview findings relevant to the research questions are presented, along with supporting direct quotations from the interviews and a discussion of the implications of the findings for each of the research questions. However, before interview findings on the final research question are presented, the research evidence is synthesised into recurring themes (Ahrens \& Dent, 1998). These recurring themes establish links to the theoretical perspective adopted for the study and demonstrate the usefulness of 'legitimacy theory' (Pentland, 1993; Power, 2003) as the appropriate theoretical lens. The findings also provide evidence that the accountancy profession's legitimating strategy in promulgating AGS1010 has led to an audit expectation gap II (Specht \& Waldon, 1992). Interview findings on auditors' perceptions of the impact of AGS-1010 on current audit practice are discussed next.

\subsection{Auditors' Perceptions of AGS-1010 and its Impact on Current Audit Practice}

The key impetus for this research study was the promulgation of AGS-1010 in 2001. However, whether or how this guidance statement has affected current practice is not known. There are two parts to this section. The first covers interview findings on auditors' perceptions of their interpretation and use of AGS-1010 and the impact of AGS-1010 on current audit practice. The second part analyses and evaluates AGS-1010 to determine whether it has the potential to provide guidance to improve audit practice. The next section covers interview findings on auditors' perceptions. 
The letters of introduction (refer to Appendix 2) sent to auditors to invite them to participate in this research explicitly referred to AGS-1010 as the basis for the study. However, fourteen of the eighteen (78\%) interviewed financial auditors admitted that they had not read AGS-1010 prior to the interviews. Therefore, they were unable to comment on it. In fact, six of the auditors were not even aware of its existence:

To be perfectly honest I haven't read it [AM 10].

I'd be completely honest and say I'm not aware of its existence [AM 11].

I didn't read it thoroughly. I am not an expert on environmental matters, so I do not know if AGS-1010 gives sufficient guidance on how auditors should recognise environmental issues in the audit process [AP 2].

On the other hand, all the public sector and government auditors and only four of the financial auditors interviewed had read AGS-1010. They considered it to be only an introductory discussion paper; a very long document setting out some principles but not providing any detailed procedural steps:

Yes, the introduction of AGS-1010 is an improvement, but really does it go far enough? I'm not sure [AP 2].

As a guideline, AG-1010 did not give direction on methodology. It is very much a discussion paper in my mind [AM 27].

AGS-1010 sets out in principle the general approach to the audit of environmental matters. It is a very long document but it doesn't give enough detail, a bit like the valuation, it doesn't give you enough details on the steps to perform and ticking them off when you get your conclusion [AP 4].

In summary, the above interview findings revealed that only four of the eighteen financial auditors interviewed had actually read AGS-1010. They considered it an introductory discussion paper only. The next section presents interview findings on the auditors' perceptions of the actual impact of AGS-1010 on audit practice.

\section{Auditors' Perceptions of the Actual Impact of AGS-1010 on Audit Practice}

The fourteen interviewed financial auditors who did not read AGS-1010, also did not think that AGS-1010 had an insignificant impact on audit practice. They commented on it being just an audit guideline, not mandatory like an audit standard. None of the financial auditors interviewed seemed to pay serious attention to it and most indicated they were likely to ignore it unless they were auditing an entity obviously exposed to environmental risks. One financial auditor even considered AGS-1010 as a "non-event" 
and another went further to say that auditors were simply not using AGS-1010. In fact, they were not even considering environmental matters in their audits:

You know it is an audit guideline as opposed to being an audit standard. As an audit standard, it supposedly becomes compulsory and then you start paying closer attention to it. It is a case of being aware it is there. When your client operates in an industry that specifically has an environmental issue, that's when it is taken out and sits in front of the desk, and you go right through it for the audit [AM 1].

I think it's a good starting point, raising your awareness that you should look beyond the straight numbers. But it is difficult. It's a guideline and you know it can't cover everything. You know it's not as weighty as the standards [AM 14].

AGS-1010 is pretty much something that's a non-event [APR 1].

AGS-1010 is only a guideline and I do not think that auditors are using it or even considering environmental matters in their audit [AP 19].

However, even though none of the financial auditors is taking AGS-1010 seriously, only one financial auditor felt that environmental matters did not warrant an auditing standard; and that AGS-1010 as a guidance statement was good enough for its intended purpose:

I think it's a good guidance statement because it guides you on procedural matters you would normally consider for your audit. I think its status as a guidance statement is appropriate and I do not think that environmental matters warrant, for example, an auditing standard of their own although they [the professional accounting bodies] might. You could come out with an auditing standard: "Thou shalt engage an expert on environmental matters", but I think that would be wrong because I think we gain sufficient appropriate evidence from applying our normal audit process [AP 17].

The six financial auditors whose clients had environmental issues indicated they relied on international standards, and considered these to be of a higher standard and more stringent than AGS-1010:

The audit work I do requires me to comply with the Local Government Act 2002 which is more prescriptive than AGS-1010. The calibre of work we already do is at a level higher than that proposed in AGS-1010. We haven't really changed our approach and we tend to get guidance from our international offices which deal with the matter for numerous countries and numerous issues [AM 13]. 
I think we are already doing a number of those things stated in AGS1010 anyway. Our bar is higher [AP 15].

No. I don't think it has really changed the way we do our audits. It's because of the way our files are set up. We refer to international auditing standards and our audits are in line with overseas auditing standards which tend to be more stringent than what we have here in the first place, so I can't think of anything which has really changed [AM 3].

Twelve of the eighteen (67\%) commented that AGS-1010 was subject to different interpretations and although the underlying theory looks easy, the practice is not.

However, it's all in the interpretation. It's quite interesting, when you read AGS-1010 and when you apply it, they are two different things. The theory looks easy but the practice is not as easy. Often you have feedback that says someone knows the guidance statement, but really they don't have a clue what it involves. At the end of the day, when it comes to application, you know the guidance statement is subject to interpretation [AM 22].

Nevertheless, of the twelve, one financial auditor cautiously suggested that their audit processes covered the requirements of AGS-1010:

I would be very careful with my answer. Comparing AGS-1010 to our internal audit standards, I'm sure that our firm's audit methods follow AGS-1010 [AP 17].

Another financial auditor felt that AGS-1010 in its present form would not facilitate any advance because it did not provide any assessment criteria:

AGS-1010 is very broad. Unless we have something specific to look at in order to give us some kind of assessment criteria, how can we move forward? [AP 26].

Sixteen of the eighteen interviewed financial auditors seemed comforted that AGS-1010 was something they could show to their clients. This would provide assurance that they have appropriate guidance on the audit consideration of environmental matters, regardless of whether AGS-1010 is referred to or not:

If anything goes wrong, if you get into a dispute or clients complain and ask "what are you doing?" You have AGS-1010 to pull out to show the client and say "there you go". It helps us in that way [AP 5].

On the other hand, all the public sector auditors declared that they are expected to comply with AGS-1010, even though it is non-mandatory audit guidance: 
The Auditor General issues his own auditing standards, which supplement NZICA auditing standards. We have to comply with both sets of standards as an auditor on behalf of the office of the Auditor General. But in this particular case the Auditor General hasn't issued any specific standard himself so we do comply with AGS-1010, although it is only a guidance statement [AP 24].

The above section presented research findings on the interviewed auditors' perceptions on AGS-1010 and its actual impact on audit practice. A summary and analysis of the above interview findings, and a discussion of their implications, are covered in section 6.3. In view of these interview findings and, particularly, the indication that AGS-1010 has an insignificant impact on audit practice, AGS-1010 was critically reviewed to make sense of the reason(s) behind the interviewees' perceptions. The results of the content review and analysis of AGS-1010 are discussed next.

\subsection{A Critical Review of AGS-1010}

The aim of reviewing AGS-1010 was to analyse its effectiveness and to evaluate its potential impact (based on what AGS-1010 states) on current audit practice. However, AGS-1010 was reviewed more critically only after the auditors were interviewed. In so doing, the reasons for the interviewed auditors' perceptions that AGS-1010 was not (actually) impacting current practice, and the reasons for auditors not adhering to the requirements of AGS-1010, could be explored. The critical review also led to research evidence indicating that 'the expectation gap II' was a consequence of issuing AGS1010 (Specht \& Waldron, 1992). The espoused purpose of AGS-1010 is discussed next, followed by a discussion of each of the issues identified in AGS-1010 that impact upon its effectiveness.

\subsubsection{The Espoused Purpose of AGS-1010}

AGS-1010 was first promulgated in 2001 by ICANZ (renamed NZICA in 2005). ICANZ acknowledged in AGS-1010 that environmental matters were becoming significant, and financial statement users were especially interested in its impact on the financial reports of those entities (AGS-1010, paragraph 1). Hence the stated purpose of AGS-1010 was "to assist auditors in developing best practices in the application of auditing standards" in cases where environmental matters were significant to the financial report of the entity. However, no new basic principles or essential procedures were established (AGS-1010, paragraph 6). AGS-1010 applied the BRA model in audit planning, and elaborated on specific factors and procedures that might be helpful in 
identifying environmental risk, defined as "the risk of material misstatements in the financial report due to environmental matters" (AGS-1010, paragraph 10d).

Two members of NZICA's Professional Standards Board (PSB) were interviewed in 2001 for their comments on AGS-1010. Both members indicated that the obligation of the PSB is to follow through international auditing standards and guidance statements and adapt them for New Zealand. The PSB is a voluntary board with only limited resources and a decision was made to adhere closely to international auditing standards. The time difference between the issuance of IAPS-1010 in 1998 and AGS-1010 in 2001 was a result of the due diligence and exposure draft process.

The analysis of AGS-1010 carried out as part of this study revealed significant concerns about whether it is likely to achieve its stated purpose. The issues identified as impacting the effectiveness of AGS-1010 are (1) the exercise of professional judgement, (2) auditors' greater reliance on client management and other experts (3) the consideration of environmental laws and regulations and (4) the existence of incidences of "doublethink" and "doublespeak" (El-Sawad, Arnold, \& Cohen, 2004; Orwell, 1949; Robb, 2003a, 2003b) (i.e. internal contradictions) in AGS-1010. These issues are discussed in the following sections.

\subsubsection{The Exercise of Professional Judgement}

The first issue impacting the effectiveness of AGS-1010 is 'the exercise of professional judgement', which is also considered as the cornerstone of auditing (Gray \& Manson, 2005). Aspects of professional judgement, particularly on materiality, are discussed in section 2.2.2. Further discussions on professional judgement in the context of AGS1010 are covered in this section.

The Canadian Institute of Chartered Accountants (CICA) (1995) defined professional judgement in auditing as:

The application of relevant knowledge and experience, within the context provided by auditing and accounting standards and rules of professional conduct, in reaching decisions where a choice must be made between alternative possible courses of actions (p. 5).

Professional judgement is emphasised in AGS-1010, as evidenced by the number of references to it and by its relationship with other issues raised in AGS-1010 itself. AGS1010 expects auditors to rely on professional judgement: (1) when identifying the 
existence of environmental matters for the entity (AGS-1010, paragraph 3); (2) when assessing its significance to warrant its consideration in the audit of financial reports (AGS-1010, paragraph 2); (3) when assessing its impact on the financial report of the entity (AGS-1010, paragraph 4), and when evaluating environmental risk (which is the risk of material misstatements in the financial report due to environmental matters (AGS-1010, paragraph 10d); all summed up as follows:

The extent to which any of the audit procedures described in the statement may be appropriate in a particular case requires the exercise of the auditor's [professional] judgement in the light of the requirements of the auditing standards and the circumstances of the entity (AGS-1010, paragraph 6).

In acknowledging that environmental matters may be complex, AGS-1010 again emphasises the importance of exercising professional judgement:

The use of professional judgement may become even more important because of the number of difficulties with respect to the recognition and measurement of the consequences of environmental matters in the financial report (AGS-1010, paragraph 44).

Various authors have identified auditor independence, objectivity and integrity (Libby \& Thorne, 2003); knowledge of facts, clients and procedures in problem solving, experience, and expertise, professional competence (Bhattacharjee \& Moreno, 2002); judgemental biases, professional scepticism (CICA, 1995; Morrill, 1996); and cultural differences (Patel, Harrison, \& McKinnon, 2002) as attributes affecting professional judgement. However, how these attributes combine to create sound professional judgement is not well understood (Morrill, 1996). Professional judgement guides the determination of what constitutes 'sufficient appropriate audit evidence' and is influenced by 'audit materiality' (which itself is problematic; refer to sections 2.2.2 and 5.2.2) and business risk considerations (refer to sections 2.2.1 and 5.2.1) whose determination also requires professional judgement. However, the relationship is not uni-directional because sufficient appropriate audit evidence significantly influences professional judgement that leads to giving the audit opinion (AS 500: Audit evidence).

Several other factors identified as also influencing professional judgement are: the degree of audit firm structure (McDaniel, 1990), audit firm procedures ((Morris \& Nichols, 1988); the existence of decision aids (Ashton, 1990); inputs from specialists or colleagues (Libby \& Luft, 1993); nature and quality of feedback available (Ashton, 
1991) and the nature of the task itself (Abdolmohammadi \& Wright, 1987). In addition, the professional judgement process is affected by facts and data, the people involved; the standards, rules and procedures (Gibbins \& Mason, 1988). Furthermore, Gibbens and Mason (1988) believed that professional judgement takes place within an environment comprising of legal, financial, risk, competitive and other factors. Similarly, the auditors who were interviewed clearly indicated many factors which had impacted their professional judgement on environmental matters: exposure to legal liability, their ability to detect environmental matters, reliance on experts and management representations; inability to maintain currency in and understanding of environmental laws and matters; additional costs; auditors' own perception of environmental matters; the application of BRA; professional judgement on materiality; application of auditing and accounting standards (refer to sections 5.2.2, and 5.2.3).

The concept of professional judgement is therefore, complex, and the process of exercising professional judgement as required by AGS-1010 is challenging in practice because existing audit standards do not provide guidance in exercising judgement, or identify the characteristics of good judgement. This was indicated by the auditors who were interviewed; especially regarding the professional judgement needed in the initial identification of environmental risks for entities where its existence might not be obvious (refer to section 5.2.2). To illustrate, consider the example of potential exposure to significant environmental risk for any entity. In accordance with their sector or industry grouping (chemical, oil and gas, pharmaceutical, mining, agribusiness and so on), some entities are naturally exposed to significant environmental risk which could give rise to possible environmental liabilities and contingencies (AGS-1010, paragraph 20). However, there are also entities whose exposure to environmental matters is not obvious. For example:

Business or operational processes that may cause contamination of soil
and groundwater, contamination of surface water or air pollution; use
hazardous substances; generate or process hazardous waste; or may
have an adverse impact on customers, employees or people that live in
the neighbourhood of the entity's sites $(A G S-1010$, paragraph $21 d)$.

For all companies, there is a greater potential for omissions and non-disclosures of environmental matters in financial reports (rather than misstatements) because, by their nature, environmental matters usually concern negative information that entities would rather omit from public disclosure. From a practical perspective, omissions and non- 
disclosures are much harder to search for than reported misstatements. Nonetheless, when identifying environmental risk factors, AGS-1010 requires auditors to exercise professional judgement based on 'technical skills' that the profession has also acknowledged "the auditor cannot be expected to possess" (AGS-1010, paragraph 14). Since auditors are not expected to have a higher 'level of knowledge with regard to environmental matters than that normally possessed by management or by environmental experts' (AGS-1010, paragraph 18), this presents a major challenge for auditors. If AGS-1010 acknowledges that auditors are not technically competent in environmental matters, how will they exercise professional judgement when dealing with environmental matters, when their professional judgement may be influenced by those attributes and factors identified in the literature and by the interviewed auditors themselves (refer to sections 5.2.2 and 5.2.3)?

The interviewed auditors who indicated that they have audited environmental matters commented that the guidelines in AGS-1010 are not prescriptive enough and are rather subjective and, even though the theory embodied in AGS-1010 appears easy to understand, its practical application is not (refer to section 6.1.1). A review of AGS1010 confirmed that although it contained many examples of environmental matters, it lacked useful guidelines on appropriate audit procedures. Hence, in light of concerns around the exercise of professional judgment, AGS-1010 could be further improved by providing more guidance on how to exercise professional judgement in detecting environmental matters and what the characteristics of good judgement are, in order to achieve its stated purpose of "assisting auditors in developing best practices in the application of auditing standards" (AGS-1010, paragraph 6). The second issue that impacts upon the effectiveness of AGS-1010 is its suggestion that auditors place greater reliance on management and other experts. This issue is discussed next.

\subsubsection{Greater Reliance on Management and Other Experts}

AGS-1010 accepted that auditors do not have adequate technical and general knowledge to deal with environmental matters (AGS-1010, paragraph 14), and therefore it suggested that auditors rely more on management (AGS-1010, paragraph 13) and client internal documentation. In particular, AGS-1010 indicated that:

To obtain a general understanding of relevant environmental laws and regulations, the auditor normally...enquires of management (including key officers for environmental matters) concerning the entity's policies 
and procedures regarding compliance with relevant environmental laws and regulations; enquires of management as to the environmental laws and regulations that may be expected to have a fundamental effect on the operations of the entity; discusses with management the policies or procedures adopted for identifying, evaluating and accounting for litigation, claims and assessments (AGS-1010, paragraph 39).

However, such reliance on management and on working in close proximity with the client raises potential concerns for auditor independence (refer to section 5.2.4 and 2.2.4). The auditor is also directed in AGS-1010 to rely on experts (lawyers, engineers and environmental experts) and, in particular, to use "the findings of environmental audits as appropriate audit evidence" (paragraph 51). In this matter, AGS-1010 refers to AS-606: Using the Work of Experts and AS-606, paragraph 8 indicates that the expert may be one engaged either by the entity or auditor, or employed by the entity. If the auditor were to rely on an expert engaged or employed by the entity, the issue of auditor independence again arises.

Auditor independence is a significant issue in the Code of Ethics: Independence in Assurance Engagements (ICANZ, 2003b) which states that auditors "must not allow prejudice or bias, conflict of interest, or influence of others to override objectivity" (p. 460, paragraph 33). However, as indicated by Bazerman, Loewenstein and Moore (2002) (refer section 5.2.1), auditors are vulnerable to bias, and have "a tendency to be influenced by clients' or experts' biases; and audit judgements are perceived as being strongly biased toward the interest of their clients" (p. 101). These authors also argued, “...it takes very little ambiguity to produce biased judgement" (p. 101). Therefore, the directive in AGS-1010, that auditors rely on management and other experts (engaged or employed by the client) is somewhat problematic as it may lead to a compromise of auditor independence resulting from (1) the "“advocacy threat', when the auditor's dependency on the client [or expert] 'subordinates' [his/her] judgement to that of the client, or (2) the 'familiarity threat', when the auditor becomes too sympathetic to the client's interests" (ICANZ, 2003b, Code of Ethics: Independence in assurance engagements, paragraph 33). Additionally, Sikka (2008, p. 22) criticised the "very model of company audits [as] flawed", going on to say that:

Company directors are the ones who hire and remunerate auditors, albeit with shareholders rubber-stamping their decisions....[hence] auditors can never be independent of the client companies or their directors. Until auditor appointment and remuneration is completely removed from the 
hands of directors and corporate officials, auditors will not have the backbone to deliver robust audits (p. 22).

Cheney (2005) reported Chuck Landes, the director of auditing and attestation at the American Institute of Certified Public Accountants (AICPA) as saying that audits have become more complicated, and auditors are increasingly relying on experts. Landes was concerned that practical guidance given to auditors relying on experts may "be out of date and weak, not recognising what's happening in the work of using experts and specialists today" (Cheney, 2005, p. 14). He also raised several practical questions:

1. To be entrusted with an audit role, what qualifications does an expert need?

2. If an expert is hired by management, do auditors test their work as if it were management's?

3. When relying on the work of expert and specialists, has the auditor exercised sufficient due diligence and applied appropriate scepticism?

4. When an expert is hired by an auditor, is that expert integral to the engagement team and does that expert comply with the audit firm's quality control standards and procedures?

5. Has the audit firm defined the parameters that determine whether an expert is integral to the team?

6. To what extent do auditors as general practitioners take responsibility for the work of experts?

7. Should expert opinions be reported separately in financial reports?

(Cheney, 2005, p. 14)

When auditors rely on the work of experts in auditing environmental matters, they too should concern themselves with the issues raised by Landes. However, a review of AS606: Using the work of an expert, confirmed that AS-606 does not provide any standard requirements on the significant issues identified above. Since AGS-1010 expects auditors to refer to AS-606 when they rely on the work of experts, and AS-606 does not provide any guidelines covering the above seven questions, the boundary between the auditor's position and the expert's position may be somewhat blurred, especially when, despite relying on the work of the expert, the auditor is ultimately responsible for the overall audit opinion. Auditors are therefore unavoidably exposing themselves to legal 
liability, especially since the auditors interviewed indicated that 'they do not have the same expertise as experts and therefore cannot always challenge the expert's assumptions, criteria and methods' (emphasis added; refer to section 5.2.4). The next section discusses the third issue that impacts upon the effectiveness of AGS-1010.

\subsubsection{Consideration of Environmental Laws and Regulations}

Often, incidences of non-compliance with environmental laws and regulations will signal environmental matters that materially affect a financial report. Hence, when able to detect such non-compliance, the auditor is potentially alerted to the existence of environmental matters for the entity, and can then assess the corresponding risk of misstatements, omissions or non-disclosures in financial reports. However, guidance given in AGS-1010 on the consideration of environmental laws and regulations as a means of detecting environmental matters is not straightforward.

AS-208: Consideration of laws and regulations in an audit established the standard for New Zealand auditors' responsibility to consider laws and regulations when auditing a financial report. 'Laws and regulations' mean statutes, regulations and common law. As with all other audit standards and in terms of Rule 11 (paragraph 97) of the Code of Ethics, auditors are compelled to comply with AS-208 for all audits. AS-208 stated that some laws and regulations are relevant to the entity and will therefore determine "the form or content of an entity's financial report or the amounts to be recorded or disclosures to be made in the financial report" (AS-208, paragraph 10). Therefore, there is an expectation that auditors understand those laws and regulations "that may have a fundamental impact on the operations of the entity and thus have financial consequences that are material to the financial report" (AS-208, paragraph 10). Hence, the auditor is required to plan and perform the audit with an attitude of professional scepticism and awareness "that the audit may reveal conditions or events that should lead to questioning whether an entity is complying with laws and regulations" (AS-208, paragraph 15). In so doing, the auditor must recognise that non-compliance with laws and regulations could result in fines, litigation or material liabilities; could jeopardise the viability of the entity; could affect the ability of the entity to continue to operate as a going concern (AS-208, paragraph 25b) or could cause the entity to cease operations (AS-208, paragraph 26). 
Non-compliance with legislation governing environmental protection is specifically mentioned in AS-208, paragraph 25c, referring to its significance in the audit standard. In the context of laws and regulations covering environmental protection, AS-208 also asserted that the auditor "must obtain a general understanding of the legal and regulatory framework applicable to the entity and the industry and to how the entity is complying with that framework” (AS-208, paragraph 23) (emphasis added). The legal and regulatory framework relevant to the current New Zealand study is the Resource Management Act 1991 (RMA). Therefore, in accordance with AS-208, the auditor is expected to have sufficient understanding of the laws and regulations covered in the $R M A$ to enable the auditor to consider its requirements when auditing assertions related to the recorded amount and disclosures of environmental matters (AS-208, paragraph 30). In particular, auditors are expected to plan and perform audit procedures to detect instances of non-compliance with the RMA. When non-compliance is detected, auditors then have to consider "whether the act of non-compliance itself is a matter to be reported in the audit report, because it is material to the readers of the financial report" (AS-208, paragraph 39), even though the non-compliance does not have a direct potential financial consequence on the financial report. Audit reporting will also be affected by non-compliance that has a material effect on the financial report, but has not been properly accounted for or disclosed in the financial report.

Non-compliance with environmental laws and regulations is a significant example of environmental risk exposure in relation to environmental matters. Yet a review of AGS1010 points to a limitation on auditors' responsibilities as outlined in AS-208, since AGS-1010 appears to guide auditors towards a different level of responsibility when dealing with environmental laws and regulations. Although AGS-1010 asserts that "auditors should recognise that non-compliance by the entity with laws and regulations may materially affect the financial report", it accepts that a breach of environmental laws and regulations is a legal determination, beyond the auditor's professional competence (AGS-1010, paragraph 14). Besides, even though consequences of violating environmental laws and regulations were given as examples of environmental matters with implications for environmental risk (AGS-1010, paragraph 10b (ii)), AGS-1010 does not require auditors to "plan the audit to detect possible breaches of environmental laws and regulations" (AGS-1010, paragraph 12). Therefore, the guideline in AGS-1010 contradicts and delimits the requirements of AS-208 insofar as environmental matters 
are concerned. This is not the only contradiction to be found in AGS-1010. Other contradictions point to the fourth and most significant issue that influences the effectiveness of AGS-1010 - the existence of 'doublethink' and 'doublespeak', and this is examined next.

\subsection{5 'Doublethink' and 'Doublespeak' in AGS-1010}

The notions of 'doublethink' and 'doublespeak' were first drawn from Orwell's (1949) literary classic 'Nineteen Eighty-Four'. 'Doublethink' means the ability of holding two contradictory beliefs in one's mind simultaneously and accepting them both (El-Sawad et al., 2004; Robb, 2003a). Lutz (1983) further explained:

It is to know and not to know, to be conscious of complete truthfulness while telling carefully constructed lies, to hold simultaneously two opinions which cancelled out, knowing them to be contradictory and believing in both of them (Lutz, 1983, p. 26).

'Doublethink' leads to 'doublespeak'. 'Doublespeak' is the ability to speak or write contradictory ideas without the writer or speaker being aware of the contradiction (ElSawad et al., 2004; Robb, 2003a, 2003b; Styles, 1984).

'Doublespeak' is language which pretends to communicate but really does not. It is language which makes the bad seem good, something negative appear positive...It is language which avoids or shifts responsibility; language which is at variance with its real and its purported meaning; language which conceals or prevents thought. 'Doublespeak' is language which does not extend thought but limits it (Lutz, 1988/1989, p. 26).

Authors like El-Sawad et al. (2004) and Robb (2003a; 2003b) have already applied the idea of 'doublespeak' in accounting contexts, hence the same idea is explored here. The evidence presented in Chapter 6 points to a strong suggestion that 'doublethink' and 'doublespeak' exists in AGS-1010. One example lies in the consideration of environmental laws and regulations. Detecting non-compliance with environmental laws and regulations is fundamental to determining the likelihood of any environmental matters existing for the entity and, consequentially, the potential for environmental risks in misstatements, omissions or non-disclosures in financial reporting. At one point, AGS-1010 notes the need for auditors to be alert to such issues:

An audit carried out in accordance with auditing standards is planned and performed with an attitude of professional scepticism recognising that the audit may reveal conditions or events that should lead to 
questioning whether the entity is complying with relevant environmental laws and regulations in so far as non-compliance could result in a material misstatement of the financial report (AGS-1010, paragraph 37).

Yet, in what appears to be a case of 'doublespeak', AGS-1010 assumed that:

... with respect to the entity's compliance with environment laws and regulations, the auditor's purpose is not to plan the audit to detect possible breaches of environmental laws and regulations... (AGS-1010, paragraph 12).

The language appears to condone avoiding, or shifting responsibility for detecting environmental matters, and allows AGS-1010 to promote two apparently contradictory 'truths'.

Regarding auditors' reliance on environmental experts, AGS-1010, paragraph 14 indicated that auditors cannot be expected to possess the technical skills of environmental experts. Thus, they are guided to seek technical advice from experts. However,

As the environmental area is an emerging speciality, the expert's professional competence may be more difficult to assess...In this situation it may be necessary for the auditor to give particular consideration to the experience and reputation of the environmental expert (AGS-1010, paragraph 14).

The language here seems to create confusion. If an auditor does not have the technical competence of the expert, how then is the auditor expected to assess the expert's professional competence? In addition, what qualifications does an expert need to be entrusted with a role in an audit?

And further,

There are few authoritative accounting standards that explicitly address the recognition, measurement and disclosure of the consequences for the financial report arising from environmental matters. However, existing accounting standards generally do provide appropriate general considerations that also apply to the recognition, measurement and disclosure of environmental matters in a financial report (AS-1010, paragraph 17).

But:

The use of professional judgement may become even more important because of a number of difficulties with respect to the recognition and 
measurement of the consequences of environmental matters in the financial report (AGS-1010, paragraph 44).

AGS-1010, paragraph 17 stated that existing accounting standards do provide appropriate general guidance on the accounting treatment and disclosure of environmental matters in a financial report. However, AGS-1010 paragraph 44 indicated that there are special difficulties with environmental matters that require greater professional judgement. Thus, are environmental matters adequately covered by existing accounting standards?

Yet another issue concerns the profession's acknowledgement that the accounting standards do not refer to environmental matters explicitly, hence the difficulties in the reporting of environmental matters are recognised. However, instead of providing explicit guidance on the reporting of environmental matters, AGS-1010 generates an expectation that auditors will use greater professional judgement. As discussed previously, how does one exercise professional judgement in an area where insufficient guidance is given? Does this mean that auditors are allowed a different standard of responsibility because of complexities in the reporting of environmental matters?

The examination of AGS-1010 presented here points to significant gaps in the guidance it provides. Despite its stated objective to provide guidance on best practices for the consideration of environmental matters in the audit of financial statements, it appears to delimit auditors' responsibilities for environmental matters. This review confirms that AGS-1010 - a lengthy document of twenty four pages - is in parts confusing, complicated and contradictory to the very audit standards it seeks to assist auditors in applying in their attestations on environmental matters. These faults have also been highlighted by the interviewed auditors (refer section 6.1). A major weakness of this guideline is its failure to specify the planning responsibilities of auditors. It also remains unclear whether auditors are expected to plan audits that provide reasonable assurance that material misstatements arising from client violations of relevant environmental legislation will be detected. A summary of the above analysis of AGS-1010, together with a discussion of its implications for current practice, is presented next.

\subsubsection{Summary and Implications of Research Findings}

This section highlights and brings together research findings on (1) auditors' perception of AGS-1010 and its impact on current audit practice and (2) the researcher's critical 
review of AGS-1010. It also analyses the implications of these research findings and attempts to provide insights into the third research issue: the effectiveness and impact of AGS-1010 on current practice.

The research findings indicated that the auditors which the researcher interviewed considered AGS-1010 to be a very long introductory discussion document that lacked detailed procedural steps. Perhaps these auditors had not taken the time to read the information sheet for participants (refer to Appendix 2) and the consent form for participating in the research (refer to Appendix 3). The findings also indicated that auditors generally do not take AGS-1010 seriously. Hence, it is not surprising that a majority of the auditors participating in the research interviews admitted that they had not read AGS-1010 prior to the interviews or were not even aware of its existence.

The research findings also indicated that at least a quarter of the interviewed auditors saw AGS-1010 as merely giving the impression of professional guidance on the audit consideration of environmental matters. Hence, the interview evidence supports Humphrey, Moizer and Turley's (1993a) observation that the significance of audit standards and guidance statements lies in the power of the image they create in asserting auditors' public interest commitments. The text of the guideline also seems to give external visibility to auditors' expertise and rigorous practices and the impression of a solution to the problem (Power, 1999).

The auditors which the researcher interviewed commented that the application of AGS1010 was subject to different interpretations. Woolf (1994) and Power (1999) also identified similar difficulties in interpreting audit standards, even where they "did look practical enough to look like guidance to outsiders" (Power, 1999, p. 25).

Overall, more than three quarters of the auditors perceived that AGS-1010 had an insignificant impact on audit practice - a non-event in practical application - and that, in general, auditors are simply not referring to AGS-1010 and not considering environmental matters in their audits. However, in contrast to the financial auditors' current position, the public sector auditors declared that they are expected to comply with AGS-1010. Nevertheless, the general perception of the auditors was that AGS1010, in its present form, would not facilitate a move forward in improving and further developing current practice to meet its espoused aims. A critical evaluation of AGS1010 confirms the auditors' general perceptions, and provides explanations for them. 
First, AGS-1010 did not establish any new basic principles or essential procedures (AGS-1010, paragraph 6). Therefore, as Humphrey and Moizer (1990) explained, these audit standards and guidance statements seem to be mere articulations of existing audit practice driven by professional self-interest. Power (1999) also made similar observations about the audit guidance on fraud when it was first issued. He criticised the audit guidance as a mere codification of common knowledge that, despite the rhetorical text, meant 'business as usual' for the auditors. Auditors were effectively directed to treat environmental matters no differently from any other audit issue.

Second, AGS-1010 emphasised the exercise of professional judgement for every aspect of the audit consideration of environmental matters (AGS-1010, paragraphs 2, 3 and 4). However, professional judgement has many attributes, making the concept of professional judgement complex (Morrill, 1996). AGS-1010 required auditors to exercise professional judgement based on 'technical skills', which the profession acknowledged 'the auditor cannot be expected to possess' (AGS-1010, paragraph 14). How could auditors exercise professional judgment when dealing with environmental matters, particularly as professional judgement can be influenced by those attributes and factors identified in the literature?

Third, AGS-1010 accepted the application of the BRA but highlighted the fact that auditors do not have adequate technical and general knowledge to deal with environmental matters (AGS-1010, paragraph 14). Therefore, it suggested that auditors rely more on management (AGS-1010, paragraph 13); client internal documentation and experts engaged or employed by the entity. This approach raised potential concerns for auditor independence and managerialistic-orientations (refer to sections 5.2.1, 5.2.4 and 6.2.3). These concerns are problematic as they could lead to the auditor subordinating his or her judgement to that of management or the expert; or the auditor may be too sympathetic to the client's interests (ICANZ, 2003b, Code of Ethics: Independence in assurance engagements, paragraph 33). Since AS-606: Using the work of an expert, does not guide auditors in how they should manage the experts; this may lead to a blurring of the boundary between the auditor's position and the expert's position.

Fourth, AGS-1010 required auditors to comply with AS-208: Consideration of laws and regulations in an audit, which expects auditors to understand those laws and regulations "that may have a fundamental impact on the operations of the entity and thus have 
financial consequences that are material to the financial report" (AS-208, paragraph 10). Hence, auditors' understanding of environmental laws and regulation should enable them to recognise any instances of non-compliance. AGS-1010 seemed to delimit the auditors' responsibilities required in AS-208, however, and appeared to be guiding auditors towards a different level of responsibility when dealing with environmental laws and regulations. Similarly, when van Peursem, Locke and Harnisch (2005) examined the audit standard on 'Going Concern' they, too, found that the audit standard did not seem to impose any additional requirement on the auditor.

Fifth, discussions covered in section 6.2.5 highlighted a number of incidences of 'doublethink' (El-Sawad et al., 2004; Robb, 2003a) and 'doublespeak' (El-Sawad et al., 2004; Robb, 2003a, 2003b; Styles, 1984) in AGS-1010, which strongly suggested that the language in AGS-1010 was intended to create confusion by promoting two apparently contradictory 'truths' that have implications for avoiding or shifting auditors' responsibility for detecting environmental matters. This supported Pong and Whittington's (1994) criticism that audit standards and guidelines do not attempt to rethink or extend the scope and technique of the audit. Rather, they attempt to consolidate the status quo and to limit the obligations and responsibilities of the auditor.

Therefore, a critical examination of AGS-1010 pointed to significant gaps in the guidance it provides. Despite its stated objective to provide guidance on best practice for the consideration of environmental matters in the audit of financial statements, it appeared to delimit auditors' responsibilities for this task. This confirmed van Peursem et al.'s (2005) observation that although a promulgation's large number of pages may give the appearance of improving professional benchmarks, the thickness of the document is not necessarily commensurate with greater quality or a more forceful mandate. Another major weakness of this guideline is its failure to specify auditors' planning responsibility. It also remains unclear as to whether auditors are expected to plan audits that provide reasonable assurance for detecting material misstatements, omissions or distortions arising from client violations of the relevant environmental legislation.

Overall, it appeared that the auditors which the researcher interviewed were justified in saying that AGS-1010, in its present form, is unlikely to impact upon future audit practice, and fails to facilitate the development and improvement of current practice. 
Nonetheless, as Power (1999) indicated, issuing an audit guidance statement is a strategy for managing new demands in (for example) the audit of environmental matters.

At this point, research findings for the first four research questions (refer to section 1.2) have been obtained from interviews of financial and public sector auditors. Hence, in accordance with Axiom 14: special criteria for worthiness (Lincoln \& Guba, 1985) (refer to section 4.2.2), there is a requirement to confirm that the interview evidence provides a credible constitution of reality (Silverman, 2005). Credibility is enhanced by theoretical generalisability (Lukka \& Kasanen, 1995). Spicer (1992) and Daly and Lumley (2002) explained that generalisability entails generalising back to theory. Llewellyn (2003) further explained that theory enables the meaning of data to be accessible and data validates the theory. The process of theorisation was applied as discussed in section 4.8, and 'legitimacy theory' is next drawn upon in order to inform the research. The next section discusses the theoretical perspective framing the current study.

\subsection{The Audit of Environmental Matters and Legitimacy}

Silverman (2005) asserted that, in order to understand the phenomena critically and to organise what is unknown, every research effort should be framed by a theoretical perspective. Section 4.8 discussed the process of theorisation. As a result of that process, 'legitimacy theory' (Pentland, 1993; Power, 2003) was identified as the most likely lens for the current study and the effect of legitimation being the audit expectation gap II (Specht and Waldon, 1992) (refer to section 3.3). Legitimation may well be an issue for the New Zealand audit profession's promulgation of AGS-1010.

The following section(s) bring together the relevant interview evidence and identifies its nexus with the reviewed literature that supports the choice of 'legitimacy theory' as the approriate theoretical framework for this research. Chapter 3 discussed the general theoretical concepts within legitimacy theory. The next section discusses legitimacy theory and the audit profession in relation to the promulgation of AGS-1010.

\subsubsection{The Auditing Profession, AGS-1010 and Legitimacy Theory}

The audit profession functions "within a society's framework of legitimate authority" (Pasewark et al., 1995, p. 77), and it relies for its status and position on the public perception that its members perform an important task with proficiency and with the 
backing of a legitimate professional body (Weirich \& Rouse, 2003). Hence, its central focus is the 'social contract' (Deegan, 2006). This requires the audit profession to provide socially-valued, audited financial statements in exchange for a virtual monopoly of audit practice and self-regulation (Baker, 1977), and enables the audit profession's long-term survival (Ashforth \& Gibbs, 1990; Guthrie \& Parker, 1989; Savage et al., 2000). Thus, maintenance of organisational legitimacy is critical to upholding the status of the audit profession (Weirich \& Rouse, 2003).

For the audit profession to continue to function in society and to be adjudged legitimate (Lindblom, 1993), it must ensure that social expectations of legitimacy of its operations are met (Deegan, 2002a). However, the audit profession, like other organisations, is not able to remain indefinitely in a state of legitimacy, as legitimacy is time- and placedependent along with changing community attitudes (Deegan, 2006). Ashforth and Gibbs (1990, p. 177) cautioned that "legitimacy is always problematic". The audit profession, like other organisations, must respond and adapt to changing community attitudes since they are dependent on those attitudes for survival (Llewellyn, 2003).

In the early 1990s, the arena in which the audit profession operates experienced turbulence (Baker, 1977). Savage, Cataldo and Rowlands (2000) observed that news media reports (as indicators of societal norms and values) were always publicising environmental disasters; and commentators (Gilkison \& KPMG, 1999; Gray \& Bebbington, 2000; Rubenstein, 1992; Watson \& Mackay, 2003) observed that environmental disasters at Exxon Valdez, Chernobyl, Love Canal, and Union Carbide at Bhopal were highly publicised in news coverage. As a result, public and political general awareness, attitudes, and concerns for environmental issues changed. Although the accountancy profession was not directly implicated in the media reports, the publicity generated from the reports did lead to many debates, suggestions and guidelines in overseas technical and academic journals, encouraging the accountancy profession to give regard to environmental accountability, accounting, environmental concerns and other related issues in mainstream accounting (Hochman, 1998; Langford, 1995; Rezaee et al., 1995; Steadman et al., 1995; Wainman, 1991). The financial auditors interviewed for this study confirmed that environmental matters were a prominent current issue in the 1990s and many journal articles were written on them (refer to section 5.1.1). However, the accountancy professions in many countries did not seem to take environmental issues seriously, and were criticised by various 
commentators (Bebbington \& Gray, 1992; Gallhofer \& Haslam, 1997; Medley, 1997; Rezaee et al., 1995; Steadman et al., 1995). Medley (1997) also observed that although many overseas accountancy professions initiated research on environmental accounting and the future role of the profession in environmental accountability, the research conclusions and recommendations for improvements did not seem to bring about change.

In more recent times, criticisms of the audit profession have intensified as a result of media and public scrutiny (Chandler, 1999) of a number of high profile corporate failures such as Enron, Worldcom, Parmalat and Health International Holdings (HIH) Insurance (Mak, Deo, \& Cooper, 2005). As a result of repeated environmental crises and audit failures the auditing profession has faced a crisis of investor confidence in financial reporting and auditing (Byrnes, McNamee, Brady, Lavelle, \& Palmeri, 2002; Thomas, 2003; Weirich \& Rouse, 2003). Self-regulation has also been scrutinised (Kinney Jr, 2005). There is a danger that, if a legitimacy gap is perceived to exist, and the continuance of previous practices is not sufficient to close that gap, the audit profession could lose its legitimacy, even where performance has been maintained or improved (Reynolds \& Mathews, 1999).

The International Auditing Practice Statement (IAPS) 1010: The consideration of environmental matters in the audit of financial statements was issued in the midst of high profile corporate failures, environmental disasters and criticisms of the audit profession. From the events that took place, the issuing of IAPS-1010 in 1998 could be seen as a strategy designed to close the legitimacy gap and to ensure the audit profession's continued legitimacy. (Dowling \& Pfeffer, 1975). IAPS-1010 also appeared timely in detracting attention from the huge impact the high profile accounting debacles had on auditors and accountants' role in accountability, protecting the public interest (Pasewark et al., 1995), and self-regulation (Baker, 1977). Lindblom (1993) considered this strategy as a symbolic activity which served to deflect attention from the main issue of concern (accounting failure) by portraying the audit profession's activities in environmental accountability as being compatible with societal norms and values (Ashforth \& Gibbs, 1990; Pfeffer, 1981). However, the above points were based on reflections made from an analysis of the extant literature. Since interview evidence is not available from the promulgators of IAPS-1010, firm conclusions cannot be made that legitimacy theory provides an explanation for the issuance of IAPS-1010. 
In the New Zealand context AGS-1010, "consistent in all material respects" with IAPS1010 (ICANZ, 2001a, Appendix 1), was issued in 2001. Interview comments made by members of the NZICA Professional Standards Board (PSB) indicated that there were no serious debates within the Institute on environmental matters. The Institute, as a member of the global accounting alliance, decided to adopt international auditing standards. Thus, the PSB simply adapted international auditing standards and guidance statements for New Zealand. In so doing, the PSB merely accepted IAPS-1010 and reissued it as AGS-1010. The three years time difference between the issuance of IAPS1010 in 1998 and AGS-1010 in 2001 was a result of the due diligence and exposure draft process. which involved the required process of issuing an exposure draft, calling for comment and then confirming the issuance of the actual AGS. Pragnell (2004), a member of the PSB, said that very little feedback was received on AGS-1010 as an exposure draft. Hence, the final AGS-1010 remained substantively unchanged from IAPS-1010.

Although the promulgation of audit standards and audit guidance statements has been identified in the literature as a legitimacy strategy, the issuing of AGS-1010 by the PSB cannot be explained by legitimacy theory. The Institute was merely following what had already been done overseas, i.e. they adopted a mimetic approach in order to maintain equivalence with global partners and not be seen to be slipping behind them. In other words, there appears to be significant grounds for arguing that the Institute did not actively pursue a legitimation strategy with respect to AGS 1010. This research finding adds to the scant literature that reports a lack of support for a legitimacy theory perspective.

Whilst legitimacy theory does not appear to explain the issuing of AGS-1010 at the profession's level, interview evidence indicated that the theory does provide an explanation for its (none) use at audit practitioners' level; and that at that level, AGS1010 can be seen as a symbolic, 'ceremonial conformity', legitimation strategy.

\subsubsection{AGS-1010: A Legitimation Strategy}

This strategy requires an organisation to adopt practices that are seemingly "consistent with social expectations, while leaving the essential machinery of the organisation intact" (Ashforth \& Gibbs, 1990, p. 181). As discussed in the previous section, over a period of time, commentators and authors (Bebbington \& Gray, 1992; Gallhofer \& 
Haslam, 1997; Medley, 1997; Rezaee et al., 1995; Steadman et al., 1995), particularly the more 'visible' public criticism, led to some disquiet in the accountancy professional arena and, in 1998 (amidst the Enron debacle), IFAC released IAPS-1010.

Findings from the current research indicated that the issuance of AGS-1010 did not result in any significant change in audit practice. Rather, the auditors interviewed saw the main value of AGS-1010 in the impression it gave of professional guidance. It gained clients' confidence that auditors were considering environmental matters in their audits of financial reports. This research also provided further support for Humphrey and Moizer's (1990) observation that official audit guidance plays little role in everyday audit work; rather it gives the appearance of addressing an issue, and providing comfort that it is being attended to, while the status quo is maintained (Fogarty et al., 1991). This has a role in creating an illusion of guidance and in legitimizing acceptance throughout the business community (Mills \& Bettner, 1992; Pentland, 1993).

Therefore, the findings of this study suggested that the promulgation of AGS-1010 may be interpreted as a ceremonial, symbolic legitimation strategy used by audit practitioners to maintain or enhance their legitimacy, with perhaps the intention of fostering the belief that the their activities and ends are congruent with the expectations, values, and norms of constituents (Richardson \& Dowling, 1986). A consequence of such a symbolic strategy is the expectation gap II, discussed next.

\subsubsection{The Expectation Gap II}

Discussions in the previous sections suggested that the publication of international guidance on environmental matters in financial report auditing was a legitimating strategy. However, Simunic (1994) suggested that such guidance might have been a response to the expectation gap between auditors and financial statement users. Findings from the current research suggested that the issuing of AGS-1010 in New Zealand was a symbolic, 'ceremonial conformity', legitimation strategy, and the literature indicated that a significant consequence of symbolic strategies is the audit expectation gap (Gray \& Manson, 2005; Humphrey et al., 1992; Porter, 1993).

The following discussion argues that the consequence of issuing AGS-1010 is the expectation gap II, i.e. the expectation gap between those responsible for formulating auditing directives - the standard setters, and those responsible for implementing such directives - the professional auditing community (Specht \& Sandlin, 2003; Specht \& 
Waldron, 1992) (refer to Figure 4 below). Specht and Sandlin (1992) commented that the implementation of audit standards and guidance statements would depend on auditors' perceptions of their efficacy: that is, whether auditors implement the audit

standard or guidance in practice will depend entirely on their perception of effective implementation; and their motivation for implementation will depend on that perception.

\begin{tabular}{|c|c|c|}
\hline $\begin{array}{c}\text { Standard setters' } \\
\text { expectations of auditors }\end{array}$ & The Expectation & $\begin{array}{c}\text { Auditors' actual } \\
\text { performance }\end{array}$ \\
\cline { 3 - 3 } & Gap II & \\
\hline
\end{tabular}

\section{Figure 4: The Expectation Gap II (The expectation gap between the standard setters and the practicing auditors)}

As discussed earlier, the issuing of audit guidance in environmental matters may be interpreted as a legitimation strategy. On the other hand, some authors (Willekens et al., 1996) considered the issuing of audit standards and guidance statements as a form of self-regulation at a time when the accounting professional monopoly on regulation is being threatened. However, van Peursem et al. (2005) indicated that the accountancy professions create a manner of 'self' through their standards. Therefore, in communicating its professional view on environmental matters and accountability, the accountancy profession could be said to be creating a manner of 'self' through AGS1010, (refer section 3.2.2). The inference is that the profession views environmental accountability as significant and worthy of consideration in the audits of entities where environmental matters are significant (AGS-1010, paragraphs 2 and 3), regardless of the fact that the guideline in AGS-1010 itself is confusing and contradictory. However, as the findings for this study indicated, the auditors themselves do not seem to accept this view of the 'professional self' through AGS-1010. This provides further evidence to support Specht and Waldon's (1992) claim that the expectation gap II exists between audit standards and guidelines setters, and the auditors themselves. Interview evidence on auditors' approaches to assessing audit materiality provided a more glaring example substantiating the existence of the expectation gap II, in that auditors continue to use 
quantitative factors when assessing audit materiality, regardless of direction from AS304: Audit materiality, which requires that they consider the significance of qualitative measures when assessing audit materiality (refer to section 5.2.2), and despite objections made by officers of the accountancy profession.

The interview findings indicated that auditors perceived AGS-1010 as having an insignificant impact on audit practice - a non-event, or no more that a public relations exercise - again pointing to AGS-1010 as a symbolic, 'ceremonial conformity' legitimation strategy (refer to section 6.1) Auditors are busy people who must read numerous promulgations and technical journals in order to keep up with professional matters. This busyness may explain the comments from auditors interviewed for this study that, on seeing that AGS-1010 was a very long guidance discussion document and not mandatory, they assumed that it did not need to be taken seriously. Furthermore, the critical review of AGS-1010 presented in section 6.2 revealed a lack of any new basic principles or essential procedures that would be helpful in overcoming auditors' concerns about their personal inadequacies in auditing environmental matters. AGS1010 emphasised the exercise of professional judgment when interpreting its rules and instructions, but these are discretionary and subject to personal judgement. Power (1999) also found this to be the case in his review of audit standards and guidance statements. A question raised is how auditors exercise professional judgment on environmental matters when they have admitted having very little basic knowledge on it and AGS-1010 is perceived as not giving adequate guidance on the audit task. In fact, it contains a number of incidences of 'doublethink' and 'doublespeak' (El-Sawad et al., 2004; Robb, 2003a), creating further confusion in avoiding or shifting auditors' responsibility for detecting environmental matters.

Despite auditors' continual assurance of serving the public interest, legitimacy with clients is essential (Power, 2003). Therefore, auditors are more likely to agree with clients' non-disclosure of environmental matters in financial reports. Moreover, the auditors interviewed for this study viewed the task of considering environmental matters as onerous, and likely to extend the scope of the audit excessively. Thus, it is not surprising that they did not really want to consider environmental matters in the audit of financial reports, despite the stated requirement in AGS-1010 that they should do so for entities exposed to significant environmental risks (AGS-1010, paragraph 2). AGS-1010 appeared to be making little impact in practical terms and, as one auditor perceived, is 
generally ignored so that environmental matters were rarely considered in company audits. Therefore the research findings again support Specht and Waldon's (1992) and Specht and Sandlin's (2003) observation that only the auditors themselves will influence whether an audit standard or guidance statement is accepted and implemented; and auditors behave in ways that fulfil their own expectations, not those of the standard setters.

The above analysis provides substantial evidence that implicates both the standard setters and the auditors themselves as having contributed to the expectation gap II. The auditors have a pre-conceived mindset about environmental matters which is somewhat prejudiced by the real concerns they have about their own role and responsibilities and the challenges they face around the audit task. Similarly, some auditors also have a somewhat fixed mindset about the assessment of audit materiality: 'whatever is not quantifiable is not material'; and it is this mindset that underpins their reluctance to deal with the environmental matters that exist for their clients. Therefore, regardless of how effective an audit standard or audit guidance is, auditors' (fixed) mindset will have significantly influenced their acceptance and implementation of it. It is evident that AGS-1010 is not as effective as it should be because of the implications the issues indicated in the document (refer to section 6.2), and give rise to the criticisms of standard setters and the standard setting process made by commentators (McEnroe, 2002; Myddelton, 2004; Pong \& Whittington, 1994; Sikka, 2001). A review of the literature on standard setting revealed that standard setting boards around the world control the standards and guidelines setting process, from its initiation to its final approval. As a result, practicising auditors do not bother to provide feedback on the final exposure drafts when they are issued for comment (refer to section 2.2.3).

Other than exposing the existence of the expectation gap II between standard setters and practicising auditors, the studies by Specht \& Waldon (1992) and Specht and Sandin (2003) did not consider the components of the expectation gap II or strategies for narrowing the gap. Taking a lead from Porter (1990a; 1990b; 1990c) and extending the theoretical concepts espoused in her study (refer to section 3.3), it can also be said that an understanding of what the components of the expectation gap II are, provides a means of narrowing it. The intermediary between the standard setters and practicing auditors is the issued audit standard or guideline. Hence, to narrow the expectation gap II is to narrow the feasibility gap and the performance gap. For this study, the feasibility 
gap is the gap between what the standard setters expects of auditors and what auditors can reasonably be expected to achieve; and the performance gap is the gap between what the standard setters can reasonably expect auditors to accomplish and their actual performance. Essentially, if accountancy professional bodies took bold, pro-active steps in serving and supporting the interests and needs of their members, instead of merely acting as regulators, these gaps could be narrowed. Better still, if the accountancy professional bodies could opt out of agency regulation (Swift \& Humphrey, 2000a; Walsh, 2000), and concentrate on meeting the needs of their members. The accountancy professional bodies are placed in an excellent position to narrow the feasibility gap by acting as change agents in modifying the pre-conceived perceptions and mindsets of auditors towards their expected roles and responsibilitues for environmental matters via compulsory continuing education and communication. Apposite topics would centre on what auditors can reasonably achieve in environmental matters (and other emerging audit issues of concern). In New Zealand, NZICA has much to learn from the Auditor General's office, which provides compulsory continuing education, technical support and advice. Public sector auditors are competent in their mandated requirement to consider environmental matters for every audit they undertake for the Auditor General.

Regarding the performance gap, the accountancy professional bodies can again act as change agents by taking steps to overcome criticisms made about the audit standardsetting process (refer to section 2.2.3). The most critical comment made is that practicing auditors are not involved or even considered when standards and guidelines are being drafted and often auditors are unaware of a new audit standard or guideline until it is a final exposure draft issued for comment. Commitment to any new audit standard or guideline would rely heavily upon the support and leadership from all the auditors throughout the audit profession. The interview evidence for this study indicated that generally there is resistance to considering environmental matters in the audit of a financial report. Therefore, getting auditors' commitment and managing resistance to change successfully, are pre-requisites for effective change and change management.

Kotter and Schlesinger (1979) suggested various strategies for overcoming resistance to change and commitment to something new. A review of the strategies suggested by them identified a number of effective strategies (refer to Table 4) and the researcher now discusses them in the context of environmental matters. Since the auditors interviewed for this study admitted to a rather weak knowledge base on environmental 
matters, education and communication should be a significant strategy to inform and position them to 'buy in' to the audit task. Chiang (2006) indicated that the mechanism for translating the consideration of environmental matters into audit practice needs improvement, and a powerful strategy for this is getting auditors' participation and involvement in setting the guidelines on environmental matters. Audit standards- and guidelines- setting boards would be unlikely to have all the necessary information required when drafting an audit standard or guideline. Substantially increasing the participation and involvement of practicing auditors in the standard-setting process, and engaging with practicing auditors on potential issues before the preliminary design work, could overcome the boards' information deficit. Beginning the process in standard-setting by allowing the auditors an opportunity to voice their concerns and perceptions about environmental matters should lead to 'buying in' auditors' commitment and actual performance. Also, their input means that the final audit guideline has greater potential to improve the quality of the audit by disseminating information on best practice (McEnroe \& Nikolai, 1983) and providing a better framework for audit decisions (Gay \& Simnett, 2003). In this way, auditors who, collectively, have the power to resist would be more committed to audit standards and guidelines that they had been involved in setting. Where there are auditors who continue to resist anything new and are having trouble adjusting, facilitation and support are extremely important. Monitoring of audit performance and compliance with audit standards should be stringent and where sub-standard performance is found, then stronger disciplinary action should be enforced by the audit practice reviewers. These are suggestions for strategies available to accountancy professional bodies around the world in order to meet the needs of their members and to monitor their members' performance in order to protect the public interest. These strategies should also reduce the expectation gap II. During the qualitative interviews, the researcher also investigated ways in which current practice could be further developed, and they are being discussed in the next section. 
Table 3: Components of the Expectation Gap II and the Means of Reducing it THE EXPECTATION GAP II

Components of the expectation gap II

Feasibility Gap

The APB to:

Accountancy

professional bodies

(APB) (across countries) to act as change agents in order to narrow the components of the expectation gap II members
- take bold, pro-active steps in serving and supporting the interests and needs of its

- opt out of agency regulation

- modify the pre-conceived perceptions and mindsets of auditors regarding the expected roles and responsibilitues for environmental matters, via compulsory continuing education and communication about what auditors can reasonably achieve in environmental matters

- provide compulsory continuing education and technical support and advice on the audit of environmental matters
Performance Gap

The APB to:

- take the necessary steps to overcome the criticisms made about the audit standards and guidance setting process

- consider the issues and concerns auditors face on environmental matters before preliminary design work is started

- increase participation and involvement of practicing auditors in the standard setting process

- obtain auditors' commitment to considering environmental matters for every audit

- Monitor audit performance and compliance with audit standards

- where sub-standard performance is found, stronger disciplinary action should be enforced by the audit practice reviewers

Extending Porter (1990a; 1990b; 1990c)

\subsection{Auditors' Perceptions of Improvements and Further Development in Current Practice}

The interviewees' perceptions on improvements and further developments towards meeting the espoused aims of AGS-1010 are categorised into two main areas: internal drivers, and external drivers. The next section presents the interviewees' perspectives on the internal drivers.

\subsubsection{Internal Drivers}

The auditors interviewed identified individual auditors and NZICA as potential internal drivers of improvements and further development in current practice. Their views on 
each internal driver are presented below, and the implications of the interview findings discussed in section 6.4.3.

\section{Individual Auditors}

Only $10 \%$ of all interviewees (financial, public sector and government auditors) considered themselves as environmentally conscious, whilst the remaining $90 \%$ commented that, although auditors are generally financially focussed, they personally consider themselves as no more environmentally aware or responsible than the general population. Therefore, inculcating personal attitudes of environmental responsibility in auditors is essential before they could be expected to take environmental matters more seriously in their audits:

We [auditors] would like to think that we are environmentally responsible, but a lot of times I don't think we have been actually. At the moment all we seem to have done is introduce AGS-1010 [AP 7].

$60 \%$ of all interviewees felt that auditors should be encouraged to specialise in auditing clients in the same industry area, in order to justify the investment in time and effort in developing specialised auditing expertise in environmental matters. Such specialisation should lead to improvements and further development in audit expertise (40\% of the remaining interviewees did not make any comments):

The more we do, the better we're going to get it right. However, it is difficult to build that knowledge when you haven't got the critical mass. Well it's easier if you specialize in auditing clients in the same industry area because you can just apply your knowledge from one to the next. So it's good that auditors work on a number of clients in the same industry because they can develop their expertise. If you've got critical mass or you've got a number of clients in the same industry, then I think your knowledge expands and you can actually put more time into it [environmental matters] and can make an investment. However, when you've got one or two clients with environmental risks exposures, it is difficult. Then you really have to rely on people in NZICA or the OAG [Office of the Auditor General] who have got more resources to apply their minds to those issues [AM 14].

One of the interviewees explained further by using an example:

If you understand the entity you are auditing, its environment, and its business; for example, if you're auditing meat companies, you know they all have similar obligations and you can compare one with the other. If one's doing something which the others are not, well you've got to ask the question: "why not?" But that's about audit expertise. Generally you tend to audit more effectively those areas you actually understand; to 
make sure the disclosures are appropriate and the liabilities are identified [AP 12].

Six of the eighteen financial auditors (34\%) were not concerned about clients' environmental awareness, but twelve of the eighteen (67\%) financial auditors interviewed commented that perhaps their client firms' managers were not aware of the impact environmental neglect could have on the company's exposure to legal liability. Hence, auditors should build a 'trust' relationship with client management, which could facilitate open dialogue and advice on how environmental risks should be appropriately dealt with and disclosed in the financial report:

One of the big problems that an organisation faces is that if it has an environmental issue which is not actually dealt with. Thus, management is opening itself up to being guilty of actually not doing something correct. So they can actually be prosecuted. Hence it's so important for us to build a relationship of trust with our client's management that enables them to understand that we are there to help them protect themselves. If an auditor has a trust relationship with the client, then he is able to help them understand the importance of ensuring that any [environmental] issues they have or any [environmental] risks that they are facing are appropriately dealt with and disclosed. Once the client understands that, we don't actually have a problem in getting information about what is there and what's not there. When we talk to our clients as part of that process, we actually ask if there is anything we need to know about their business that could impact them, either on the audit or in the financials or in the business or whatever. Normally if they've got something, they'll tell you straight out. In the $51 / 2$ years I've been here, I've not yet had a situation where I've had a client not tell me something which I found out about later [AP 21].

On the other hand, all public sector and government audit clients' are forced to consider environmental awareness:

Again, we are mandated by the Local Government Act 2002 to consider environmental matters for every audit, thus our clients have no choice but to report on and discuss environmental matters with us (AP 23).

The following paragraphs present the interviewees' perspectives on how NZICA could motivate improvements and further development in current audit practice.

\section{NZICA, the Institute}

It is mandatory for auditors to comply with audit standards. Hence, to communicate to practicing auditors that the accountancy profession is serious about its role and responsibility for environmental matters, all the interviewees perceived that the institute should have promulgated an audit standard instead of an audit guidance statement. Only 
then would auditors be forced to consider environmental impacts in their audits and include them in their audit programmes:

Change the status of AGS-1010 from an audit guidance statement to an audit standard. Codify it like they have done with the other auditing standards which previously were messy. As an audit standard, it forces auditors to seriously consider environmental impacts; it then becomes part of the actual audit program and you have to pay more than just lip service to it; you have to comply with the auditing standards [AM 1].

NZICA could be pushing auditors to consider environmental matters more through those auditing standards [AM 20].

However, three of the twenty-seven interviewees (12\%) felt that the more demanding requirements of the new International Financial Reporting Standards being implemented in New Zealand would bring about improvements in accounting for environmental matters (other interviewees did not comment on this issue). This should result in more clarity for the auditors:

There is more depth in the International Accounting Standards on impairment testing, on contingent liabilities and specifically on decommissioning. This would be quite a development for New Zealand accountants as they would have to account for something that is 20 years away. That will definitely happen and will require information to be audited accordingly [AP 17].

All the interviewees perceived that NZICA is well positioned to spearhead improvements in current practice by promoting education and general awareness of environmental matters. This could be carried out by discussing environmental matters in Institute journals and running training courses and seminars on audit practice. However, the more significant question is whether auditors are interested enough to attend them:

Bring environmental issues back into the journal again to provide education on general awareness. If an auditor went out to a freight forwarders company, all the auditor would see are trucks and storage facilities, and the auditor may not be taking into consideration that there would be a hazardous material storage facility on site. What happens if the hazardous materials leaked? The auditor may not be aware of it. From my past experience in auditing a trucking firm, I don't think environmental matters made up a major consideration because it wasn't a key part of the business [AM 1].

Awareness is probably the biggest thing. I can't think of ever having seen an NZICA training session or anything on environmental matters. They could possibly run courses and seminars but whether they would really get the attraction to run something specific on the environment I don't 
know. Certainly I could see the usefulness in using real examples as horror stories on contingent liabilities or whatever [AM 11].

I think that NZICA could play a role here. I remember going to a course a long time ago when they did something on auditing non-financial information. Environmental matters are in a similar area as other nonfinancial reporting issues which are not that easy to audit. It's not like auditing a bank section or auditing an area where you can say this is what you need to do for this, this and this. Non-financial information in general is not like that. You can't very easily specify it, you have to look at its reasonableness; you have to agree to what support there is available and get experts if necessary. All those sorts of things, but it is not that easy to do; thus it's something NZICA could look at providing some assistance on [AM 14].

Two of the interviewees $(8 \%)$ went further, to suggest that education on general awareness of environmental matters should start at university level:

\begin{abstract}
Auditors are obliged to actually force improvement and further development in current audit practice to start happening and force reporting to go in that direction. We probably could do it but I think it's going to be a long term process. Maybe the universities should be the ones that started off that process because they the ones who start people's careers [AP 21].
\end{abstract}

Five of the twenty-seven auditor interviewees (19\%) expressed concern for the smaller audit firms, which lack resources for professional development on environmental matters. They felt that these smaller firms would require greater support from NZICA in providing further training on environmental matters.

I think perhaps that small firms do not know where to start when dealing with environmental matters. They are really on their own and they actually have to research for themselves which can be very difficult. That's where the professional accounting body is so important. They can train by using case studies which helps the auditors to think: Okay so those are the types of things I need to be looking for. What are the triggers? What are the signals that there's something going on there that I need to be aware of? If auditors are taken through a process in their training, even if it's with only one or two little case studies, auditors are exposed to an awareness of environmental matters which will assist them in their sceptical approach. The training should focus on the kind of questions that should be asked by auditors when discussing with management on business management control, environment etc because the questions will pull out any information on whether there's a problem. The training could also be taken down to a practical level. Here's a case study, what are the key questions that you would ask which would form a little check list of questions which auditors could go through and ask every time they're meeting with a client. It is the initial identification of 
the environmental problem that poses the difficulty. It's asking the right questions; the real issue is asking the right questions. If I ask the right questions, I'm more likely to get the information I need. And that's what is needed [AP 21].

In summary, the suggestions made for improving and further developing current auditing practice are as follows: inculcating personal attitudes of environmental responsibility; specialising in clients in similar industries; advising on clients' exposure to legal liability as a consequence of environmental risk exposure; issuing audit standards on environmental matters instead of audit guidance statements. Suggestions were also made that NZICA promote education and general awareness of environmental matters. The following paragraphs present the interviewees' perspectives on how drivers external to the audit profession could potentially motivate improvements and further development in current audit practice.

\subsubsection{External Drivers}

The interviewed auditors identified three potential drivers external to the audit profession: public pressure, media pressure and legislators. Each external driver is discussed in the following paragraphs; the implications of all these interview findings are discussed later in section 6.4.3

\section{Public Pressure}

Ten of the eighteen (56\%) financial auditors interviewed saw investors and public pressure as potential drivers of improvement and further development in current practice. Investors and public demands for full disclosures of companies' environmental obligations and liabilities in the financial reports would require auditors to consider them in their current practice. However, they further commented that it seemed unlikely investors would force the issue as they appeared to be more interested in profit-making. Hence, investors must advocate for full disclosures of environmental matters before accountants and auditors take them seriously:

I think it's going to have to be driven by the users of financial reports demanding for reporting on environmental matters and also that the information be audited. But really it depends on who the users are; who are the owners? In the public sector the users are the taxpayers who want to know if the government or quasi government bodies are being environmentally responsible. The taxpayers may get some action. However, company shareholders have one and a half eyes on the size of the dividend cheque. So it has to be driven essentially and eventually by 
the investors. Information will be only provided if the investors want them badly enough [APR 18].

If investors put great pressure on companies to make full disclosures in the financial reports on their environmental obligations and liabilities, then companies which want to gain public attention and favour will make those disclosures in the financial reports. Then you will have financial auditors auditing those disclosures as part of their audits [AP 12].

\section{Media Pressure}

Seven of the twenty-seven (26\%) interviewees observed that media publicity on highprofile environmental problems and disasters would obviously alert everyone, including auditors, to the severity of environmental matters, and to companies' responsibility for environmental management and reporting (the remaining twenty interviewees offered no comment on this issue.). Illustrative quotations include:

Until the horror stories on environmental matters start coming out, we would not be particularly aware of them [AM 11].

You would probably need some real high-profile cases like AFFCO [a New Zealand meat works company] who failed their environmental obligation to clean up and to sort out their storm water problem to be highly publicised by the media, in order to make auditors have an awareness of the possibility of environmental matters for a company [AP $11]$.

More importantly, the audit practice reviewer focussed on the 'fear factor' as perhaps the greatest attention-grabber and motivator for improvement and further development in current practice. Auditors would react most urgently out of fear of losing large sums of money from court prosecutions and fear of reputation loss due to failure to consider environmental matters in audits:

Well the only way to make anything work infallibly in audit is for some auditor to get it wrong and be sued and lose a lot of money. That's been a real attention grabber. And until that happens it's quite difficult to make them take it seriously. I'm being a little bit facetious here because there are many auditors in New Zealand who have high professional standards, and certainly take their work very seriously, but they will take it a lot more seriously if someone's been sued and lost. Fear is a great motivator [APR 18].

Its only when something really bad happens that everyone starts to deal with it [AM 1]. 


\section{The Legislated Mandate}

All the interviewed auditors perceived that currently, there appears to be no incentive for companies to fulfil their environmental obligation because the law is too lenient. Unless a contaminated site is being sold, the site owner is not obliged to remediate the land. Also, the fines and penalties for breaching environmental laws are not hefty enough to deter companies from further breaches. Besides, in relation to the profit line, the fines and penalties are often considered too immaterial to impact upon the decisionmaking of financial statement users. Thus, auditors generally do not seem to bother about them.

Therefore, to bring about any improvement in environmental management, reporting and auditing, current environmental laws must be more rigorous and enforced seriously, holding delinquent companies liable for any unlawful environmental activities, forcing companies to take their environmental obligations more seriously, and providing full accounts of their obligations. Penalties and fines for breaching environmental laws should also be of a magnitude that it fits the 'environmental crime'. Only then will auditors begin to consider environmental matters seriously in their audit of financial reports. The following quotations illustrate this view:

Contamination will just hold in the ground and contaminated land cannot be sold. However, current environmental law does not require companies to fix their contaminated land if they are not selling the land. So that's why there are so many 'abandoned' unoccupied meat work company sites in different New Zealand towns. All meat work companies have contamination on their sites, but so long as the sites are not sold, they'll never have to fix it up. Hence companies just keep their contaminated land. It's only when they sell or intend to sell the land that they need to remediate the land [AP 15].

In winter the air in Christchurch is polluted because people keep burning coal and wood fires. Unless there's legislation against the burning, it will remain with us. Legislation must be enforced, but enforcement must be realistic, for example in some of these cases where companies are being prosecuted, court fines are cheaper than implementing some kind of system to get rid of the pollution problem [AP 16].

Fines and penalties must fit the crime. Currently, the statutory cap on company or directors' liabilities is two hundred thousand dollars fine and a maximum prison sentence of two years. However, I've never heard of anybody in New Zealand, and never be it a director or manager or whoever is responsible for any environmental problems actually being sent to prison. I've never heard of any company being fully fined up to the two hundred thousand dollars maximum either. It's normally twenty 
five thousand dollars or fifty thousand dollars. Really, it is often the operations of big corporations that are exposed to significant environmental risks. Hence, if you are looking at a corporation with a turnover of four hundred million dollars and a profit bottom line of say between twenty million dollars and fifty million dollars depending of what the nature of the company is, a fifty thousand dollars fine is a small charge, so it would slip under the higher materiality level. Therefore auditors as part of the enforcers don't seem too serious about it [AM 1].

On the other hand, all the public sector and government auditors further commented that a legislated requirement for mandatory reporting and auditing of environmental matters in financial reports (similar to the Local Government act 2002) would force financial auditors to focus on them for every audit:

If it's mandatory to report on environmental matters, then that would form a very useful base for further development. If it's not mandatory, people won't do that. If you have a big stick, if it's a legislative requirement, then yes, they have to do that. When accountants have to report on environmental matters then the auditors have to audit them [AM 22].

It is a fair point to note that if something is not mandatory then who takes it seriously? [AP 26]

To be honest, until legislation requires corporate reporting on environmental matters, a lot of them say, "Look, we've got other things to do than worry about environmental reporting. We are always interested, but until it is a mandatory requirement, there's not too much emphasis on that [AM 22].

Whilst a majority of the interviewees $(80 \%)$ seemed interested in improving and further developing current practice, $20 \%$ of them foresaw resistance to moving forward, because some auditors would show no real interest in environmental matters despite recommendations made for developments to current practice. They also perceived that NZICA would prefer the status quo and better-defined targets:

At the present time, reporting of environmental matters is by way of implication of generally accepted accounting practices (GAAP), but GAAP is not explicit about the accounting treatment and disclosure requirement for environmental matters. There is also no legislated requirement for the audit of environmental matters and auditors themselves are not interested. Thus it is unlikely that auditors will move forward with this agenda [AP 19].

I foresee there would be a resistance to moving forward because it is another compliance cost for the companies. Besides, NZICA would prefer 
to deal with more defined targets; environmental matters are not easy to clarify and audit [AM 1].

A summary of all the above findings and their implications for auditors and the audit profession follow next.

\subsubsection{Summary and Implications of Research Findings}

This section brings together the research evidence on auditors' perception of potential improvements and further development of current practices in order to meet the espoused aims of $A G S$-1010. It also analyses the implications of these findings for auditors and the New Zealand professional body, NZICA.

The research findings indicated that potential drivers for the improvement and further development of current practice are as follows. First, encouraging some auditors to specialise in auditing clients who operate in environmentally sensitive industries could assist them in developing expertise in environmental matters (Mononey \& Simnett, 2006). This observation was also made by Collison and Gray (1997), and supported by Low's $(2004$, p. 201) findings that “the auditors' knowledge of the client's industry improves their audit risk assessments and directly influences that nature and the perceived quality of their audit planning decisions". The findings of the current research also suggested auditors could build a 'trust relationship' with client management to facilitate a two-way dialogue on environmental matters. However, Oliverio (2004, p. 14) explained that auditors must be certain that management understands that they [both the auditors and management] have an "overriding responsibility to serve the public interest and [are] committed to providing credibility to the financial statements". This suggests that auditors compel both the client and all audit team members to fulfil their responsibility and convince the client to present the financial information included in financial statements fairly. Yet, the findings also indicated that auditors are somewhat dependent on management in their business risk approach to audit planning. Also, to preserve their self-interest "auditors seem unlikely to "bite the hand that feeds them", (Porter, 2008, p. 7). Therefore, it appears likely that management is better able to influence their auditors unduly than vice versa. Additionally, financial auditors need to change their mindset on how they assess materiality and start to consider qualitative factors in their assessment of materiality and the discharge of their obligation to protect the public interest. They also need to have an open mind and be willing to take on board whatever is expected of them in protecting the public interest and complying with the 
regulatory requirements, even though this may seem challenging. The future for auditors will only get harder because, in time, they will have to cope with the recent requirement to verify the accounting for carbon footprints, in compliance with the Kyoto Protocol (Cummins, 2007). They will, therefore, continue to face bigger, but very similar, issues related to the widening scope of environmental matters.

The second potential driver is the accountancy profession. The research findings indicated that NZICA should have promulgated an audit standard on environmental matters that guides its implementation instead of an audit guidance statement. The suggestion made supports Oliverio's (2004, p. 16) observation that "implementation has lacked the professional judgement expected of independent auditors". According to Chiang (2006), auditors generally seemed unable to translate their personal views on environmental issues to their professional practice; their beliefs did not seem to impact their professional practice; and they did not feel they had the technical knowledge required to audit environmental matters. This empirical evidence provides support for Gray's (2000b, p. 248) comments that although "accountants are well trained in auditing (as in accounting)...universities need to produce "independent critical thinkers", and particularly, "...in the field of social, environmental...accounting, reporting and auditing" (p. 263). Hence, for auditors to become more concerned with environmental matters, as individuals and as a group, their attitude needs to shift to where their boundaries of consideration extend (Bebbington et al., 1994; Deegan, Geddes, \& Staunton, 1996). Moreover, as Chiang (2006, p. 23) indicated "the mechanism for translating the consideration of environmental issues into audit practice also needs improvement before auditors can become confident and fully engaged in their consideration of environmental matters in financial audits". Findings from the current research indicate that NZICA is best positioned as a driver to spearhead improvements in practice. NZICA is seen as having much to offer by promoting education, starting at university level, on general awareness of environmental matters, in line with the views of Collison and Gray (1997). Additionally, Collison and Gray (1997) found that the extent of an auditor's consideration of environmental matters was a function of the individual's awareness of, and training in environmental matters. The research evidence raised a similar concern that smaller audit firms in particular lacked resources for professional development on environmental matters. Thus, they require greater support from NZICA. . 
The third potential driver is the demand from investors and the public for full disclosures of companies' environmental obligations and liabilities in financial reports. Full disclosure would oblige auditors to audit the environmental information. However, the findings highlighted general concerns that the investors may be unlikely to force the issue, as they appear more interested in their return on investments.

The fourth potential driver is media-publicised high-profile environmental debacles. Porter (2008) indicated that auditors tend to be more reactive than pro-active, hence, it took the recent accounting debacles around the world to introduce more stringent auditor independence requirements and major revisions to the international auditing standards on audit planning and consideration of fraud and material misstatements in audit practice. Therefore, it may also require highly publicised environmental debacles for auditors to become organized as a matter of urgency and to consider environmental matters in their audit practice seriously.

The fifth potential driver is a legislative mandate. The research findings indicated that currently, there appears to be no incentive for companies to fulfil their environmental obligation, because the law is too lenient and the fines and penalties often too immaterial. Therefore, current environmental laws must be toughened up and enforced seriously, and penalties and fines for breaching environmental laws should be of a magnitude that fits the 'environmental crime'.

The research evidence also indicated that, currently in New Zealand, reporting of environmental matters in financial reports is not mandatory, thus, there is no requirement to focus on them unless they have a significant impact on financial reporting. Notably, a legislative mandate directed the public sector auditors interviewed for this study to audit environmental matters, specifically, for their clients. As pointed out by Collison and Gray (1997, p. 148), “...legislation at national level is clearly an important influence on audit change". This is clearly the case for the audit practice of public sector auditors in New Zealand, as confirmed by Frost (2007) who appeared to be in agreement with Porter's observation that:

Given the exponential increase in societal, political and media interest in environmental and social (or ethical) matters in recent years, and in climate change in particular, it seems likely that, in the not-too-distant future, it will be commonplace for external auditors to be required by legislation or regulation to audit at least some of the information 
published by the entities on their carbon footprint and other environmental and social activity (Porter, 2008, p. 6) .

However, although the research evidence showed general support for improvement and development in current practices, it also revealed some resistance to moving forward. Such resistance must be addressed, since auditors will soon have to deal with even more complex issues, including the auditing of companies' carbon footprints.

Overall, the research findings have implications for individual auditors and the auditing profession. It seems that the way forward in improving audit practice for environmental matters is complex in practice, owing to a wide range of factors as indicated in the previous discussion. Hence, it appears that perhaps the only practical and effective way forward is the implementation of a legislated mandate. This insight is based on the reported experiences of the public sector auditors whose audit practices for environmental matters are actually forced upon them by the legislated mandate embodied in the Local Government Act 2002. All other drivers for improvements and further development of current audit practice identified by the auditors interviewed for this study could easily flow out of the legislated mandate.

\subsection{Chapter Summary}

This chapter presented the research evidence on the following questions: (4) does AGS1010 impact current practice and, if so, how; and (5) how may current practice be improved and further developed to meet better the espoused aims of AGS-1010? Additionally, this chapter synthesised the research evidence into recurring themes that connect with key concepts of 'legitimacy theory', used to inform the research study. The following summary highlights the significant research findings.

All the financial auditors agreed that AGS-1010 had little impact on current practice. They perceived AGS-1010 as an introductory document that they did not take too seriously. Additionally, the practical application of AGS-1010 presented challenges, as it was subject to different interpretations. A critical review of AGS-1010 pointed to several explanations for the perception that AGS-1010 had not affected audit practice. In contrast, the public sector auditors were directed by the Auditor General to abide by the requirements of AGS-1010.

The promulgation of AGS-1010 can be interpreted as a symbolic, 'ceremonial conformity' legitimation strategy. It was issued at a time of media and public scrutiny of 
high profile environmental disasters and corporate failures, thus detracting focus from the huge, negative impact these accounting debacles had on auditors and accountants. The evidence presented here also suggests that the consequence of issuing AGS-1010 has been the expectation gap type II between standard setters and practising auditors. Given the apparently limited impact of AGS-1010, it is pertinent to consider how current practice might be improved and further developed to meet the espoused aim of AGS-1010. A number of suggestions were highlighted in the research evidence, the most significant being: the possibility that the New Zealand Government might step in to impose a legislative mandate, as is the case for the public sector auditors whose audit practices are mandated by the Local Government Act 2002; and the potential for the NZICA to work more closely with auditors in standard-setting, education and support, and in spearheading development initiatives.

The next chapter concludes the thesis, considers the contributions of the research findings to the literature, and to theory, practice and policy, and makes recommendations for future research. 


\section{CHAPTER 7: RESEARCH CONCLUSIONS, CONTRIBUTIONS AND RECOMMENDATIONS}

Businesses' activities impact the natural environment daily - a matter of obvious concern to society, yet few companies' financial reports disclose information on environmental matters. Many readers of financial reports therefore remain unaware of the existence, and significance for the company, of environmental matters (Gray, Collison et al., 1998). Since environmental matters are of growing interest to the users of financial reports (AGS-1010, paragraph 1), auditors, as society's corporate watchdogs, must ensure they consider environmental matters when auditing companies whose environmental matters have a significant impact on their financial reports. To date auditors have not been taken to task for failing to ensure that environmental matters are properly disclosed in financial reports. However, since the Enron and Arthur Andersen debacle, auditors are under increased scrutiny and must take precautions to ensure that they do not fail in their duty to protect the public interest by neglecting environmental matters. Since little is known of current practice related to this audit task, this study is a timely examination of an important issue.

Twenty-seven auditors in New Zealand participated in interviews that sought their views on the following research questions in the context of AGS-1010: The consideration of environmental matters in the audit of a financial report:

1. How do auditors generally perceive the consideration of environmental matters in the audit of financial reports?

2. What common approaches and practices do auditors undertake when auditing environmental matters?

3. Do auditors face any challenges in the audit of environmental matters? If so, what are they?

4. Does AGS-1010 impact current practice and, if so, how?

5. How may current audit practice be improved and further developed to meet better the espoused aims of AGS-1010?

This chapter draws on the synthesised research evidence presented in Chapter 5 and Chapter 6 to reflect on the key contributions this study makes to audit literature, theory, practice and policy. The aim is to highlight the significance of this research so that it will not just "sit on the shelf", but will help to push forward the boundaries of audit 
practice and research. The next section discusses the contributions this research makes to the extant literature and audit theory.

\subsection{Contributions to the Literature}

This study generally addresses a dearth in 'qualitative' audit research, the extant literature on audit practice and, specifically, understandings of how auditors consider environmental matters when they audit financial reports. It also demonstrates the usefulness of legitimacy theory for informing studies of audit practice such as this one. Each contribution is discussed in the following sections.

\subsubsection{Contributions to Qualitative Audit Research}

Sections 1.3 and 4.2 presented the rationale for conducting this research. They demonstrated that many authors (Beattie et al., 2001; Humphrey, 2008; Power, 2003) have strongly criticised the current approach to audit research, which is predominantly quantitative and focused on testing the validity of hypotheses which, as Gendron (2006) pointed out, are often removed from the realities of auditors' practice. Commentators have criticised current audit research as having accomplished little in bridging the knowledge gap in 'audit technologies' (Hopwood, 1996; Humphrey \& Moizer, 1990; Jeppesen, 1998), and critiqued the ways in which professional audit work, competence and skill are constructed and reproduced across countries (Cooper \& Robson, 2006). Other authors have observed a serious gap between the study of auditing in action and in practical settings (Beattie et al., 2001; Humphrey, 2008; Power, 2003), and the role of auditing in producing legitimacy (Power, 2003). Hence, Humphrey (2008) strongly encouraged research that might lead to a better understanding of the realities of audit practice in its broader social, organisational and regulatory contexts.

The purpose of this research was to understand better the relatively unknown experiences of auditors' current practices in the consideration of environmental matters when auditing financial reports. Auditors were asked for their views and their experiences of current practices, making this the type of research which many authors (Covaleski et al., 1998; Gendron, 2000, 2006; Humphrey, 2008; Sullivan, 1993) strongly advocate as being of interest to accounting practitioners and stakeholders. Therefore, this study addresses many of the concerns and criticisms of authors and commentators. It significantly contributes to the limited body of qualitative audit research by addressing the gaps in prior audit research on the 'how' and 'why' questions 
about audit practice. These issues have to date been largely ignored, along with the views and perceptions of practising auditors. The next section summarises the contributions this study makes to the extant literature and specific knowledge gaps.

\subsubsection{Contributions to Extant Literature and Specific Knowledge Gaps}

The extant literature is somewhat scant on the topic of 'auditors and environmental matters'. The only significant prior research is reported in Collison (1996) and Collison and Gray (1997), as discussed in section 2.3. Their key research findings were as follows: although auditors acknowledged the growing importance of environmental matters, they admitted their lack of general awareness, especially regarding the possible environmental risk for their clients; and auditors risk under-emphasising environmental issues and their financial consequences. However, it is now more than ten years since these findings were reported and more than fourteen years since the research interviews were conducted. Even after the International Auditing Practice Statement 1010: The consideration of environmental matters in the audit of financial statements was issued in 1998 no follow up research was conducted to examine its impact on the issues raised in Collison's (1996) study. Therefore, a significant knowledge gap exists in the literature. Moreover, the voices of New Zealand auditors have never been heard on their role and responsibilities regarding environmental matters. Hence, little is known about their perceptions of this aspect of current audit practice and the challenges it brings. Although carried out in the New Zealand context, Chiang's (2006) study on auditors' perceptions of environmental matters was unable to probe these issues because of the limitations posed by its survey questionnaire method. The study reported in this thesis addresses the knowledge gaps identified above, since these issues formed the basis of the guiding research questions. Furthermore, this study meets Collison and Gray's (1997) call for reports from auditors from other jurisdictions on the issues raised in their study. This study therefore bridges a knowledge gap in the literature by advancing and updating the findings of Collison (1996) and Collison and Gray (1997). It enhances understanding of an audit phenomenon that has been little examined as well as adding geographical variation to the existing literature on audit practice via its New Zealand context.

Specifically, this research has contributed to the knowledge gap on auditors' current practices in the audit of environmental matters. The research evidence, and its 
implications for audit practice, were presented, analysed and interpreted in Chapter 5 and Chapter 6 and can be summarised as follows. As far back as the 1990s, New Zealand auditors were aware that company activities that affected the environment could lead to environmental matters that impact financial reporting. However, concerns with environmental matters lost their prominence when the Enron and Arthur Anderson debacle took centre stage (in the late 1990s). Since then, despite the introduction of AGS-1010 in 2001, environmental matters have been generally treated no differently from other audit issues. Auditors reluctantly considered environmental matters in their audits, but tended not to search for environmental matters in 'provisions' and 'contingent liability' accounts. Furthermore, auditors were generally too financially focussed to reflect on the non-financial impact of environmental matters on company business specifically. New Zealand auditors also admitted that they are not up to date with the ever-increasing number of legal promulgations and their clients' actual or potential exposure to environmental matters. Hence, some auditors questioned their own ability to form an opinion on environmental matters.

The research findings also indicated that auditors did not change their audit approach when considering environmental matters for their clients; they just applied the common approach they are familiar with: (a) applying the business risks assessment approach, (b) assessing materiality, (c) applying accounting and auditing standards, and (d) relying on experts. Detailed discussions of each aspect of the approach were presented in sections 2.2 and 5.2. In summary, the business risks assessment approach for considering environmental matters is somewhat managerialistic and offers little or nothing to environmental accountability (refer to section 5.2.1). Whether an environmental matter is audited depends on its materiality, and the assessment of materiality is predominantly based on quantitative measures (refer to section 5.2.2). This approach fundamentally precludes auditors from considering environmental matters as contingent liabilities in accordance with NZ IAS 37. In appraising the significance of environmental matters, auditors also tended to rely on non-audit specialists who were generally appointed by their client companies (refer to section 5.2.4).

The auditors who were interviewed commented on the many challenges they faced in their audit task. Generally, auditors admitted their inability to detect environmental matters initially (refer to sections 5.1.1 and 5.1.4) and their lack of expert knowledge to audit environmental matters effectively. The business risks assessment approach to 
audit planning requires auditors to be reliant on management, experts and others for information on environmental matters: hence, the challenge is for auditors to remain objective and uninfluenced in their judgements. The disclosure of existing environmental matters for companies depends on many factors, but unless initial disclosures are made to the auditors, any omissions of environmental disclosures are unlikely to be detected. Auditors' dependence on a numerical threshold for assessing materiality, together with their general disregard for 'unquantifiable' environmental matters, suggests that environmental matters are simply not captured in the audit of financial reports.

New Zealand auditors expressed concerns that the experts they relied on were not always objective because they were mostly appointed by client companies. They were also concerned about their inability to assess the quality of an expert's work because they were not always knowledgeable enough to challenge the expert's assumptions, criteria and methods. Hence, the tendency is for auditors to assume that an expert's membership of a professional body is an adequate measure of professional competence and quality work. Therefore, in taking responsibility for the work of experts when forming their audit opinion on environmental matters, auditors are potentially exposing themselves to legal liability if the information, evidence and opinions of experts are not credible or reliable.

The auditors interviewed commented on the impact of AGS-1010 on current practice. They perceived AGS-1010 as having an insignificant impact on current practice; in fact, they perceived it as not being applied. Those auditors who took the time to read AGS1010 commented that it was a very long discussion document, did not establish any new rules or essential procedures and would not be taken seriously. Some of the auditors interviewed had never read AGS-1010, whilst others did not even realise it existed. Regardless of whether the auditors had actually read AGS-1010, many of them were of the opinion that the very existence of AGS-1010 had the potential to create an impression to clients and the public that environmental matters were appropriately considered in audits, and that auditors were committed to the public interest. Nonetheless, the application of AGS-1010 was subject to different interpretations, reflecting the need for auditors to exercise professional judgement in every aspect of the audit of environmental matters. 
By contrast with financial auditors, public sector auditors were required by the Local Government Act 2002 to search out environmental matters for every audit they undertook on behalf of the Office of the Auditor General. Their assessment of audit materiality considered qualitative factors, which included public health and safety risk factors (refer to section 5.2.2). To deal with environmental matters in their audits, the public sector auditors were given extensive training on this issue (refer to section 5.2.3).

In sum, the extant literature on auditors and environmental matters is rather scant. In particular, issues surrounding environmental matters are under-researched and underdocumented, and auditors themselves are concerned about the lack of information and knowledge on an audit issue that potentially exposes them to legal liability. This study addresses this important, emergent issue in audit practice and updates the research conducted more than ten years ago by Collison (1996) and Collison and Gray (1997). On both counts, it makes a significant contribution to the extant literature. The next section discusses the contributions made by this study to theory.

\subsection{Contributions to Theory}

Chapter 3 discussed the role of audit in producing legitimacy in organisations and society, the audit profession's production and seeking of legitimacy in society and the market, legitimacy at the level of audit practice, and the rationale for using legitimacy theory to inform the current research. The prior literature pointed to the relevance of legitimacy theory ideas for considering the research questions underpinning this study. The identification of key themes arising from the interview evidence then confirmed legitimacy theory as an appropriate theoretical lens for informing the analysis of the findings. The next sections outline the theoretical insights to emerge from this study.

\subsubsection{A Legitimacy Theory Perspective}

According to van Peursem, Locke and Harnisch (2005), the accountancy profession creates a manner of 'self' and communicates about itself through standards made available to every auditor and the general public (refer to section 2.2.3). From the size of the document, it is obvious that a significant amount of time and effort was put into the discussion and writing of IAPS-1010 (internationally) which was later adopted in New Zealand as AGS-1010. It is clear from AGS-1010 and IAPS-1010 that the accountancy profession (both internationally and in New Zealand) are concerned that environmental matters are becoming significant to an increasing number of entities 
because these issues are of growing interest to the users of financial reports. It is also clear that environmental matters can be complex and may therefore require additional consideration by auditors. Moreover, concerns for environmental matters have also been voiced outside promulgations such as AGS-1010 (in New Zealand) and IAPS-1010 (internationally). Various accountancy professional bodies (AICPA, 1992; ICAEW, 2000) and top ranking officers (Lickiss, 1991; Sylph, 2005) have urged practicing auditors not to neglect environmental risk assessment and management as part of corporate governance (refer to sections 2.1 and 2.3). Information that has been communicated within and outside such audit guidelines suggests that the accountancy profession does have a level of concern for environmental matters. That concern led to the issuing of IAPS-1010 and its New Zealand counterpart AGS-1010 in order to assist auditors to develop good practice by providing guidance on applying auditing standards in cases when environmental matters are significant to financial reports. However, neither IAPS-1010 nor AGS-1010 has established any new basic principles or essential audit procedures. Instead they both guide auditors in the application of relevant audit standards in the context of environmental matters.

As a credible professional body, NZICA should be doing, and should be seen to be doing, the right thing in protecting the public interest. Issuing AGS-1010 appeared consistent with protecting the profession's interest therefore, because environmental matters are obvious issues of public interest. Yet, comments made by members of the New Zealand Professional Standards Board (refer to section 6.2.1) did not indicate that the promulgation of AGS-1010 was prompted by any fundamental concerns with practice, or how NZICA was publicly perceived. Rather, its issuance was in line with NZICA's accepted policy to adopt international auditing standards and guidance statements. IAPS-1010 was issued as AGS-1010 to New Zealand auditors without any substantial changes. NZICA did not have any input into the promulgation of IAPS-1010 by the IAASB; it merely accepted what was issued by the IAASB.

Although the issuing of audit standards and audit guidance statements as a legitimacy strategy is well noted in the literature, that theory does not seem to provide any explanation for the promulgation of AGS-1010 by NZICA. In the New Zealand context, there was no evidence of any significant debate on environmental issues within the profession. As indicated by members of the NZICA Professional Practice Board, NZICA was merely following what had already been done overseas i.e. they adopted a 
mimetic approach to maintain equivalence with global partners. Thus, at the level of the audit profession, AGS-1010 does not appear to have served a role in supporting legitimacy. This research evidence provides a contrast to much of the extant literature that has discussed the promulgation of accounting standards as a legitimation strategy (refer to section 3.2).

On the other hand, the interview evidence indicated that AGS-1010 has served a role in supporting legitimacy at the level of audit practitioners' (Carpenter \& Dirsmith, 1993; Dirsmith \& McAllister, 1982; Power, 1992; 1995, 2003). Evidence from this study suggests that AGS-1010 is not effective in guiding the audit task (refer to sections 6.1 and 6.2); and that auditors are challenged in this aspect of their audit task (refer to section 5.1). Amongst other things, they lack confidence in detecting environmental matters in the first instance. They also are unable to stay current with the prolific environmental laws and regulations and are highly dependent on other experts. Additionally, they are concerned that the task of auditing environmental matters is onerous, increasing the scope of the audit and in turn increasing audit cost. Hence, there is a tendency for New Zealand auditors to omit the consideration of environmental matters for companies operating outside 'environmentally risky' industries. Without even considering its content, some auditors have already deemed AGS-1010 unimportant by virtue of its nature as an audit guidance statement rather than an audit standard. Yet, a number of auditors admitted that AGS-1010 did serve a purpose as a legitimating strategy. They perceived AGS-1010 as giving an impression to their clients and others that environmental matters were being appropriately considered in their audits. This was typical of a 'ceremonial conformity symbolic strategy' (Ashforth \& Gibbs, 1990; Richardson \& Dowling, 1986) (refer to section 6.3.2).

Therefore, the contribution this research makes to theory is the identification of AGS1010 with a ceremonial/legitimation role at the level of audit practitioners'. Although the 'ceremonial conformity symbolic strategy' idea has come up before in the auditing literature, the theory was extended by interview findings that illustrated a professional legitimation strategy at work in the field of auditing environmental matters and that the researcher was able to link to the theoretical notion of the expectation gap II. This has not been done before. The next section covers the contribution this study makes to identifying the existence of the expectation gap II (Specht \& Waldon, 1992; Specht \& Sandlin, 2003). 


\subsubsection{The Expectation Gap II}

One of this study's significant contributions is its identification of the theoretical concepts underlying the expectation gap II. The notion of the expectation gap II was first proposed by Specht \& Waldon (1992), and its continuing existence was confirmed by Specht \& Sandlin (2003). They noted differing expectations between accounting/auditing standard setters and the public whose interests they serve, and noted that this overall expectation gap can be thought of as comprising two elements: the expectation gap I (the difference in expectations of financial statement users and the auditors) and the expectation gap II (the difference in expectations of standard setters and the auditors). Section 6.3.3 identified the existence of the expectation gap II both in the context of AGS-1010: The consideration of environmental matters in the audit of a financial report and AS-304: Audit materiality. Specht and Waldon (1992) and Specht and Sandin (2003) indicated that only the auditors themselves were able to influence the acceptance and implementation of an audit standard. However, their studies did not examine the issues exemplifying the expectation gap II and the strategies for narrowing this gap. Hence, another contribution made by this study is the identification of issues exemplifying the expectation gap II and strategies for narrowing the gap (refer section 6.3.3). Important factors contributing to the gap were: the preconceived mindsets of the auditors themselves; criticisms related to standard-setting boards across countries; and the actual standard-setting process. Perhaps the most significant strategies for narrowing the expectation gap II are for accountancy professional bodies to involve more practicing auditors in the standard-setting process and also to better serve, facilitate and support the needs of its members. Such an approach would ultimately serve and protect the public interest. In reality, there is more to the role of the accountancy professional bodies as audit regulators than just issuing audit standards and guidelines. Setting audit standards should not be seen as a regulatory tool, rather it should be seen as a means of benchmarking best practice.

To sum up this section, this study (i) contributes to the literature on the legitimatising aspects of audit which, according to various commentators, is currently underresearched and under-documented (Humphrey, 2008; Power, 2003); and (ii) draws on insights from legitimacy theory to extend the theoretical concept of the expectation gap II, with significant implications for the role of audit in governance and society. Prior literature has considered the expectation gap I but has largely ignored the expectation 
gap II, to the detriment of a better understanding of audit practice. A greater awareness of the expectation gap II has significant implications for standard setters and for accountancy professional bodies wishing to serve the needs of their members whilst, at the same time, protect the public interest. The next section discusses the contribution of this study to policy and practice.

\subsection{Contributions to Practice and Policy}

The evidence from this study suggests the following potential contributions to practice and policy. The next section discusses the contributions made to audit practice.

\subsubsection{Contributions to Practice}

The research evidence from this study focuses attention on current practices in the audit of environmental matters. Presently, current general audit practice covers four main components: the business risk approach; professional judgement on materiality; the application of accounting and auditing standards; and relying on the work of other experts (refer to sections 2.2 and 5.2). The most significant concerns arising from the interview evidence for each of the four main components were as follows: (i) the business risk approach is managerialistic in its orientation, a concern that Gray (2000b) argued offered little or nothing to corporate accountability; (ii) auditors must depend to some extent on the work of other experts because of their lack of expertise in environmental matters; (iii) there is no explicit accounting standard on environmental matters and auditors confirmed that they tended to refer to the accounting standard on 'provisions, contingent liabilities and contingent assets'; (iv) generally, the preference of auditors is to apply quantitative criteria when assessing materiality; the general perception among auditors is, therefore, that if environmental matters (or any other audit issue) cannot be quantified then they are considered to be immaterial and do not warrant separate disclosure or verification. This is perhaps the most fundamental factor impairing the consideration of environmental matters in auditing financial reports, revealed by this study. Unless the above fundamental concerns for the four components of audit practice are improved, auditors are exposing themselves to potential legal liability. Sections 6.1 and 6.2 discussed the research evidence on the effectiveness of AGS-1010 in guiding current practice. The conclusion arrived at was that AGS-1010 is not effective. This may be the consequence of the board's control of the audit standardsand guidelines-setting process and their failure to involve auditors, whose early 
participation would draw attention to the issues of concern that need to be factored into the process.

New Zealand auditors indicated during the research interviews that environmental matters are one of the many audit issues they have to deal with, and that the approach they follow is similar to resolving all other audit issues. The research evidence on current practice in the consideration of environmental matters in financial reports provides an insight into auditors' general practices regarding all audit issues. If they are currently perceived as being under-responsive towards environmental matters, can they be expected to respond adequately to the significant forthcoming challenge of carbon accounting, which is in many ways similar in nature to the challenges of auditing environmental matters, albeit even more complex? NZICA and other accountancy professional bodies around the world need to review current practices and benchmark best practices in order to improve public stakeholder and shareholder confidence in the work of auditors, thereby potentially reducing criticisms and litigation against them.

The auditors who were interviewed identified some specific strategies to improve current practice and meet better the espoused aims of AGS-1010. They suggested that auditors should make an effort to develop specialised expertise in environmental matters and acquire specialised knowledge of the industries in which their audit clients operate. This is expected to improve their risk assessments, which, in turn, should improve their audit planning decisions (refer to section 6.4). The auditors also felt it necessary for NZICA and other accountancy professional bodies to issue an accounting standard to guide the measurement, recognition and full disclosure of environmental matters regardless of the quantum involved. Further, a need was expressed for the accountancy profession to be proactive in educating accountants on various auditing and accounting issues pertaining to environmental matters (refer to section 6.4). This suggestion echoes the concern raised by Swift \& Humphrey (2000a) that the accountancy professional body should act as a "trade association" serving the interests and needs of its members.

Most significantly, the interview findings revealed a much more fundamental problem. Generally, current and common audit practice is riddled with issues of concern, and inadequacies. As well as potentially allowing environmental matters to be overlooked, these deficiencies could lead to other audit issues being ignored. For auditors to be more effective in their audit practice (and in protecting the public interest), audit methodology 
needs a major review and re-vamp, and the auditors themselves need to change their attitudes and mindsets in their approach to auditing. The next section considers the contribution of this study to policy.

\subsubsection{Contributions to Policy}

Public sector auditors are compelled by the Local Government Act 2002 to consider environmental matters for every audit, are so are intensively trained to search out environmental matters in their audits. The findings of this study revealed that these public sector auditors conduct the most rigorous examination of environmental matters in published financial reports, setting best practice standards from which all auditors and NZICA have much to learn. This suggests that a more stringent legislative framework, similar to that already governing public sector audits, may offer the greatest potential to redirect practice in the private sector, not only for financial auditors, but also for accountants and company directors. The Government has the potential to act as a change agent in promoting this by:

(1) mandating company reporting on environmental matters via the Financial Reporting Act 1993

(2) compelling company directors to manage and report on environmental matters by way of the Companies Act 1993

(3) Imposing substantial financial penalties ( $\$ 100,000$ 's and perhaps a jail sentence) for non-compliance with the legislated requirements of the Companies Act 1993 and the Financial Reporting Act 1993, thus pressuring company accountants and directors to consider more seriously and urgently their responsibilities for managing and reporting environmental matters.

To support such legislative changes, NZICA could follow the lead of the Auditor General in prioritising and mandating the audit of environmental issues for all company audits by issuing an audit standard on environmental matters (refer to section 6.4.2) in place of the current audit guideline.

Putting pressure on accountants, directors and auditors to manage, report and audit environmental matters in accordance with legislated mandates (via the Financial Reporting Act 1993 and the Companies Act 1993) and an audit standard (from NZICA) would propel environmental matters to the centre-stage of the practice and professional 
agenda. This would place pressure on the accountancy profession to develop the technical competency of all accountants and auditors in regard to environmental matters (refer to section 6.4.2). This perhaps is the only significant strategy that would force the accountancy profession and company directors to consider and safeguard the public interest in environmental matters for the collective well-being of society.

\subsection{Limitations of the Study}

The findings and conclusions of this study should be considered in the light of the relevant research limitations discussed below.

This is a qualitative interview study and the participants were selected based on their availability (refer to section 4.5.4). A number of auditors who were initially approached did not wish to participate. However, every effort was made to gather the views from senior auditors (partners and managers only) from all the major firms in New Zealand in order to seek a range of perspectives. The researcher had no prior knowledge of the extent of the research participants' involvement and experience in environmental matters, so this approach introduced an element of randomness in the selection.

AGS-1010 is similar in all material aspects to IAPS-1010 and AGS-1036: The consideration of environmental matters in the audit of a financial report (issued in Australia). However, AGS-1010 may differ from the audit guidance or standards issued on environmental matters in other countries, so its context is specific to New Zealand. Nevertheless, there is a dearth in the extant literature on auditors and environmental matters: hence, this study may provide the impetus and background for similar studies to be conducted in other countries.

This study's general reflection on issues such as standard-setting, professional education and the need to exercise auditor judgement were developed in the context of environmental matters. However, particular issues identified from such reflections warrant further examination in other audit research contexts. The next section makes suggestions for future research. 


\subsection{Recommendations for Future Research}

Every completed study will lead to some suggestions for future research. Recommendations to emerge from the study reported here are as follows.

The research evidence from this study indicated that ineffective audit standards and guidelines are possibly the consequence of ineffective audit standards- and guidelinessetting processes. This accords with other literature in which audit standard setters and the standard/guideline-setting process have been criticised (Baker, 1993, 2004; Carmichael, 1995; McEnroe \& Martens, 1998; Sikka, Willmott, \& Lowe, 1989; Walsh, 2000) (refer to section 2.2.3). However, little research has so far been conducted to identify improvements and further developments of present practices. Hence, further research on different aspects of audit standards and guidelines setting is recommended. This would provide deeper insights and greater understanding of what actually takes place in the auditing standard-setting process, thus, narrowing the gap in the literature.

Auditors invariably rely on the work of other specialists, however AS-606: Using the work of an expert, does not provide any of the standard requirements for supporting the practical questions raised by Landes, the Director of Auditing and Attestation at the AICPA (Cheney, 2005) (refer to section 6.2.3). Landes was concerned that practical guidance given to auditors relying on experts may "be out of date and weak, not recognising what's happening in the work of using experts and specialists today" (Cheney, 2005, p. 14). Hence there is scope for future research to provide answers to the questions raised by Landes and to define more clearly the boundary between the auditor's position and the expert's position that currently is somewhat blurred.

The research findings indicated that public sector auditors are setting the standards of best practice in the audit of environmental matters. Future research should be undertaken to understand better their audit methodology in the audit of environmental matters. This would be beneficial to financial auditors beyond the public sector, and might establish a framework for considering further directives (or standards) to ensure a more widespread movement towards best practice in this area.

Since the extant literature on the research topic is limited, the researcher suggests this study be replicated in other countries, in order to determine whether those countries following different guidelines fare better, and whether New Zealand auditors can, therefore, learn something from other countries. 


\subsection{Concluding Remarks}

This study has addressed a gap in the literature related to auditors' consideration of environmental matters in the audit of financial reports. It has also made a unique and important contribution to examining the practices of New Zealand auditors and soliciting their views on the issues and concerns they face. The findings shed light on some interesting aspects of practice in the audit of environmental matters in financial reports, as well as offering reflections on the significance of AGS-1010 for audit practice in New Zealand. The findings raise issues regarding the role and duties of auditors in regards to environmental matters and the ongoing challenges they face in balancing the expectations of society - as reflected by standard setters - and the practicalities of working at the margins of their professional knowledge and judgement. 


\section{APPENDIX 1: JOURNAL PUBLICATIONS AND CONFERENCE PRESENTATIONS}

Please note that the following completed papers have been subjected to peer-review.

\section{Journal Publications}

Chiang C. (2007). Environmental matters in the audit of financial reports. Chartered Accountants Journal, v 86/4, p. 44.

Chiang C. (2006). Auditors' perceptions of environmental issues; and its implication for the consideration of environmental matters. New Zealand Journal of Applied Business Research, v 5/2, p. 17-24.

Chiang C. and Lightbody M. (2004). Financial auditors and environmental auditing in New Zealand. Managerial Auditing Journal, v 19/4, p 224-234.

\section{Conference Presentations}

Chiang, C (2008). Guiding best practice or legitimating current practice? An examination of AGS-1010 on the consideration of environmental matters in the audit of a financial report. A paper to be presented at the 20th Asian-Pacific Conference on International Accounting Issues, November 9 - 12; Paris, France.

Chiang, C. and Northcott, D. (2008). Audit materiality and environmental matters in financial reports: Some interview evidence. A paper presented at the 2008 North American Congress on Social and Environmental Accounting Research (1st CSEAR Summer School in North America), Concordia University, July 7-9, Montreal, Canada.

Chiang, C. (2007). The consideration of environmental matters in financial reports: Some preliminary evidence on current practices. A paper presented at the 5th Asia Pacific Interdisciplinary Research in Accounting (APIRA) Conference, July 8-12, Auckland, NZ.

Chiang, C (2005). Auditors' views on the significance of environmental matters and their impact on the audit function: Some New Zealand evidence. A paper presented at the Accounting and Finance Association of Australia and New Zealand (AFAANZ) Conference, 3-5 July, Melbourne, Australia.

Chiang, C. (2005). Financial auditors and environmental matters: A review of the literature. A paper presented at the $4^{\text {th }}$ Australasian Centre for Social and Environmental Accounting Research (CSEAR), March 30 - April 1, Melbourne, Australia.

Chiang, C. (2002). An analysis of the role of NZ financial auditors and the degree of their involvement in environmental audits. A paper presented at the Accounting and Finance Association of Australia and New Zealand (AFAANZ) Conference, July 8-10, Perth, Australia. 


\title{
APPENDIX 2: INFORMATION FOR PARTICIPANTS
}

\author{
[DATE] \\ Dear [PARTICIPANT],
}

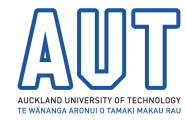

I am a Senior Lecturer in the Auckland University of Technology's Business Faculty and am currently undertaking research towards my $\mathrm{PhD}$; for which I am also a recipient of NZICA's PhD Scholarship. I am writing to request your assistance in this research project. My principal supervisor is Professor Deryl Northcott and my advisor is Professor Keith Hooper, both of the Business Faculty at Auckland University of Technology.

The aim of this project is to understand current practice in regard to the audit of environmental matters in financial reports. This project is exploratory and involves collecting the views of audit practitioners in New Zealand. Views will be sought on auditors' current practices and any issues and challenges faced in carrying out these audits. The results of this research will assist audit practitioners to benchmark their current practice in regard to the audit of environmental matters in financial reports and to identify potential improvements to audit performance.

It would be much appreciated if you could take the time to comment on issues related to the $\mathrm{PhD}$ topic and any other information that may assist me with the research study in an interview discussion which should not take any more than an hour.

Should you be happy to offer your comments, you are assured of complete confidentiality. Raw data (interview tapes and emails) will be kept secure. The research data will be available only to me and my principal supervisor. Results of the study will be published in aggregate form via the doctoral thesis, academic papers and conference presentations. Participants will be identified only by generic job titles without disclosing their institutional affiliations. This study has ethical approval from the Auckland University of Technology Ethical Committee (AUTEC reference no: 05/84 dated 16 May 2005). Any concerns you may have regarding the conduct of the research should be notified to the Executive Secretary, AUTEC, Madeline Banda, madeline.banda@aut.ac.nz, 9179999 ext 8044.

Yours sincerely,

Christina Chiang

Senior Lecturer, School of Business

AUT University

Private Bag 92006

Auckland 1020

New Zealand

Office: WF938, $9^{\text {th }}$ Floor, WF Building, 42 Wakefield Street, Auckland

Email: christina.chiang@ aut.ac.nz

Phone: 09-921 9999 ext 5720; Facsimile: 09-921 9990 


\section{APPENDIX 3: CONSENT TO PARTICIPATE IN RESEARCH}

Title of Project: $\quad$ The audit of environmental matters in financial reports:

Views of New Zealand audit practitioners on current pra

Project Supervisor: Professor Deryl Northcott

Researcher:

Christina Chiang

- I have read and understood the information provided about this research project (Information Sheet dated .....)

- I have had an opportunity to ask questions and to have them answered.

- I understand that the interview will be audio-taped and transcribed.

- I understand that I may withdraw myself or any information that I have provided for this project at any time prior to completion of data collection, without being disadvantaged in any way.

- If I withdraw, I understand that all relevant tapes and transcripts, or parts thereof, will be destroyed.

- I agree to take part in this research.

- I wish to receive a copy of the final report from the research: tick one: Yes O

No O

- I understand that published data will not report the names or affiliations of informants and will use generic job titles only.

Participant signature:

Participant name:

Participant contact details (if appropriate):

Date:

Approved by the Auckland University of Technology Ethics Committee on 16 May 2005, AUTEC Reference Number 05/84

Note: The Participant should retain a copy of this form. 


\section{APPENDIX 4: INTERVIEW GUIDE}

1. How do you perceive your own awareness of environmental matters?

2. What is your perception of auditors' general awareness of environmental matters for accounting and auditing purposes?

3. How do you generally perceive the consideration of environmental matters in the audit of financial reports?

4. In your view, what are the perceptions of auditors on the significance of environmental matters to their practice and also to their clients?

5. What is your perception of the current role of auditors in the audit task?

6. What common approach and practice do you undertake when auditing environmental matters?

7. Do you apply, and how do you apply the following aspects in audit practice to the audit of environmental matters: (1) the business risk assessment approach in planning; (2) assessment of materiality levels, (3) application of accounting and auditing standards and (4) reliance on the work of experts?

8. Do you face any challenges in the audit of environmental matters? If so, what might they be?

9. Does AGS-1010 impact current practice and if so, how?

10. How may current practice may be improved and further developed to meet better the espoused aims of AGS-1010?

\section{Closing Questions}

11. Have I omitted any questions that in your opinion are important for understanding the audit of environmental matters?

12. Who do you recommend I interview next? 


\section{REFERENCE LIST}

Abdolmohammadi, M., \& Wright, A. M. (1987). An examination of the effects of experience and task complexity on audit judgments. The Accounting Review, LXII(1), 1-13.

Abeysekera, I., \& Guthrie, J. (2003). How is intellectual capital being reported in a developing nation? Accounting and Accountability in Emerging and Transition Economies, Supplement 2, 149-165.

Adams, C., Hill, W. Y., \& Roberts, C. B. (1995). Environmental, employee and ethical reporting in Europe. London: (ACCA Research Report no. 41), Association of Chartered Certified Accountants.

Adamson, B., \& Shailer, G. (1998). Greening the audit. Charter, 84-85.

Ahrens, T., \& Dent, J. F. (1998). Accounting and organizations: Realizing the richness of field research. Journal of Management Accounting Research, 10, 1-39.

Ahuvia, A. (2001). Traditional, interpretive, and reception based content analyses: Improving the ability of content analysis to address issues of pragmatic and theoretical concern. Social Indicators Research, 54(2), 139-159.

AICPA. (1992). The CPA Letter. Audit Risk Alert.

Anderson, J. C., \& Frankie, A. W. (1980). Voluntary social reporting: an iso-beta portfolio analysis. The Accounting Review, 55(3), 467-479.

Anderson-Gough, F. (2004). Using computer assisted qualitative data analysis software: Respecting voices within data management and analysis. In C. Humphrey \& B. Lee (Eds.), The real life guide to accounting research. A behind-the-scenes view of using qualitative research methods (pp. 373-390). Oxford: Elsevier.

Anonymous. (1998). Auditing environmental matters in the accounts. Management accounting, 76(6), 5.

Appleton, J. V. (1995). Analysing qualitative interview data: addressing issues of validity and reliability. Journal of advanced nursing, 22, 993-997.

Arena, M., \& Azzone, G. (2007). Internal audit departments: Adoption and characteristics in Italian companies. International Journal of Auditing, 11(2), 91114.

Ashforth, B. E., \& Gibbs, B. W. (1990). The double-edge of organizational legitimation. Organizational Science, 1(2), 177-194.

Ashton, A. H. (1991). Experience and error frequencies knowledge as potential determinants of audit expertise. The Accounting Review(April), 218-239.

Ashton, R. H. (1990). Pressure and performance in accounting decision settings: practical effects of incentive. Feedback and justification. Journal of Accounting Research(Supplement), 148-180.

Association, A. A. (1973). A statement on basic auditing concepts. Saratosa, Florida.: American Accounting Association.

Baker, C. F., \& Owsen, D. M. (2002). Increasing the role of auditing in corporate governance. Critical Perspectives on Accounting, 13, 783-795.

Baker, C. R. (1977). The structural response of the Large CPA Firm to its environment. International Journal of Accounting, 12(2), 69-80.

Baker, C. R. (1993). Self-regulation in the public accounting profession: The structural response of the large public accounting firms to a changing environment. Accounting, Auditing, and Accountability Journal, 6(2), 68-80. 
Baker, C. R. (2004). What do we mean by accounting for the public interest? Paper presented at the 4th Asia Pacific Interdisciplinary Research in Accounting Conference (4-6 July), Singapore.

Ball, A., Owen, D. L., \& Gray, R. H. (2000). External transparency or internal capture? The role of third party statements in adding value to corporate environmental reports. Business Strategy and the Environment, 9(1), 1-23.

Bamber, E. M., \& Iyer, V. M. (2007). Auditors' identification with their clients and its effect on auditors' objectivity. Auditing, 26(2), 1-24.

Baylin, G., MacDonald, L., \& Richardson, A. J. (1996). Accounting standard-setting in Canada, 1864-1992: A theoretical analysis of structural evolution. Journal of International Accounting, Auditing \& Taxation, 5(1), 113-131.

Bazerman, M. H., Loewenstein, G., \& Moore, D. A. (2002). Why good accountants do bad audits. Harvard Business Review(November), 97-102.

Beattie, V., Brandt, R., \& Fearnley, S. (2001). Behind closed doors: what company audit is really about. Basingstoke: Palgrave.

Bebbington, J., \& Gray, R. (1990). The greening of Accountancy - Accounting for a better environment. Accountants' Journal(September), 17-20.

Bebbington, J., \& Gray, R. (1992). Where have all the accountants gone? . Accountancy, 109(March), 28-19.

Bebbington, J., Gray, R., Thomson, I., \& Walters, D. (1994). Accountants' attitudes and environmentally-sensitive accounting. Accounting and Business Research, 24(94), 109-120.

Bell, S. (1992). Environmentally sensitive: Practical audit and accounting concerns associated with environmental liability. Pennsylvania CPA, 62(3), 18-25.

Bell, T., Marrs, F., Solomon, I., \& Thomas, H. (1997). Auditing organizations through a strategic systems lens. KPMG Peat Marwick LLP.

Bell, T. B., Peecher, M. E., \& Solomon, I. (2005). The 21st century public company audit. Conceptual elements of KPMG's global audit methodology. Montvale, NJ: KPMG.

Bell, T. B., \& Solomon, I. (2002). Cases in strategic systems auditing. New York: KPMG/University of Illinois.

Best, P. J., Buckby, S., \& Tan, C. (2001). Evidence of the audit expectation gap in Singapore. Managerial Auditing Journal, 16(3), 134-144.

Bewley, K. (1993). The green team. CA Magazine, 44-46.

Bhattacharjee, S., \& Moreno, K. (2002). The impact of affective information on the professional judgments of more experienced and less experienced auditors. Journal of Behavioral Decision Making, 15(4), 361-377.

Billing, R., Buisman, J. A., Willis, A. D., \& Wilson, R. W. (1994). Environmental issues pose major challenges to accountancy profession. International Federation of Accountants Newsletter, 18(1), 24.

Blokdijk, J. H., \& Drieenhuizen, F. (1992). The environment and the audit profession: A Dutch research study. European Accounting Review, 1, 437-443.

Bogdan, R. C., \& Biklen, S. K. (1982). Qualitative research for education: An introduction to theory and methods. Boston: Allyn and Bacon, Inc.

Booth, P., \& Cocks, N. (1989). Power and the study of the accounting profession. In C. D.J. \& T. M. Hopper (Eds.), Critical Accounts: Basingstoke: MacMillan.

Boyd, J. (2000). Actional legitimation: No crisis necessary. Journal of Public Relations Research, 12(4), 341-353.

Brent, E. (1984). Qualitative computing: approaches and issues. Qualitative Sociology, $7(1 / 2), 34-60$. 
Briloff, F. (1990). Accountancy and society: A covenant desecrated. Critical Perspectives on Accounting, 1(1), 5-30.

Brown, P. (2001). Politics, processes and the future of Australian Accounting Standards. Abacus, 3, 267-296.

Browning, J. A. (1994). Review engagements in review. CA Magazine, 127(8), 38-39.

Buhr, N. (1998). Environmental performance, legislation and annual report disclosure: The case of acid rain and Falconbridge. Accounting, Auditing \& Accountability Journal, 11(2), 163-190.

Burrowes, A. (2006). United States: E-filing the way to go. Chartered Accountants Journal, February, 66.

Byington, J. R., \& Sutton, S. G. (1991). The self-regulating profession: An analysis of the political monopoly tendencies of the audit profession. Critical Perspectives on Accounting, 2, 315-330.

Byrnes, N., McNamee, M., Brady, D., Lavelle, L., \& Palmeri, C. (2002). Accounting in crisis; Reform is urgent; here's what needs to be done. BusinessWeek, 3767(January 28), 44-44.

Cadbury. (1992). The report of the Committee on the financial aspects of corporate governance: The Code of best practice. London: Gee Professional Publishing.

Campbell, D. J. (2000). Legitimacy theory or managerial reality construction? Corporate social disclosure in Marks and Spencer PLC corporate reports, 19671997. Accounting Forum, 24(1), 80-.

Carmichael, D. R. (1995). The Audit Agenda. Accounting Horizons, 9(4), 143-148.

Carmichael, D. R. (2006). How new risks standards differ from past practice. Accounting Today, Sept 18, 14-15.

Carpenter, B., \& Dirsmith, M. W. (1993). Sampling and the extraction of knowledge in the auditing profession: an extended institutional theory perspective. Accounting, Organizations and Society, 18, 41-63.

Carpenter, V. I., \& Feroz, E. H. (1992). GAAP as a symbol of legitimacy: New York State's decision to adopt generally accepted accounting principles. Accounting , Organizations and Society, 17(7), 613-643.

Cavana, R. Y., Delahaye, B. L., \& Sekaran, U. (2001). Applied business research: Qualitative and Quantitative methods. Sydney: John Wiley \& Sons Australia, Ltd.

Chadick, B., Rouse, R. W., \& Surma, J. (1993). Perspectives on environmental accounting. The CPA Journal, January, 64-69.

Chandler, R. A. (1997). Conflict, compromise and conquest in setting auditing standards: The case of the small company qualification. Critical Perspectives on Accounting, 8, 411-429.

Chandler, R. A. (1999). Critics' use of satire against the auditing profession: A short historical note. Accounting, Auditing and Accountability, 12(1), 129-133.

Cheney, G. (2005). ASB asks IAASB to look at use of specialists in audits. Accounting Today, April 18-May 1, 14-15.

Chewning, E. G., \& Higgs, J. L. (2002). What does "materiality" really mean? The Journal of Corporate Accounting \& Finance, 13(4), 61-71.

Chiang, C. (2006). Auditors' perceptions of environmental issues and its implications for the consideration of environmental matters. New Zealand Journal of Applied Business Research, 5(2), 17-24.

Chiang, C., \& Lightbody, M. (2004). Financial auditors and environmental auditing in New Zealand. Managerial Auditing Journal, 19(2), 224.

Chowdhurry, R., \& Innes, J. (1998). A qualitative analysis of the expectations gap in the public sector of Bangladesh. International Journal of Auditing, 2, 247-261. 
Chua, W. F. (1986). Radical developments in accounting thought. Accounting Review, 61(4), 601-632.

CICA. (1993). Environmental costs and liabilities: Accounting and financial reporting issues. Toronto: The Canadian Institute of Chartered Accountants.

CICA. (1995). Professional judgement and the auditor. Toronto: CICA.

Colbert, J. L., \& Scarbrough, C. (1993). Environmental issues in a financial audit: Which professional standards apply? Managerial Auditing Journal, 8(5), 26-32.

Collier, J., Doolittle, I., \& Broke, P. (1993 August). Accountants Digests: Environmental Disclosures. London: ICAEW.

Collison, D. (1996). The response of statutory financial auditors in the UK to environmental issues: A descriptive and exploratory case study. British Accounting Review, 28, 325-349.

Collison, D., \& Gray, R. (1997). Auditors' responses to emerging issues: A UK perspective on the statutory financial auditor and the environment. International Journal of Auditing, 1(2), 135-149.

Collison, D., Gray, R., \& Innes, J. (1996). The financial auditor and the environment. London: ICAEW.

Collison, D., \& Slomp, S. (2000). Environmental accounting, auditing and reporting in Europe: The role of FEE. The European Accounting Review, 9(1), 111-129.

Conrad, P., \& Reinharz, S. (1984). Computers and qualitative data: editors' introductory essay. Qualitative Sociology, 7(1/2), 3-15.

Cooper, D. J., \& Robson, K. (2006). Accounting, professions and regulation: locating the sites of professionalization. Accounting, Organizations and Society, 31(4/5), 415-444.

Cornell, D. W., \& Apostolou, B. (1991). Auditing for violations of environmental laws. The National Public Accountant, 36(7), 16-16.

Covaleski, M. A., Dirsmith, M. W., Heian, J. B., \& Samuel, S. (1998). The calculated and the avowed: Techniques of discipline and struggles over identity in Big Six public accounting firms. Administrative Science Quarterly, 43(2), 293-327.

Cox, R. (2001). Audit Guidance Statement 1010: The consideration of environmental matters in the audit of a financial report. Chartered Accountants Journal, 80(1), 54.

Craig, J. L. (1994). Serving the profession's assurance function. The CPA Journal, 64(1), 36.

Craig, R. J., \& Diga, J. G. (1996). Financial reporting regulation in ASEAN: Features and prospects. The International Journal of Accounting, 31(2), 239-256.

Crawford, M., \& Stein, W. (2002). Auditing risk management: Fine in theory but who can do it in practice? International Journal of Auditing, 6, 119-131.

Crowley, C., Harre', R., \& Tagg, C. (2002). Qualitative research and computing: methodological issues and practices in using QSR NVivo and NUD*IST. International Journal of Social Research Methodology, 5(3), 193-197.

Cummins, R. (2007). The long and short of emissions trading. Chartered Accountants Journal(October), 6-7.

Curtis, E., \& Turley, S. (2007). The business risk audit - A longitudinal case study of an audit engagement. Accounting, Organizations and Society, 32(4-5), 409-432.

Daly, J., \& Lumley, J. (2002). Bias in qualitative research design. Australia and New Zealand Journal of Public Trust, 26(4), 299-300.

Davies, J. (1993). Automated tools for qualitative research. In N. G. Fielding \& R. M. Lee (Eds.), Using Computers in Qualitative Research (pp. 54-72). London: Sage. 
Dedoulis, E. (2006). The Code of Ethics and the development of the auditing profession in Greece, the period 1992-2002. Accounting Forum, 30(2), 155-178.

Deegan, C. (2002a). Introduction: the legitimising effects of social and environmental disclosures - A theoretical foundation. Accounting, Auditing \& Accountability Journal, 15(3), 282-311.

Deegan, C. (2002b). The legitimising effect of social and environmental disclosures - A theoretical foundation. Accounting, Auditing \& Accountability Journal, 15(3), 282-311.

Deegan, C. (2006). Legitimacy theory. In Z. Hoque (Ed.), Methodological issues in accounting research: Theories and methods (pp. 161-181). London: Spiramus.

Deegan, C., Geddes, S., \& Staunton, J. (1996). A survey of Australian accountants' attitudes on environmental reporting. Accounting Forum, 19(2/3), 143-163.

Deegan, C., \& Gordon, B. (1996). A study of the environmental disclosure practices of Australian corporations. Accounting and Business Research, 26(3), 187-199.

Deegan, C., \& Rankin, M. (1996). Do Australian companies report environmental news objectively? An analysis of environmental disclosures by firms prosecuted successfully by the Environmental Protection Authority. Accounting, Auditing \& Accountability Journal, 9(2), 50.

Deegan, C., \& Rankin, M. (1997). The materiality of environmental information to users of annual reports. Accounting, Auditing \& Accountability Journal, 10(4), 562-583.

Deegan, C., Rankin, M., \& Tobin, J. (2002). An examination of the corporate social and environmental disclosures of BHP from 1983-1997: A test of legitimacy theory. Accounting, Auditing \& Accountability Journal, 15(3).

Deegan, C., \& Samkin, G. (2006). New Zealand Financial Accounting (3rd ed.). Auckland: McGraw-Hill Irwin.

Dembkowski, S., \& Hammer-Lloyd, S. (1995). Computer applications - a new road to qualitative data analysis? European Journal of marketing, 29(11), 50-62.

DiMaggio, P. J., \& Powell, W. W. (1983). The iron cage revisited: Institutional isomorphism and collective Rationality in organizational fields. American Sociological Review, 48(2), 147-160.

Dirsmith, M. W., \& McAllister, J. P. (1982). The Organic vs. the mechanistic audit. Journal of Accounting, Auditing and Finance(Spring), 214-228.

Dixon, R., Mousa, G. A., \& Woodhead, A. D. (2004). The necessary characteristics of environmental auditors: A review of the contribution of the financial auditing profession. Accounting Forum, 28(2), 119-138.

Dixon, R., \& Woodhead, A. D. (2006). An investigation of the expectation gap in Egypt. Managerial Auditing Journal, 21(3), 293-302.

Dolan, A., \& Ayland, C. (2001). Analysis on trial. International Journal of Market Research, 43(4), 377-389.

Dowling, J., \& Pfeffer, J. (1975). Organizational legitimacy: societal values and organisational behaviour. Pacific Sociological Review, 18(1), 122-136.

Drass, K. A. (1980). The analysis of qualitative data. Urban Life, 9(3), 332-353.

Durbin, T. E., \& Summo, J. M. (1994). When auditors use specialists. Journal of Accountancy, August, 47-49.

Economist, T. (1990, 3 March). Split profit, p. 62.

El-Sawad, A., Arnold, J., \& Cohen, L. (2004). 'Doublethink': The prevalence and function of contradiction in accounts of organizational life. Human Relations, 57(9), 1179-1203.

Fadzly, M. N., \& Ahmed, Z. (2004). Audit expectation gap: the case of Malaysia. Managerial Auditing Journal, 19(7), 897-915. 
Ferrier, R. J. (1985). Auditing standards and guidelines. In D. Kent, M. Sherer \& W. Turley (Eds.), Current issues in Auditing (pp. 120-133). London: Harper \& Row.

Fiedler, B., \& Lehman, G. (1995). Accounting, accountability and the environmental factor. Accounting Forum, 19(2/3), 195-204.

Fleming, P. D. (1993). AICPA convenes environmental issues roundtable. Journal of Accountancy, 175(4), 18-19.

Flint, C., Fraser, I. A. M., \& Hatherly, D. (2008). Business risk auditing: A regressive evolution? - A research note. Accounting Forum, 32, 143-147.

Fogarty, J. A., Graham, L., \& Schubert, D. R. (2006). Assessing and responding to risks in a financial statement audit. Journal of Accountancy, July, 43-49.

Fogarty, T. J. (1994). Structural-functionalism and financial accounting: Standard setting in the US. Critical Perspectives on Accounting, 5(3), 205-226.

Fogarty, T. J. (1998). Accounting standard setting: A challenge for critical accounting researchers. Critical Perspectives on Accounting, 9(5), 515-523.

Fogarty, T. T., Heian, J. B., \& Knutson, D. L. (1991). The rationality of doing 'nothing': Responses to legal liability in an institutionalised environment. Critical Perspectives on Accounting, 2(3), 201-226.

Frazer, I. A. M., \& Lin, K. Z. (2004). Auditors' perceptions of responsibilities to detect and report client illegal acts in Canada and the UK: A comparative experiment. International Journal of Auditing, 8, 165-184.

Gallhofer, S., \& Haslam, J. (1997). The direction of green accounting policy: Critical reflections. Accounting, Auditing \& Accountability Journal, 10(2), 148-174.

Gay, G. (2002). Bridging the business dynamic into the audit. Australian CPA, 72(1), 66.

Gay, G., \& Simnett, R. (2003). Auditing and Assurance Services in Australia (2nd ed.). Australia: McGraw-Hill Australia.

Gendron, Y. (2000). Openness to context-based research: the gulf between the claims and actions of Big Six firms in the USA. Accounting, Auditing \& Accountability Journal, 13(2), 175-196.

Gendron, Y. (2006). Professional cornerstone: What viewpoints context-based research reveals regarding auditor independence. CA Magazine(November), 49-51.

Gendron, Y., \& Suddaby, R. (2004). Professional insecurity and the erosion of accountancy's jurisdictional boundaries. Canadian Accounting Perspectives, $3(1), 85-115$.

Georgiou, G. (2002). Corporate non-participation in the ASB standard-setting process. The European Accounting Review, 11(4), 699-722.

Gibbins, M., \& Mason, A. (1988). Professional judgment in financial reporting. Toronto: CICA.

Gilkison, B. (1992). Coy Kiwi companies. Accountants' Journal(May), 64-65.

Gilkison, B. (1993). WASTED: A user's guide to the Mapua problem. Accountants' Journal(November), 54-56.

Gilkison, B. (1994). Accounting for degradation. The Mapua problem revisited. Accountants' Journal, March, 59-64.

Gilkison, B., \& KPMG. (1999). Accounting for a clean green environment. Nelson.: Anchor Press Ltd.

Gill, G. S., Cosserat, G., Leung, P., \& Coram, P. (2001). Modern auditing \& assurance services. Sydney: John Wiley \& Sons Australia, Ltd.

Gillham, B. (2000). The research interview. London: Continuum.

Gist, W. E., \& Shastri, T. (2003). Revisiting materiality. The CPA Journal, 73(11), 6063. 
Glaser, B. G., \& Strauss, A. L. (1967). The discovery of grounded theory: Strategies for qualitative research. Mill Valley, CA: Sociology Press.

Goddard, A., \& Powell, J. (1994). Accountability and accounting. Using naturalistic methodology to enhance organizational control - A case study. Accounting, Auditing \& Accountability Journal, 7(2), 50-69.

Gray. (2000a). Current developments and trends in social and environmental auditing, reporting and attestation: A review and comment. International Journal of Auditing, 4, 247-268.

Gray, I., \& Manson, S. (2005). The audit process. Principles, practice and cases (3rd ed.). London: Thomson Learning.

Gray, R. (1990). The accountant's task as a friend to the earth. Accountancy, June, 6568.

Gray, R. (2000b). Current developments and trends in social and environmental auditing, reporting and attestation: A review and comment. International Journal of Auditing, 4, 247-268.

Gray, R., \& Bebbington, J. (2000). Environmental accounting, managerialism and sustainability: Is the planet safe in the hands of business and accounting? Advances in Environmental Accounting \& Management, 1, 1-44.

Gray, R., \& Bebbington, J. (2001). Accounting for the environment (2nd Edition ed.). London: Sage Publications Ltd.

Gray, R., Bebbington, J., Collison, D., Kouhy, R., Lyon, B., Reid, C., et al. (1998). The valuation of assets and liabilities: Environmental law and the impact of the environmental agenda for business. London: ICAEW.

Gray, R., Collison, D., \& Bebbington, J. (1998). Environmental and social accounting \& reporting. In Financial reporting today: Current trends and emerging issues 1998. London: Accountancy Books.

Gray, R., Kouhy, R., \& Lavers, S. (1995). Corporate social and environmental reporting: A review of the literature and a longitudinal study of UK disclosures. Accounting, Auditing \& Accountability Journal, 8(2), 47-77.

Gray, R., Owen, D., \& Maunders, K. (1991). Accountability, corporate social reporting and the external social audits. Advances in Public Interest Accounting, 4, 1-21.

Grimwood, M., \& Tomkins, C. (1986). Value for money auditing - towards incorporating a naturalistic approach. Financial Accountability \& Management., 2(4), 251-272.

Guba, E. G. (1978). Toward a methodology of naturalistic inquiry in educational evaluation.Unpublished manuscript, Los Angeles: UCLA Center for the Study of Evaluation.

Guthrie, J., \& Parker, L. D. (1989). Corporate social reporting: A rebuttal of legitimacy theory. Accounting \& Business Research, 19(76), 343-352.

Hackston, D., \& Milne, M. J. (1996). Some determinants of social and environmental disclosures in New Zealand companies. Accounting, Auditing \& Accountability Journal, 9(1), 77-108.

Hannabuss, S. (1996). Research interviews. New Library World, 97(1129), 22-25.

Harding, X. (1994). Environmental liability and the banker-valuer relationship. New Zealand Valuers' Journal, 10-14.

Harte, G., \& Owen, D. (1992). Current trends in the reporting of green issues in the annual reports of United Kingdom companies. In D. Owen (Ed.), Green reporting: Accountancy and the challenge of the nineties (pp. 166-200). London: Chapman \& Hall.

Hatherly, D. (1998). Is the risk-driven audit too risky? Accountancy, August, 86. 
Hatherly, D. (1999). The future of auditing: the debate in the UK. The European Accounting Review, 8(1), 51-65.

Herrbach, O. (2006). The art of compromise? The individual and organisational legitimacy of "irregular auditing". Accounting, Auditing \& Accountability Journal, 18(3), 390-409.

Hines, D. R., \& Jackson, G. S. (1994). Environmental problems: How far must you go? The Practical Accountant, 27(3), 52-60.

Hines, R. D. (1989). Financial, accounting knowledge, conceptual framework projects and the social construction of the accounting profession. Accounting, Auditing \& Accountability Journal, 2(2), 72-92.

Hochman, J. A. (1998). Cleaning up environmental accounting. National Public Accountant, 43(4), 20-24.

Holmes, D. (1999). Sustainable development reporting. Australian CPA, 69(2), 22-23.

Holstein, J. A., \& Gubrium, J. F. (1998). Active interviewing. In D. Silverman (Ed.), Qualitative research. Theory, method \& practice. London: Sage.

Hooks, J. (1996). Degradation - The role of accounting. Chartered Accountants Journal(April), 63-64.

Hopwood, A. G. (1996). Probing further into auditing and its consequences. Accounting, Organizations and Society, 21(217-218).

Hronsky, J. J. F., \& Houghton, K. A. (2001). The meaning of defined accounting concept: regulatory changes and the effect on auditor decision making. Accounting, Organisations and Society, 26(2), 123-139.

Huberman, A., \& Miles, M. B. (1994). Data management and analysis methods. In N. K. Denzin \& Y. S. Lincoln (Eds.), Handbook of Qualitative Research. Thousand Oaks, C.A.: Sage.

Huizing, A., \& Dekker, H. C. (1992). The environmental issue on the Dutch political market. Accounting, Organizations and Society, 17(5), 427-448.

Humphrey, C. (1991). Audit expectations. In M. Sherer \& S. Turley (Eds.), Current issues in auditing (pp. 3-21). London: Paul Chapman Publishing.

Humphrey, C. (2001). Audit research - Looking beyond North America. Critical Perspectives on Accounting, 12, 369-376.

Humphrey, C. (2008). Auditing research: a review across the disciplinary divide. Accounting, Auditing \& Accountability Journal, 21(2), 170-203.

Humphrey, C., \& Moizer, P. (1990). From techniques to ideologies: An alternative perspective on the audit function. Critical Perspectives on Accounting, 1, 217238.

Humphrey, C., Moizer, P., \& Turley, S. (1992). The audit expectation gap - Plus change, plus c'est la meme chose? Critical Perspectives on Accounting, 3(2), 137-162.

Humphrey, C., Moizer, P., \& Turley, S. (1993a). Protecting against detection: the case of auditors and fraud? Accounting, Auditing \& Accountability Journal, 6, 39-62.

Humphrey, C., Moizer, P., \& Turley, W. S. (1993b). The audit expectation gap in Britain: An empirical investigation. Accounting and Business Research, 23(Summer), 395-411.

Humphrey, C., \& Owen, D. (2000). Debating the 'power' of audit. International Journal of Auditing, 4(1), 29-50.

Hunter, T. (1999). Boardroom greening - Do environmental concerns have any value for shareholders? The Independent, 16 June, 20.

ICAEW. (1992). Business accountancy and the environment: A policy and research agenda. London: ICAEW.

ICAEW. (1996). Environmental issues in financial reporting. London: ICAEW. 
ICAEW. (2000). Environmental issues in the audit of financial statements. London: ICAEW.

ICANZ. (1993). Statement of concepts for general purpose financial reporting (SC). In New Zealand Accounting Standards. Wellington: Institute of Chartered Accountants of New Zealand.

ICANZ. (1998a). AS 100: Objective of and general principles governing an audit. In New Zealand Codified Auditing Standards and Audit Guidance Statements. Wellington: ICANZ.

ICANZ. (1998b). AS 208: Considerations of laws and regulations in an audit. New Zealand Codified Auditing Standards and Audit Guidance Statements.

ICANZ. (1998c). AS 304: Audit Materiality. In New Zealand Codified Auditing Standards and Audit Guidance Statements. Wellington.

ICANZ. (1998d). AS 402: Risk assessments and internal control. In New Zealand Codified Auditing Standards and Audit Guidance Standards.

ICANZ. (1998e). AS 518: Other information in a document containing an audited financial report. New Zealand Codified Auditing Standards and Audit Guidance Statements.

ICANZ. (1998f). AS 702: The audit report on an attest audit. In New Zealand Codified Auditing Standards and Audit Guidance Statements.

ICANZ. (2001a). AGS 1010: The consideration of environmental matters in the audit of a financial report. In New Zealand Codified Auditing Standards and Audit Guidance Statements. Wellington: ICANZ.

ICANZ. (2001b). New Zealand Codified Auditing Standards and Audit Guidance Statements. Wellington: Institute of Chartered Accountants of New Zealand.

ICANZ. (2003a). Code of Ethics. In New Zealand Codified Auditing Standards and Audit Guidance Statements. Wellington: ICANZ.

ICANZ. (2003b). Code of Ethics: Independence in assurance engagements. Wellington: ICANZ.

IFAC. (1995). The audit profession and the environment. New York: IFAC.

Ingram, R. W. (1978). An investigation of the information content of (certain) social responsibility disclosures. Journal of Accounting Research, Autumn, 270-285.

Ingram, R. W., \& Frazier, K. B. (1980). Environmental performance and corporate disclosure. Journal of Accounting Research, 18(2), 614-622.

Iskandar, T. M. (1996). Industry type: A factor in materiality judgements and risk assessments. Managerial Auditing Journal, 11(3), 4-11.

Jarratt, D. G. (1996). A comparison of two alternative interviewing techniques used within an integrated research design: A case study in outshopping using semistructured and non-directed interviewing techniques. Marketing Intelligence \& Planning, 14(6), 6-10.

Jennings, M., Kneer, D. C., \& Reckers, P. M. (1993). The significance of audit decision aids and pre-case jurist's attitude on perceptions of audit firm culpability and liability. Contemporary Accounting Research, 9, 489-507.

Jeppesen, K. K. (1998). Reinventing auditing, defining consulting and independence. European Accounting Review, 7, 517-539.

Kinney Jr, W. R. (2005). Twenty-five years of audit deregulation and re-regulation: What does it mean for 2005 and beyond? Auditing, 24(Supplement), 89-109.

Kirman, C. (2003). Care required in sustainable development reporting. Chartered Accountants Journal of New Zealand, 82(9), 66.

Knechel, W. R. (2007). The business risk audit: Origins, obstacles and opportunities. Accounting, Organizations and Society, 32(4-5), 383-408. 
Kotter, J. P., \& Schlesinger, L. A. (1979). Choosing strategies for change. Harvard Business Review, 57(2), 111-120.

Kranacher, M. (2007). Determining materiality: Relativity and professional judgement. The CPA Journal, 77(8), 80.

Krieger, S. (1984). Fiction and social science. In N. K. Denzin (Ed.), Studies in Symbolic Interaction (pp. 269-286). Greenwich: CT: JAI Press.

Krippendorff, K. (2004). Content analysis: An introduction to its methodology (second ed.). London: SAGE Publications.

Kurunmaki, L. (2004). A hybrid profession - the acquisition of management accounting expertise by medical professionals. Accounting, Organizations and Society, 29, 327-347.

Langford, R. (1995). Accountants and the environment. Accountancy, 115(1222), 2-8.

Lee, M. R., \& Fielding, N. G. (1991). Computing for qualitative research: options, problems and potential. In N. G. Fielding \& R. M. Lee (Eds.), Using Computers in Qualitative Research (pp. 1-13). London: Sage.

Lee, T. (1994). Financial reporting quality labels: The social construction of the audit profession and the expectations gap. Accounting, Auditing \& Accountability Journal, 7(2), 30-50.

Lemon, W. M., Tatum, K. W., \& Turley, W. S. (2002). Developments in the audit methodologies of large accounting firms. London: Auditing Practices Board, ICAEW.

Leung, P., Coram, P., \& Cooper, B. (2006). Modern Auditing and Assurance Services (3rd ed.). Sydney: John Wiley \& Sons Australia, Ltd.

Libby, R., \& Luft, J. (1993). Determinants of judgement performance in accounting settings: Ability, knowledge and environment. Accounting. Organizations and Society, 18(5), 425-450.

Libby, T., \& Thorne, L. (2003). Virtuous auditors. While virtue is back in fashion, how do you define it and measure its importance to an auditor's role? $C A$ Magazine(November), 45-47.

Lickiss, M. (1991). Measuring up to the environmental challenge. Accountancy, 107(1169), 6.

Lincoln, Y. S., \& Guba, E. G. (1985). Naturalistic inquiry. Beverley Hills, CA: Sage.

Lindblom, C. K. (1993). The implications of organisational legitimacy for corporate social performance and disclosure. Paper presented at the Critical Perspectives on Accounting Conference, New York.

Llewelyn, S. (2003). Methodological Issues. What counts as "theory" in qualitative management and accounting research? Accounting, Auditing \& Accountability Journal, 16(4), 663-708.

Lofland, J., \& Lofland, L. H. (1984). Analysing social settings. Belmont, C.A: Wadsworth Publishing Company, Inc.

Low, K. Y. (2004). The effects of industry specialization on audit risk assessments and audit-planning decisions. The Accounting Review, 79(1), 201-219.

Lucy, S., \& Hayes, C. (2004). Directors' duties, sustainability: Are you being true and fair? The Independent(31 March), 10.

Lukka, K., \& Kasanen, E. (1995). The problem of generalizability: Anecdotes and evidence in accounting research. Accounting, Auditing \& Accountability Journal, 8(5), 71-90.

Lutz, W. (1988/1989). Doublespeak. Public Relations Quarterly, 33(4), 25-30.

Lutz, W. D. (1983). Corporate doublespeak: Making bad news look good. Business and Society Review(Winter), 19-22. 
Mak, T., Deo, H., \& Cooper, K. (2005). Australia's major corporate collapse: Health International Holdings (HIH) Insurance "May the force be with you". Journal of American Academy of Business, 6(2), 104-112.

Maltby, J. (1995). Environmental audit: Theory \& practice. A survey of environmental consultants' views on the purpose of audit. Managerial Auditing Journal, 10(8), $15-26$.

Manson, S., \& Zaman, M. (1999). Lobbying the Auditing Practices Board: Analysis of responses to the expanded audit report. Accounting Forum, 23(1), 11-34.

Maurer, J. G. (1971). Readings in organization theory: Open-system approaches. New York: Random House.

McDaniel, L. S. (1990). The effects of time pressure and audit program structure on audit performance. Journal of Accounting Research(Autumn), 267-285.

McEnroe, J. (2000). The Auditing Standards Board and the auditing standard-setting process. Internal Auditing, July/August, 25-31.

McEnroe, J. (2002). An analysis of post-expectation gap voting behaviour by the ASB. Abacus, 38(3).

McEnroe, J., \& Martens, S. (1998). An examination of the auditing standards promulgating process involving SAS No. 69. Journal of Accounting and Public Policy, 17, 1-26.

McEnroe, J., \& Nikolai, L. A. (1983). Voting patterns of Big Eight representatives in setting accounting and auditing standards. Journal of Business Research, 11, 7789.

McGuinness, W., \& Sharpe, S. (2001). Accounting for hazardous substances and genetically modified organisms. Chartered Accountants Journal, October, 6568.

McKee, T. E., \& Elifsen, A. (2000). Current materiality guidance for auditors. The CPA Journal, 70(7), 54-57.

Medley, P. (1997). Environmental accounting - What does it mean to professional accountants? Accounting, Auditing \& Accountability Journal, 10(4), 594-600.

Messier Jr., W. F., Martinov-Bennie, N., \& Eilifsen, A. (2005). A review and integration of empirical research on materiality: Two decades later. Auditing: A Journal of Practice \& Theory, 24(2), 153-187.

Miles, M., \& Huberman, A. (1994). Qualitative data analysis: An expanded sourcebook. London: Sage.

Mills, S. K., \& Bettner, M. S. (1992). Ritual and conflict in the audit profession. Critical Perspectives on Accounting, 3(2), 185-200.

Milne, M., \& Patten, D. M. (2002). Securing organizational legitimacy: An experimental decision case examining the impact of environmental disclosures. Accounting, Auditing \& Accountability Journal, 15(3), 372-405.

Milne, M. J., \& Adler, R. W. (1999). Exploring the reliability of social and environmental disclosures content analysis. Accounting, Auditing \& Accountability Journal, 12(2), 237-256.

Mitchell, A., \& Sikka, P. (1993). Accounting for change: The institutions of accountancy. Critical Perspectives on Accounting, 4(1), 29-52.

Mononey, R., \& Simnett, R. (2006). The impact of industry specialization on business risk identification and evaluation. Paper presented at the American Accounting Association, 2006 Annual Meeting, August 6-9.

Monroe, G. S., \& Woodliff, D. R. (1994). An empirical investigation of the audit expectation gap: Australian evidence. Accounting and Finance, 34(1), 47-74.

Morgan, G. (1983). Social science and accounting research: A commentary on Tomkins and Groves. Accounting, Organisations and Society, 8(4), 385-388. 
Morrill, J. (1996). Professional judgement and the auditor. Contemporary Accounting Research, 13(1), 371-378.

Morris, M. H., \& Nichols, W. D. (1988). Consistency expectations: Materiality judgements and audit firm structure. The Accounting Review, 63(2), 237-254.

Morrison, M. A. (2004). Rush to judgement: The lynching of Arthur Anderson and Co. Critical Perspectives on Accounting, 15(3), 335-375.

Munter, P., \& Sacasas, R. (1996). Accounting and disclosure of environmental contingencies. CPA Journal, 66(1), 36-41.

Myddelton, D. R. (2004). Unshacklying Accountants. London: The Institute of Economic Affairs.

Nilsen, R. D., . (2005). Searching for analytical concepts in the research process: Learning from children. International Journal of Social Research Methodology, $8(2), 117-135$.

Niskanen, J., \& Neiminen, T. (2001). The objectivity of corporate environmental reporting: a study of Finnish listed firms' environmental disclosures. Business Strategy and the Environment, 10, 29-37.

Nue, D. (1991). Trust, impression management and the public accounting profession. Critical Perspectives on Accounting, 2(3), 295-313.

O'Donovan, G. (2002). Environmental disclosures in the annual report: Extending the applicability and predictive power of legitimacy theory. Accounting, Auditing \& Accountability Journal, 15(3), 344-371.

O'Dwyer, B. (2001). The legitimacy of accountants' participation in social and ethical accounting, auditing and reporting. Business Ethics: A European Review, 10(1, January), 27-39.

O'Dwyer, B. (2002). Managerial perceptions of corporate social disclosure: An Irish story. Accounting, Auditing \& Accountability Journal, 15(3), 406-436.

O'Dwyer, B. (2003). Conceptions of corporate social responsibility: the nature of managerial capture. Accounting, Auditing \& Accountability Journal, 16(4), 523557.

Okike, E. (2004). Management of crisis. The response of the auditing profession in Nigeria to the challenge to its legitimacy. Accounting, Auditing \& Accountability Journal, 17(5), 705-730.

Oliverio, M. E. (2004). Auditors as leaders. The CPA Journal, 74(1), 14-16.

Orwell, G. (1949). Nineteen eighty-four. London: Penguin.

Owen, D., Swift, T., Bowerman, M., \& Humprey, C. (2000). The new social audits: accountability, managerial capture or the agenda of social champions? European Accounting Review, 9(1), 81-98.

Owen, D. L., Gray, R. H., \& Bebbington, J. (1997). Green accounting: cosmetic irrelevance or radical agenda for change? Asia Pacific Journal of Accounting, 4(2), 175-198.

Owens, R. G. (1982). Methodological rigor in naturalistic inquiry: Some issues and answers. Educational Administration Quarterly, 18(2), 1-21.

Pasewark, W. R., Shockley, R. A., \& Wilkerson, J. E. (1995). Legitimacy claims of the auditing profession vis-a-vis the behaviour of its members: An empirical examination. Critical Perspectives on Accounting, 6, 77-94.

Patel, C., Harrison, G. L., \& McKinnon, J. L. (2002). Cultural influences on judgments of professional accountants in auditor-client conflict resolution. Journal of International Financial Management and Accounting, 13(1), 1-31.

Patton, M. Q. (1990). Qualitative evaluation and research methods (2nd ed.). Newbury Park, CA: Sage Publications, Inc. 
Patton, M. Q. (2002). Qualitative evaluation and research methods. London: Sage, Newbury Park.

Pentland, B. T. (1993). Getting comfortable with the numbers: auditing and the microproduction of macro-order. Accounting, Organizations and Society, 18, 605-620.

Pentland, B. T. (2000). Will auditors take over the world? Program, technique and the verification of everything. Accounting, Organisations and Society, 25(3), 309312.

Pfeffer, J. (1981). Management as symbolic action: The creation and maintenance of organizational paradigms. Research in Organizational Behavior, 3, 1-52.

Pong, C., \& Whittington, G. (1994). The working of the auditing practices committee three case studies. Accounting \& Business Research, 24(94), 157-176.

Porter, B. A. (1990a). Bridging the audit expectation - performance gap. Accountants Journal, October, 42-48.

Porter, B. A. (1990b). The knowledge gap - significant contributor to the liability and credibility crisis. Accountants Journal(July), 20-27.

Porter, B. A. (1990c). Unreasonable expectations and deficient standards. Accountants Journal, September, 40-45.

Porter, B. A. (1993). An empirical study of the audit expectation-performance gap. Accounting and Business Research, 24(93), 49-68.

Porter, B. A. (2008). Farewell Editorial - A glimpse of the history of IJA. International Journal of Auditing, 12, 3-7.

Power, M. (1991). Auditing and environmental expertise: between protest and professionalisation. Accounting, Auditing \& Accountability Journal, 4(3), 30-42.

Power, M. (1992). From common sense to expertise: Reflections on the prehistory of audit sampling. Accounting, Organizations and Society, 17(1), 37-62.

Power, M. (1993). Auditing and the politics of regularly control in the UK financial services sector. In S. Picciotto, J. McCahery \& C. Scott (Eds.), Corporate control and accountability (pp. 187-202). Oxford: Oxford University Press.

Power, M. (1995). Auditing, expertise and the sociology of technique. Critical Perspectives on Accounting, 6(4), 317-339.

Power, M. (1997). The Audit Society: Rituals of verification: Oxford University Press.

Power, M. (1999). The Audit Society: Rituals of verification. (2nd ed.): Oxford University press, Oxford.

Power, M. (2000). The audit implosion: Regulating risk from the inside. London: ICAEW.

Power, M. (2003). Auditing and the production of legitimacy. Accounting, Organisations and Society, 28(4), 379-394.

Pragnell, H. (2004). The process of issung AGS 1010. Auckland.

Prasad, A., \& Prasad, P. (2002). The coming of age of interpretive organizational research. Organizational Research Methods, 5(1), 4-11.

Putnam, L. L. (1983). The interpretive perspective: An alternative to functionalism. In L. L. Putnam \& Pacanowsky (Eds.), Communication and organizations: An interpretive approach (pp. 31-54). Newbury Park: Sage.

Rahman, A. (1991). Due process and user participation in standard setting. Australian Accountant, 61(5), 28-35.

Reynolds, M. A., \& Mathews, M. R. (1999). The environment and the accountant as ethical actor. Advances in environmental accounting and management, 1, 83100.

Rezaee, Z., Szendi, J. Z., \& Aggarwal, R. (1995). Corporate governance and accountability for environmental concerns. Managerial Auditing Journal, 10(8), 27-33. 
Richards, L., \& Richards, T. (1991). The transformation of qualitative method: computational paradigms and research processes. In N. G. Fielding \& R. M. Lee (Eds.), Using Computers in Qualitative Research (pp. 38-53). London: Sage.

Richardson, A. J., \& Dowling, J. B. (1986). An integrative theory of organizational legitimation. Scandinavian Journal of Management Studies, November, 91-108.

Robb, A. J. (2003a). Depreciation doublespeak. The National Business Review(March $14)$.

Robb, A. J. (2003b). Doublespeak dogs double-entry. The National Business Review(11 April).

Rockness, J. W. (1985). An assessment of the relationship between US corporate environmental performance and disclosure. Journal of Business Finance \& Accounting, 12(3), 339-354.

Rodgers, W., \& Housel, T. J. (2004). The effects of environmental risk information on auditors' decisions about prospective financial statements. European Accounting Review, 13(3), 523-540.

Rogers, G. (2004). Environmental transparency: 5 areas for concern. Financial Executive, 20(4), 53-57.

Rubenstein, D. B. (1992). Bridging the gap between green accounting and black ink. Accounting, Organizations and Society, 17(5), 501-508.

Rubin, H. J., \& Rubin, I. S. (2005). Qualitative interviewing (2nd ed.). California: Sage Publications.

Russell, G. W. (1992). Being accountable for the environment. CMA Magazine, December/January, 10.

Salome, R., \& Galluccio, G. (2001). Environmental issues and financial reporting trends: A survey in the chemical and oil and Gas Industries. FEEM Working Paper No. 32.2001, June.

Savage, A., Cataldo, A. J., \& Rowlands, J. (2000). A multi-case investigation of environmental legitimation in annual reports. Advances in Environmental Accounting \& Management, 1, 45-81.

Schacter, M. (2005). Boards face new social responsibility. CA Magazine, May, 12.

Schwandt, T. A. (2001). Dictionary of qualitative inquiry (2nd ed.). Thousand Oaks, CA: Sage Publications.

Searcy, D. L., \& Mentzer, J. T. (2003). A framework for conducting and evaluating research. Journal of Accounting Literature, 22, 130-167.

Sethi, S. P. (1978). "Advocacy advertising - the American experience. California Management review, 11, 55-67.

Sherer, M., \& Kent, D. (1983). Auditing and Accountability. London: Pitman Publishing Inc.

Shocker, A. D., \& Sethi, S. P. (1973). An approach to incorporating societal preferences in developing corporate action strategies. California Management review, Summer, 97-105.

Sikka, P. (1992). Audit policy making in the UK. The case of 'the auditor's considerations in respect of going concern'. European Accounting Review, 1, 2534.

Sikka, P. (2001). Regulation of accountancy and the power of capital: some observations. Critical Perspectives on Accounting, 12(2), 199-211.

Sikka, P. (2002). The politics pf restructuring the standard setting bodies: the case of the UK's auditing practices board. Accounting Forum, 26(2), 247-260.

Sikka, P. (2008). Watching the watchdogs. The Guardian(31 march). 
Sikka, P., Puxty, A., Willmott, H., \& Cooper, C. (1998). The impossibility of eliminating the expectations gap: Some theory and evidence. Critical Perspectives on Accounting, 9, 299-330.

Sikka, P., Willmott, H., \& Lowe, T. (1989). Guardians of knowledge and public interest: Evidence and issues of accountability in the UK Accountancy profession. Accounting, Auditing and Accountability, 2(2), 47-71.

Silverman, D. (2005). Doing qualitative research. London: Sage Publications.

Simnett, R., Vanstraelen, A., \& Chua, W. F. (2007). Assurance on general purpose nonfinancial reports: An international comparison. Paper presented at the 13th International Symposium on Audit Research, 22-23 June, Shanghai, China.

Simunic, D. A. (1994). New auditing standards - Mostly smoke and mirrors? CGA Magazine, September, 23, 79.

Smith, M. L. (1981). Naturalistic Research. Personnel and Guidance Journal, May, 585-589.

Specht, L., \& Waldon, D. (1992). Auditor perceptions of statements on Auditing Standards 53 and 54: A study of demographics and perceptions of efficacy. Journal of Applied Business Research, 8(2), 87- 95.

Specht, L. B. (1992). The auditor, SAS 54 and environmental violations. Journal of Accountancy, 174(6), 67-72.

Specht, L. B., \& Sandlin, P. (2003). Auditor perceptions of SAS 99: Do two expectation gaps still exist? Journal of Applied Business Research, 20(4), 25-32.

Specht, L. B., \& Waldron, D. G. (1992). Auditor perceptions of statements on auditing standards 53 and 54: A study of demographics and perceptions of efficacy. Journal of Applied Business Research, 8(2), 87-95.

Spicer, B. (1992). The resurgence of cost and management accounting: A review of some recent developments in practice, theories and case research methods. Management Accounting Research, 3(1), 1-37.

Stake, R. E. (2000). Case studies. In N. K. Denzin \& Y. S. Lincoln (Eds.), The handbook of qualitative research (2nd ed., pp. 435-454). Thousand Oaks, CA: Sage Publications.

Stamp, E., \& Moonitz, M. (1978). International Audit Standards. Londom: Prentice Hall International.

Steadman, M. E., Green, R. F., \& Zimmerer, T. W. (1995). Advising your clients about environmental accounting issues. Managerial Auditing Journal, 10(8), 52-55.

Strauss, A., \& Corbin, J. (1990). Basics of qualitative research: Grounded theory procedures and techniques. London: Sage.

Street, D. L., \& Shaughnessy, K. A. (1998). The quest for international accounting harmonisation: A review of the standard setting agendas of the IASC, US, UK, Canada and Australia, 1973-1997. The International Journal of Accounting, 33(2), 179-209.

Styles, E. (1984). Doing a double take on 'Doublespeak'. Wall Street Journal(April, 12).

Suchman, M. (1995). Managing legitimacy: strategic and institutional approaches. Academy of Management Review, 20(3), 571-610.

Sullivan, J. B. (1993). The impact of auditing research on auditing practice. Auditing, $12(2)$.

Surma, J. (1992). Accounting for environmental costs. Journal of Accountancy, 173(3), 51-56.

Swift, T., \& Humphrey, C. (2000a). Great expectations?: The dubious financial legacy of quality audits. British Journal of Management, 11(1), 48-63.

Swift, T., \& Humphrey, C. (2000b). Great expectations?: The dubious financial legacy of quality audits. British Journal of Management, 11(1). 
Sylph, J. (2005). Corporate sustainable management and environmental management accounting. Paper presented at the International Federation of Accountants, Bangkok, Thailand, November 24.

Taylor, D. W., Sulaiman, M., \& Sheahan, M. (2001). Auditing of environmental management systems: A legitimacy theory perspective. Managerial Auditing Journal, 16(7), 411-422.

Teasley, H. (1995). "Green" auditing. CGA Magazine(November), 21, 67.

Tesch, R. (1991). Software for qualitative researchers: analysis needs and program capabilities. In N. G. Fielding \& R. M. Lee (Eds.), Using computers in qualitative research (Vol. 16-37). London: Sage.

The Security Exchange Commission. (1999). Materiality (SEC Staff Accounting Bulletin No. 99). Washington, DC: SEC.

Thomas, C. W. (2003). Enron and beyond: What's the World coming to? The CPA Journal, 73(1), 9.

Thompson, P., \& Cowton, C. J. (2004). Bringing the environment into bank lending: Implications for environmental reporting. British Accounting Review, 36(2), 197-219.

Tilt, C. A. (1994). The influence of external pressure groups on corporate social disclosure. Accounting, Auditing \& Accountability Journal, 7(4), 47-72.

Todd, C., \& Stafford-Bush, S. (1995). Environmental issues and financial statements. Chartered Accountants Journal, 63-65.

Tomkins, C., \& Groves, R. (1983a). The everyday accountant and researching his reality. Accounting, Organizations and Society, 8(4), 361-374.

Tomkins, C., \& Groves, R. (1983b). The everyday accountant and researching his reality: Further thoughts. Accounting, Organisations and Society, 8(4), 269-289.

Turley, S. (2004). Research and public practice accounting. In C. Humphrey \& B. Lee (Eds.), The real life guide to accounting research. Oxford: Elsevier Ltd.

Turner, N., Grownow, S., \& Prescott, G. (1993). Environmental management systems and property valuation. Integrated Environmental Management, 22 (September), 15-17.

van Peursem, K. A., Locke, J., \& Harnisch, N. (2005). Going concern guidance for New Zealand auditors: transitions in communicative acts. Critical Perspectives on Accounting, 17, 109-137.

van Puersem, K. A., \& Pratt, M. J. (2003). Auditing Theory and Practice in New Zealand (4th ed.): Prentice hall.

Vaughan, S., \& Mulliken, D. (2007). It's not easy being green. International Financial Law Review, February, 1-4.

Wainman, D. (1991). Balancing nature's books. CA Magazine, 124(3), 16-21.

Walsh, B. (2000). The future of self-regulation for the accountancy profession. Accountancy Ireland, February, 18-19.

Walsh, B., \& Lavall, T. (1998). Beyond bean counting. Microtimes, www.microtimes.cpm/162/research.html.

Watson, M., \& Mackay, J. (2003). Auditing for the environment. Managerial Auditing Journal, 18(8), 625-630.

Weetman, P. (2001). Controlling the standard-setting agenda: the role of FRS 3. Accounting, Auditing \& Accountability Journal, 14(1), 85.

Weil, J. (2004). Behind the wave of corporate fraud: A change in how auditors work. The Wall Street Journal, March 25, 10.

Weinstein, E. A. (2007). Materiality: Whose business is it? The CPA Journal, 77(8), 2429. 
Weirich, T. R., \& Rouse, R. W. (2003). Auditing struggles with crisis of confidence. The Journal of Corporate Accounting \& Finance, May/June, 19-25.

Welles, C. (1988). "What led Beech-Nut down the road to disgrace". Business week, 124-126, 128.

Willekens, M., Steele, A., \& Miltz, D. (1996). Audit Standards and auditor liability: A theoretical model. Accounting \& Business Research, 26(3), 249-264.

Willmott, H. (1986). Oganizing the profession: A theoretical and historical examination of the development of the major accountancy bodies in the UK. Accounting, Organizations and Society, 11(6), 555-580.

Willmott, H., Cooper, D. J., \& Puxty, T. (1993). Maintaining self-regulation: making 'interests' coincide. Accounting, Auditing \& Accountability Journal, 6(4), 68-83.

Wiseman, J. (1982). An evaluation of environmental disclosures made in corporate annual reports. Accounting, Organizations and Society, 53-63.

Woolf, E. (1994). Auditing standards: Can small firms comply? Accountancy, 113(1209), 84.

Xiao, Z., \& Pan, A. (1997). Developing accounting standards on the basis of a conceptual framework by the Chinese Government. The International Journal of Accounting, 32(3), 279-299.

Young, J. J. (2003). Constructing, persuading and silencing: the rhetoric of accounting and standards. Accounting, Organizations and Society, 28, 621-638.

Zeff, S. A. (1998). Independence and standard setting. Critical Perspectives on Accounting, 9, 535-543.

Zuber, G. R., Elliot, R. K., Kinney Jr, W. R., \& Leisenring, J. J. (1983). Using materiality in audit planning. Journal of Accountancy, March, 42-54. 